\title{
LOS EMPLEADOS RURALES, SU DIVERSIDAD, SU RELACION CON LA PRODUCCION Y SU APORTE AL DESARROLLO RURAL
}

\author{
Juan Andrés Castro
}

Trabajo de Tesis para ser presentado como

requisito parcial para optar al Título de

MAGISTER SCIENTIAE EN PROCESOS LOCALES DE INNOVACION Y DESARROLLO RURAL (PLIDER)

\author{
UNIVERSIDAD NACIONAL DE LA PLATA \\ FACULTAD DE CIENCIAS AGRARIAS Y FORESTALES \\ DEPARTAMENTO DE DESARROLLO RURAL \\ CARRERA DE MAESTRIA \\ La Plata, Argentina
}

Mes y año (que figuran en el Acta de aprobación) 
LOS EMPLEADOS RURALES, SU DIVERSIDAD, SU RELACION CON LA PRODUCCION Y SU APORTE AL DESARROLLO RURAL

Juan Andrés Castro

Doctor Iran Veiga

Director de tesis 
LOS EMPLEADOS RURALES, SU DIVERSIDAD, SU RELACION CON LA PRODUCCION Y SU APORTE AL DESARROLLO RURAL

\author{
Juan Andrés Castro
}

Aprobada por:

Julio Elverdin, Ing. Agrónomo M. Sc.

Christophe Albaladejo, Ing. Agrónomo Dr.

Guillermo Neiman, sociólogo Dr. 


\section{AGRADECIMIENTOS}

- Al Consejo de administración del Centro Educativo para la Producción Total N¹9 Juan Eulogio Barra, por valorar la formación de sus cuadros técnicos y haberme dado la posibilidad de hacer esta maestría.

- A mi director de tesis Dr. Iran Veiga, por su apoyo, su paciencia y su constante intención de colaborar con esta tesis y por su presencia reiterada en el terreno.

- En el nombre de Pedro y Guillermo, a la facultad de Cs. Agrarias y Forestales, pionera en el área del desarrollo rural, a la que debo mi profesión.

- A mis compañeros de maestría, ahora amigos, por compartir de corazón abierto estos tres años de trabajo, por soñar y trabajar por un país y un campo mejor para todos.

- En el nombre de Christophe, al proyecto INTERRA y a todo el cuerpo docente de la maestría por su aporte al desarrollo rural.

- A mis compañeros en el CEPT por cubrirme en el trabajo cotidiano en los momentos de mayor demanda de tiempo de esta maestría.

- A Barbara Bellone, por su dedicación y paciencia para cumplir con nuestros constantes pedidos y recordarnos nuestras obligaciones.

- A los compañeros de CANPO por organizarse, motivarme a militar y a seguir formándome para el proyecto nacional y popular.

- A los empleados rurales por su aporte a la patria, hasta ahora no reconocido.

- Al M. Sc. PLIDER Daniel Intaschi, a Bruno Santamaría y Elisa Rodríguez por su apoyo y sus concejos durante todo el proceso de la maestría.

- Por último a mi familia, que me apoyo y me tuvo paciencia durante todo este proceso. 


\section{INDICE}

Introducción general

paginas

1Planteo del problema

2 Justificación social del tema 3

3 Estado de conocimiento sobre el tema

3.1 Enfoques teóricos $\quad 7$

4. Pregunta de investigación 12

5. Objetivos 12

5.1 Objetivo general 12

$\begin{array}{ll}5.2 \text { Objetivos específicos } & 12\end{array}$

6 Hipótesis planteadas 13

CAPITULO 1: Descripción de la zona de estudio

1.1 El distrito de Chávez $\quad 14$

1.2 Cambian las actividades productivas 18

1.3 Los pueblos $\quad 22$

1.3.1 De la Garma $\quad 24$

1.3.2 Juan Eulogio Barra 27

\section{CAPITULO 2: Materiales y métodos}

2.1 Introducción 29

2.2 Métodos cuantitativos 31

2.2.1 Encuestas 31

2.2.2 Cálculo de ingresos familiares 35

2.3 Métodos cualitativos 36

2.3.1 Observación 36

2.3.2 Investigación documental 37

2.3.3 Entrevistas 38 
CAPITULO 3: Los trabajadores rurales

3.1 Introducción 41

3.1.1 Relevamiento 41

3.1.2 Tipología $\quad 44$

3.2.1 Trabajadores de producciones primarias 45

3.2.1.1 Empleados agrícolas $\quad 45$

3.2.1.1.1 El tractorista de campo 45

3.2.1.1.2 Los equipos de chacra 47

3.2.1.2 Empleados ganaderos $\quad 54$

3.2.1.3 Empleados ganaderos correntinos 58

3.2.1.4 Empleados de campos mixtos 61

3.2.2 Trabajadores de servicios a la producción: 63

3.2.2.1 Alambradotes 63

3.2.3 Trabajadores sin empleo estable 65

CAPITULO 4: Las actividades extrasalariales de los empleados rurales y sus familias

4.1 Introducción 69

4.2 Oficios camperos $\quad 75$

4.2.1 Sogueros y talabarteros 75

4.2.2 Domadores 79

4.2.3 Alambradores y otros trabajos 81

4.3 Producciones familiares 82

4.3.1 Producciones de autoconsumo 82

4.3.2 Producciones para venta 86

4.3.2.1 Cría de cerdos $\quad 87$

4.3.2.2 Tambo 90

4.3.2.3 Cría de aves $\quad 92$

4.4 Lo que genera el esparcimiento: 94

caballos, cantores y asadores

4.5 El aporte de la familia: el trabajo de la mujer 98 
CAPITULO 5: Los núcleos de sociabilidad

5.1 Introducción 102

5.2 Núcleos de sociabilidad en el pueblo 104

5.2.1 El Fútbol y los clubes 104

5.2.2 Bares, bochas y barajas 108

5.2.3 Veterinarias y escritorios $\quad 112$

5.2.4 Talleres y galpones 114

5.2.5 Oficina de UATRE y Osprera: espacio de mujeres 116

5.3 Núcleos de sociabilidad en el campo 119

5.3.1 Las carneadas 119

5.3.2 Las destrezas: pruebas de rienda, sortija y jineteada 121

5.3.3 Las escuelas rurales $\quad 125$

5.3.4 Lo nuevo, playas y balnearios locales 128

$\begin{array}{ll}\text { CONCLUSIONES GENERALES } & 131\end{array}$

$\begin{array}{ll}\text { BIBLIOGRAFIA } & 142\end{array}$

ANEXOS

ANEXO 1 FOTOS 150

ANEXO 2 LISTADO DE PERSONAS ENTREVISTADAS 161

ANEXO 3 OTROS EMPLEADOS QUE FUERON CONSULTADOS 164 PARA ESTE TRABAJO.

ANEXO 4 LUGARES OBSERVADOS CON REGISTRO DE FOTOS 165 Y COMPORTAMIENTOS SOCIALES

\section{INDICE DE GRAFICOS Y TABLAS}

Grafico 1 Ubicación del distrito de Gonzáles Chávez en la provincia de Buenos Aires

pag. 14

Grafico 2 Plano de la zona de estudio

pag. 15

Grafico 3, Imagen satelital de Pedro Prospero Lasalle

pag. 23

Grafico 4, Imagen satelital de De la Garma y zona de quintas

pag. 24 
Grafico 5, Imagen satelital de Juan Eulogio Barra y sus alrededores

pag. 27

Grafico 6 Ubicación de empleados entrevistados

pag. 43

Grafico 7 Distribución de escuelas rurales en zona de estudio

pag. 126

Tabla 1- Características climáticas del distrito de Gonzáles Chávez

Tabla 2- EAPS en el distrito de Gonzáles Chávez

pag.16

pag. 18

Tabla 3- Evolución de la superficie agrícola y existencias ganaderas

pag. 19

Tabla 4- Distribución de la población rural

pag.21

Tabla 5- encuesta a empleados rurales

pag. 42

Tabla 6- características de equipos de chacra

pag 48

Tabla 7- contratación de mano de obra transitoria en G. Chávez pag. 68

Tabla 8- tabla de ingresos salariales y extra-salariales

pag. 71

\section{RESUMEN}

Este trabajo de investigación aborda el tema de los empleados rurales de la región sudeste de la provincia de Buenos Aires, en una zona mixta del distrito de Adolfo Gonzáles Chávez, dentro de la cual se encuentran los pueblos de De la Garma y Juan E. Barra.

Se clasifico a los distintos tipos de empleados con base en su actividad asalariada y se profundizo sobre la existencia de de otras actividades productivas o de servicios que se hagan en el marco de actividades familiares definidas como multiocupación rural, debido a la características también rurales de estas actividades extrasalariales.

Se distingue un grupo de trabajadores agrícolas, que viven en su mayoría en los pueblos y que trabajan en los equipos de chacra de la zona. En general no realizan actividades de autoconsumo salvo los que viven en quintas y su multiocupación pasa por hacer changas en el campo o en la construcción durante las épocas que no trabajan en el campo y por el trabajo de las mujeres en el pueblo.

El otro grupo esta constituido por trabajadores ganaderos con características muy disímiles, sobre todo en lo referente a la morada familiar, ya que la mayoría vive con su grupo familiar en el campo, también a las costumbres y espacios de socialización y sobre todo a la posibilidad de realizar actividades productivas y de servicios que mejoren sus vínculos con sus vecinos y con los pueblos cercanos. 
Se destacan las actividades referidas al vinculo con el caballo, los entretenimientos de destrezas, las carreras y las jineteadas. A su vez existen un numero grande de servicios que se despliegan en este rubro y que van desde la confección de prendas hasta el amansado, la animación artística y el asado de carne.

El otro grupo de actividades esta vinculado con la producción de alimentos, básicamente animales de granja y sus productos como huevos y leche, elaboración de chacinados. En este tema existe una gran variedad de situaciones que se corresponden con la distinta disponibilidad de alimentos, de espacio y de historia familiar en cada una de la producciones. Habiendo desde empleados con rodeo vacuno propio, hasta los mencionados productores de cerdos y aves.

Esta situación de multiocupación no es un hecho solo del empleado sino que abarca también al resto de la familia que colabora en las actividades, incluso conduciendo muchas de ellas. Esto ha permitido una vinculación mas amplia y rica con sus vecinos, con los pueblos cercanos y dentro de la familia ha permitido una mejoría en la situación de cada uno de los integrantes, principalmente de la mujeres y jóvenes.

En cuanto a los espacios y formas de socialización de estos empleados multiactivos, también tiene características distintivas según sea el grupo de empleados, siendo los talleres y galpones los mas característicos de los empleados agrícolas y las fiestas criollas de destrezas las de los empleados ganaderos. A su vez existen espacios como los bares, el club y el fútbol donde la concurrencia es variada. En todos los espacios se ve una presencia de distintos tipos sociales, tanto rurales como urbanos haciendo que los espacios vistos en este trabajo trasciendan a los empleados y sean espacios de socialización de toda la comunidad de la región, tanto rural como urbana.

Se destaca la importancia de la posibilidad que hoy tienen los empleados de tener movilidad a través de autos y camioneta lo que mejoro y amplio sus espacios de socialización.

En términos metodológicos se realizaron encuestas y entrevistas en profundidad a empleados e informantes de los distintos tipos de actividades y espacios de socialización. También se realizaron observaciones en los eventos de socialización y en los lugares donde se realizan las fiestas de destrezas criollas, carreras y partidos de fútbol, así como en talleres, bares y veterinarias.

Palabras claves: empleados rurales, multiocupación rural, sociabilidad, pueblos rurales 


\section{ABSTRACT}

This research is about the rural employees in the south east region of Buenos Aires province, in a mixed zone in Adolfo Gonzáles Chaves' district, where De la Garma and Juan E. Barra villages are.

The different kind of employees were classified depending on their wage-earning activity and other productive activities or services in the family framework, defined as rural multi-occupation, were studied in depth due to the rural characteristics of these extra-wage activities.

There is a group of farmworkers who mostly live in the towns but they work in the zone farm equipments. Mostly they do not do self consumption activities, except for the people who live in the farms and they do multi-occupation tasks there or work as builders when they do not work in the field and also women who work in town.

The other group is about livestock workers with very different characteristics referred to their familiar home as they live in the country, their customs and socilization 'spaces and the possibility of doing productive activities and services to improve links with their neighbours and nearby towns.

Horse activities are stood out, skill entertainments and horse racing. There are many servicies depending on this sector from making garments to tame animals, artistic animation and barbecue meat.

Another activity group has to do with food production, basically farm animals and their products such as eggs and milk, and preparation of cold out. Here there is a variety of situations depending on the different food availability, place and family history about each production since there are employees with their own bovine roundup and also pigs and fowls producers.

This multi-occupation situation is carried out not only by the employee but also by this family who sometimos leads most of the activities. This situation has enable a better entailment with their neighbours and nearby towns. Within the family there has been an improvement in each member, mainly in women and youg people.

There are different places and socialization ways depending on the characteristics of the emplyee's group. Farmworkers enjoy their leisure in workshops and sheds, while livestock workers like creole festivals. There are another places where employees go to: clubs and bars and they also like football. In these places there are rural and urban 
people, so these spaces are treated as socialization areas.

Nowdays, most employees have a car or a van which allow them to expand their socialization areas.

Surveys and interviews were done to employees and informants of the different kind of activities and socikalization areas, to enable this work. Observations were also made in the places where creole festivals, horse racing and football matches were performed, also en workshops, bars and vet shops.

Key-words: rural employees, rural multi occupation, sociability, rural villages. 


\section{INTRODUCCION GENERAL}

\section{PLANTEO DEL PROBLEMA}

La región pampeana en general y la zona agrícola mixta del sudeste en particular, tienen características que las hacen muy aptas para la producción agropecuaria, principalmente referida a cereales de invierno como trigo y cebada y a ganadería bovina.

De la Garma y su zona rural de influencia están ubicados en el centro norte del distrito de Adolfo Gonzáles Chávez, y corresponden en todas sus características a la denominada región sudeste de la provincia de Buenos Aires, con una variedad de producciones que van desde la ganadería de cría hasta la agricultura intensiva.

En la actualidad, como plantean varios autores (Bendini, 2003 ; Aparicio y Benencia, 1999 ; Murmis, 1996) estas actividades productivas vienen siendo fuente de expulsión constante de mano de obra, que condicionan a productores y empleados rurales a que se adapten y modifiquen trabajos, hábitos, y costumbres para conservar el trabajo y seguir siendo parte del medio rural.

"La expansión de la agricultura capitalista no derivó en la consolidación de una clase trabajadora estable y permanente; por el contrario, en algunos casos se ha venido desarrollando en detrimento de su formación" (Neiman y Quaranta, 2000). En tal sentido, en el agro latinoamericano en general se ha ido acentuando la inestabilidad, la informalidad, y la desprotección legal de los trabajadores rurales, haciéndose sentir con mayor intensidad en los sectores más débiles, con escasa capacidad de visibilización y respuestas a la situación.

En la literatura, gran parte de los trabajos de investigación científica abordan la problemática de la mano de obra rural desde el análisis de los productores, estando muy estudiado el sector de los productores empresariales, familiares y el campesinado.

En cambio las investigaciones del sector de los empleados rurales han tenido un menor desarrollo, siendo en Argentina Floreal Forni (1993), Guillermo Neiman (2001) y Miguel Murmis (1998) de los principales referentes en la temática.

En el mismo sentido, vale aclarar que la información suministrada por los censos según la forma en la que están diseñados y como se llevan adelante en terreno, hace muy difícil relevar datos sobre las actividades productivas llamadas de 
granja y mucho menos las actividades productivas llevadas a cabo por los empleados rurales en los establecimientos. En esa situación, este trabajo trata de generar información de terreno sobre los empleados rurales y sus actividades productivas que estarán disponibles para su libre utilización, pretendiendo ser un aporte a la promoción del desarrollo rural en la región.

Introduciéndonos en el sector de los empleados rurales en la Argentina, existen una serie de características que lo hacen complejo para el análisis, que incluye además de los cambios en las actividades productivas, procesos de cambio en la radicación de los trabajadores y sus familias.

En este sentido se plantean dos fenómenos que ocurren simultáneamente, uno es la sostenida disminución de la población económicamente activa (PEA) rural sobre la PEA total a nivel país, y el otro fenómeno es la creciente radicación urbana de esta PEA rural.

En este tema de la radicación urbana se plantean dos situaciones diferentes (Neiman y Bardomas, 2001). En la región pampeana el cambio en los sistemas productivos con un aumento de servicios a la producción y a la comercialización, exige un grado de especialización mayor de los trabajadores en un contexto de mayor urbanización de los sectores rurales.

En cambio en sectores extra-pampeanos (por ejemplo Cuyo, Río Negro, NOA) el aumento de la mano de obra asalariada esta asociada a la expansión de las actividades agroindustriales, con fuerte estacionalidad en los requisitos de mano de obra, fundamentalmente de cosecha y empaque.

Todos estos cambios han generado una situación donde también ha aumentado la rotación de empleos en todos los sectores, pero más frecuente en los empleos de menor remuneración y condiciones de vida mas difíciles. Murmis sostiene que "no solo aparece la existencia de una gama de formas de inserción en el proceso productivo ligada a nuevas formas de capital, sino también la generalización de situaciones de inserción precaria, siempre vistas como tan típicas de la situación agraria" (Murmis, 1998).

Varios autores llaman la atención sobre la necesidad de incorporar los contextos sociales y culturales en el análisis de la movilidad de trabajadores en tanto interfaces de negociación y conflicto. Es interesante destacar el papel que juegan las redes sociales para la movilización de mano de obra rural y los sistemas de enganche e intermediación en su contratación. Aspectos que no siempre resultan transparentes 
pero que condicionan los procesos de inserción social como de vulnerabilidad de importantes volúmenes de trabajadores y trabajadoras rurales, incluyendo jóvenes.

Se desarrolla un entramado de relaciones de proximidad (amigos, parientes, conocidos del pueblo) o de relaciones menos personales (transportistas, capataces, sindicalistas, agencias de empleo, agentes del estado, iglesias); que intervienen en la regulación de la oferta de trabajadores y de la demanda de las empresas (Lara, 1998; Bendini et al, 2002), aunque no siempre en las mejores condiciones para los trabajadores.

En la zona que abarca este trabajo, esto se ve ejemplificado con la incorporación de trabajadores ganaderos de origen correntino, chaqueño y entrerriano, que consolidados en sus trabajos, van trayendo a familiares y amigos a trabajar y vivir en esta zona, y se incorporan en la vida social de la comunidad sin demasiados problemas.

Los empleados rurales en general son la mayoría de los habitantes del medio rural disperso en nuestra zona de estudio, los que dependen y a su vez utilizan todas las oportunidades y las falencias que tiene el territorio. Por lo tanto son los que justifican la existencia de escuelas, caminos rurales, salas de primeros auxilios, almacenes y comercios rurales y toda la infraestructura social disponible. El resto de los empleados rurales vive en los pueblos desde donde se movilizan para sus lugares de trabajo con modalidades y frecuencias muy dispares.

Es un interés de este trabajo poder poner en visibilidad la diversidad de estos empleados, como se vinculan entre si y con los pueblos rurales y como afecta a estas posibilidades de vinculación hacia adentro y afuera de la familia la existencia de actividades productivas y de servicios que se complementan con su condición de asalariados.

\section{JUSTIFICACION SOCIAL DEL TEMA}

En primer término es necesario dejar claro la elección de De la Garma y su zona de influencia. En este sentido el pueblo forma parte del territorio donde el CEPT como agente de desarrollo y yo en particular junto a mi familia, llevamos adelante todas nuestras acciones y construimos la gran mayoría de nuestros vínculos. Este doble papel de agente de desarrollo como parte del CEPT y habitante del pueblo de 
De la garma me asigna la doble responsabilidad de cumplir con mi trabajo como profesional, pero además me moviliza para trabajar, participar y aportar a la construcción de una sociedad mas justa y solidaria para mis hijos y todos los que habitamos este lugar.

A su vez De la Garma, como ya hemos planteado en la descripción geográfica, es una zona de transición agro-climática y de suelos que deriva en la presencia de distintas actividades productivas y por lo tanto con empleos rurales con diversas características. Este factor genera distintos tipos de empleados y genera distintas sociabilidades de cada tipo que son uno de los ejes de estudio de la tesis.

Además se va a abordar la problemática desde las distintas miradas que pueden tener las comunidades rurales, las instituciones y el estado en sus dimensiones locales, provinciales y nacionales.

Desde lo personal y como técnico de terreno de la Federación de Centros Educativos para la Producción Total (FACEPT) formo parte de los que creen que la reserva de conocimientos, experiencias y actitudes hacen al poblador rural protagonista de su propio destino y tiene un profundo sentido emancipador. Esto, en un sector in visibilizado de la sociedad, que ha sufrido las consecuencias del modelo neoliberal no solo desde la destrucción del empleo sino además desde la desvalorización de lo rural, sus formas de vida y sus costumbres; es sin duda un elemento digno de poner en valor.

Una línea que aborda el tema concreto de la multiocupación es la creación en el marco de la educación agraria provincial del área de formación profesional para jóvenes en oficios rurales y producción dictado por los propios productores familiares, artesanos y referentes de oficios con apoyo organizativo desde cada comunidad

Los mas jóvenes, bombardeados tecnológicamente por elementos que poco tienen que ver con su vida rural, empiezan a tomar, valorizar y rescatar las trayectorias sociales y productivas de sus familias y a ponerlas al servicio de una nueva forma de producir y relacionarse con su comunidad.

En este marco el CEPT trabaja con los jóvenes que en su gran mayoría son hijos de empleados rurales, el sentido emancipador de las producciones familiares y el trabajo asociativo, de las libertades que le genera la multiactividad pensada desde lo productivo y a través de los vínculos y las satisfacciones sociales y culturales que le generan a cada uno de los participantes.

Para los habitantes del medio rural, reconocerse en la diversidad, es saber que no 
se termina la vida en el medio rural cuando uno pierde el trabajo, que la vida vivida (conocimientos, experiencia y vínculos) en el medio rural tiene valor, y es fundamental a la hora de buscar nuevos empleos o de continuar con propuestas productivas auto generadas, compartidas con vecinos y que se convierten en forma de vida.

El fenómeno de migración rural -urbano trae aparejado en las comunidades del interior una fuerte interpelación a sus valores, sus lugares, sus trabajos, en definitiva a su territorio. Tomar dimensión de este proceso, de cuales han sido y son los elementos puestos en juego por los empleados rurales para adaptarse y permanecer en algunos casos y para comenzar un nuevo tipo de vida en otros, forma parte de los justificativos de esta investigación.

Cómo las estrategias de vinculación, los saberes ancestrales y la educación formal, definen la viabilidad de distintos proyectos de vida, el rol del empleo rural y sus variantes, entre ellas la morada familiar. La tesis supone un esclarecimiento y una visibilidad de la variabilidad de actores que todavía trabajan y viven en el campo y que son cada ves mas, protagonistas necesarios del territorio.

Es importante recalcar que en términos generales los empleados rurales como tales no son tan abordados como sujetos de investigación en la bibliografía y menos aún son considerados actores verdaderos e importantes en el desarrollo rural, en este sentido el movimiento CEPT ha venido demostrando lo contrario en los territorios rurales más variados dentro de la provincia de Bs. As.

Para los municipios y comunas, conocer cuales son los actores que viven realmente en el campo, como se relacionan y actúan con el territorio, saber que muchos empiezan a aparecer además como productores de alimentos frescos, sanos, de la zona, que empiezan a generar un tejido productivo que absorbe e incorpora mano de obra que de otra manera seria sujeto de asistencia municipal (con una complejidad por todos conocida) es muy importante.

A su vez le permite al municipio pensar y promover formas de integración con sectores industriales y de cadena de valor que de otra forma no podrían ser instalados, ejemplo de esto serian pequeños frigoríficos locales para animales menores, sala de elaboración de conservas, salas de extracción de miel, etc., todos generadores de mano de obra, ingresos, vínculos, en definitiva aumento de oportunidades.

También es útil para los municipios poder identificar cuales son las cosas que motivan al poblador rural, sus relaciones, sus tiempos libres y las demandas sociales y culturales que normalmente las resuelven por la vía privada, con el fin de hacer 
realmente un abordaje integral de la vida rural y empezar a plantear estrategias de intervención que superen las actuales que en términos generales resultan escasas y poco integradoras.

Para los gobiernos provinciales y nacionales significa tener herramientas para poder empezar a solucionar el gran problema de las mega-urbanizaciones, frenando el flujo de emigración, reconstruyendo el tejido rural e invirtiendo ya no en asistencia en la ciudad sino en producción e infraestructura en el campo, no ya solamente desde una mirada productiva sino entendiendo al territorio rural en su conjunto, expresado en los habitantes reales del campo, los empleados. De esta manera el gobierno además de lo dicho, esta ejerciendo su soberanía alimentaría como parte de su función intrínseca.

También pone al estado a pensar en un nuevo marco regulatorio en términos generales, legal, bromatológico, laboral, fiscal, etc. que escape de la trampa del mercado, que hizo que no se pueda producir alimentos en las comunidades sino se es una mega empresa, desconociendo la realidad que acontece todos los días en el medio rural.

Para los habitantes comunes de los pueblos y ciudades la importancia pasa por establecer otro vinculo con el empleado rural, que lo acerca a lo rural, que lo vincula con los actores y su realidad y que le ofrece la posibilidad de consumir productos frescos y sanos, como los consumen los mismos pobladores. Esta nueva vinculación moviliza también otros valores del medio rural que tiene que ver con su cultura, sus costumbres y su relación con la naturaleza.

Por lo tanto, lo que tenemos para demostrar es que garantizando horas de trabajo en el campo, todos los días, con producciones diversas, sanas y frescas, en armonía con el medio ambiente, trabajando en familia y con vecinos (agricultura familiar), generando organización comunitaria, podemos satisfacer las necesidades que le permitan a las familias vivir dignamente en su lugar, sin necesidad de emigrar a buscar otras cosas y el trabajo que no existe en su zona. 


\section{ESTADO DE CONOCIMIENTO SOBRE EL TEMA - ENFOQUES TEORICOS}

Para la realización de la revisión bibliográfica se tomaron en consideración aspectos que tienen que ver con la pregunta de investigación como pluriactividad, multiocupación, empleados rurales, pueblos rurales.

En el análisis de los empleados rurales o trabajadores rurales dependientes, comenzamos con una conceptualización realizada por ANSALDI W. (1995): «trabajador rural es quien, a cambio de un salario percibido en dinero y generalmente complementado en especie (alimentación y vivienda), vende su fuerza de trabajo a un productor rural, un chacarero, un contratista de maquinaria agrícola, un acopiadorcomercializador de granos, cereales o ganado y/o un propietario de carros, quienes según Marina Bustamante y Gabriela Inés Maldonado se apropian del «plusvalor» por él generado".

Desde el punto de vista académico del análisis del empleado rural, es posible observar por un lado la influencia de los enfoques e intereses propios de la tradición de la sociología agraria y, por otro, de las perspectivas de análisis más afines a la sociología del trabajo. Mientras que la primera recupera ciertas dimensiones y enfoques clásicos que vinculan la problemática del trabajo agrario tales como la estructura agraria, la población y la tecnología; la segunda incorpora aspectos que tienen que ver con el funcionamiento de los mercados de trabajo y de los trabajadores/as así como de otros agentes vinculados al sistema productivo (Neiman, 2010).

En este sentido en Argentina han sido autores como Murmis en 1994 y Lara en 1998 quienes entre otros plantearon distintas combinaciones entre producción y trabajo que incluyen en diferente medida cambios tecnológicos, crecientes requerimientos de calidad de la producción, nuevos requisitos de calificaciones y de competencias, la profundización de la precariedad laboral, creciente residencia urbana y multiocupación de los trabajadores, y que estos procesos se pueden dar de diversas formas, incluso en forma simultanea o superpuesta.

Neiman y Quaranta (2000) plantea la tensión tradicional entre el trabajo permanente y el estacional con una tendencia al aumento de este último con dos fenómenos que conviven, por un lado una disminución real de los empleos fijos y por otro lado una especificidad y multiplicidad en los trabajos transitorios.

Neiman y otros en 2010 hacen un análisis muy minucioso de las demandas 
laborales de las principales producciones del país y para los cereales en pampa húmeda confirma lo que venimos planteando desde el problema mismo y es la escasa cantidad de trabajo requerido en la etapa productiva como también el aumento dentro de este del trabajo temporario y la figura del contratista.

Cloquell (citada por Murmis, 1996) hace un análisis sobre los trabajadores desempleados y con ocupaciones parciales y enumera los distintos mecanismos que articulan los estados nacionales provinciales y locales para el abordaje de este tema.

Varios autores citados por Neiman (Alfaro, 1999; Aparicio y otros, 2004; Bendini y Gallegos, 2001) plantean el aumento en los últimos 10 años del fenómeno de tercerización de trabajadores, vía empresas de empleo o seudo-cooperativas de trabajo que en realidad lo que hacen es desligar a las empresas agropecuarias de la relación de dependencia generando un vínculo de servicio con la cooperativa. Esto es cada vez más frecuente en las producciones regionales y en la actividad de cosecha, quedando por el momento fuera de nuestro trabajo de análisis.

Analizando la estructura y posibilidades del sindicalismo en el agro de la Argentina, Forni y Neiman (2001) sostienen que están relacionados con las condiciones del proceso de trabajo, el tipo de actividad, los cambios técnicos y las características que asumen los respectivos mercados de trabajo, quedando en la actualidad un cuadro complejo con mayor visibilidad en las producciones que plantean un vínculo estrecho con la industria y con productos de mucho trabajo manual.

En el marco de los trabajos referidos al tema de pluriactividad, Clara Craviotti (2000) hace un abordaje de la multiplicidad de combinaciones entre actividades productivas, profesionales y comerciales que se vienen desarrollando en el medio rural con una mirada desde los nuevos actores y su vínculo con las actividades externas.

Según menciona Guillermo Neiman (2001), en las últimas décadas numerosos estudios dan cuenta de la importancia que ha cobrado la "agricultura a tiempo parcial" entre las explotaciones familiares de algunos países de Europa, EEUU y Canadá. Mientras algunos autores prefieren plantear ese fenómeno en términos de agricultura "part-time" versus "full time" poniendo el acento en el tiempo dedicado al trabajo directo del productor y su familia en la agricultura, otros adoptan la denominación "pluriactividad" en contraposición a "monoactividad" haciendo mayor hincapié en la combinación de ocupaciones y su importancia para los ingresos de la familia. En este sentido vamos a trabajar con el concepto de empleados monoactivos para hacer referencia para los empleados que teniendo o no posibilidades no realizan ninguna 
actividad productiva extra a su trabajo

En su trabajo con Jiménez, Blanco y Bardomas (2006), plantean una variedad de causas de esta pluriactividad y describen algunos cambios de funciones con acciones concretas hacia adentro de la familia:

Producción familiar y actividad doméstica (mujeres y niños);

Trabajo fuera del predio (jóvenes);

Trabajo de producción en el predio (adultos).

Este concepto de funciones hacia adentro de la familia tiene una importancia dentro del trabajo de tesis ya que es uno de los argumentos fuertes desde donde vamos a trabajar los vínculos que se generan en esas situaciones y como afectan a los distintos miembros de la familia.

En este sentido es interesante el aporte que realiza Rossana Vitelli (2002)sobre la relación entre pluriactividad y genero en el sector agropecuario uruguayo. Establece la pluriactividad como una construcción ya no atribuible al productor o empleado rural en nuestro caso, sino como un proceso de reorganización familiar donde el peso del trabajo de la mujer y de los otros integrantes del hogar toma cada vez mas importancia. Plantea también otros impactos que tiene el proceso de la pluriactividad mas allá de los ingresos económicos y rescata la ruptura de la visión de trabajador familiar no remunerado, mejorando su autoestima y estableciendo una nueva relación con la familia, distinta respecto del modelo anterior.

También reflexiona sobre los otros componentes del circulo familiar y como en la medida que van creciendo los chicos estos se incorporan al trabajo a través de las producciones familiares, estas se vuelven mas pluriactivas y mejoran su calidad de vida.

En Brasil, Schneider (1999) identifica actividad económica con mercados de trabajo en áreas rurales, que interactúa y articula con el trabajo en el predio, generando en muchos caso una adecuación de las actividades de la chacra a las actividades propias del trabajo afuera, los define como colonos-operarios.

Plantea a su vez un aspecto que es muy interesante y que interpreta a la pluriactividad ya no como una respuesta coyuntural a problemas de empleo sino que responde a una tendencia generalizada que se viene dando desde hace tiempo y responde a nuevas formas de inserción en la división social del trabajo.

En concordancia con Schneider (1999) consideramos el carácter permanente de la pluriactividad como un tipo de combinación de actividades mas o menos 
estabilizadas y no un planteo coyuntural de crisis como se considera en muchos casos.

Con un planteo mas cercano a nuestro abordaje de la problemática de los empleados rurales, Giarraca y Aparicio (1991) plantean el concepto de multiocupación para analizar el caso de cañeros en Tucumán, que alternan su trabajo en pequeñas chacras de actividades de autoconsumo y subsistencia, con el trabajo temporal en la agroindustria (cañera y limonera). En base a lo que estamos trabajando se adapta muy bien a la situación de los empleados rurales de nuestra zona, que si bien tiene diferencias sobre todo en cuanto a la temporalidad del mismo, plantean la alternancia y la presencia de un trabajo asalariado.

Un planteo similar de multiocupación plantea Martha Radonich (2003) para trabajadores frutihórticolas de Neuquén, diferenciando en su análisis su condición de migrantes y su localización periurbana marginal y como esto influye en sus alternativas laborales y las de sus esposas e hijos.

Para este trabajo vamos a tomar este concepto de multiocupación desde una óptica del empleado como una de las estrategias que tienen los empleados rurales de superar sus precarias condiciones de empleo, salariales y de capitalización para mejorar su calidad de vida y lo vamos a definir como multiocupación rural, diferenciándolo así a los planteos de pluriactividad que vienen derivados de un deterioro de la condiciones de productor, como de las situaciones de los empleados temporarios de economías regionales que alternan empleos industriales o urbanos con su actividad rural de base.

Se va a ir construyendo este concepto de multiocupación rural partiendo del análisis de la situación de empleados rurales, sean permanentes, temporarios o desocupados que además se convierten en productores de alimentos y servicios dentro del mismo sector rural, ya no solamente agrario.

Entendemos que si bien la pluriactividad es un concepto que comparte una gran cantidad de componentes con el concepto de multiocupación, hace referencia a la participación de productores rurales de origen, pequeños y medianos sin distinción como así también le dedica un capitulo importante a los nuevos actores rurales que en muchos casos provienen de otros sectores como el profesional y el de empresarios de origen urbano.

Sin embargo resulta interesante el aporte que hace el estudio de las distintas posibilidades de trabajo en los pueblos rurales, en las pequeñas ciudades y 
últimamente en esta nueva modalidad de trabajo a distancia.

También resulta importante el análisis que Schneider (1999) en este marco de pluriactividad realiza de lo que se llama trabajo no agrario en el medio rural, que si bien no es una alternativa muy difundida en nuestra zona, interesa mencionarlos como posibles estrategias de desarrollo y promoción de empleos en el medio rural.

Por estos motivos optamos por trabajar con el concepto de multiocupación con las particularidades que ya hemos descripto en párrafos anteriores.

En cuanto al tema de pueblos rurales Hugo Ratier (2009) nos plantea la importancia de buscar para nuestro pueblo los motores de sociabilidad y como estos derivan de acuerdo a las distintas características de cada uno de los actores (empleados rurales y otros) en la formación de los llamados núcleos de sociabilidad.

Recalca también, las características de los pueblos en este fenómeno que Mendras (1978) define como interconocimiento donde cada uno conoce el mundo actual y pasado de todos.

Sobre los pueblos del territorio en estudio, vale aclarar que el termino "pueblo rural" engloba varias acepciones que nos van a facilitar su significado. Tal como lo marcan en su trabajo de 2008 sobre revisión del concepto de ruralidad, Castro y Reborati coinciden en señalar que en una gran cantidad de países incluyendo Argentina, la definición mas utilizada se refiere a la cantidad de personas que forman parte de una aglomeración urbana, en este caso la cantidad de 2000 personas es lo que de define en términos estadísticos como limite de un conglomerado rural, a partir de ahí seria un conglomerado urbano.

Evidentemente existe un acuerdo generalizado de que esta visión dicotómica ruralurbano carece hoy día de significado e infiere a una interpretación geográfica muy alejada de la realidad. Una propuesta superadora que se esta proponiendo es avanzar sobre la dimensión poblacional del concepto para ir a una dimensión mas espacial. El concepto de territorio introduce una serie de variables como son el uso de suelo, la construcción de redes de centros poblados, la topografía y la distancia. El cambio en la complejidad del término hace que sea de más difícil implementación y por eso todavía esta en proceso de evolución.

Desde lo antropológico, Ratier (2009) plantea la existencia de una cultura rural bonaerense, que engloba una serie de características que también se observan en nuestras comunidades de estudio y que van desde un culto a lo gauchesco a través de asociaciones, fiestas cívicas, deportivas ecuestres y religiosas, el uso de vestimenta 
características; hasta la existencia de formas económicas no orientadas exclusivamente por el lucro, como actividades solidarias, etc.

Si bien la penetración de la globalización ya es un hecho verificable a través de la presencias de la mayoría de los avances tecnológicos actuales (Internet, televisión satelital, telefonía móvil, etc.) existe un alto sentido de pertinencia y de construcción de identidad que sigue muy activo.

\section{PREGUNTA DE INVESTIGACION}

Como influyen las actividades productivas de los empleados rurales en los vínculos dentro de la familia y en su relación con la vida social de los pueblos y su entorno?

\section{OBJETIVOS}

\subsection{OBJETIVO GENERAL}

Caracterizar la dimensión productiva de las estrategias de reproducción social de los empleados rurales de la zona de De la garma y Juan E. Barra y su influencia en las relaciones sociales y de trabajo de las familias de los empleados y en el desarrollo del territorio.

\subsection{OBJETIVOS ESPECIFICOS}

a- Caracterización de los empleados rurales según: su actividad salarial, tipo de familia, condiciones de empleo y estudio de los hijos.

b- Caracterizar las actividades extra salariales (con énfasis en las productivas) de las familias de los empleados rurales.

c- Estudiar en que medida el desarrollo de actividades productivas contribuye a crear nuevos vínculos sociales entre las familias estudiadas y otros actores en la zona de estudio.

\section{6-. HIPOTESIS}


- La realización de actividades diversas extra asalariadas está relacionada con ciertas características del empleado: actividad salarial, residencia, tipo de familia, tamaño y cantidad de empleados del establecimiento, asistencia al secundario técnico, y otras acciones de desarrollo.

- La multiocupación pasa por la participación directa de otros miembros de la familia. Esto cambia las actividades realizadas por sus integrantes, sus vínculos en el seno familiar y sus vínculos sociales locales. El hecho de que la mujer o los chicos sean responsables de una producción puede mejorar su situación y su autoestima a partir de la generación de ingresos y vínculos.

- la realización de actividades productivas cambia los vinculos sociales de la flias de empleados rurales con sus vecinos y con el pueblo, esto pasa por la constitucion de redes de comercializacion directa, trueque, aumentar la frecuencia de viajes. 


\section{CAPITULO 1: DESCRIPCION DE LA ZONA DE ESTUDIO}

\subsection{Descripción de la zona, el distrito de Chávez}

El distrito de A. G. Chávez se encuentra en lo que se denomina zona mixta del sur bonaerense y dentro de esta en una sub-zona denominada mixta sur y a su vez dentro de esta sub-zona estamos en la parte llamada continental de la misma.

En términos de zonas agro ecológicas el distrito comparte claramente dos zonas bien diferenciadas y una zona de transición.

El sector del noroeste del distrito corresponde a la denominada depresión de Laprida, sector bajo, con problemas de calidad de suelo, hidro-mórficos, con exceso de sales en agua y con periodos de anegamiento importante. Con algunas características similares a la depresión del salado lo diferencia sus temperaturas medias mas bajas lo que genera una oferta de pastizales naturales de inferior calidad y mucho mas estacionada. Además la depresión y la zona de transición presenta tosca en y cercana a superficie lo que dificulta el almacenaje de agua.

La zona este (ruta nac. 3) plantea características de una zona con lomadas, con drenaje de agua hacia el mar, final del sistema de Tandilia que brinda características de buena calidad de suelo, aumento de la profundidad a medida que nos acercamos al mar y un milimetraje mayor.

Existe en la zona central del distrito una interface que plantea la integración de los dos sistemas que genera un mosaico de tipos de suelo y relieve que le den las características de zona mixta. Se forman en esta zona gran cantidad de lagunas que limitan con campos de excelente calidad agrícola y lomas de tosca sin aptitud. Esta complejidad permite que en los establecimientos tengan zonas agrícolas y ganaderas contiguas que van a influir en los planteos productivos. Es precisamente esta zona central donde se encuentran ubicadas las localidades de De la Garma y Juan e. Barra, base del área de análisis del trabajo.

Esta característica de zona mixta favorece la presencia tanto de empleados agrícolas como ganaderos, generando una variabilidad de situaciones de empleo que nos interesa conocer. Pero a su vez nos abre el interrogante de cómo cada uno de estos grupos de empleados ha podido desarrollarse y generar características que les son propias y que los distinguen del resto de la población rural. 
Ubicación del distrito de Gonzáles Chávez en la provincia de Buenos Aires

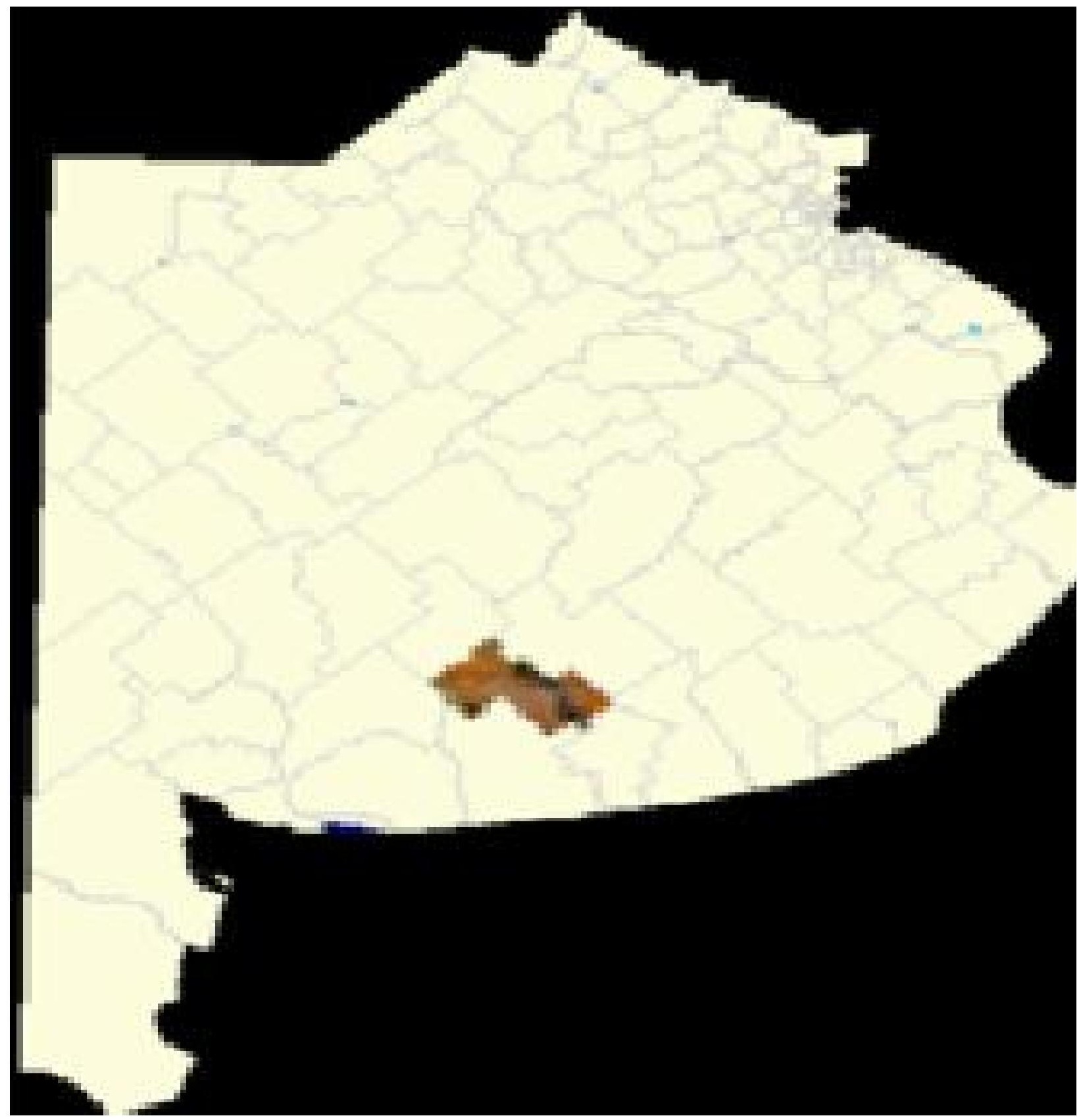

Fuente: Raíces Pampeanas

También en este sentido, es interesante como esta zona va cambiado sus actividades productivas de acuerdo a las adecuaciones de mercado que se van sucediendo en los distintos ciclos y estas generan movilidad, aparición/desaparición de trabajos y adaptación de los empleados a las nuevas condiciones. 
En toda la zona se plantea la limitante para la actividad agrícola que significa la presencia de tosca de carbonatos de calcio en profundidades que van de $80 \mathrm{~cm}$ hasta la superficie en las lomadas. Este gradiente de profundidad en la que se encuentra la tosca va aumentando hacia el este.

Tabla 1 - Características climáticas del distrito de Gonzáles Chávez

\begin{tabular}{|c|c|c|c|}
\hline Pp media anual & $\mathrm{T}^{\circ}$ media de enero & $\mathrm{T}^{\circ}$ media de julio & Días libres de hel. \\
\hline $702,3 \mathrm{~mm}$ & $22,3^{\circ} \mathrm{C}$ & $7,4^{\circ} \mathrm{C}$ & 210 (OCT-ABR) \\
\hline
\end{tabular}

Fuente: Chacra experimental de Barrow, área climatología

La zona tiene una temperatura máxima media de $29.5^{\circ} \mathrm{C}$, en el mes de enero y una temperatura mínima media de $2.2^{\circ} \mathrm{C}$, en el mes de julio.

El otoño es la estación con un balance de positivo de evapotranspiración, lo que beneficia a los cultivos de cereales de invierno. En el resto del año las precipitaciones se distribuyen uniformemente. Este fenómeno afecta también, según lo planteado por varios entrevistados, las condiciones de transitabilidad de los caminos, influyendo en temas muy sensibles a la población rural como son la posibilidad de salir del campo, la asistencia de los chicos a la escuela y a los centros de salud.

También se presenta granizo y pedrisco acompañados por fenómenos eléctricos, principalmente en verano, pero no se dan con frecuencia. Las sequías son raras pero en los últimos años han sido muy severas.

En cuanto a los establecimientos agropecuarios del distrito, hay una gran diversidad que se manifiesta en cada una de las zonas agro-ecológicas antes mencionadas. Conviven en el distrito grandes establecimientos de firmas importantes nacionales y extranjeras, productores medianos y pequeños propietarios de parcelas de subdivisión familiar.

Desde hace tiempo se registra una tendencia a la concentración de las explotaciones, con una fuerte disminución en la cantidad de las de menor tamaño y un aumento en las explotaciones grandes que trabajan mas de 1000 has. 
Plano de la zona de estudio

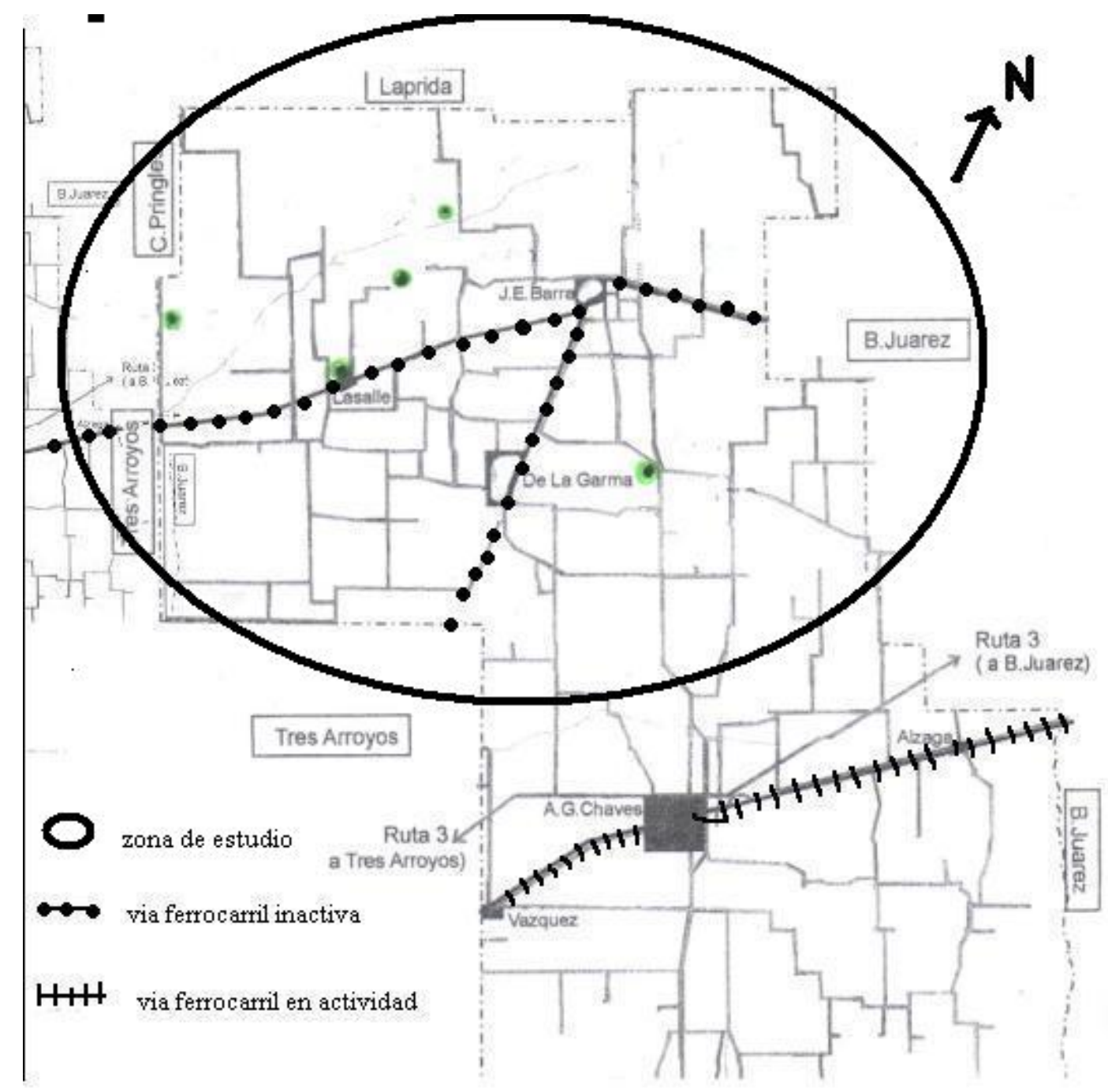

Fuente: CEPT 19 Juan E. Barra

Es sin embargo importante destacar que la movilidad parcelaria ha sido mucho menor, dando la información de que ha aumentado el trabajo sobre campo arrendado y esto tiene influencias también sobre los empleos rurales y sus condiciones laborales. Generalmente las parcelas de arrendamiento no tienen el tamaño suficiente ni las comodidades de trabajo necesarias para establecer un empleado estable en el caso de la actividad ganadera, motivando que el empleado viva en otro puesto o que directamente viva en el pueblo y se traslade con el productor o por sus medios al campo a trabajar en forma diaria o con una frecuencia mayor. 
En cuanto a las parcelas de destino agrícola, generalmente no cuentan con instalaciones, ya que se arriendan lotes por separado y esto obliga a establecer el centro de actividades en otro lugar. Si el productor tiene campo, se organiza en el mismo y sino en las afueras de los pueblos como referiremos mas adelante. En otro sentido la modalidad de arrendamiento le permite a los productores agrícolas maximizar la ocupación de su parque de herramientas lo que permite ampliar el tamaño de las empresas pero en paralelo disminuye el numero final de productores como mencionamos anteriormente y se observa en la disminución vista entre los censos del 1988 y del 2002 (ver tabla 2).

En el cuadro de más abajo se muestra cual es el rango de superficies y la cantidad de establecimientos en cada grupo, notando una disminución de la cantidad total de establecimientos y un incremento en la franja de establecimientos de más de 1000 has.

Tabla 2 - EAPS en el distrito de Gonzáles Chávez

\begin{tabular}{|l|c|c|c|c|c|}
\hline & $\begin{array}{c}\text { Hasta } \\
200\end{array}$ & $\begin{array}{c}\text { De 200 a } \\
500 \text { has. }\end{array}$ & $\begin{array}{c}\text { de } 500 \text { a } \\
1000 \text { has }\end{array}$ & $\begin{array}{c}\text { Mas de } \\
1000 \text { has }\end{array}$ & Total. \\
\hline EAPs 88 & 160 & 190 & 108 & 69 & 527 \\
\hline Has. & $14.184,8$ & $63.509,8$ & $76.760,3$ & 179.676 & 334.131 \\
\hline EAPs 02 & 76 & 86 & 89 & 91 & 342 \\
\hline Has. & 8.335 & 28.468 & 63.910 & 201.873 & 302.585 \\
\hline
\end{tabular}

Fuente: CNA 1988 y CNA 2002

\subsection{Cambian las actividades productivas}

Las actividades productivas han sufrido en las últimas dos décadas grandes cambios tecnológicos que han motivado un cambio en las características, funciones y en la organización del trabajo mas industrial, con variaciones en cantidad de recurso humanos (empleados rurales) y en las formas de relacionarse que se utilizan para el buen funcionamiento de los sistemas productivos (Forni y Neiman, 1991).

La incorporación de la técnica de siembra directa en el distrito comenzó en los años 1999-2000 de manera simultanea a la aparición de la soja transgénica de grupos bajos adaptada a zonas mas frías como la nuestra (prácticamente no se hacia soja en la zona en la versión convencional). La utilización de glifosato permitió incorporar lotes a agricultura que estaban en zonas de transición con malezas difíciles como gramón y 
ray grass criollo, ampliando notablemente el área agrícola (ver tabla 3).

La siembra de soja en directa consolido un proceso ya existente de contratismo rural, en este caso de siembra directa, que sumado a la utilización de la técnica en trigos, verdeos y en el doble cultivo cebada - soja de segunda, genero un amplio mercado para este servicio, modificando notablemente la forma de hacer agricultura en la zona.

Sin embargo estos cambios tecnológicos y productivos no han sido expresados por todos los productores de manera similar, lo que ha generado una gran diversidad de formas de trabajo y por consiguiente un abanico muy grande de empleados rurales con características y funciones diferentes y por consiguiente con estilos de vida y modelos de desarrollo distintos.

Si bien hay un uso masificado de la técnica de siembra directa en la zona de estudio, la presencia de productores asociados a APRESID ( Asociación de Productores de Siembra Directa) que en el año 2005 crearon la filial Tres Arroyos de APRESID ha generado un núcleo de productores mas tecnológicos que basaron su actividad en la agricultura de cosecha, y que se mueven de manera empresarial.

Tabla 3 - Evolución de la superficie agrícola y de las existencias de bovinos para carne en el área de influencia de la CEI Barrow. (Tres Arroyos, Gonzales Chaves, Dorrego y San Cayetano) Superficie total de los cuatro partidos $=1.707 .683$ ha

\begin{tabular}{|c|c|c|c|}
\hline & Año 1987 & Año 2007 & Año 2010. \\
\hline $\begin{array}{c}\text { Superficie } \\
\text { agrícola (ha.) }\end{array}$ & 1104489 & 1450908 & 1438412 \\
\hline Fina (ha.) & 840000 & 759945 & 735808 \\
\hline Guesa (ha.) & 464489 & 690963 & 702604 \\
\hline $\begin{array}{c}\text { Existencias } \\
\text { bovinas (cab) }\end{array}$ & 797273 & 844372 & 736689 \\
\hline $\begin{array}{c}\text { Vacas (\%) } \\
\text { Terneros/vacas }\end{array}$ & 37,5 & 38,6 & 38,9 \\
\hline
\end{tabular}

Fuente: Área ganadería, Chacra Experimental Integrada Barrow

Si bien el trabajo de Duhalde et al (2011) refiere a los cuatro distritos del área de 
influencia de la Chacra de Barrow, es completamente representativo de lo que sucede en nuestra área de estudio. Donde observamos un aumento del $40 \%$ del área agrícola en los últimos 20 anos, representado por un incremento de $51 \%$ del área destinada a granos de cosecha gruesa, principalmente soja, equiparando prácticamente la superficie destinada a granos finos, muy característicos de esta región.

En cuanto a la situación ganadera, ha existido un proceso de intensificación que como plantea Duhalde et al. (2011), supone un mejor índice de producción de terneros y una mayor concentración de la actividad de cría, manteniendo el numero general de vacas, dejando espacios para la actividad agrícola, fundamentalmente para la incorporación de soja en la rotación.

En la zona ganadera la utilización de siembra directa en la siembra de verdeos de invierno (básicamente avena y ray grass) permitió una mejora en su utilización por la mejor situación de piso y esto genero una progresiva incorporación de la técnica, que al no tener maquinaria propia la realizaban con la modalidad de contratismo rural.

Los cambios en la realidad productiva se observan también en el aumento de las actividades realizadas por productores grandes incorporando el servicio de siembra a terceros con su maquinaria propia a lo que se le han sumados otros servicios mas nuevos como el embolsado de cereales y la cosecha de granos.

La aparición de nuevos actores (pluriactividad) como profesionales y comerciantes también contribuyo en la zona a este fenómeno de cambio, siendo en general personas mas proclives a incorporar estas tecnologías.

En otro segmento se destacan las estrategias adaptativas de pequeños y medianos productores, la sobrevivencia de las unidades familiares vinculadas también a estrategias de pluriactividad, y la multiocupación de los trabajadores rurales y golondrinas unida a su creciente movilidad territorial (Bendini 2003).

Clara Craviotti (2006) manifiesta que "entre las profundas transformaciones que experimenta el medio rural de la Argentina, una de ellas es la declinación de la agricultura como fuente de empleo y de la fase propiamente agrícola de la producción agroalimentaria".

A pesar de ello en los últimos años ha habido un corrimiento de la frontera agrícola motivado por los aumentos de los niveles de rentabilidad relativa que llevaron a la ganadería a ocupar espacios con menos aptitud y menor superficie.

En nuestra zona esto se nota en el número total de empleados que ha disminuido notablemente, pero simultáneamente se observa la presencia de nuevos empleos en 
el sector de servicios al agro y de comercialización como lo veremos con más detalle en capítulos siguientes. Otra particularidad es que por lo observado en las empresas de la zona de estudio, estos trabajos no agrarios creados en el área de servicios no corresponden totalmente a ex empleados rurales, sino que son empleos administrativos y técnicos generados en el sector urbano.

Si bien no tenemos los datos del distrito de Gonzales Chaves en particular, en términos generales se puede observar que se bien el total de población rural disminuye, hay un aumento relativo de la población rural que vive agrupada en pequeños pueblos y ciudades rurales en detrimento de la población que vive dispersa en espacio abierto o en agrupaciones que no superen los 2000 habitantes.

Tabla 4 - Distribución de la población rural

\begin{tabular}{|c|c|c|}
\hline Total del país & Año1991 & Año 2001 \\
\hline Población Rural total & 4.179 .418 hab. & 3.828 .180 hab. \\
\hline Agrupada & 1.118 .092 hab. & 1.223 .533 hab. \\
\hline Dispersa & 3.061 .326 hab & 2.604 .647 hab. \\
\hline Prov. De Buenos Aires & Año1991 & Año 2001 \\
\hline Población Rural total & 608.265 hab. & 502.962 hab. \\
\hline Agrupada & 181.185 hab. & 202.582 hab. \\
\hline Dispersa & 427.080 hab. & 300.380 hab. \\
\hline
\end{tabular}

Fuente INDEC, Censo Nacional de Población y Vivienda 1991 y 2001. 


\subsection{Los pueblos}

El nacimiento del pueblo de De la Garma como el de Juan E. Barra responde como en la gran mayoría de los pueblos de la región al periodo que acompaña a la expansión del sistema ferroviario diseñado para poder sacar a puerto toda la mercadería que se genero en esta zona a partir de la completa liberación para la producción. Esto se concreto a través del genocidio y dominación de los pobladores aborígenes conocido como "la campaña del desierto" realizado en la segunda mitad del siglo 19.

Los dos pueblos en estudio están ubicados sobre el tendido de la línea ferroviaria Barrow - Laprida que incluyo las estaciones de Vaquerías, Claudio Molina, De la Garma y Juan E. Barra y que quedo inconcluso desde ahí hasta Laprida. La construcción se inicio en 1909 y termino en 1912

Las estaciones se ubicaron estratégicamente cada $17-20 \mathrm{~km}$. una de otra, garantizando una logística de acopio y transporte de productos del campo, que luego fue acompañado con el transporte de pasajeros, muy utilizado por los pobladores de la zona.

Con posterioridad, en el año 1929 se construye el ramal Barra - Chillar de 76 Km. y Barra - Dorrego de $118 \mathrm{Km}$. generando en Barra una estructura ferroviaria importante, con cruce de vías, una colonia de once casas y soltería, maquina de dar vuelta locomotoras y un pequeño taller de reparación. En este ramal esta ubicada la estación de Pedro Prospero Lasalle, otrora un paraje muy activo tanto social como productivamente y que en la actualidad se encuentra solamente con la escuela primaria y jardín de infantes.

Este paraje de Lasalle supo tener una actividad muy intensa debido a la presencia de varias empresas acopiadoras de cereales, hacienda lanar y vacuna, generando un gran movimiento de empleados rurales durante la época de cosecha y esquila. 
Foto 1, Imagen satelital de Pedro Prospero Lasalle

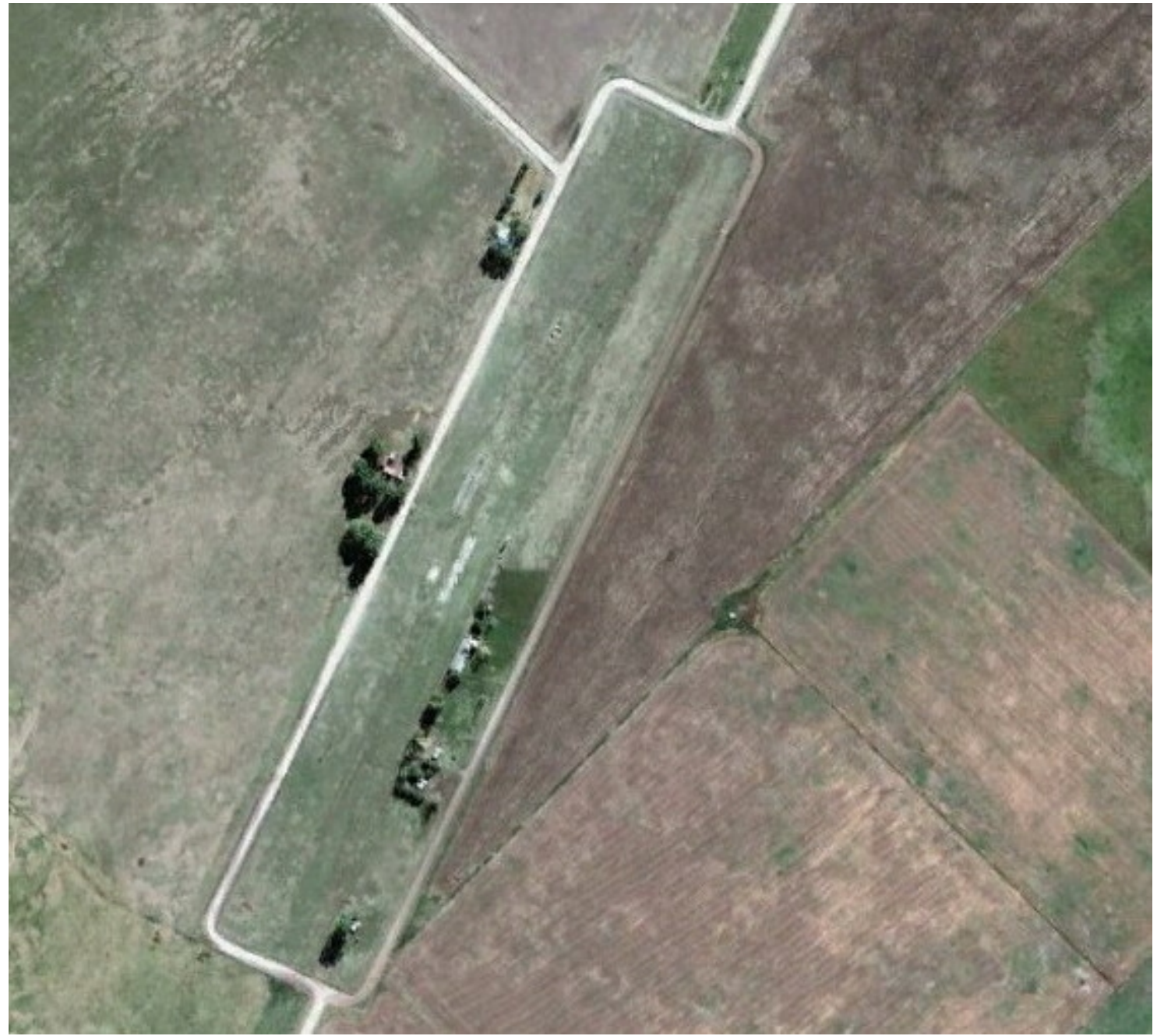

Fuente: Google Earth

Sin embargo al desaparecer el ferrocarril y al no poder contar en esos momentos con energía eléctrica para el funcionamiento de las plantas de silo, las principales firmas mudaron su acopio a De la Garma, llevándose consigo las familias que vivían en esa estación. Posteriormente cerro el club social, muy conocido por sus fiestas sociales, campeonatos de fútbol de campaña y bochas, un lugar de socialización muy sentido por la comunidad rural de la zona. 


\subsubsection{De la Garma}

Foto 2, Imagen de la localidad de De la Garma y zona de quintas

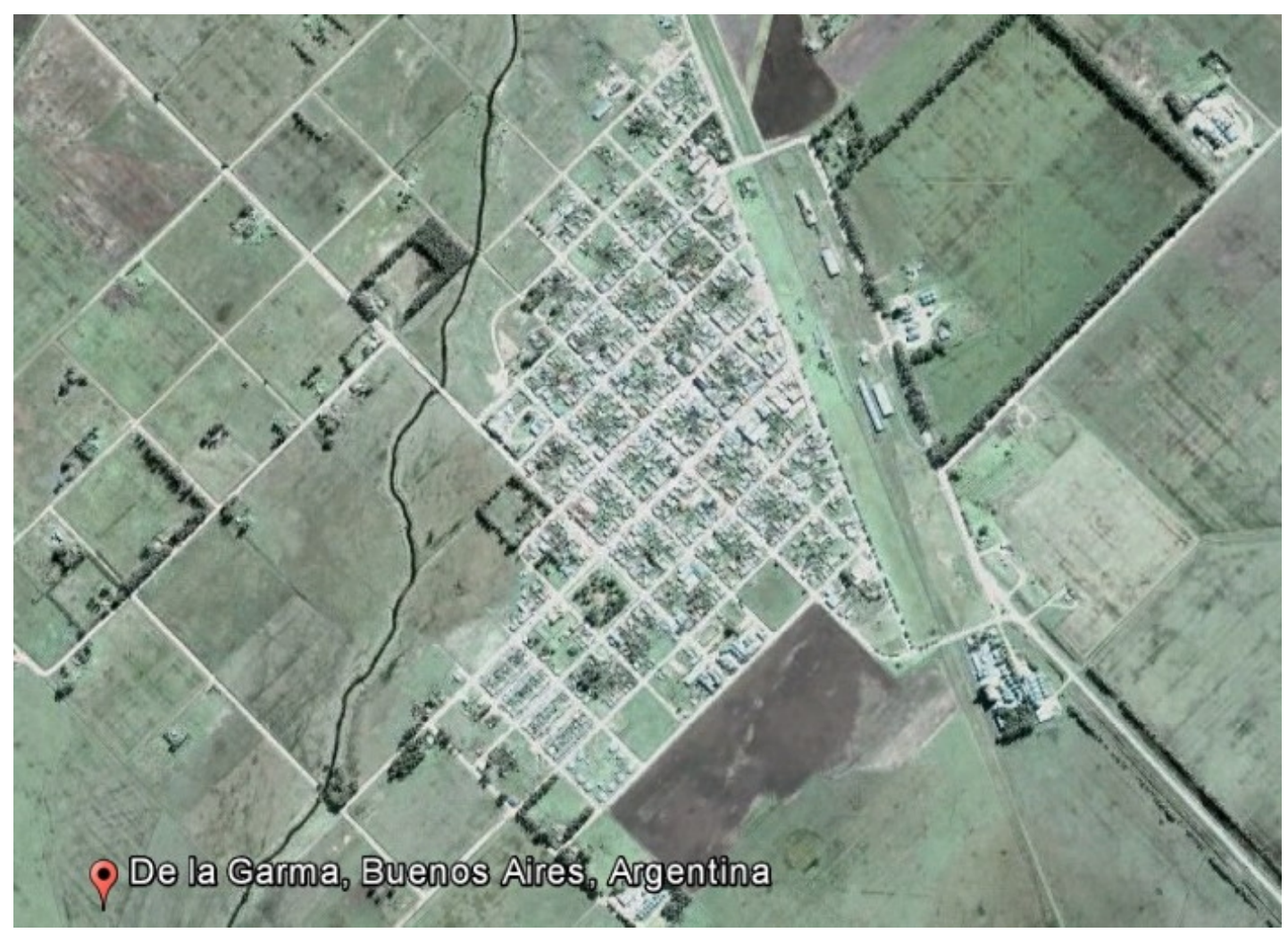

Fuente: Google Earth

El pueblo se funda formalmente en diciembre de 1912, sobre las vías del ferrocarril, si bien era una estación de paso, la importancia de los establecimientos cercanos hizo que el pueblo pronto se expandiera a través de la concreción de un loteo y el afincamiento de una cantidad importante de almacenes, talleres y escritorios.

En ese momento pertenecía al distrito de Benito Juárez hasta que en 1916 se crea el distrito de Adolfo Gonzáles Chávez. La existencia de propietarios de grandes campos y a su vez comerciantes y profesionales, hizo que el pueblo tenga un desarrollo vertiginoso desde sus comienzos favoreciendo la radicación de numerosas firmas comerciales del sector agropecuario (escritorios de hacienda, acopiadores de cereales, barracas de cueros y productos del lugar, talleres, etc.) como de otros rubros (tiendas de ropa, almacenes de ramos generales, hoteles, restoranes, etc.)

En la década del 20 la localidad ya superaba ampliamente los 1000 habitantes y seguía teniendo una afluencia importante de persona de los distritos vecinos que veían 
una posibilidad de desarrollo en este pueblo floreciente.

La constante evolución plantea la incorporación de servicios comunitarios y comerciales que generan una dinámica diaria donde la población rural también participa activamente. Muestra de esto es la creación del registro civil, escuela primaria, sala de primeros auxilios con medico permanente, como así también la existencia de un periódico local y la creación de una sucursal del Banco de la Provincia de Buenos aires.

En la década del 50 con la población establecida en el orden de los 2000 habitantes, comienzan a realizarse servicios urbanos como los primeros asfaltos en las calles centrales, la ampliación de la escuela primaria la extensión del servicio de luz eléctrica y el servicio telefónico. En la década del 60 se plantea la construcción del asfalto que une al pueblo con la ruta nacional 3 teniendo que ser repavimentado a mediados de la década del 70.

En el año 1968 se crea la escuela secundaria, hecho que favorece la educación de numerosos chicos que no cuentan con la posibilidad de viajar a Chávez o Tres Arroyos en busca de una escuela. Como solía suceder en épocas de gobiernos no legítimos, la escuela recibe el nombre de " coronel Álvaro Barros" militar destacado en la zona durante el genocidio conocido como campaña el desierto.

A partir de la década del 70 la comunidad se estabiliza en la cantidad de 1800 habitantes, población que mantiene con altibajos hasta la actualidad. En 1977 deja de pasar por De la Garma el tren de pasajeros quedando el servicio solamente para cargas.

En la década del 80 aprovechando la construcción de una planta de bombeo del gasoducto que une el norte de Neuquén con Buenos Aires se incorpora en la comunidad el servicio de gas natural, incluso mucho tiempo antes que este servicio este disponible en la ciudad cabecera.

En el año 1990 deja de funcionar el tren de cargas y se cierra la estación del ferrocarril, terminando un ciclo de progreso que difícilmente se pueda volver a reeditar. Además del cierre de los ramales se procedió al levantamiento de todas las vías y durmientes, al desmantelamiento de los galpones y maquinarias ferroviarias en lo que va a quedar en la historia como una de las estafas mas grandes que sufrió el estado nacional en época de gobiernos democráticos.

Si bien esto impacto fuertemente en la dinámica de la localidad, fueron sin duda Juan E. Barra y los pequeños parajes de la zona (conocidas como estaciones) las que 
sufrieron las mayores consecuencias. Salvo el caso de Barra que todavía existe con una población mucho menor a la anterior, el resto de los parajes han desaparecido por completo quedando prácticamente sin pobladores y con el funcionamiento de una escuela rural a la que asisten los alumnos de la zona.

Cabe destacar que además de la destrucción del tejido social que tenían estas comunidades, que en algunos caso sobrevive a través de organizaciones gauchescas o productivas, se ha producido una perdida total de infraestructura social y productiva por la destrucción luego del abandono de las estaciones del ferrocarril, de clubes de campo y estructuras productivas como silos, galpones de estiba y corrales de carga de hacienda, tanto públicos como privados. Todos estos hechos contribuyen al gran éxodo de pobladores sucedido durante esta época.

Es interesante destacar como novedoso, por lo menos en nuestra zona la adjudicación de un barrio de 24 viviendas construidas por el ex Fo.Na.Vi (Fondo Nacional de Vivienda, organismo nacional dedicado a la construcción y financiación de viviendas en todo el territorio argentino) al sector social de empleados rurales en actividad. Esto genero una expectativa en un sector que hasta el momento no había sido tenido en cuenta en las políticas de vivienda. Sin embargo era condición para ser sujeto de adjudicación, habitarla en forma permanente. Es en términos prácticos la institucionalización de la modalidad de trabajo sin familia en el medio rural.

Sin embargo esto no se alcanzo a efectivizar en su totalidad ya que fueron muy pocas familias las que hicieron este cambio, muchas de las cuales ya vivían alquilando en el pueblo por la escolaridad de sus hijos jóvenes. La mayoría de las familias la utilizo como vivienda familiar de los fines de semana y luego fue morada de los hijos que venían a hacer la secundaria o que formaban pareja y la utilizaban como primera vivienda.

En la actualidad, De la Garma posee una estructura urbana con la mayoría de los servicios estando en construcción en sus etapas finales el servicio de cloacas y la reestructuración de servicios de residuos sólidos urbanos. 


\subsubsection{Juan Eulogio Barra}

Foto 3, Imagen de la localidad de Juan Eulogio Barra y sus alrededores

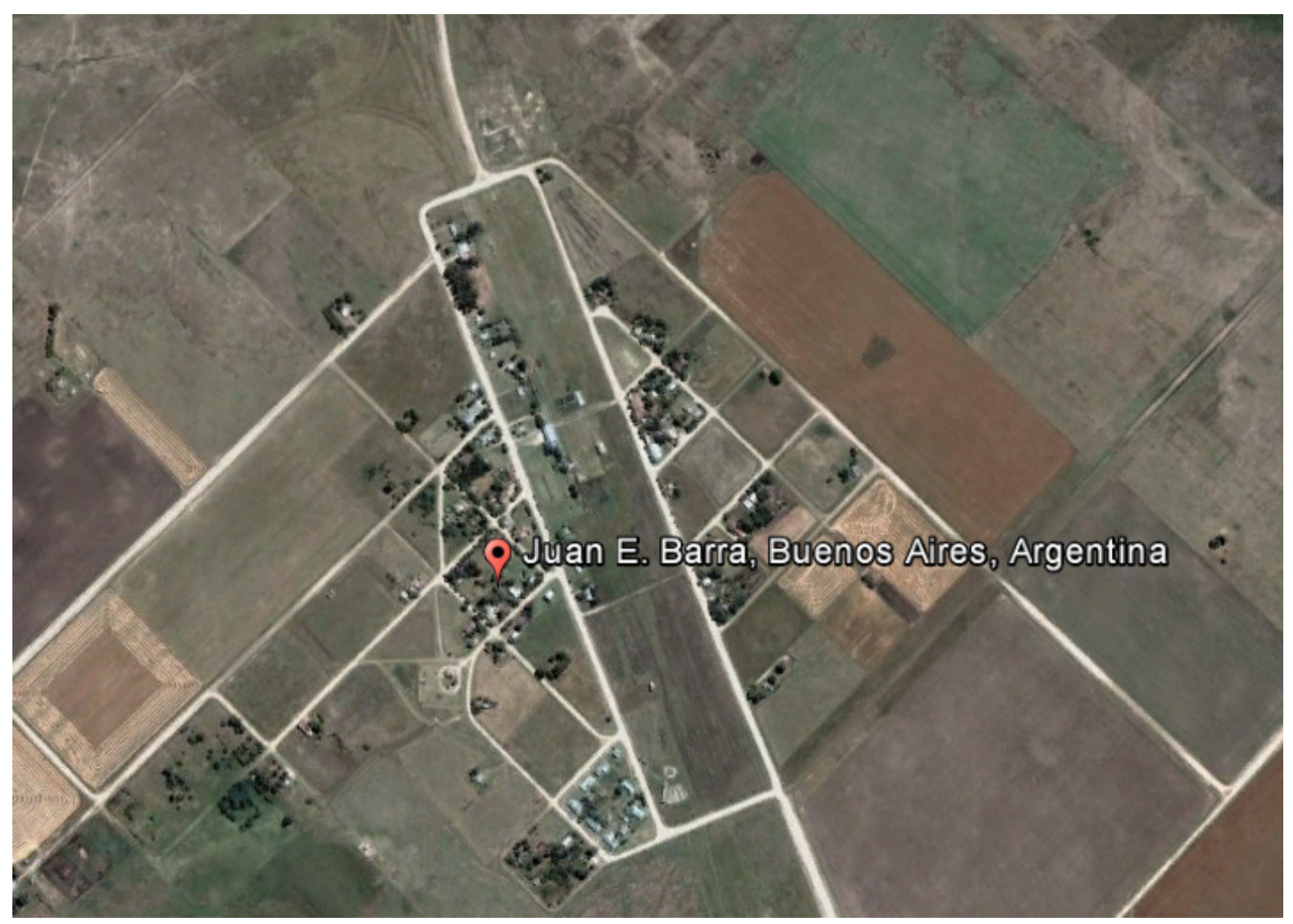

Fuente: Google Earth

La historia de Barra comparte sus inicios con De la Garma, la diferencia se establece por su ubicación más cercana a la zona ganadera y por la impronta ferroviaria que le dio su condición de cruce de ramales. Esto trajo aparejado un perfil más dependiente de las actividades vinculadas al ferrocarril, que luego actuó como definitorio ante el cierre del mismo.

Su perfil más ganadero hizo también que no se establecieran grandes comercios vinculados con los cereales quedando organizada una pequeña estructura de aprovisionamiento de las grandes estancias ganaderas de la zona.

La localidad no posee un acceso asfaltado si bien su acceso entoscado es transitable prácticamente siempre, salvo algunas excepciones producidas durante época de grandes inundaciones $(1980,2002)$ donde el camino se corto y el servicio se vio restringido al uso de emergencia con la utilización de tractores para transitar.

En los últimos años, la comunidad se ha visto beneficiada por la presencia de 
varios servicios entre los que se encuentran 2 escuelas secundarias, un servicio de agua potable con red domiciliaria, la presencia de servicio de enfermería tiempo completo y la construcción de 7 viviendas en el marco de programas estatales.

En la actualidad esta activo el club, teniendo la actividad de fútbol y el salón de fiestas para eventos sociales de la comunidad y la organización de bailes populares. La nueva comisión también organiza en forma anual, una jineteada a fin de año que ya tiene ganado un renombre regional. 


\section{CAPITULO 2: Materiales y métodos}

\section{1- Introducción}

Este trabajo de tesis se realiza en el marco de la maestría PLIDER en la sede La Plata en la cohorte 2010. Esto implica la simultaneidad del proceso de elaboración de la tesis y el cursado propiamente dicho.

Durante el primer año se planteo la elaboración del proyecto de tesis que culmino en febrero de 2011 y que luego de su defensa en abril dio comienzo a la investigación propiamente dicha.

En primera instancia se planteo una primera aproximación a la realidad general a través de una encuesta sencilla e introductoria que nos permita dimensionar en una etapa temprana las producciones y las trayectorias que tienen los empleados rurales de la zona. La misma se le realizo a los distintos tipos de empleados (agrícolas, ganaderos, mixtos, desempleados), que viven en la zona de estudio y que tienen trabajos en blanco. Esta situación de empleados registrados nos permite poder identificarlos, saber donde trabajan y si lo hacen en establecimientos donde además existen otros empleados.

Este primer contacto nos permite tener un barrido territorial importante permitiéndonos identificar por cercanía a aquellos empleados vecinos que viviendo en el campo no están registrados en la obra social y que de otra manera seria muy difícil identificar. A este grupo se suma el de los empleados ocasionales que realizan actividades de changas en forma autónoma, que por vivir en el pueblo o en la zona de quintas son mucho mas fáciles de visualizar y por lo tanto de ser estudiados en este trabajo.

Se realizaron un total de 45 encuestas a empleados rurales del área en estudio sobre un total de 145 empleados registrados, de los cuales 14 son empleados de un megatambo de reciente creación y 19 son trabajadores de las plantas de silos y estibadores changarines, con domicilio y características urbanas, por consiguiente no están incluidos en nuestro colectivo de estudio. Por lo tanto se encuesto casi el $40 \%$ de los empleados asalariados de la zona, eligiendo por lo menos un empleado de cada establecimiento.

Con respecto a los empleados sin registrar, si bien no están incluidos en las encuestas, si son tenidos en cuenta a la hora de realizar las entrevistas, ya que su 
situación de radicación mayoritaria en el pueblo permite una fácil identificación.

En este mismo sentido surge del relevamiento de empleados que la mayoría de los empleos estables en el sector ganadero están registrados, quedando pocos establecimientos ganaderos donde no se pudo establecer la situación de los empleados. Existe sin embargo una situación que sucede en estas empresas y es el no registro de los trabajadores temporarios que van a hacer changas por día en los corrales o en la época de parición.

Además se recurrió a informantes calificados como son el agente de la Fundación de Aftosa del distrito con sede en De la Garma, y a la titular de la oficina de la obra social de los empleados (UATRE) que nos brindo toda la información disponible así como el acceso a la base de datos de los beneficiarios.

A través de un análisis de interés realizado con el director de tesis se elaboro un listado sobre las características que tendrían que reunir los grupos de personas de las cuales se le realizaría una entrevista personalizada.

En una etapa posterior durante fines de 2012 y el verano de 2013 se realizaron las entrevistas en profundidad a los empleados rurales de las distintas actividades, a empleados de origen correntino, a empleadores, a personas encargadas de espacios de socialización y a autoridades de las comunidades involucradas.

Durante el proceso de investigación se realizaron observaciones y registros fotográficos en los eventos y lugares de socialización de los empleados rurales, tanto los del pueblo como los realizados en la zona rural y en parajes cercanos. En este marco se registraron también opiniones de distintos tipos de empleados referente a los temas que se desarrollaban y a sus experiencias en cada una de las situaciones planteadas.

Esta tesis ha tenido también el aporte en la discusión y observación del territorio realizado por un grupo de maestrandos PLIDER en la actividad T2 de la maestría que se realizo en las localidades de De la Garma, Juan E. Barra y Gonzáles Chávez entre los meses de junio y diciembre de 2012 con una estadía en territorio durante el mes de agosto.

Si bien el trabajo de investigación utilizará un enfoque metodológico cualitativo para el abordaje de la realidad de cada uno de los grupos de empleados rurales, su forma de interpretar la realidad, sus expectativas y sus realizaciones, también se realizaran análisis cuantitativos referidos sobre todo a aspectos productivos y económicos que influyan en la forma de vida de los entrevistados. 
Luego de la encuesta se realizo una selección de 15 empleados rurales a la que luego se le sumaron 6 empleados mas totalizando 21 empleados rurales para ser entrevistados tratando de poder dejar plasmado en este proceso de selección la variabilidad de situaciones vinculadas a la multi-ocupación familiar y a la diversidad de situaciones en las cuales estos empleados ponen en juego sus experiencias productivas y sociales utilizando el criterio de los que pueden mostrar avances y se reconocen productores y que han mejorado sus producciones en los últimos años.

También se eligieron empleados monoactivos, sin otra actividad productiva familiar para la comparación con los otros trabajadores.

Se le realizaron entrevistas semidirigidas a cada empleado y su grupo familiar. También se entrevisto a 5 personas y representantes de instituciones del pueblo que nos ayudaron a identificar vínculos con los pobladores rurales y su participación en la vida social del pueblo.

Con estas entrevistas se pretende investigar sobre las producciones, las trayectorias laborales, los ingresos y el vínculo que tienen con la producción

De la interacción de los dos análisis se plantea una tipificación de empleados agrupados por actividad de dependencia y relacionado con producción propia.

\section{2 - Métodos cuantitativos}

\subsubsection{Encuesta}

Si bien se ha discutido mucho sobre si la encuesta es considerada una técnica cuantitativa o cualitativa, se coincide con la opinión de Ángela Redondo Gonzáles (1998) que la define como una técnica mixta. Sin embargo la agrupamos a los fines de este trabajo de tesis en el grupo de métodos cuantitativos porque vamos a utilizar la operatividad de los resultados y su amplitud en el numero de encuestados.

Según Ángela Redondo González (1998) podríamos definir a la encuesta como "el conjunto de métodos, generalmente estadísticos, que permiten el estudio sistemático de determinados problemas (generalmente sociales y políticos), con el fin de reunir acerca de esto, observaciones rigurosas y formular hipótesis que puedan explicar los hechos observados".

En este sentido la posibilidad de rescatar a través de una serie de preguntas 
acotadas, seleccionadas y factibles de sistematizarse y analizarse en forma estadística nos permite hacer una primera aproximación a la diversidad de empleados rurales de la zona de trabajo de una manera rápida y sencilla, y en un tiempo acotado.

Sin embargo tenemos que señalar algunas de las limitaciones metodológicas que tiene que ver con la oralidad de la respuesta y la distancia que se manifiesta entre lo que el encuestado piensa y lo que es capaz de decir y que quede registrado como su respuesta.

Otra limitación tiene que ver con la durabilidad de las respuestas, que al ser circunstanciadas en un tiempo y lugar determinado, no tienen porque ser definitivas ni permanecer vigentes en el tiempo, pudiendo cambiar rápidamente según se den las circunstancias de los hechos.

Se realizaron 45 encuestas a empleados rurales de toda la zona de estudio. La encuesta se organizo en base a las siguientes preguntas, las que fueron realizadas a los empleados en sus hogares o se concretaron en su lugar de trabajo, dependiendo de la disponibilidad de los mismos.

1- Edad?

2- Donde vive su grupo familiar?

3- Estado civil y composición familiar?

4- Actividad en la que trabaja en relación de dependencia?

5- Si trabaja solo en el campo o lo hace junto con otros empleados?

6- Pluriactividad del empleado, si el hace otras cosas.

7- Pluriactividad de la familia, si la esposa o los chicos realizan otra actividad.

8- Si tiene producciones de animales de granja para autoconsumo?

En cuanto a los datos que se relevaron, se realiza una descripción de cada uno.

TRABAJADOR NUMERO: se identifican los productores con un numero a los efectos de guardar la intimidad de los encuestados y sus familias, quedando los nombres y su correspondiente numero en manos del investigador.

EDAD: Se computa la edad del empleado a cumplir durante el año 2013.

DONDE VIVE: en este ítem se plantea conocer cual es el domicilio familiar, donde esta 
radicado. En este sentido tenemos empleados que viven en los establecimientos donde trabajan, se conocen estadísticamente como población dispersa y mas allá de tener o no casa en el pueblo, desarrollan toda su vida familiar en el campo.

ESTADO CIVIL: Acá nos interesa saber si el empleado esta casado como para saber su posibilidad y sus expectativas de generar mas actividad mas allá de su empleo. En este caso se pregunto el estado actual, mas allá de si su estado ha sido permanente en este ultimo tiempo.

HIJOS: En este ítem se contabilizan los hijos que están en el ámbito familiar, que conviven en el seno familiar incluido los que trabajan y viven con la familia. No se contabilizan los hijos mayores que han formado otro hogar y no viven con esta familia.

ACTIVIDAD: en este ítem se pregunta sobre la actividad principal que realiza en su trabajo el empleado encuestado. Se considera como empleado agrícola al que trabaja su mayor parte del tiempo con maquinaria agrícola. Muchos de ellos forman parte de equipos de trabajo que trabajan en empresas que brindan servicios a terceros.

El trabajo en ganadería es el que se realiza en el marco del trabajo con animales, fundamentalmente bovinos. Tanto a campo abierto como en corrales que existen en muchos establecimientos. Los empleados llamados mixtos son los que realizan todas las actividades en los establecimientos, tanto con hacienda y como con herramientas para labores agrícolas.

Quedan relevados trabajos de empleados domésticos en casas del medio rural, como así también la existencia de empleados administrativos que trabajan en establecimientos grandes de la zona.

AGRUPAMIENTO: Este ítem explica la situación laboral de cada empleado en lo referido a su rol dentro de un grupo o su trabajo solo y a cargo del establecimiento. Los trabajos que denominamos agrupados son en establecimientos en los que trabajan mas de una persona y se mantiene una distribución del trabajo que normalmente trae implícitos rangos y remuneraciones diferenciales. Esta forma de trabajo es independiente de la residencia del trabajador, pero generalmente conviven empleados con su familias y un número de empleados con familia en una localidad cercana. 
MULTIOCUPACION EMPLEADO: Este ítem es referido a la realización de alguna actividad extra-asalariada que tenga el empleado rural. Entran en este rubro además de producción de animales de granja, para autoconsumo y venta, la producción y amansado de caballos, los trabajos en soga, alambre y otros servicios que puedan reportar ingresos familiares. Cabe aclarar que en este rubro se consignaron las multiocupaciones que se realizan en el medio rural y sus actividades, no registrándose en este muestreo multiocupaciones urbanas, vinculadas generalmente al rubro de la construcción, muy típico en otras épocas.

MULTIOCUPACION FAMILIAR: Acá queremos relevar la existencia de otra actividad vinculada al resto de la familia. En este sentido planteamos una situación surgida de la encuesta y tiene que ver con agrupar en este ítem a todas las actividades, rurales o no, que realizan los otros miembros de la familia que no sea el empleado rural, sean estos su esposa o hijos jóvenes.

No se discrimina en esta etapa si el trabajo es de la mujer o de los hijos, pero en el caso de las familias que viven en los pueblos, el dato de la multiocupación familiar esta vinculada en su gran mayoría al trabajo como servicio domestico o algún trabajo vinculado al sistema publico, ya sea en el sector educativo (maestra o portera) o al sector salud (enfermera o mucama). En el caso de los jóvenes se le computan las changas que frecuentemente hacen en sus lugares de residencia y en general en las familias rurales se incluyen acá la realización de producciones de autoconsumo y venta ligadas a animales de granja.

PRODUCCIONES: En este ítem se señala la existencia de producciones de animales, sogas $u$ otros productos que se vinculen con las actividades familiares o del empleado mencionadas en las columnas anteriores. Se tiene en cuenta las producciones de autoconsumo no testimoniales (que justifiquen realmente un ahorro para el grupo familiar), como también las producciones (animales de granja y vacunos) y los servicios (animales para doma o juegos de rienda) destinados a venta o alquiler de terceros y que generan un aporte de dinero. No se aclara en esta encuesta cual es el estado de registración que tienen en esta actividad complementaria, manejándose generalmente en el mercado informal todo lo referido a animales de granja y chacinados caseros. Lo referido a animales de alquiler para domas o pruebas de 
rienda tiene una formalidad mayor por cuestiones referidas al seguro de accidentes.

A su vez se realizo el posicionamiento geográfico de cada empleado y su familia con el apoyo del personal de la Fundación para el control de aftosa (FUSAV), el administrador de un grupo de estancias de la zona, el medico veterinario Bodo Von Saldern y de personal del consorcio caminero del distrito de Chávez.

En forma simultánea se realizo un relevamiento de los "equipos de chacra" locales que existen en la zona de estudio donde se realizaron 22 encuestas a los trabajadores de esos equipos, este relevamiento es realizado para visualizar un sector que ha quedado fuera de la encuesta anterior.

Estos empleados agrícolas no pertenecen a ningún campo en particular, trabajan en empresas de servicios que tienen radicados sus galpones mayoritariamente en los pueblos y salen a hacer la campaña y se quedan en las casillas donde estén trabajando. En este relevamiento también pregunto sobre la situación laboral del trabajador, si esta o no registrado como empleado rural.

\subsubsection{Calculo de ingresos familiares}

Este indicador se refiere a la intención desde la investigación de poder dimensionar en los distintos tipos de empleados y actividades productivas el ingreso que las familias perciben que reciben de cada actividad y la importancia relativa que estos tienen sobre los ingresos familiares totales.

Se intenta a través de las entrevistas poder dimensionar los acuerdos extrasalariales y los ingresos percibidos por productos o servicios que venden y también poder cuantificar si se puede las producciones de autoconsumo. Cabe aclarar que los salarios denominados "de gobierno" son de publico conocimiento y se estiman para todos los empleados de acuerdo a una tabla que rige los mismos de acuerdo a su rango y especialidad dentro de cada establecimiento.

Se recalca el carácter estimativo del número debido a la privacidad de la información que en muchos casos es aproximada y estimada sin ningún tipo de registros. Si rescatamos como importante lo que denominamos como "percepción" sobre la real importancia de los distintos ingresos y que valoración tienen de ellos los mismos empleados rurales, esto ya desde una perspectiva mas cualitativa del análisis. 


\subsubsection{La observación}

La observación es un hecho natural de uso cotidiano por todo el mundo. En el medio rural esta observación es la fuente de saberes y experiencias que dominan el imaginario rural (de Sardan J.P.,1995).

En el marco de la investigación social, la observación se puede convertir en una herramienta muy importante para la recolección de datos e interpretación de fenómenos que ocurren en la sociedad, pudiéndose diferenciar entre la observación común y la científica. Esta última se realiza sobre un grupo o evento determinado, es llevada de manera ordenada, sistematizando y registrando resultados, tratando de establecer relaciones, efectos y alcances de los fenómenos observados (Ruiz Olabuenaga, Ispizua; 1989).

En esta investigación se realizo lo que Marradi et al (2007) denomina como "observación directa", que es cuando el investigador-observador toma contacto directo con el suceso social a investigar.

Se utilizo para observar los distintos espacios de socialización de los empleados rurales, su hábitos, modales, vestimentas y actitudes con sus pares y con otras personas, los vínculos que despliegan en estas fiestas, tanto los sucedidos en espacios rurales como en los pueblos y ciudades.

Se utilizo además la toma de fotografías para hechos puntuales y personas que perderían su magnitud y su gracia ante una simple descripción escrita.

Se caracterizaron también por ser observaciones directas de los hechos tal cual estaban sucediendo y en ningún caso se necesito armar un montaje fotográfico a estos fines, en lo que se denomina observaron no controlada.

En el caso de las domas, juegos de rienda y el fútbol, mi rol de técnico CEPT y dirigente de un club local me permitió realizar una observación participante de estos eventos. Esto resulto de mucho interés para poder captar sin ruidos externos los verdaderos comportamientos, opiniones y actitudes de las personas que formaban parte de cada acontecimiento. Se facilito mucho la tarea de observación y permitió rescatar muchos detalles del comportamiento social de los empleados en situación de compartir con otros los mismos intereses.

Las observaciones se registraban a través de grabaciones, de apuntes en el 
cuaderno de campo y de registros fotográficos del propio observador.

Los lugares de observación surgen de los propios relatos de las actividades que realizaban los empleados y otros actores entrevistados a lo largo de esta tesis.

En este sentido se observaron los siguientes espacios de socialización:

Lugares observados con registro de fotos y comportamientos sociales

1- fiesta de destrezas gauchas en Barra.

2- Carreras de sortija en el CEPT.

3- Reunión de bochas en bar de Latorre.

4- Desfile gaucho aniversario del pueblo de Barra.

5- Festejos de centenario de De la Garma.

6- Lunes después de carrera en taller de Durquet.

7- Veterinaria de Carlos Maria Yañez.

8- Carreras de autos zonales en Gonzáles Chávez.

9- Partido de fútbol de liga regional tres Arroyos, clásico entre Agrario de De la Garma y Deportivo de Barra.

10- Asamblea de la comisión del CEPT.

11- Planta de silos de Cooperativa agraria de Tres Arroyos en De la Garma.

12- CEPT 19.

\subsubsection{La investigación documental.}

Coincidiendo con Valles( 1997), creemos que la investigación documental constituye un primer paso obligado en cualquier investigación social, sobre todo cuando se trata de investigar un sector social disperso y de poca visibilidad.

Para esta investigación, se trabajo con varias fuentes de información de distintos grados de precisión y profundidad

Para una aproximación a las cantidades y situación de dependencia se trabajo con los censos agropecuarios de 1988 y de 2002, siendo parcial y poco fiable la información del censo realizado en el año 2008 (se realizo en pleno proceso de lockout patronal de las 4 entidades rurales nucleadas en la denominada "mesa de enlace", generando un gran numero de abstenciones y datos poco fiables).

También se utilizaron los censos poblacionales del año 2001 y 2010 para establecer los números de pobladores rurales y urbanos. 
Resulto de mucha importancia para la investigación, ya en términos más locales, la posibilidad de trabajar con la base de datos de la obra social de los trabajadores rurales (OSPRERA) sucursal De la Garma, que nos permitió analizar las poblaciones de los distintos establecimientos y la cantidad y edad de los integrantes de las familias, haciendo mas sencilla la tarea del posicionamiento geográfico de cada una para la realización de la encuesta y posterior entrevista en los caso que se determinaron.

Ha resultado muy útil e interesante los documentos trabajados que provienen de la biblioteca personal del señor Osvaldo Furlani, 84 años, historiador del sector de los empleados rurales de la zona y dirigente histórico del gremio rural (FATRE, Federación Argentina de Trabajadores Rurales y Estibadores) en su época de esplendor organizativo a partir de la década del 50.

Como plantea Valles (1997), para esta etapa previa e indispensable de investigación documental, son validos trabajos de investigación científica, registros públicos y privados, estadísticas propias de los sectores productivos y de los empleados rurales, como así también de las escuelas y clubes de campo.

\subsubsection{La entrevista semidirigida o semiestructurada}

En el marco del trabajo de terreno, las entrevistas realizadas fueron grabadas con permiso de los entrevistados con un grabador Digital Panasonic RR-US300 que facilito el trabajo con las mismas. Durante la entrevista también se sacaron fotos digitales sobre las producciones familiares y otras actividades de interés que se ubican en el anexo fotos.

Luego fueron desgravadas todas las entrevistas realizadas y se elaboro un resumen de cada entrevista con la información de los temas útiles para los distintos capítulos y en que minutos y segundos de las entrevistas fueron expresados. Este formato nos permitió organizar los contenidos de las entrevistas y poder recurrir a ellos llegado el momento de trabajar algún ítem en particular ubicando rápidamente a los empleados en cuestión y en que parte de la entrevista se trato el tema para abordarlo en forma completa.

La entrevista ha sido planteada por varios autores (Fidelli y Marradi,2006; Valles,1997; Alonso, 1998) como la técnica mas usada y difundida en los trabajos empíricos realizados en las ciencias sociales.

Sin embargo su uso ampliado no ha significado el uso exclusivo de la técnica y ha sido acompañado de otras técnicas en las distintas áreas de las ciencias sociales. En 
la tradición antropológica la entrevista ha sido utilizada como complemento de la observación de campo, técnica a la que se considera como la más importante en esta rama. En cambio en la sociología y otras ramas de los estudios sociales constituye la principal técnica de investigación aunque como ya dijimos, no la única.

Utilizando la clasificación propuesta por Fidelli y Marradi (1996) utilizando el criterio del grado de libertad concedido a los protagonistas de la entrevista, nuestra practica se situaría en la categoría definida como "entrevista personal semi estructurada", en la que planteamos un contacto personal cara a cara con el entrevistado, con algunos casos de entrevistas a todo el grupo familiar.

Si bien el trabajo estipulado con el director suponía un abordaje ordenado de los temas de interés afín a esta investigación, se permitió cierto grado de dispersión que se lograba sobre todo en temas de interés particular de los distintos tipos de empleados, quedando para afuera de la entrevista charlas y comentarios vinculados a situaciones locales que nos unían en tanto somos todos pobladores de la misma zona.

Cabe destacar que todas las entrevistas a empleados rurales se hicieron en sus propios hogares, en el campo los que viven y trabajan ahí, y en el pueblo para los empleados que trabajando en el campo tienen su hogar y familia en alguno de los pueblos involucrados en este trabajo. Esto genera sin dudas un plus en el establecimiento del vínculo entrevistador-entrevistado que mejora el nivel de disposición y descripción detallada de las respuestas.

El tipo de entrevista que realizamos en este trabajo, podría definirse también en el marco de la denominación de "entrevista en profundidad", debido a que la información que se intenta relevar no es una descripción de un hecho social o natural, sino la interpretación personal, propia, contada su carga histórica de los acontecimientos vividos por el.

Pero sin dudas la validez e importancia que pueda tener el resultado de la entrevista va a estar condicionada por la capacidad del entrevistador de generar empatía con el entrevistado y que contribuya a generar un clima favorable para la comunicación.

Siguiendo a Valles (1997) quien plantea una serie de preguntas para poder determinar una alternativa útil al momento de seleccionar los entrevistados, hemos determinado en forma conjunta con el director, cuales serian los perfiles de los entrevistados y dentro de estos cuales serian los mas capaces de comunicar la información requerida con mas precisión. Esta estrategia utilizada se conoce con el 
nombre de muestreo intencional (Valles, 1997).

Guía de aspectos a relevar en las entrevistas

Situación laboral : experiencia en la actividad, relación de dependencia, forma de trabajo, habilitación laboral, tiempos de trabajo, visión a mediano y largo plazo.

Multiocupación: actividades productivas o servicios extra-salariales, disposición de espacios e insumos, mercado, actual y futuro, intenciones de ampliar, involucramiento de la familia en la actividad, ingresos y gastos, destino de los ingresos

Familia: componentes, organización interna, actividades que realizan, participación en el trabajo y las producciones, salidas al pueblo, manejo de lo servicios(salud, educación de los chicos, comunicación, provisión de insumos), tiempos y espacios de sociabilización, proyectos a desarrollar. 


\section{RESULTADOS Y DISCUSION}

\section{CAPITULO 3 - LOS TRABAJADORES RURALES}

\section{1-INTRODUCCION}

\subsection{1- RELEVAMIENTO}

Como se expreso en el capitulo anterior, se realizo un relevamiento de los empleados rurales de la zona de estudio y de influencia escolar del CEPT 19, a los cuales se les realizo una pequeña encuesta que nos permitió obtener una serie de datos rápidos para poder cuantificar a priori cuales serian los grupos de interés para luego realizar las entrevistas.

Para esto se procedió a realizar una entrevista con la encargada de la oficina de OSPRERA de la localidad de De la Garma, quien nos facilito gentilmente los registros de los afiliados al servicio y nos dio su parecer sobre varios temas de interés del sector.

Además se realizo un trabajo de posicionamiento e identificación de los empleados con ayuda de personal de SENASA y de privados; marcándolos sobre una imagen satelital.

Los resultados de esta encuesta, si bien algunos son analizados en este segmento, también son material de análisis en el capitulo que refiere a empleados ganaderos y al que refiere a las actividades productivas y situaciones de multi-ocupación de los distintos tipos de empleados. 
Tabla 5 - encuesta a empleados rurales

\begin{tabular}{|c|c|c|c|c|c|c|c|c|c|}
\hline $\begin{array}{l}\text { Tb. } \\
\mathrm{n}^{\circ}\end{array}$ & Edad & $\begin{array}{c}\text { Donde } \\
\text { vive }\end{array}$ & Casado & Hijos & Actividad & $\begin{array}{l}\text { Agrupa } \\
\text { miento }\end{array}$ & multi emple. & $\begin{array}{l}\text { multi } \\
\text { fam }\end{array}$ & Produc \\
\hline 1 & 35 & Dlg & $\mathrm{Si}$ & 2 & Agrícola & $\mathrm{Si}$ & No & $\mathrm{Si}$ & No \\
\hline 2 & 59 & Dlg & $\mathrm{Si}$ & No & Mixta & $\mathrm{Si}$ & No & No & No \\
\hline 3 & 63 & campo & $\mathrm{Si}$ & 1 & Agrícola & No & No & $\mathrm{Si}$ & No \\
\hline 4 & 45 & campo & $\mathrm{Si}$ & 2 & Ganadería & No & $\mathrm{Si}$ & no & $\mathrm{Si}$ \\
\hline 5 & 49 & campo & Viuda & 4 & Domestica & $\mathrm{Si}$ & No & si & $\mathrm{Si}$ \\
\hline 6 & 55 & Dlg & $\mathrm{Si}$ & 2 & Ganadería & $\mathrm{Si}$ & No & si & No \\
\hline 7 & 65 & campo & $\mathrm{Si}$ & No & Ganadería & No & $\mathrm{Si}$ & si & $\mathrm{Si}$ \\
\hline 8 & 45 & Barra & No & No & Ganadería & $\mathrm{Si}$ & No & no & No \\
\hline 9 & 50 & campo & Viudo & 1 & Ganadería & No & No & si & No \\
\hline 10 & 29 & campo & $\mathrm{Si}$ & 3 & Mixta & No & $\mathrm{Si}$ & si & $\mathrm{Si}$ \\
\hline 11 & 39 & Dlg & C & 5 & Ganadería & $\mathrm{Si}$ & $\mathrm{Si}$ & no & No \\
\hline 12 & 29 & Dlg & $\mathrm{Si}$ & 4 & Agrícola & $\mathrm{Si}$ & No & no & No \\
\hline 13 & 68 & Dlg & $\mathrm{Si}$ & No & Agrícola & $\mathrm{Si}$ & No & si & No \\
\hline 14 & 41 & campo & $\mathrm{Si}$ & 3 & Ganadería & $\mathrm{Si}$ & $\mathrm{Si}$ & si & No \\
\hline 15 & 32 & campo & $\mathrm{Si}$ & 3 & Ganadería & $\mathrm{Si}$ & $\mathrm{Si}$ & no & $\mathrm{Si}$ \\
\hline 16 & 55 & Barra & $\mathrm{Si}$ & 3 & Ganadería & No & $\mathrm{Si}$ & no & $\mathrm{Si}$ \\
\hline 17 & 49 & campo & $\mathrm{Si}$ & 2 & Ganadería & No & $\mathrm{Si}$ & no & $\mathrm{Si}$ \\
\hline 18 & 39 & campo & $\mathrm{Si}$ & 3 & Ganadería & $\mathrm{Si}$ & $\mathrm{Si}$ & no & No \\
\hline 19 & 54 & Dlg & $\mathrm{Si}$ & 3 & Ganadería & No & $\mathrm{Si}$ & si & $\mathrm{Si}$ \\
\hline 20 & 56 & Dlg & $\mathrm{Si}$ & No & Mixta & No & No & si & No \\
\hline 21 & 30 & campo & $\mathrm{Si}$ & 3 & Ganadería & $\mathrm{Si}$ & $\mathrm{Si}$ & si & $\mathrm{Si}$ \\
\hline 22 & 52 & Dlg & $\mathrm{Si}$ & 1 & Ganadería & & No & si & No \\
\hline 23 & 57 & Dlg & $\mathrm{Si}$ & 1 & Ganadería & $\mathrm{Si}$ & No & si & No \\
\hline 24 & 52 & campo & $\mathrm{Si}$ & 2 & Ganadería & $\mathrm{Si}$ & $\mathrm{Si}$ & si & $\mathrm{Si}$ \\
\hline 25 & 51 & Barra & $\mathrm{Si}$ & 2 & Ganadería & Agrupado & $\mathrm{Si}$ & si & $\mathrm{Si}$ \\
\hline 26 & 51 & Dlg & $\mathrm{Si}$ & 2 & Agrícola & $\mathrm{Si}$ & $\mathrm{Si}$ & no & No \\
\hline 27 & 41 & Dlg & $\mathrm{Si}$ & 4 & Mixta & $\mathrm{Si}$ & No & si & No \\
\hline 28 & 64 & campo & $\mathrm{Si}$ & No & Mixta & No & $\mathrm{Si}$ & si & $\mathrm{Si}$ \\
\hline 29 & 37 & campo & $\mathrm{Si}$ & 2 & Ganadería & No & $\mathrm{Si}$ & no & $\mathrm{Si}$ \\
\hline 30 & 63 & Barra & $\mathrm{Si}$ & No & Ganadería & $\mathrm{Si}$ & No & no & No \\
\hline 31 & 55 & campo & $\mathrm{Si}$ & No & Ganadería & No & $\mathrm{Si}$ & no & $\mathrm{Si}$ \\
\hline 32 & 35 & campo & $\mathrm{Si}$ & 1 & Mixta & No & $\mathrm{Si}$ & no & No \\
\hline 33 & 53 & campo & $\mathrm{Si}$ & No & Ganadería & No & $\mathrm{Si}$ & no & $\mathrm{Si}$ \\
\hline 34 & 24 & campo & $\mathrm{Si}$ & 2 & Ganadería & $\mathrm{Si}$ & $\mathrm{Si}$ & no & $\mathrm{Si}$ \\
\hline 35 & 57 & campo & $\mathrm{Si}$ & 3 & Ganadería & $\mathrm{Si}$ & No & $\mathrm{si}$ & No \\
\hline 36 & 45 & Dlg & $\mathrm{Si}$ & 2 & Mixta & $\mathrm{Si}$ & No & si & No \\
\hline 37 & 51 & campo & $\mathrm{Si}$ & 4 & Ganadería & $\mathrm{Si}$ & $\mathrm{Si}$ & si & $\mathrm{Si}$ \\
\hline 38 & 63 & Dlg & No & No & Agrícola & $\mathrm{Si}$ & No & no & No \\
\hline 39 & 35 & Dlg & $\mathrm{Si}$ & 3 & Agrícola & No & No & si & No \\
\hline 40 & 36 & campo & $\mathrm{Si}$ & 3 & Ganadería & No & $\mathrm{Si}$ & si & $\mathrm{Si}$ \\
\hline 41 & 34 & campo & $\mathrm{Si}$ & 2 & Mixta & $\mathrm{Si}$ & No & no & No \\
\hline 42 & 43 & Dlg & $\mathrm{Si}$ & 2 & Mixta & $\mathrm{Si}$ & No & si & No \\
\hline 43 & 33 & campo & $\mathrm{Si}$ & 2 & Ganadería & $\mathrm{Si}$ & No & no & No \\
\hline 44 & 63 & campo & $\mathrm{Si}$ & No & Ganadería & No & No & no & No \\
\hline 45 & 36 & Dlg & $\mathrm{Si}$ & 1 & Agrícola & $\mathrm{Si}$ & No & si & No \\
\hline
\end{tabular}


Ubicación de empleados entrevistados

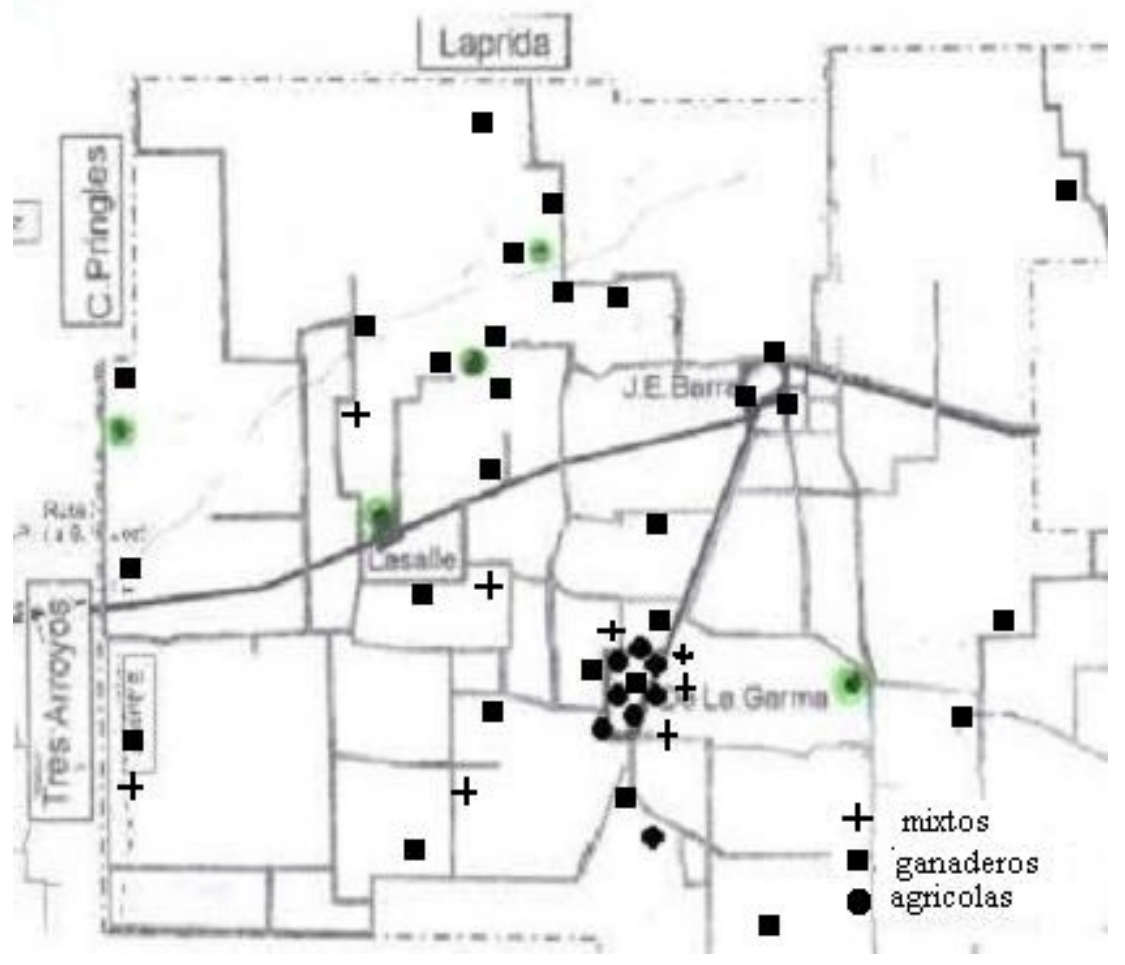

Analizando los datos de la tabla 5 se pueden observar algunas relaciones que se pueden resultar pertinentes a este trabajo.

En primer lugar si analizamos la edad de todos los trabajadores rurales nos encontramos con un promedio de edad de 46 años, siendo de 45 en el campo y de 49 en el pueblo. Esto nos refiere un trabajador medio con experiencia de $18-20$ años de trabajo, lo que significa un cúmulo de experiencias importante y un estilo de vida bastante definido.

Sin embargo resulta muy llamativo que las familias de los empleados no tengan integrantes mayores (jubilados), estando en la mayoría de los casos los empleados con hijos. Supone también establecer una estrategia de conseguir una casa en el pueblo para cuando el trabajador se jubila porque en términos generales no tiene la posibilidad de seguir viviendo en el campo. En este sentido últimamente se han construido barrios en los pueblos de De la Garma y Barra que plantean soluciones a esta problemática, y que generan expectativas entre el grupo de trabajadores rurales.

Tal cual surge mas adelante en una entrevista, queda muy claro que el trabajo en el campo es para gente con familia, al menos el matrimonio ya que todos las personas 
encuestadas que trabajan y viven en el campo son casadas o viudas, no habiéndose registrados en esta encuesta personas solteras como empleados rurales con radicación en el campo.

Del total de 45 entrevistados 24 (el 53\%) viven en el campo de los cuales el $75 \%$ son empleados ganaderos y el $17 \%$ son mixtos. Estos coinciden con lo que venimos planteando en este trabajo sobre la radicación urbana de los empleados agrícolas que queda confirmada más adelante en las encuestas realizadas a los empleados de equipos de chacra.

Con respecto a las producciones de autoconsumo de los empleados que viven en el campo, el $67 \%$ tiene algún tipo de producción para este fin, pero cuando incluimos a todos los empleados disminuye al $40 \%$. Siguiendo con este análisis este porcentaje desciende a apenas $14 \%$ cuando nos referimos a los empleados que viven en el pueblo, siendo todos ellos empleados ganaderos.

Resulta un dato interesante de la encuesta general que los empleados que viven en el pueblo de Barra que han sido relevados, todos son empleados ganaderos, ratificando lo planteado cuando describíamos a la comunidad con un marcado perfil ganadero que influye directamente en sus actividades laborales, sociales y de esparcimiento.

\subsubsection{Tipología}

Para poder realizar un análisis diferenciado y con mayor grado de detalle se realiza una clasificación de los empleados rurales de acuerdo a la actividad que se desarrollan en los campos o las empresas en las cuales trabajan. Esto nos permite agrupar a los empleados con una serie de características comunes que faciliten su abordaje sociocultural. En tal sentido se eligió las dos categorías de diferenciación laboral mas difundidas y que generan sentido de pertinencia entre los mismos trabajadores y la identificación de los habitantes de los pueblos como son los empleados ganaderos por un lado y los agrícolas por otro, generando una categoría intermedia para los empleados de establecimientos mixtos donde se realizan las dos actividades en forma integrada.

También se analizan los trabajadores rurales que se consideran como tal pero que en la actualidad están desempleados o realizan trabajos por día (changas). Quedan fuera de este grupo los trabajadores temporarios. Se van a describir características de 
empleados agrícolas, ganaderos, mixtos y desempleados.

Si bien se va a realizar una clasificación de los trabajadores que se encuentran en la zona de estudio de este trabajo, estas categorías estarían presentes también en toda la región pampeana húmeda.

\subsubsection{TRABAJADORES EN PRODUCCION PRIMARIA}

\subsubsection{Empleados agrícolas}

En cuanto a los empleados de la actividad agrícola conocidos en la región pampeana como "tractoristas" o "maquinistas", los cambios en los sistemas de trabajo ha sido tan grandes que en muchos casos han modificado sus formas de vida radicándose en las zonas urbanas al igual que los propietarios de los equipos.

Según surge del análisis de las encuestas, tenemos dos situaciones aplicables a los trabajadores agrícolas, por un lado el caso de los trabajadores agrícolas que trabajan en un equipo de chacra para un contratista, que tiene su origen en viejos arrendatarios que al ser desplazados de sus campos se convirtieron en contratistas rurales o en jóvenes hijos de productores que ya incursionaron en maquinaria en la era de la siembra directa. Por otro lado los que trabajan como tractoristas en establecimientos productivos y viven en el campo con su familia.

"Antes el patrón vivía con los padres en el campo, tenían vacas y hacían cosecha, alambraban y hacían labores a una estancia. Cuando se mudaron al pueblo compro una cosechadora y yo empecé a trabajar con ellos, hacemos la gira por Patagones, Dorrego, venimos acá y nos vamos a Villegas con el trigo y la cebada. Con soja teníamos mas trabajo en Villegas y América pero ahora este año nos quedamos acá, en Tres Arroyos y en Juárez, cerca por los gastos del movimiento...después nos quedamos acá, construimos el galpón, arreglamos la maquina, la casilla, le pusimos el aire al tractor."

José, empleado agrícola, De la Garma, 26-4-013

\subsection{El tractorista de campo}

El tractorista antiguo (anterior a la década del 90) que vivía en el campo con su familia porque tenía que llevar a cabo varias tareas para realizar un cultivo, se convirtió en sembrador y se especializo en siembra directa con la consiguiente reducción de la ventana de labores. El trabajo en el campo con varias actividades sobre un mismo lote 
de cultivo, se convirtió en el trabajo de siembra en varios campos con movilidad y viviendo en casillas durante largos periodos de tiempo.

Además cumplen cada vez mas funciones en la alimentación de hacienda con el mixer y otras actividades ganaderas. Convirtiéndose de a poco en empleados mixtos porque trabajan también en ganadería aunque ligados al tractor.

El aumento de la superficie cultivada bajo siembra directa trajo aparejada una disminución en la cantidad de empleados, que han visto aumentadas sus capacidades de trabajo por el aumento en el ancho de labor experimentado por las maquinarias. Esta situación si bien se da en términos generales, ha tenido un impacto mayor en los planteos de alto perfil tecnológico (G. Preda y M Blanco en Neiman compilador, 2010).

"Hay menos operarios, sabes que pasa vos andabas en un tractor Fiat, un Hanomag de 60 o $70 \mathrm{hp}$, ahora nosotros andamos en un tractor de 180 caballos, andamos con una sembradora de $8 \mathrm{mts}$ Antes en mis comienzos andaba con una sembradora $4 \mathrm{mts}$ y un tractorcito que andaba a 3 kilómetros, hoy ando con una sembradora de 8 metros y a ocho kilómetros, nos es para generalizar pero un día normal sembrando soja y no la paramos hicimos 79 has, no es siempre pero podes hacer un promedio de 60 has. Antes en toda la furia hacías 25 o 30 has".

Horacio, empleado agrícola, De la Garma, 10-12-12.

"Mucha gente en la directa no creía, sigue con idea de arar y rastra de disco, empezaron a ir a exposiciones, los ingenieros empezaron a llenarles la cabeza que no había que arar, que no había que echar hacienda, el barbecho que le llaman ellos, con agroquímicos y hemos tenido rendimientos buenísimos de 2700 kilos de soja.

Yo no creía, tuve la suerte de trabajar con una maquina al principio y me bajaba, miraba, no me parecía, por ahí sembrábamos entre las pajas, pero después nacía y rendía.

Entre los tractores mas grandes, esto de la directa, se simplifica, cuando yo empecé a trabajar con este patrón, tenia 4 empleados porque se disqueaba y se araba, ahora lo hacemos mi hijo y yo."

Horacio, empleado agrícola, De la Garma, 10-12-12.

La temporada de siembra en la zona de estudio tiene una época de siembra de verdeos corta desde el 15 febrero al 30 marzo, una siembra principal de granos finos desde 1 junio hasta 15 agosto y una siembra de granos gruesos que va desde 1 noviembre hasta 30 diciembre. Estos tiempos pueden variar un poco de acuerdo a las lluvias pero mantienen una lógica similar, a su vez dentro de esas ventanas de siembra todos los días no son aptos, por motivos de lluvia o pérdida de humedad de siembra. En estos casos donde se achican los días para sembrar es muy común que se agregue un turno más de siembra, para poder cumplir con los compromisos. 
"Ahora trabajo muchas horas por día cuando sembramos, hasta 14 horas y paso sin comer pero te rinde, la siembra esta duro 18 días y ya teníamos todo sembrado. En soja de segunda hacemos dos turnos y sembramos todo el día, hacemos $50-55$ hectáreas por día, sino no alcanza porque la maquina es chica, entonces con dos turnos rinde."

Darío, empleado agrícola y contratista de siembra directa. Est. San Juan, 19-7-13.

\subsection{Los equipos de chacra}

Se entiende por equipo de chacra a las empresas que se dedican al laboreo del suelo y actividades relacionadas con la siembra y la cosecha, teniendo todas las herramientas necesarias como así también las instalaciones portátiles y los elementos para realizar los trabajos. En el caso de contratistas aplicadores de agroquímicos son mas específicos y en su mayoría trabajan para terceros (G. Preda y M Blanco en Neiman compilador, 2010)

El relevamiento tipo encuesta se realizo sobre los equipos de chacra que son de la zona y sobre los cuales se han realizado las observaciones de este grupo laboral. Quedan fuera de este análisis los empleados rurales que siendo agrícolas por su función específica con maquinaria agrícola, forman parte de establecimientos que se dedican a la siembra y cosecha de sus propios campos y de otros arrendados en la zona cercana. Estos trabajadores agrícolas han sido tenidos en cuenta en la encuesta general que se realizo a los empleados rurales, ya que forman parte de establecimientos productivos con empleados estables.

Vale la aclaración que los nombres de los titulares de los equipos de chacra son de fantasía, y corresponden a los sobrenombres que tiene los dueños de los equipos, no así los nombres de los empleados que corresponden a los nombres de pila, como a lo largo todo el trabajo. Todos los equipos de chacra con la excepción de "el gallego" y "el chelo" responden a las características citadas arriba en lo concerniente a que son hijos jóvenes (30-40 años) de productores medianos que se capitalizaron y prestan servicios en la zona (el zurdo, el serio, el paisano, el negro).

Vemos en la encuesta que realizamos a los equipos de chacra de la zona de estudio que estos contratistas rurales se han armado con productores que en la actualidad no tienen campo propio y en algunos casos siembran como arrendatarios algunos lotes, este es el caso del chelo, el negro, el serio, el gallego y el paisano.

En el caso del zurdo y del zorro, tienen campo propio y lo explotan en forma mixta 
y familiar siendo su actividad principal el contratismo rural.

Quedan exceptuados de este relevamiento los equipos de chacra o servicios que no son de la zona pero que trabajan en la misma sobre todo en las épocas de cosecha y en situaciones puntuales donde aparecen algunos equipos de fumigación terrestre.

En el caso de los equipos de siembra, generalmente son los equipos locales los que hacen el trabajo, no habiendo disponibilidad de equipos ajenos a la zona.

Tabla 6 - Características de equipos de chacra A

\begin{tabular}{|c|c|c|c|c|c|c|c|}
\hline Equipo & $\begin{array}{l}\text { Situación } \\
\text { laboral }\end{array}$ & \begin{tabular}{|l} 
Donde \\
viven
\end{tabular} & $\begin{array}{r}\text { están } \\
\text { casados }\end{array}$ & Hijos & $\begin{array}{l}\text { Multiocup. } \\
\text { Emplead. }\end{array}$ & $\begin{array}{l}\text { Multiocup. } \\
\text { Familia }\end{array}$ & Producción \\
\hline $\begin{array}{r}\text { El } \\
\text { zurdo }\end{array}$ & B & \begin{tabular}{|c|} 
De la \\
Garma \\
\end{tabular} & $\mathrm{Si}$ & 2 & No & No & No \\
\hline & $\mathrm{N}$ & Dlg & No & No & Temp. & No & No \\
\hline El chelo & $B$ & Dlg & $\mathrm{Si}$ & No & No & $\mathrm{Si}$ & No \\
\hline & $B$ & Dlg & $\mathrm{Si}$ & 2 & No & No & No \\
\hline & $\mathrm{N}$ & Dlg & No & No & Temp. & No & No \\
\hline $\begin{array}{r}\text { El } \\
\text { negro }\end{array}$ & $\mathrm{N}$ & \begin{tabular}{|l|} 
Barra \\
campo
\end{tabular} & No & No & Temp. & No & No \\
\hline & $\mathrm{n}$ & \begin{tabular}{|l|} 
Barra \\
campo \\
\end{tabular} & No & No & Temp. & No & No \\
\hline $\begin{array}{c}\text { El } \\
\text { gallego }\end{array}$ & $\mathrm{n}$ & Dlg & $\mathrm{Si}$ & 3 & $\mathrm{Si}$ & $\mathrm{Si}$ & $\mathrm{Si}$ \\
\hline & $\mathrm{n}$ & Dlg & No & No & No & No & No \\
\hline & $b$ & Dlg & $\mathrm{Si}$ & 1 & No & $\mathrm{Si}$ & No \\
\hline & $\mathrm{n}$ & Dlg & No & No & Temp. & No & No \\
\hline & $\mathrm{n}$ & Dlg & $\mathrm{Si}$ & No & No & $\mathrm{Si}$ & No \\
\hline & $\mathrm{b}$ & Dlg & $\mathrm{Si}$ & 1 & $\mathrm{Si}$ & $\mathrm{Si}$ & No \\
\hline $\begin{array}{r}\text { El } \\
\text { zorro }\end{array}$ & $\mathrm{n}$ & Barra & No & No & $\mathrm{Si}$ & No & $\mathrm{Si}$ \\
\hline & $\mathrm{n}$ & Barra & No & No & No & No & No \\
\hline & $\mathrm{n}$ & Barra & $\mathrm{Si}$ & 2 & No & $\mathrm{Si}$ & No \\
\hline & $b$ & Barra & $\mathrm{Si}$ & 1 & $\mathrm{Si}$ & No & No \\
\hline & $\mathrm{n}$ & Barra & No & No & No & No & No \\
\hline & $n$ & Barra & No & No & No & No & No \\
\hline $\begin{array}{r}\mathrm{El} \\
\text { serio }\end{array}$ & $\mathrm{n}$ & Dlg & $\mathrm{Si}$ & No & No & $\mathrm{Si}$ & No \\
\hline $\begin{array}{c}\text { El } \\
\text { paisano }\end{array}$ & $\mathrm{n}$ & Dlg & $\mathrm{Si}$ & No & Temp. & $\mathrm{Si}$ & No \\
\hline & $\mathrm{n}$ & Dlg & $\mathrm{Si}$ & No & Temp. & $\mathrm{Si}$ & No \\
\hline
\end{tabular}

Tanto los contratistas como sus empleados están radicados en las pequeñas comunidades rurales (pueblos rurales) que están cercanas a sus zonas de trabajo, como también en ciudades chicas y medianas vinculadas al medio agropecuario 
En la zona de De la Garma estos empleados que viven en el pueblo adquieren de a poco una cultura también urbana, sobre todo con relación a los hábitos familiares, los chicos asisten a la escuela del pueblo, al club, al ciber, etc. y las mujeres generan vínculos, que se profundizan por compartir muchas actividades sociales y muchas veces lazos familiares. En muchos casos los empleados son jóvenes que todavía no formaron su familia y se adaptan mejor a este ritmo de vida con tiempos continuos de trabajo fuera del hogar pero no registran la experiencia de vivir en el campo en forma continua salvo los casos que han vivido como hijos de empleados rurales radicados en establecimientos rurales.

En la columna referida a su situación laboral, donde figura B de blanco, referido al trabajo registrado y $\mathrm{N}$ de negro referido al trabajo no registrado. Se aclara que a los fines de este trabajo, se computa como trabajo no registrado a una modalidad muy común en el sector agrícola que es la de inscribir como monotributista (que brinda un servicio y hace su propia factura) a los empleados, desligándose de sus responsabilidades patronales y causando perjuicios a los derechos laborales de los empleados. En muchos casos los empleados no están enterados de esta maniobra hasta que sucede algún accidente o se necesita la obra social por algún motivo.

"A mi me pagan el monotributo porque también me sirve para las changas yo hago pintura y albañilería y a veces me piden factura entonces le doy esto, en lugar de pagarme la jubilación me paga el monotributo, para mi es lo mismo, el seguro me lo paga aparte."

Ricardo, empleado agrícola y albañil tiempo parcial, De la Garma, 15-8-12.

Es por eso que aun estando inscriptos en monotributo son consignados en este trabajo como trabajadores en negro.

"Trabajo en negro porque no trabajo corrido todo el año, antes cuando trabajaba en la estancia si estaba en blanco ... pero ahora que es por poco tiempo estoy así nomás, igual cuando me accidente me pago todo, los remedios todo y me dio algo porque no podía laburar y fui de cocinero"

José, empleado agrícola, De la Garma, 26-4-13.

En el caso de su situación como multiocupados abarca al $45 \%$ de los entrevistados haciendo la distinción como temporarios a los empleados que trabajan solamente en los meses de actividad agrícola de siembra y cosecha y el resto del tiempo tienen ocupaciones urbanas de changas en la construcción o en el sector de parques y jardines, leña y caza comercial de liebres. Este grupo representa el $31 \%$ de los trabajadores agrícolas. 
Este proceso de multi-ocupación supone una estrategia laboral con ciertas similitudes a lo que plantean Bendini y Radovich (2003) para el caso de los trabajadores estacionales de alto valle de Río Negro, donde su trabajo agrícola temporal responde a una estrategia laboral mas compleja que incluye también a las otras actividades laborales y a las situaciones laborales y de morada del grupo familiar. Esta característica plantea una diferenciación bastante evidente con lo que observamos para el resto de los empleados, que aunque tengan una actividad extra agrícola, su perfil, su preferencia y su referenciación son vinculadas al ser rural.

Como venimos sosteniendo desde el comienzo del trabajo, este proceso se viene consolidando con el tiempo y se empieza a establecer como característico de este rubro laboral, aun en pequeñas comunidades rurales como las del terreno de estudio.

Como se ve en la encuesta, existe una relación positiva entre la edad de los empleados, con gran proporción de jóvenes (casi la mitad de los empleados encuestados son solteros o con parejas jóvenes, muchos sin hijos aun), y su residencia, en su gran mayoría viven en el pueblo, cosa que contrasta mucho cuando se la compara con el sector de los empleados ganaderos que en su gran mayoría están casados y viven con su familia en el campo.

Con respecto a la forma de pago, mas allá de su situación de registro laboral que ya hemos mencionado, existe un gran variación en las formas de arreglo, pero surgen de las entrevistas dos formas mayoritarias de acuerdos.

En primer termino citamos la forma de pago a porcentaje de facturación, esta forma es muy extendida y esta vinculada en muchos casos con la situación de no registro laboral. En estos casos estamos hablando que en los servicios de siembra y cosecha los empleados cobran entre el 8 y el $12 \%$ de los trabajos libres de gastos, es decir sin el traslado ni la comida que corren por cuenta de los contratistas. Esta variación surge de las distintas situaciones que se pueden dar en cuanto a como se hacen los trabajos, aumentando el porcentaje cuando no se trabaja en el invierno en el galpón y estando cercano al $8 \%$ cuando el operario esta en blanco y en el invierno tiene el trabajo de reparación de la maquinaria que se paga aparte.

Como se trabaja? Hay de todo, como ser a mi me dieron a elegir, yo estoy por mes, yo tenia a soledad que estaba estudiando, entonces me convenía porque yo tenia gastos de alquiler todos los meses y esas cosas. En cambio Juan Pedro esta a porcentaje, que se cobra en estos trabajos el $8 \%$ de lo que cobra el contratista en siembra y cosecha, en los meses de trabajo fuerte el gana mas plata que yo, pero cuando estamos en el galpón el ya no gana lo mismo que yo. Tendrías que trabajar todo el año a \% para que sea mejor, hay gente que lo hace pero nosotros no. 
Horacio, empleado agrícola, De la Garma, 10-12-12.

En otras situaciones relevadas la diferencia del pago esta determinada por la presencia o no del contratista durante el trabajo, siendo mejor pago cuando el operario esta solo y a cargo de todo el trabajo, situación que se da con mayor frecuencia en las labores de siembra, ya que en cosecha siempre los equipos son de mas de una persona, por lo menos dos.

"En la soja de primera siempre pago el $10 \%$ porque estoy yo, en cambio en la de segunda que yo estoy con la cosecha de cebada y trigo, pago el $12 \%$ y tengo a dos muchachos que ya los fui probando en la soja de primera, también como este año, casi siempre me ayuda mi sobrino que para la segunda ya termino las clases."

Darío, empleado agrícola y contratista de siembra directa, Est. San Juan, 19-7-13.

En cuanto al tipo de trabajo y cual es la forma en la que los equipos de chacra organizan sus trabajos, estas varían de acuerdo a la especialización que van logrando los equipos de maquinaria y las características de los contratistas, logrando una variedad interesante de analizar.

Por un lado tenemos al equipo del chelo que trabaja desde hace muchos años en el rubro y concentra casi la totalidad de sus trabajos en atender a una estancia grande (4500 Has.) de la zona donde hace mas de 15 años que les realiza los trabajos de roturación antes y ahora de siembra y cosecha. Prácticamente toda su actividad gira en torno a esta empresa lo que tiene muchas ventajas a la hora de conocer y establecer vinculo con los dueños del campo pero a su vez lo hace muy dependiente de un sola empresa. Esto también se debe a que este contratista es uno de los mas grandes (64 años) y ya no quiere salir ni probar otras experiencias.

Solamente se dedica a dos maquinas y las tiene siempre en buen estado y con mucha tecnología de apoyo, ahora esta incursionando en la agricultura de precisión, ya que es un buen negocio para el y una exigencia de la empresa.

"Cuando viene algún técnico que son tipos macanudos, los llamamos y a veces que no lo soluciona por teléfono tienen que venir, y se los largo a Juan Pedro (el hijo de 41 años) que ya entiende mas de computación y todas esas cosas y después el me las va transmitiendo a mi, pero si vos tenes ganas de aprender, podes, ahora con el monitor de siembra no paramos hasta que la maquinita no te dice, antes teníamos que para cada dos vueltas y bajarse a fijarse en todos los tubos, ahora con el monitor hacemos con la misma maquina entre 8 y 10 has mas, así que al patrón le conviene se paga solo aunque sea caro. Si bien no andamos con la ultima tecnología andamos con cosas que yo no soñaba." 
Horacio, empleado agrícola, De la Garma, 10-12-12.

Tanto el equipo del zurdo como el negro también poseen los servicios de siembra directa y cosecha, pero a diferencia del equipo anterior realizan trabajos para una variedad de productores medianos y chicos distribuidos en la zona. En ninguno de los tres casos realizan muchos kilómetros, manejándose en un área que abarca alrededor de 50-70 kilómetros, llegando hasta Tres Arroyos, Laprida y Juárez. Si bien tienen la casilla de apoyo, siempre que los tiempos muertos son mayores que un día se vuelven al pueblo y luego salen cuan do estén las condiciones dadas.

Existen equipos que se especializan en una sola actividad y por lo tanto tienen maquinarias de mayor tamaño y prestación, exigiendo una mayor movilidad de los mismos para aprovechar distintas ventanas de trabajo en distintas zonas.

El equipo de el paisano es especializado en siembra directa y posee una sembradora de última tecnología y un tractor nuevo, por consiguiente este es el equipo que mas territorio recorre, trabajando incluso para pools de siembra en toda la región, arrancando en Patagones y terminando en la zona de Tandil.

El equipo del serio se dedica a la cosecha, teniendo una sola maquina de mucho ancho de labor y tecnología. Estos recorren varias zonas de trabajo que van desde el sur de la provincia hasta Villegas y América en la época de soja. Luego guardan las maquinas en el galpón y se dedican a reparar y arreglar los equipos hasta la próxima campaña.

"Antes íbamos mas al norte, hasta La Pampa, a cosechar girasol pero eso se termino, no hay mas girasol, ahora andamos en la fina acá y mas al sur, en Pedro Luro donde viven los suegros del patrón y nos consiguen como 2000 has todos los años, damos la vuelta por Dorrego con Cebada y venimos acá a hacer la cebada y el trigo de los clientes, todo clientes trabajamos, estamos como 2 meses afuera, necesitaríamos una maquina mas para tardar menos.... En la gruesa nos vamos al norte, a América donde hay mucha soja y mucho maíz para hacer pero cuando llueve te clavas y a veces estas una semana en la casilla, sino nos volvemos."

José, empleado agrícola, De la Garma, 26-4-13.

En estos tipos de equipos ya tiene casillas con mayores comodidades (aire acondicionado, tv satelital, freezer) porque pasan mucho tiempo fuera de la localidad y a veces a muchos kilómetros de distancia, teniendo que aguantar los días sin trabajo en la casilla, salvo que ocurran grandes lluvias y por 5 o 6 días no puedan trabajar, en este caso se vuelven al pueblo.

Cabe destacar que los equipos del zorro y el gallego prestan una variedad grande 
de servicios a productores locales pero se van extendiendo y se amoldan a los nuevos requerimientos de servicios a terceros.

El gallego presta servicios de fumigada con 2 aplicadores terrestres y un avión (los servicios originales), 2 equipos de siembra, una cosechadora, dos fertilizadores, un camión y dos enrolladoras.

"Al principio, después que me echaron porque se vendió el campo estuve sin laburo, con los chanchos solamente, ahora ya estoy bien, con mucho trabajo, yo ando en un fumigador y Maico, mi hijo mas chico anda en una fertilizadora y después pasa a la arrolladora y sino va a la sembradora, yo sigo en el fumigador casi todo el año porque hay trabajo siempre..., los chanchos los abandone un poco, decí que tengo comida y los cuida un poco Andrea, sino con el laburo que tengo en la maquina los tendría que dejar."

Rubén "Perico", trabajador agrícola, multiocupado familiar, De la Garma, 3-7-12.

Este equipo tiene una alta cantidad de trabajo en forma permanente durante casi todo el año debido a la variedad de trabajos que realizan, si bien trabaja mucha gente en forma permanente, la rotación de trabajadores es muy alta y cambian permanentemente de operarios, sobre todo los auxiliares.

El equipo del zorro tiene su labor distribuida en 2 equipos de siembra, dos cosechadoras, una enrolladora y dos camiones. Además este contratista siembra 1200 has propias y tiene 1000 vacas de cría con engorde a corral. Este equipo se caracteriza por tener una alta incidencia de trabajadores jóvenes, amigos de los hijos trabajadores del contratista que se van quedando en el equipo de trabajo. Todos comienzan sin registrar, estando en blanco básicamente los encargados de los camiones. 


\subsubsection{Empleados ganaderos.}

En esta actividad, las transformaciones sufridas por los cambios en las actividades tienen otras características, habiendo sido distinto el proceso según sea la actividad de cría o de engorde de ganado.

Como surge del análisis de la encuesta y de las entrevistas posteriores se pueden establecer varias características que tiene que ver con el trabajo de los empleados ganaderos.

Los campos ganaderos de cría en general han quedado como unidades de producción grandes, con empleados que viven en el campo con la familia y que en los casos de los entrevistados tienen una vida y una historia relacionada con las actividades ganaderas y en menor medida con actividades agrícolas.

"Empecé ni bien termine la primaria, me quisieron hacer estudiar y quise trabajar...a los tres días de terminar la escuela empecé de mensual, tres años en el Mauleon. $Y$ después me fui al Espinillo dos años más. Después me fui al pueblo a trabajar por día."

Mauro, empleado ganadero y domador de caballos, De la Garma, 15-10-12.

"Primero empecé de changas, a salir con Cachila, para aprender a trabajar, igual vio algo sabia porque fui a la secundaria agropecuaria en Laprida, así que sabia bastantito...estuve dos años viviendo en el campo y Daniela en el pueblo. Después nos fuimos a un puesto lejos, sin luz y ahora estoy acá, siempre en el campo" Jairo, empleado ganadero y multi-ocupado familiar, est. San Francisco, 10-2-13.

Según los datos relevados para este trabajo, el $75 \%$ de los trabajadores ganaderos vive en el propio campo donde trabaja y el $25 \%$ restante vive en los pueblos cercanos como Juan E. Barra y De la Garma. Estos datos si bien son un poco mas altos, concuerdan con los planteado por Quaranta (2010) sobre la base de los datos del censo agropecuario 2002 marcando la tendencia a que se de este proceso creciente de radicación urbana de los empleados ganaderos, aun a pesar de lo que ellos mismos suelen manifestar en la distintas entrevistas.

"Si me sale un puesto hoy me voy, siempre que los nenes no tengan que ir a caballo a la escuela como fui yo, de efectivo me voy, con la familia con mas ganas.

En el campo te la rebuscas, tenes una perdiz, una mula, una liebre, se te pone duro el pan, lo pones al horno y te lo comes, en el pueblo vas y compras pan fresco... te lo digo porque lo he hecho".

Mauro, empleado ganadero y domador de caballos, De la Garma, 15-10-12. 
Siguiendo con este planteo se observa también coincidencia en la apreciación sobre la distribución de los empleados ganaderos, donde los establecimientos que agrupan a varios empleados juntos son muchos menos en cantidad, pero representan mas del $60 \%$ de los puestos de trabajo, generalmente con una escalafón dentro de la organización del personal y con un capataz o mayordomo según el tamaño del establecimiento. El resto son los denominados "encargados", que trabajan como empleados únicos en un establecimiento y lo hacen bajo la tutela del dueño del campo.

"Yo estoy solo, tengo que recorrer en el tractor, imagínate que por mi problema (le falta una pierna por un accidente con tractor en su juventud) no puedo andar a caballo, pero hago todo en el tractor, recorro, doy rollo y ración y después me vengo a casa tranquilo después de comer, en el tractor... dos veces por semana vienen las dueñas, gente buena que vive en Laprida y les quedo el campito acá... este trabajo me cambio la vida, ahora tengo trabajo, a ellos les conviene, tengo tarjeta de crédito, cuando... vos me conoces antes no me alcanzaba para nada con los chicos chiquitos, tenia solamente la pensión, ahora trabajo tranquilo, tengo un autito para ir a comprar la mercadería a Chaves o Laprida, los fines de semana por ahí me voy a una fiesta, estoy bien así trabajando solo en el campo, se me dio."

Néstor, trabajador ganadero, Juan E. Barra, 20-5-12.

Con respecto a este tema los entrevistados reconocen como mas favorable para ellos la posibilidad de trabajar en campos mas chicos, "chacras", donde ellos sean los únicos responsables de los trabajos, así pueden ser reconocidos sus esfuerzos y valorados a la hora de realizar algún pedido desde ellos como empleados. Además en su mayoría lo vincularon directamente a la posibilidad de realizar otras actividades productivas propias según lo veremos mas adelante.

"Siempre te conviene trabajar solo, si vos trabajas en una estancia con cuatro mas y queres pedir aumento, lo tenes que pedir para los cuatro y ya es mas difícil. Siempre tenes algún compañero que trabaja menos, otro que protesta, es mas difícil, ahí los arreglos siempre son flojos. Si queres tener algún animalito, todos tienen que tener permiso para que sea justo entonces no te dan nada. Sin embargo si estas solo vos arreglas el trabajo una vez por mes o por semana con el dueño y queda todo bajo tu responsabilidad, así saben si trabajas bien o no."

Darío, empleado agrícola y contratista de siembra directa, est. San Juan, 19-7-13.

Si bien Darío es en la actualidad empleado agrícola y contratista de siembra, su comentario refiere a su empleo anterior en un campo mixto ganadero y expresa la sensación que tienen muchos empleados ganaderos y mixtos sobre esta situación de ser trabajadores únicos en un establecimiento, donde además en muchos de ellos la presencia y el trabajo del dueño son escasos y esporádicos, estando incluso la toma 
de algunas decisiones importantes a cargo del empleado que oficia de encargado general.

Otro dato interesante que surge de la encuesta tiene que ver con la asociación que existe entre los trabajadores ganaderos que forman parte de estructuras laborales mas grandes con varios empleados en la misma firma a los cuales llamamos agrupados y la residencia familiar en el pueblo cercano, casi el $70 \%$ de los ganaderos agrupados tiene domicilio familiar en el pueblo y dependiendo de las distancias al trabajo, viene a la casa los fines de semana y muchos vienen una noche entre semana, mientras sus familias desarrollan sus actividades en el pueblo.

Según consignan los entrevistados, la existencia de muchos empleados en una firma, incluso casi siempre hay uno o mas que si viven en el campo, permite que el resto pueda disponer de sus horarios en forma independiente, no teniendo que permanecer en forma obligatoria en el establecimiento.

"Yo estoy en el campo todos los días pero cuando termino a veces me vengo al pueblo a ensayar con los muchachos y los sábados y domingos salgo para hacer mis actuaciones en las fiestas de la zona, cuando tengo guardia no puedo pero a veces cambio con los muchachos que viven en el campo con su familia y se quedan, mas a fin de mes, que están secos, así salgo tranquilo."

Hugo, trabajador ganadero y artista zonal, Juan E. Barra, 15-12-12.

Siguiendo en esta línea que nos plantea Hugo, se observa además que la mayoría de los empleados que realizan este tipo de vinculo familia-trabajo son personas grandes, en su mayoría mayores de 50 años y que tienen hace tiempo su familia afincada en el pueblo, de hecho muchos han manifestado que vinieron por la escuela de los chicos pero después no se fueron mas.

Si bien puede parecer un detalle, últimamente se ha tornado muy valorado en las contrataciones de empleados, los hábitos familiares de permanencia nocturna en el campo debido a los problemas de abigeato que han sucedido en la zona y que están vinculados directamente a la presencia o no de los empleados rurales y su familia.

"Yo no contrato solteros, es muy complicado, como no tienen familia se van al pueblo, al club, o a veces andan de novio y están todos los días en el pueblo, te dicen que vuelven pero después no vienen, y a veces se les rompe el auto o no le arranca con la helada y que haces, te queda el campo vacío y te roban, en cambio el tipo que tiene familia quiere terminar de laburar para irse a su casa a descansar, no piensa en irse al pueblo, aunque hay algunos que van el que es nacido y criado en el campo, no se va.... yo tengo empleados que son hijos de empleados viejos e incluso ya tengo nietos trabajando en los campos que han estado como familia toda la vida."

Vodo, medico veterinario, administrador y empleador, de la Garma, 23-8-12. 
Es por esto también que se observa según los datos relevados que la casi totalidad de los empleados que viven en el campo están casados y lo hacen con sus familias, sobre todo los empleados que están solos en sus campos.

Este fenómeno sin embargo tiene variaciones regionales que tiene que ver como explicaremos mas adelante con la posibilidad de contar con servicios básicos, fundamentalmente la escolarización de los hijos

Uno de los principales cambios que han sufrido los planteos ganaderos es la creciente mejora en las instalaciones fijas y en el manejo del alambrado eléctrico que han generado un manejo mas preciso de la hacienda y del forraje, por consiguiente un empleado puede manejar mas cantidad de animales (E.Casina y G. Neiman en Neiman compilador, 2010).

"Este campo así como lo ves tiene como 30 kilómetros de eléctrico, todo con eléctrico callejones y parcelitas, así nos mejoro, antes el pasto no nos alcanzaba nunca pero ahora tenemos las pasturas y le hacemos un sorgo y con eso nos sobra pasto siempre nos sobra pasto. El fanático es Jorge, que es veterinario y hace ecografías también, pero es fanático del alambrado eléctrico."

Juan, empleado mixto y multi-ocupado tambero, De la Garma, 2-3-13.

El otro cambio que viene aconteciendo es el creciente uso de la moto y el cuatriciclo en reemplazo del caballo, sobre todo en estancias grandes con mucha hacienda y potreros para recorrer. Esto derivo que en los grandes establecimientos existan menos empleados ganaderos que años atrás y que estos estén más solos y distanciados entre si y respecto del casco principal del establecimiento. Aun así estos establecimientos siguen explicando la mayoría del trabajo que existe hoy en el sector ganadero de la zona.

"Caballo casi no hay mas, todo moto y cuatriciclo, acá no porque el campo tiene siempre mucha agua, pero en el campo anterior recorría en moto, 15-20 minutos y estaba de vuelta ... pero encontras una vaca atrancada y que haces?... por ahí le tiras el lazo si, pero donde te gano te lleva a la rastra con moto y todo, como haces? En cambio con el caballo es mas antigua pero ... mas seguro.

Los hermanos San Román dicen que hacían maravillas con las motos, encerraban, capaban, volteaban vacas todo, pero andaban de a dos, acá cada uno anda solo, tiene su sección, si se te complica pedís ayuda al compañero que esta cuadro por medio y va, no hay problema, pero va en el orgullo de cada uno, si lo puedo hacer solo lo hago solo.

Jairo, empleado ganadero y multi-ocupado familiar, est. San Francisco, 10-2-13.

Otros cambios tecnológicos tiene que ver con la introducción de verdeos en 
reemplazo de campos naturales y el manejo rotativo de esos verdeos. Además se incorpora la suplementación alimenticia y en muchos casos se encierran terneros en corrales para poder terminar su proceso previo a la venta, conocidos como feed lot. (E.Casina y G. Neiman en Neiman compilador,2010).

"Ahora tenes que manejar tractor también, mi cuñado no sabia pero el patrón le enseño y ahora maneja, lleva rollos da de comer todo, yo no sabia tampoco pero ahora me animo a terraplenar y todo, si tenes ganas es fácil aprender, si no manejas tractor es mas difícil, estas mas abajo, para peón nomás."

Luciano, empleado ganadero de origen correntino, est. Don Pedro, 5-5-13.

\subsubsection{3 los empelados ganaderos correntinos}

Los cambios mencionados en los párrafos anteriores, sumados a la tendencia vista con anterioridad de un aumento de radicación en los pueblos con el consiguiente cambio en las condiciones básicas de vida (acceso a la educación, a la salud, otros) como las que existen en los trabajos en el campo ha determinado una escasez de personal capacitado en el manejo de rodeos que hizo que se recurriera a contratar gente de otras provincias como Corrientes, Chaco y Entre Ríos que se ubican en establecimientos grandes o de alto nivel tecnológico (E.Casina y G. Neiman en Neiman compilador, 2010).

Cuando entrevistamos a estos empleados de origen correntino, ellos también manifestaban la conveniencia (de forma similar se manifestaron otros entrevistados) de trabajar en chacras donde sean empleados únicos y responsables del establecimiento.

"Tenemos un extra a fin de año y otro a mitad, a veces en la estancia es raro, es el sueldo nomás, esto es mucho mejor así... el patrón ve todo lo que haces, es mejor que este el patrón y no el encargado.... así cuando vos le pedís el ya sabe que te vio trabajar y te responde".

Luciano, empleado ganadero de origen correntino, est. Don Pedro, 5-5-13.

Con respecto a este grupo de empleados de origen correntino, se ponen en juego lo que Lara (1998) y Bendini et al. (2002), plantean como el desarrollo de un entramado de relaciones de proximidad, donde el lazo afectivo es el principal vinculo de relación.

En este sentido se entrevisto a dos familias, una de origen correntino y otra de origen chaqueño pero que en general son identificados como correntinos por los 
pobladores nativos de la zona, dado que las características sociales, las vestimentas y sobre todos los acentos son difíciles de distinguir.

Lo primero que surge cuando se va desarrollando la entrevista y que es un dato en común es el tiempo que pasa entre que viene a trabajar y cuando empiezan a socializar, que en un caso fueron mas de 3 años (el chaqueño), estando hasta ese momento solamente residiendo en el campo y haciendo una acumulación de capital con fines de armarse de los muebles, electrodomésticos y por ultimo el vehículo, para recién ahí poder manejarse con mayor independencia.

En cuanto a las razones que manifiestan sobre las causas de porque se vienen, se encuentran por un lado la falta de trabajo para jóvenes en general y por otro lado la diferencia de salarios al momento de estar trabajando formalmente.

"A mí me trajo mi hermano el ya había venido antes, a el, lo trajo un amigo de el vio... estuvo un año y pico y después me trajo a mi. La gente que se viene normalmente viene así... si les gusta se quedan y si no. vio, como todo, mi cuñado este antes se vino, el tenia trabajo allá pero ganaba poco eh, por lo menos acá ganaba 4.000 y allá 2.000 pesos vio, la mitad."

Luciano, empleado ganadero de origen correntino, est. Don Pedro, 5-5-13.

"Como me trajeron a mi, sigo trayendo gente, casi todos parientes, hasta ahora no me fallo ninguno, espero que sigan así... vienen por la plata, allá es poca plata y ahora esta complicado allá ... ahora hay mucha chacra"

Miguel, empleado ganadero de origen chaqueño, est. La Colonia, 3-11-12.

Es muy interesante la visión que tiene sobre sus características y sobre las causa de por que los traen a ellos habiendo empleados de la zona sin trabajo o con posibilidades de trabajar, plantean como una condición distintiva su carácter pacifico, de no reclamo y veneración al patrón (tan típico en lo que Albaladejo (2004) denomina pacto agrario) y de habito al trabajo duro y a destajo.

"Allá se usa mucho y lo que pasa piden mucha gente de allá porque son mas... no reclaman... vio que, uno los porteños que es bravo... porque el tema de la plata, las leyes, los juicios... ya trabaja en horarios, el tema de acá es que trabajan muchos horarios, allá ya son mas piqueros... si estas en blanco y es así, en general allá... tenes que andar todo el día allá, te controlan mucho, ya es mas piquero que acá vio... los patrones ya son mas bravos, mas exigentes vio..."

Luciano, empleado ganadero de origen correntino, est. La Colonia, 3-11-12.

En cuanto a la residencia familiar, los entrevistados y sus amigos y pariente según cuentan ellos en la entrevista viven en los establecimientos donde trabajan, tanto en 
forma de trabajadores a cargo del establecimiento como agrupados en campos mas grandes.

Es claro de observar que es una opción que es exclusivamente utilizada por personas jóvenes, todos los que vienen son jóvenes, generalmente con familia chica o parejas recién casadas que inician su vida juntos en la zona con un promedio de edad que no supera los veinte años.

"Pasando los 50 ya no vienen mas, para sacarles las costumbres ya no pueden, por ahí vienen prueban y si no se hallan se van... porque tienen que vender toda sus cositas para venir y si se vuelven ya no tienen nada es difícil que vengan." Miguel, empleado ganadero de origen chaqueño, est. La Colonia, 3-11-12.

En cuanto a las mujeres de los empleados de origen correntino, se ven los primeros años de su arribo con mucha actividad vinculada a la crianza de sus hijos y o sobrinos y en menor medida a actividades de crianza de animales para autoconsumo. Sin embargo en algunos casos trabajan en actividades domesticas o de cocineras en las casas de los dueños o cocinando para otros empleados. Se pudo observar durante la entrevista su posición relegada en la charla sobre producción y otros temas como política y economía, sin embargo son las encargadas de llevar adelante todas las gestiones que tienen que ver con la educación de los chicos y con la salud de la familia. Concurren a las reuniones de la escuela, y van a la boca de expendio de la obra social por trámites de salud, a hacer las compras y la provista para la semana.

Todas manejan en el campo para llevar los chicos a la escuela donde socializan con otras mujeres mientras esperan a sus hijos, pero si hay que ir mas allá maneja el varón.

Los dos entrevistados manejan la posibilidad de volver a visitar la familia al norte, aunque manifiestan que les resulta muy difícil volver cuando pasan un tiempo allá, por eso eligen ir muy poco, para no tener la sensación de querer quedarse allá.

"Para vivir allá, hay vida allá... para trabajar acá, se extraña mucho cuando se vuelve por eso no vamos seguido, allá tenemos nuestra gente, nuestra costumbre y uno se vuelve a acostumbrar enseguida, es fácil acostumbrarse de vuelta a esa vida."

Luciano, empleado ganadero de origen correntino, est. Don Pedro, 5-5-13.

Es interesante la respuesta que coincidentemente plantean cuando se los interpela sobre la posibilidad de realizar otra actividad productiva, para generar ingresos extras, todos plantean su conformidad con su situación de empleados y se sienten bien así, 
no piensan en realizar ninguna otra actividad extra, aduciendo fundamentalmente buenos arreglos y conformidad con sus empleos, aunque en muchos casos los arreglos so muy distintos entre ellos. Solamente crían aves y cerdos para autoconsumo y huerta en el caso de los chicos que van al CEPT.

\subsubsection{Empleados de campos mixtos}

En esta zona la competencia por los suelos de mayor calidad termino prácticamente con los cultivos forrajeros perennes (pasturas polifíticas base alfalfa y festuca) y estos fueron incorporados a rotación agrícola permanente, por consiguiente deja de funcionar el sistema productivo de recría y terminación de hacienda gorda a pasto.

Por lo tanto, los animales que se producen en las zonas del campo sin aptitud agrícola, son vendidos al destete en su gran mayoría o en algunos casos los productores que viven en el campo o tienen personal fijo en el mismo, los recrían y engordan en confinamiento (encierres a corral) y los venden gordos en el mercado (E.Casina y G. Neiman en Neiman compilador). Esto genera un cambio en el tipo de mano de obra que se sucede en la zona con aptitud agrícola.

La actividad invernada, supone una mano de obra mas intensa y necesariamente asentada en el establecimiento para manejar pasturas, parcelas y rotaciones que requieren mucha atención para evitar problemas comunes como timpanismo, hipocalcemias e intoxicaciones. Por lo tanto en los campos que la actividad de invernada compartía espacio con la cría y la agricultura, ha dejado de ser necesario estar todos los días trabajando y controlando el sistema productivo.

Según lo visto en las entrevistas los empleados que siguen viviendo en el campo mixto tiene la exigencias diarias ligadas ahora a la actividad ganadera intensiva, en su mayoría a la actividad de engorde de hacienda propia en pequeños corrales conocidos como "encierres" o feedlots caseros" (existen 17 feedlots habilitados por SeNaSA en el distrito con 8500 animales encerrados) y en algunos casos de cabañas.

"Cuando estoy en la época de toros, tres meses antes del remate, casi todo el invierno, tengo que darle de comer todos los días a la misma hora, a las 7 de la mañana y a las 5 de la tarde, ni siete menos 10 ni siete y diez, en punto. El toro es un animal de mucha costumbre y tenes que darte cuenta que si esta empachado, si esta molesto, tenes que estar muy pendiente. Después del remate afloja, podes salir los fines de semana".

Darío, empleado agrícola y contratista rural, est. San Juan, 19-7-13. 
"Este campo se usa para la hacienda de ocasión, tenemos las pasturas con eléctrico y damos ración...el patrón compra por ahí cualquier cosa, enfermos flacos y eso, total es veterinario y los cura después los engordamos... cuando veo una para ordeñar me la aparto y la ordeño con las otras... tengo tractor para dar rollo y la comida la doy a lata, total no son muchos."

Juan, empleado mixto y multiocupado tambero, de la Garma, 2-3-13.

En cambio cuando en los campos mixtos quedo solamente la actividad de cría, que es menos demandante en trabajo y salvo en la época de parición que se requiere una frecuencia mayor, se resuelve con visitas del productor y el empleado que se convirtió en agrícola o con algún empleado temporario.

En este sentido surge de los distintos relevamientos cierta similitud entre las cantidades de empleados que trabajan en campos mixtos y viven en el campo con los que viven en el pueblo, teniendo como estos como característica que están en su mayoría en campos con mas personal o que están muy cerca del pueblo.

En muchos casos estos empleados han ocupado las quintas alrededor del pueblo y como veremos mas adelante desempeñan en ellas actividades productivas varias, incluso habitan en las mismas.

Sin embargo esto no trajo aparejado en muchos casos la disminución en el stock de cabezas de ganado, que permaneció y en algunos casos aumento en base a una mejor utilización de recursos forrajeros y a un aumento de carga animal y una distinta composición de las categorías aumentando la cantidad de vientres en relación con animales de invernada (E.Casina y G. Neiman en Neiman compilador, 2010).

Para este proceso ayudo también la instalación en la localidad de una planta de fabricación de alimentos balanceados para cerdos y bovinos, mejorando los precios y la logística para conseguir un alimento para dar en los corrales.

Se ha dado también en la zona, el paso de ser empleado mixto a convertirse en ganadero, ya que han sido varios los establecimientos que han tercerizado toda la agricultura y queda para manejo propio la hacienda, mas allá si la actividad es cría, engorde o cabaña. Este proceso se da, según lo visto en las entrevistas en campos con dueños y empleados de edad, donde la continuidad de la empresa esta en duda.

"Antes yo hacia todo, chacra hacienda todo, ahora tengo los tractores guardados en el galpón y se arrienda todo lo de agricultura, nos quedamos atrasados con la maquinaria... yo estimo que cuando se muera la dueña esto se desarma en mil pedazos, son 6 herederos de Buenos Aires, casi arriendan todo, pero a mi me falta 
poco para jubilarme y tengo 37 años en la firma, no me van a indemnizar." Abel, empleado mixto y multiocupado familiar, est. La Posada, 5-4-13.

Evidentemente este grupo de empleados ha demostrado una buena adaptación a los cambios y en muchos casos han tenido que adaptarse y cambiar de oficio para poder mantener su trabajo, incluso muchos de estos han incursionado en trabajos fuera del establecimiento o se han convertido en multi-ocupados.

"Yo vengo del tambo, soy tractorista, hago alambrado, gracias a dios aprendí a hacer de todo, así me la rebusco.... Acá no se hace nada de afuera, todo lo hago yo y me paga aparte, es un arreglo que hice yo. A veces trabajo con la familia, así como la ves a Brisa (12 años) trabaja a la par mía, le gusta el campo

Juan, empleado mixto y multiocupado tambero, De la Garma, 2-3-13.

E: Es un paisano completo?

Sergio: no para ser paisano... hay que hacer de todo... trabajar con hacienda yo se, esquilar a tijera se, domar caballos no es mi fuerte pero se, se arar, se disquear, se hacer un trenzado pero no... paisano no soy, para eso me falta mucho, que soy? yo soy un peón rural"

Sergio, empleado ganadero y artesano de cuero, Juan E. Barra, 20-5-13.

\subsubsection{TRABAJADORES EN SERVICIOS A LA PRODUCCION}

Si bien los trabajos que se realizan en los servicios a la producción no son tenidos en cuenta desde el punto de vista estatutario y legal como trabajos rurales y por consiguiente no son amparados por las leyes laborales del peón rural, son actividades muy importantes y definitorias en la mayoría de las trayectorias laborales de todos los empleados rurales y que forman parte en muchos casos de una calificación extra que les ayuda a conseguir y mantener empleos y que en varios de ellos forma parte de la multi-ocupación con el aporte de ingresos extras para la familia.

\subsubsection{Empleados alambradores}

Este trabajo denominado genéricamente "en el alambre" es uno de los mas exigentes y mas pesados desde lo físico, lo que motiva a que en su mayoría sea llevado a cabo por gente joven.

Como se describe mas adelante cuando hablemos de los jóvenes rurales, existe como forma generalizada de trabajo la comparsa de alambrada, formada y dirigida por un dueño y con un grupo que habitualmente ronda entre los 4 y 5 operarios. No es muy común que un mismo alambrador tenga mas de una comparsa, pero generalmente sucede cuando hay mucho trabajo en una estancia grande y se 
organizan dos grupos de trabajo en dos secciones distintas.

Los trabajadores jóvenes, en muchos casos menores de edad, que abandonan la escuela secundaria tradicional y en menor medida el CEPT (esto se debe a la posibilidad que brinda el sistema de alternancia para que los jóvenes dispongan de tiempo continuo para trabajar en la estadía del hogar) tiene en la alambrada su primera experiencia laboral fueras del ámbito familiar, convirtiéndose en la mayoría de los casos entrevistados como una experiencia definitoria negativa, debido principalmente a la rudeza del trabajo y al rigor climático que afecta a este tipo de trabajo, siempre a la intemperie y sobre todo en invierno.

"Trabaje todo el invierno con el flaco, cuando salía del CEPT, casi me muero de frío, estábamos en la casilla pero la nueva la tiene Darío, nosotros estamos en la casilla vieja, sin baño. Ganas bien si no te digo pero llega a la noche y no te quedan ganas ni de bañarte a veces, aparte con el frió que hace. Deci que yo después me vengo al CEPT y descanso. Cuando terminé de pagar la moto no fui mas"

Alejandro, estudiante del CEPT y empleado alambrador, Juan E. Barra, 13-4-13.

El trabajo rudo de por si se agrava en nuestra zona debido a la presencia de planchas tosca calcárea que hacen que el pozo se tenga que realizar con barreta y en muchos casos con martillo neumático.

Generalmente se trabaja "en campaña" estando toda la semana en la casilla conviviendo con todo el grupo de trabajo. Si bien el trabajo se paga por día y es a destajo, siempre se corta los sábados por la mañana y se regresa al trabajo los lunes, debido básicamente a la exigencia de los trabajadores jóvenes por salir los fines de semana.

"Yo trabaje con Fernández cuando me quede sin laburo en el campo donde esta papa, hicimos un corral en lo de Khun de 60 pozos de 1,40 metros, todo con martillo neumático, fue tremendo, a la noche se te movían los músculos solos. Estuvimos como 20 días allá... menos mal que pude conseguir otra cosa, sino se me complicaba."

Eduardo, empleado mixto, est. El Zorro, 10-4-13.

Es un trabajo de altísima rotación por varias causas, por la exigencia física, por motivos de conflicto en la cuadrilla, por problemas en el arreglo del jornal, la comida, etc. En nuestra zona, la paga diaria supera normalmente el precio de un día de changa normal, lo que lo hace atractivo para los jóvenes desempleados y que lo ven como una rápida capitalización inicial para comenzar su vida laboral.

Es notorio el impacto que produce en los jóvenes esta primera experiencia laboral negativa, llevando en muchos casos (la mayoría) a una negación del trabajo rural y a 
su migración hacia áreas urbanas y su inclusión en el mundo del trabajo urbano, principalmente como peones en el rubro de la construcción y en muchos casos comenzando un itinerario de trabajos vinculados al sector publico que incluyen asistencia social.

"Cuando deje la escuela me fui a trabajar con Darío en la alambrada, me jodi la columna, trabajaba como un loco, y viste que cuando sos chico te pagan menos, te hacen laburar mas, lo único que comíamos bien en la casilla.... Cuando salí de ahí me fui para el pueblo, al campo no voy mas, estuve trabajando de albañil y aprendí el oficio, ahora trabajo por mi cuente y tengo muchísimo laburo, ya me compre todas las herramientas, la camioneta y estoy por comprar otra"

Agustín, ex trabajador de alambrada y constructor, G. chaves, 20-3-13.

Sin embargo esta mala experiencia laboral a edad temprana se convierten en un plus de calificación, sobre todo para empleados en campo chicos donde el empleado único realiza tareas de mantenimiento y reparación de alambrados, que en la mayoría de los casos se cobran aparte del sueldo, generando ingreso extras para el empleado.

Las personas que logran acostumbrarse y que luego de varios años logran hacerse del oficio, buscan de organizar su propia comparsa como lo vimos con Roberto al que entrevistamos en su lugar de trabajo.

"Yo empecé a trabajar de chico con mi papa, a los 12 años yo trabajaba con mi papa y mi tío y a los 17 me fui solo, organice mi propia cuadrilla y me metí en una estancia en Olavarría que estuve tres años trabajando, cuando salí de ahí me vine para esta zona y acá me case y me quede, en la cuadrilla me quedaron 4 chicos, dos sobrinos y dos que trabajan conmigo hace mucho, todos en blanco porque ahora no te dejan entrar a las estancias sino... en las vacaciones lo traigo al mas grande de mis chicos para que vaya aprendiendo, tiene 12 , igual que yo cuando empecé."

Roberto, alambrador (ex empleado), De la Garma, 20-3-13.

\subsubsection{TRABAJADORES SIN EMPLEO ESTABLE}

En este sector se van a incluir a los trabajadores rurales que están sin trabajo estable. Se va a distinguir esta categoría de la de trabajador temporario porque este sabe que tiene un trabajo pero en una época del año determinada, en cambio estos empleados que se van a abordar no tienen fijo ningún empleo con las consecuencias que eso implica.

En general viven en los pueblos y en las afueras de los mismos en el sector de quintas. Los que están en el sector de quintas, tienen en general actividades relacionadas a las producciones de autoconsumo, de las cuales tienen experiencias desde siempre y ahora muchos han aumentado sus actividades y generan volúmenes 
para la venta o canje. Además realizan changas y las mujeres trabajan como empleadas domésticas en el pueblo.

El otro grupo que vive en el pueblo se adapta a la vida urbana si bien tienen changas en el sector rural, cada vez más aparecen como mano de obra en el rubro de la construcción.

"Me cansaron, me canse de que me exploten. Trabaje 15 años en la firma, una vez lleve 22 toros a Palermo, dormía en los boxes y que me dieron, una sidra y un pan dulce... ahora vivo acá en el pueblo, tengo cualquier cantidad de laburo por día, además corto el pasto o limpio algún terreno y gano mucho mas que en el campo...si no me pagan 70008000 peso de bolsillo no voy ni loco, que trabajen ellos".

Julio, trabajador sin empleo fijo, De la Garma, 15-7-13.

En términos generales cuando los empleados se encuentran sin trabajo reciben asistencia del estado de diversas formas, asignación universal, desempleo, canasta de comida, planes, empleo municipal, etc. (Cloquell, 1996).

"Acá en el pueblo trabajo a la mañana en la cooperativa, hasta las 11 en la municipalidad, vistes se conoce, hacemos de todo, después me voy al campo a trabajar por día, pero ahora hace nueve meses que trabajo con Carlos María, por día así que estoy bastante bien, aunque si sale un puesto me voy. Ella trabaja en casa de familia y después tenemos los nenes..."

Mauro, empleado ganadero y domador de caballos, de la Garma, 15-2-12.

Provienen de empleos tanto del sector ganadero como del agrícola y en ese sentido mantienen las preferencias laborales aunque suelen aceptar cualquier oferta de trabajo.

"Ahora trabajo en la feria, hay dos veces por mes, es todo en blanco... son tres o cuatro días de trabajo cada remate, en este ultimo lo lleve a Manu para que maneje las tranqueras... después trabajo con un señor de Tandil que tiene campo por acá y así me la rebusco... ya me acostumbre...yo siempre estuve el en campo, para el lado de Bunge, luego el campo se desalquilo y me dijeron que espere que cuando alquilaban de vuelta me llevaban de nuevo pero no paso nada todavía. Ella ya trabaja en blanco, en la casa de una doctora, a la tarde."

Manuel, trabajador ganadero sin empleo fijo, Benito Juárez, 19-4-13.

Como vimos en los relatos, en este grupo de trabajadores también hay diversidad de situaciones donde un grupo de empleados se visualiza temporalmente sin trabajo de peón estable pero piensa en volver a serlo en lo inmediato. Otro grupo, quizás los de mas edad como el caso de Julio, ya están organizando su vida en torno a vivir en el pueblo y piensan volver solo en situaciones de mucha diferencia económica.

Existe otra categoría de trabajadores llamados golondrinas, vinculados fundamentalmente a la actividad de cosecha de papa semilla. La gran cantidad de empleados que arriban para este trabajo con la modalidad de cuadrillas de trabajo a 
destajo con morada en los propios campos, genera que a pesar que en la zona tiene mucha importancia para el comercio local de alimentos y servicios, este periodo de cosecha es muy corto y no incide en gran medida en los comportamientos sociales del pueblo. Por este motivo este grupo de trabajadores no van a ser tenidos en cuenta en el trabajo, dejando en claro que en el futuro pueden ser sujetos de investigación, sobre todo relacionados con el fenómeno de tercerización de empleados rurales y su problemática social.

Como se muestra en el cuadro de abajo, las actividades en las que se concentra la mayor actividad de trabajadores no permanentes están vinculadas a los trabajos que se realizan en el marco de la preparación de tierra para la siembra y la siembra propiamente dicha, concentrada básicamente en los meses de mayo, junio y julio para la siembra de granos finos y noviembre y diciembre para la siembra de granos gruesos.

La otra actividad que concentra mayor cantidad de empleo temporario es la actividad ganadera, en estos casos con una distribución mas uniforme a lo largo del año generando en muchos casos una cierta regularidad vinculadas a una visita al campo por semana que realizan los dueños de las explotaciones ganaderas.

"Le recorro a Cabodevilla, de Laprida, el viene me busca en casa me lleva al campo y mientras el hace el asado y la señora acomoda un poco la casa, yo recorro la hacienda, reviso los molinos y arreglo algún alambre, a veces cambio la hacienda de lote, pero se maneja así nomás, extensivo, con vacas de cría y nada mas, pa la 5 de la tarde estoy en casa, me paga y listo, ni un problema. Siempre viene una vez por semana salvo cuando hay que cargar que nos quedamos 2 días en el campo."

Julio, trabajador sin empleo fijo, De la Garma, 15-7-13.

Existen en este sentido trabajadores que combinan dos o tres trabajos de este tipo y generan un ingreso "estable " a lo largo del año pero que en casi ningún caso se rige bajo el amparo del trabajo registrado.

Existen otras actividades con un impacto menor en el empleo y tiene que ver con el trabajo de cosecha y con las actividades de mantenimiento de alambrados, poda para leña y esquila de lanares.

Tabla 7 - contratación de mano de obra transitoria en Gonzáles Chávez

\begin{tabular}{|c|c|c|c|c|c|c|c|c|}
\hline $\begin{array}{c}\text { Contratación } \\
\text { directa de } \\
\text { mano de } \\
\text { obra } \\
\text { transitoria. }\end{array}$ & Total & $\begin{array}{l}\text { Roturación } \\
\text { y siembra }\end{array}$ & $\begin{array}{l}\text { Mantenimiento } \\
\text { de cultivos }\end{array}$ & $\begin{array}{l}\text { Cosecha } \\
\text { de } \\
\text { granos }\end{array}$ & Esquila & $\begin{array}{l}\text { Manejo } \\
\text { de } \\
\text { ganado }\end{array}$ & Otras & $\begin{array}{c}\text { Sin } \\
\text { discriminar }\end{array}$ \\
\hline
\end{tabular}




\begin{tabular}{llrrrrrrrr}
\multicolumn{1}{c}{$\begin{array}{l}\text { Adolfo } \\
\text { Gonzales }\end{array}$} & $\begin{array}{l}\text { EAP } \\
\text { Chaves }\end{array}$ & 141 & 48 & 8 & 20 & 27 & 79 & 11 & - \\
Jas & darna & 7.736 & 2.955 & 882 & 572 & 162 & 2.411 & 7 & - \\
\hline
\end{tabular}

Fuente : CNA 2002. 


\section{CAPITULO 4}

\section{LAS ACTIVIDADES EXTRA-SALARIALES DE LOS EMPLEADOS RURALES Y SUS FAMILIAS}

\subsection{Introducción}

En este capitulo vamos a mostrar y analizar los datos y los relatos relevados de la encuesta, las entrevistas y las observaciones respecto a las distintas actividades que realizan los distintos grupos de empleados rurales de la zona.

Para poder realizar una primera aproximación decidimos agrupar estas actividades según se puedan relacionar o no con su actividad original de asalariado y su vinculación con el pueblo y los otros espacios de socialización.

En la primer parte vamos a trabajar con lo que denominamos oficios camperos, relacionados directamente con la actividad de empleados rurales, y que hacen referencia a oficios y habilidades que han adquirido a lo largo de su trayectoria laboral, con mayor o menor grado de profundización, pero que le sirven para lograr a través de estas actividades ingresos y vínculos extras a los estrictamente relacionados con su situación laboral.

En otro grupo de actividades vamos a agrupar las vinculadas a la producción de animales de granja y mayores, ya sea en forma directa como en las distintas alternativas que impliquen agregado de valor. Estas actividades vinculadas en su gran mayoría a experiencias y conocimientos adquiridos en el ámbito familiar, casi siempre rural.

También resulta importante analizar en este segmento además de la venta y producción de animales, como realizan la provisión de insumos para sus producciones, como trabajan con el asesoramiento profesional y como utilizan los espacios de comercialización disponibles según su situación laboral y sus espacios de sociabilidad.

En un tercer grupo vamos a abordar las actividades vinculadas a los espacios de esparcimiento en el medio rural, ya no utilizados solamente por estos actores sino que cada vez mas son aprovechados por una población mas amplia que incluye a habitantes de pueblos y ciudades cercanas.

Por ultimo vamos a hacer un abordaje de las situaciones de multiocupación familiar, 
donde la mujer y los chicos a veces, juegan un rol muy importante en la generación de nuevos ingresos y en la construcción de vínculos sociales.

En la tabla 8 se pretende mostrar de forma comparativa cuales son los ingresos aproximados estimados para las actividades salariales y para el resto de las actividades que realizan las familias y que nosotros a los efectos de esta investigación definimos como multi-ocupaciones familiares, incluyendo tanto las realizadas por los empleados como las hechas por los miembros de su familia.

Para una mejor interpretación de la tabla, se agruparon los empleados de acuerdo a su actividad salarial primaria definidas en el capitulo anterior. Refiriendo con el número 1 a los empleados agrícola, con el 2 a los ganaderos, con el 3 a los mixtos y con el 4 a los empleados sin empleo estable. También se distinguió a los empleados según su lugar de residencia familiar, poniendo una "P" a los aviven con su grupo familiar en el pueblo y con una "C" a los que moran con sus familias en el campo.

Los datos en general surgen de los relatos de los propios entrevistados, siendo estimados sobre los datos de ventas y gastos que las distintas actividades conllevan.

En el caso de los ingresos salariales, los que tienen un asterisco en la cifra significa que incluyen un arreglo extra-salarial conocido en el sector como "habilitación" y que por su seguridad y regularidad se incluye en el salario mensual aunque en la mayoría de los casos no figura en los recibos de sueldo y son percibidos en forma anual o semestral según la actividad productiva.

Cuando nos referimos en la tabla a los ingresos de las actividades extra-salariales, estos están expresados en forma de ingresos mensuales para facilitar su análisis comparativo, pero como veremos mas adelante la mayoría de las actividades tienen cierta estacionalidad en el ingreso a lo largo del año que varían según los tipos de producciones. 


\begin{tabular}{|c|c|c|c|c|c|}
\hline empleados agrícolas & $\begin{array}{l}\text { ing. } \\
\text { Salarial }\end{array}$ & actividades extra-salariales & ingreso & canales de comercialización & $\begin{array}{l}\$ \\
\text { auto }\end{array}$ \\
\hline Horacio (1) P & 4500 & Esposa tareas domesticas & 1500 & No produce para autoconsumo & 0 \\
\hline José (1) P & 4000 & Esposa tareas domesticas & 1300 & no produce para autoconsumo & 0 \\
\hline \multirow[t]{3}{*}{ Perico (1) P } & 3500 & Esposa tareas domesticas & 1300 & & \\
\hline & & Lechones 280/año a \$150lg & 3500 & minorista local faenado y lechonero & 700 \\
\hline & & Huevos 150 gallinas & 900 & & 100 \\
\hline Dario (1) C & 3500 & contratista rural & 5000 & productores vecinos De la Garma & \\
\hline \multirow[t]{5}{*}{ Jairo (2) C } & 4500 & Soga & 1000 & venta por encargo a vecinos & \\
\hline & & Amansado & 700 & misma estancia donde trabaja & \\
\hline & & Huevos 120 gallinas & 500 & mayorista a almacenes & 100 \\
\hline & & carne de potro & 1000 & venta por encargo a vecinos & \\
\hline & & producciones autoconsumo & & & 600 \\
\hline \multirow[t]{2}{*}{ Juan (2) P } & 4000 & Tambo & 800 & venta por encargo a vecinos & \\
\hline & & producciones autoconsumo & & & 1100 \\
\hline Mario* (2) C & 5500 & producciones autoconsumo & & & 600 \\
\hline Luciano* (2) C & 5800 & & & no produce para autoconsumo & 0 \\
\hline \multirow[t]{3}{*}{ Felipe (2) C } & 4000 & Hacienda propia & 3000 & a mercado de invernada & \\
\hline & & Esposa transportista & 2000 & transporte escolar & \\
\hline & & producciones autoconsumo & & & 800 \\
\hline \multirow[t]{2}{*}{ Sergio (2) $\mathrm{P}$} & 3500 & Soga & 1500 & por pedido en la zona & \\
\hline & & producciones autoconsumo & & & 300 \\
\hline \multirow[t]{4}{*}{ Chacho (2) C } & 4000 & Jinete & 700 & domas de la zona & \\
\hline & & Amansado & 1500 & estancia y zona & \\
\hline & & Lechones 120/año a $150 \mathrm{dlg}$ & 1500 & minorista en Benito Juarez & \\
\hline & & producciones autoconsumo & & & 500 \\
\hline Nestor (2) P & 3500 & asistencia estatal & 2200 & no produce para autoconsumo & 0 \\
\hline Hugo (2) P & 3500 & artista folklórico & 1600 & fiestas zonales & 0 \\
\hline \multirow[t]{3}{*}{ Marcelo (2) C } & 3500 & Lechones 180/año a $200 \mathrm{lg}$ & 3000 & minorista en Laprida & \\
\hline & & Pollos & 800 & minorista en Laprida & \\
\hline & & producciones autoconsumo & & & 500 \\
\hline Julian (2) C & $5500^{*}$ & Amansado & 2000 & a jinetes de destrezas & \\
\hline \multirow[t]{3}{*}{ Alberto (3) C } & $5000^{*}$ & $\begin{array}{l}\text { producciones autoconsumo } \\
\text { Hacienda propia }\end{array}$ & 2000 & a mercado de invernada & 500 \\
\hline & & Amansado & 1500 & a particulares vecinos & \\
\hline & & producciones autoconsumo & & & 900 \\
\hline Abel (3) C & 4500 & Esposa comerciante & 4500 & localidad De la Garma & \\
\hline \multirow[t]{3}{*}{ Mauro (4) $\mathrm{P}$} & & $\begin{array}{l}\text { producciones autoconsumo } \\
\text { Trabajo estatal }\end{array}$ & 1300 & cooperativa de trabajo en DLG & 500 \\
\hline & & Amansado & 1000 & a productores de la zona & \\
\hline & & Changas ganaderas & 2400 & con productor de la zona & \\
\hline \multirow[t]{5}{*}{ Manuel (4) P } & & Changas ganaderas & 2000 & con productor de la zona & \\
\hline & & Amansado & 1000 & con productor de la zona & \\
\hline & & Negocios con caballos & 1500 & minorista en Benito Juárez & \\
\hline & & Esposa empleada domestica & 1300 & en Juárez & \\
\hline & & producciones autoconsumo & & & 500 \\
\hline \multirow[t]{3}{*}{ Julio (4) P } & & Changas urbanas & 2800 & & \\
\hline & & Changas ganaderas & 1200 & & \\
\hline & & Esposa empleada domestica & 1300 & & \\
\hline
\end{tabular}


Cuando se refiere a canales de comercialización, se citan los utilizados mas comúnmente por los entrevistados y que surgen de sus propios relatos, teniendo en algunas producciones canales alternativos de comercialización que se utilizan para la colocación de excedentes como en el caso de las ventas de lechones vivos a lechoneros en la zafra de invierno o la venta a comercios como en el caso de los huevos en verano.

En este sentido, si bien no se puede apreciar mucho desde la tabla debido a que en términos generales no se hace mucha publicidad sobre el tema (por la marginalidad sanitaria y legal de la situación), pero si surge de los relatos, es la elaboración de chacinados que como veremos mas adelante agregan mucho valor a los animales aunque tienen fines puntuales ya que una producción regular de cantidad seria visible y factible de multas.

En lo referido a los ingresos por producciones de autoconsumo, se realizo una estimación sobre la base de las producciones de cerdos y chacinados para consumo familiar y producción de huevos y carne de pollo. En términos generales esta vinculado también al tamaño de la familia y si bien tiene cierta estacionalidad hacemos referencia a un valor mensual para su uso comparativo en la tabla de ingresos.

Analizando la tabla con las consideraciones hechas anteriormente se pueden establecer algunas relaciones que son interesantes de analizar y que definen en muchos casos las características que toman los distintos tipos de trabajos y sus posibilidades concretas de multi-ocupación.

\section{Análisis de algunas relaciones}

La primera relación que podemos establecer tiene que ver con la radicación familiar y la posibilidad de realizar actividades. En este sentido los empleados de radicación urbana o en zona de quintas. Vemos una relación directa entre radicación urbana y la dificultad de realizar producciones tanto de autoconsumo como de venta, salvo en el caso de Perico y Manuel que su radicación en zona de quintas y sus familias amplias les permiten la realización de varias producciones de autoconsumo y para venta.

"Nosotros trabajamos todos, los chicos tienen los animales que les dan de comer, buscan cereal, a veces consiguen mucho y lo vamos a buscar con la camioneta, tienen la quinta del CEPT, los perros todo lo atienden ellos... ahora cada uno agarro un potro para domar, si le salen bien ya tienen otra changa y así se tienen que hacer, yo les enseño a domarlos de abajo porque estoy pesado, ellos se suben sin problemas."

Manuel, trabajador ganadero sin empleo fijo, Benito Juárez, 19-4-13. 
Esta radicación urbana permite a las esposas de los trabajadores emplearse en trabajos domésticos en casas de familia, que si bien tienen cierta estabilidad laboral, los salarios no son elevados. Esto sucede en la mitad de los casos relevados, quedando fuera de esta situación algunas familias cuya situación familiar es más compleja y le impide a las esposas salir a trabajar por el momento aunque siempre manifiestan interés de aportar al ingreso familiar.

Esta situación de posibilidad de ingresos junto a la escolaridad de los hijos son los principales argumentos esgrimidos por las familias para su radicación, aunque como en el caso de Perico, Manuel, Mauro y Julio su radicación urbana comenzó con un despido y luego se quedaron en el pueblo y organizaron su actividad familiar con base en el domicilio familiar urbano.

En cuanto a la actividad salarial, se observa una vinculación directa ya explicada en capítulos anteriores entre empleados agrícolas y residencia urbana y por consiguiente con pocas posibilidades de realizar actividades de multi-ocupación que vayan más allá del empleo de la esposa e hijos, salvo el caso de Perico que ya hemos explicado.

En cuanto a los ingresos propios de las actividades salariales, tienen como característica en común que son bajos comparados con salarios urbanos de empleados de comercio o trabajadores públicos y esto, a nuestro entender, confiere a los ingresos extra-salariales un carácter suplementario y no complementario como se pretende analizar a estos aportes en la economía familiar de los empleados rurales, incluso en los principios de nuestra propia investigación.

Sin duda esta mirada de los aportes de los empleados multiocupados como suplementarios, nos introduce en el terreno de investigar si realmente el salario de un trabajador rural alcanza para una vida digna en el medio rural disperso, si bien lo vamos a platear concretamente, por el momento esta discusión esta fuera del alcance de esta tesis, quedando abierta la inquietud para posteriores estudios sobre el tema.

Analizando las actividades extra-salariales, podemos distinguir dos grupos, uno vinculado a la producción primaria y otro a actividades de servicios y oficios rurales diversos.

En el caso de producción primaria se refiere a la cría de animales para consumo o venta como invernada, tanto de cerdos como de vacunos, que generan según lo que podemos ver en este trabajo ingresos mayores a las otras actividades y servicios.

Esto implica sin embargo poder contar con una estructura productiva basada en 
instalaciones y capital de producción (plantel de animales de cría) que en caso de bovinos son valores altos que implican varios años de ahorro y capitalización de ingresos excedentes.

Esta situación también implica un tipo de arreglo especial que permita la crianza de animales que no es muy frecuente en los campos de esta zona y que se logran en los casos Alberto y Felipe a través de una trayectoria laboral importante en la misma empresa y que se traduce en la posibilidad de tener un rodeo propio dentro del rodeo general de la firma.

En el caso de los oficios y servicios que se brindan en el medio rural, tienen cada vez mas importancia los ligados al tema del caballo y de las fiestas de destreza, que si bien no son de una continuidad garantizada, la amplia difusión de estas fiestas ha hecho que se genere una regularidad relativa que permite tomar en serio esta actividad como generadora de ingresos para los empleados que las realizan.

Se observa también que existe cierta vinculación entre las familias que producen alimentos (lechones, chacinados, huevos, carne) y sus comunidades de origen, que en muchos casos como Felipe, Marcelo y Julián no son las comunidades mas cercanas, pero que implican un habito de visita y estadía en los tiempos libres que se mantiene mas allá de la radicación laboral de la familia. Esto nos da también una medida de que la producción de excedentes no puede ser absorbida por la población rural del vecindario y tiene que ser comercializada en las comunidades cercanas, generando incluso excedentes que no pueden ser comercializados en la zona como sucede con la zafra de lechones que se produce en invierno y que tiene que ser comercializada en gran parte como lechón vivo de invernada a través de la figura de intermediarios extra zona conocidos como "lechoneros" que compran al barrer a un precio sustancialmente mas bajo que los precios minoristas conseguidos en la zona.

Otra relación clara se establece entre los empleados ganaderos y la posibilidad de realizar el trabajo de amansado de caballos, tanto para los propios campos como para terceros e incluso para venta de animales mansos para destrezas. Esto genera un plus en la actividad ganadera que es aprovechado por muchos empleados y que le da cierta estabilidad a esta forma de ingresos.

Es interesante comparar la paridad en los ingresos que logra un empleado sin trabajo fijo versus los salarios de un empleado con trabajo estable, tanto agrícola como ganadero. Si bien los empleados sin trabajo estable logran juntar un ingreso que según sus relatos les permite cubrir sus gastos diarios, ven como un problema no 
poder producir aunque sea alimentos para autoconsumo y como plantea Mauro un aumento en los gastos en la vida en el pueblo, además de la dependencia de factores como el clima para lograr cierta estabilidad laboral.

Es importante rescatar también, que salvo el caso de Mauro que tiene participación en una cooperativa de trabajo de administración municipal que le lleva cuatro horas de trabajo diarias, el resto de los trabajadores rurales sin empleo fijo no recibe planes sociales mas allá de la asignación universal por hijo y que esta destinada a los gastos de los niños y que se vinculan con la escolaridad y los planes de salud obligatorios.

En este sentido ha sido el estado, representado por lo municipal, que mediante distintas estrategias ha garantizado en épocas anteriores los ingresos mínimos familiares ante la falta de trabajo aun en el sector informal de los pueblos como los de este trabajo y en el medio rural en general, marcando una diferencia sustancial con los momentos actuales de la realidad.

\subsection{OFICIOS CAMPEROS}

\subsubsection{Sogueros y talabarteros}

En este grupo de actividades vemos conjugada la tradición gauchesca trasmitida de generación en generación o como lo manifestaban en las entrevistas, la trasmisión de saberes a través de compañeros de trabajo que le enseñan a los más jóvenes.

Es una actividad artesanal, donde cada soguero se produce su propia materia prima a través del procesamiento del cuero de animales faenados normalmente en los propios establecimientos. Si bien en su gran mayoría la soga es con cuero de vacunos, para la confección de costura y cueros de mayor finura se utiliza cuero de potro y en menor medida de chivo.

Surge de las entrevistas que este oficio plantea dos orientaciones a la hora de definir los trabajos a realizar, por un lado todo lo que es soga de trabajo, tanto nuevo como arreglo, de uso cotidiano, compuesto básicamente por riendas, bozales, cabezadas y lazos, y que son de mucho movimiento en la gente de a caballo.

"A mi me enseño un hombre que estaba en el puesto que yo estaba antes, un hombre mayor que sabia y a mi me gusta y aprendí algo...yo hago trabajos sin apuro, me encargan, porque recién a esta hora puedo entrar, después de trabajar y a veces vengo re cansado que note da ni ganas... hago un trabajo medio bruto, así para 
trabajo nomás, no se trabajar fino como Saltape, yo hago todo a lo de antes, la sobo con la rueda, hago todo el proceso. Lo lonjeo todo yo, y se lo vendo a la gente de acá, de De la Garma, de todos lados".

Jairo, empleado ganadero y multi-ocupado familiar, est. San Francisco, 10-2-13.

Por otro lado hay gente que trabaja "mas fino" y que se dedican a hacer cosas mas chicas como rebenques, cuenta ganado, llaveros, vainas, y otras cosas para lucir en fiestas gauchas y en ocasiones de reuniones y otros eventos. También se dedican a realizar algún trabajo grande de recado o sogas pero ya no para trabajo sino para lucir fundamentalmente en desfiles tradicionalistas, muy comunes en esta región y en toda la provincia.

En nuestro caso Sergio nos contaba que el hace todo el proceso pero que en caso de estos sogueros finos muchos ya compran el cuero trabajado para ahorrar tiempo y ellos se dedican a trabajarlo. Si bien se utiliza básicamente cuero, estos artesanos ya manejan también metales de valor en forma de argollas o dedales llamados cuentas, estas son de alpaca en general y en algunos casos de plata e incluso hay trabajos que incluyen plata y oro.

Cabe destacar que si bien los dos sogueros entrevistados trabajan actualmente en el campo, Jairo como vimos vive con su familia en un puesto y llega del trabajo directamente a su casa donde lo esperan su esposa y sus tres hijos pequeños, por eso en muchos casos prioriza la convivencia familiar al trabajo en soga.

En el caso de Sergio es distinto porque tiene su familia en el pueblo de Juan E. Barra, regresa los sábados al medio día y a veces los miércoles a la tarde y se vuelve el jueves a la mañana, entonces esta actividad lo ayuda y entretiene a la hora de los tiempos libres entre las jornadas de trabajo en el campo.

"Yo empecé de chico, me enseño mi abuelo, y hago de todo pero ahora estoy haciendo cosas chicas, retejido de cabos de cuchillos, trenzas de 8, 1012 tientos, ahora hago esto nomás, porque estoy trabajando en la estancia... vos vistes que hago todo, salo, estaqueo, corto, sobo, todo yo, me gusta... trabajo por pedido viste, porque te lleva mucho tiempo y por ahí no se vende, además hoy casi todo lo que hago es para desfile o lucir puesto, con iniciales, cuentas de alpaca y hasta hice una cabezada con cuentas viejas de plata para un recado de plata que ya estaba armado."

Sergio, empleado ganadero y artesano de cuero, Juan E. Barra, 20-5-13.

Si bien es muy común en las fiestas gauchas e incluso en aniversarios y festivales la venta de estos elementos, la mayoría proviene de vendedores ambulantes conocidos como pilcheros o mercachifles y que tiene elementos fabricados en forma industrial generalmente en el norte del país. 
Esto esta relacionado por un lado con la dificultad de tener stocks y grandes cantidades como lo manifestaban los entrevistados, y por otro lado hay un problema comercial, ya que los precios de estos elementos artesanales implican en muchos casos un proceso de adecuación y corrección para un uso particular, que hace que no se pueda definir en ese momento (ver fotos en el anexo).

En general muchos empleados ganaderos tienen como habito la confección de sus propios elementos de trabajo realizado a modo de hobby, se han mostrado satisfechos a la hora de plantear esta actividad como generadora de ingresos extras y en muchos caso generadora de prestigio entre pares, y reconocimiento en general.

En este sentido el reconocimiento se plantea por dos vías, una es la posibilidad de la propiedad y de lucir la prenda, el recado y el caballo. Denota además del buen gusto, la posibilidad económica de afrontar la compra de una prenda fina y lujosa, formando en ciertos casos parte de la descripción de tal o cual persona "fulano, el de la rastra de oro y plata del gauchito gil".

La otra vía esta ligada al orgullo gaucho del soguero, identificado en la comunidad y que en término generales siempre luce trabajos propios de los más refinados, no es costumbre que los trabajadores artesanos usen prendas de otros, salvo que sean muy vistosas y denoten un vínculo de mucha amistad con el que la confecciono.

"Yo empecé haciendo por gusto, después vendía así nomás, cuando estuve sin trabajo fijo, pare la olla con esto, así que mira lo que te digo. ... a parte mira lo que te digo: fui profesor, de la municipalidad me pagaron para que les enseñara a los chicos en un taller en el hogar agrícola, los sábados a la tarde, si vos vieras como aprendían los chicos, se entusiasmaron mucho.... Y la ultima, fui actor, me filmaron para una película sobre paisanos de campo unos chicos de La Plata que hacen cine independiente"

Sergio, empleado ganadero y artesano de cuero, Juan E. Barra, 20-5-13.

Tal como se desprende del discurso de Sergio y en menor medida de Jairo, esta ocupación extra genera satisfacciones y una sociabilidad diferente que excede a lo económico. Sin dejar de negar el impacto en los ingresos familiares que en realidad tiene, les ha permitido ser reconocidos por toda su comunidad e incluso por otras personas ajenas a su entorno, generando esto un enorme orgullo y pudiendo ser también capitalizado desde el punto de vista económico en el futuro.

Esto se vio claramente cuando en el marco del aniversario del pueblo se presento la película sobre paisanos, con el salón del club lleno, y en la cual se encontraba Sergio y otros dos trabajadores más de la localidad. 
"Esto es para toda la vida, ahora no puedo mucho porque estoy en la estancia, pero cuando me jubile me voy a dedicar a esto, porque sigo aprendiendo, mirando, me falta poco para jubilarme ahora con la ley nueva ya en dos años me jubilo"

Sergio, empleado ganadero y artesano de cuero, Juan E. Barra, 20-5-13.

En cuanto al análisis económico de la actividad, es de destacar que como toda actividad artesanal, el principal factor de producción es el trabajo del soguero, ya que los insumos como dijimos anteriormente son conseguidos prácticamente sin costo en los lugares de trabajo.

Las herramientas a utilizar también son generalmente de confección casera y consisten básicamente en leznas, agujas y cuchillos para coser y cortar el cuero.

En cuanto a los ingresos, si bien es difícil poder tener un detalle sobre la continuidad de los mismos, los entrevistados manifiestan que siempre están haciendo entre 2 y 3 trabajos en forma simultanea y que obtienen en forma mensual un promedio de 1000 a 1200 pesos, habiendo meses con menos ingresos y meses con mas, vinculados a la época de pruebas de rienda y domas que comienzan en la primavera.

La forma de pago no siempre es dinero, es muy común el canje por animales, potros o cerdos para carnear, como así también el intercambio con elementos que están ligados al propio trabajo y que luego el soguero los arregla y los vende, o cueros de animales, básicamente toros, esto es muy común en el tema de lazos y de recados, según nos comentaban los entrevistados. También existe en algunos casos debido al elevado precio de algunos trabajos el pago en cuotas, donde prima el vínculo entre las personas ante la inexistencia de papel alguno.

Es importante destacar que en el caso de Sergio, esta actividad le permitió superar una etapa de desempleo rural durante los años 2002 y 2003 , y donde su trabajo en soga fue la principal fuente de ingreso de su familia, estando por eso muy satisfecho y reconociendo la importancia de este oficio alternativo.

Resulta interesante que en ambos casos esta actividad de sogueros no es la única estrategia de multi-ocupación familiar, que incluye en ambos casos una actividad muy intensa de sus compañeras en otras actividades que van desde el trabajo domestico en casas de familia hasta la atención de producciones de autoconsumo. 


\subsubsection{DOMADORES}

En este grupo de actividades vamos a incluir a una buena cantidad de trabajadores entrevistados, seguramente por la gran difusión y valor que tienen estas actividades al momento de plantearlas directamente como una estrategia muy difundida de capitalización, además que como fuente de ingresos corrientes.

El primer capital con el cual los chicos de nuestra zona se introducen en el mundo adulto de la comercialización es con los caballos, se observa frecuentemente en la escuela o e el CEPT como entre ellos se compran y venden caballos, potros y petisos.

Esta aclaración sobre la utilización de la doma de caballos como estrategia de capitalización, surge directamente de la forma en la que se realiza la operación y la poca rigurosidad en cuanto a los tiempos de entregas de caballos mansos.

Existen muchas posibilidades de desarrollar esta actividad que varían según también una gran diversidad de arreglos en las formas de trabajo. Encontrándose dos situaciones que podríamos definir como los extremos y dentro de los cuales se encuentran los demás.

Por un lado están los arreglos en los cuales los establecimientos no tienen caballos y estos son propiedad de los empleados, que tienen permiso para tener una manada y que los tienen que utilizar para el trabajo en el campo, esta estrategia es típica de estancias grandes donde se utiliza mucho caballo durante todo el año.

"Nosotros tenemos la manada nuestra que sacamos para trabajar acá en la estancia, pero también sacamos reservados para las jineteadas y vendemos también.... tengo ahora 46 yeguas de cría y estamos saliendo con 6 o 7 caballos a las domas.... Amanso pocos para trabajar, el que no sale arisco para la doma lo amanso para nosotros y si no lo vendo, pero tengo la mayoría de yeguas".

Martin, empleado ganadero y tropillero, fiesta criolla Juan E. Barra, 15-12-12.

Este trabajo que nos plantea Martín tiene el nombre de "tropillero" y esta ligado a la provisión de animales para las fiestas de jineteada que se realizan por toda la zona, funciona como una actividad paralela que la realizan como mucho conocimiento y mucha pasión (ver fotos en el anexo).

En el otro extremo esta la situación en la que todos los caballos son propiedad del campo, y que los empleados que amansan caballos cobran un monto preacordado cuando entregan al encargado un caballo manso. No tienen la posibilidad de tener sus propios caballos y de ser posible solamente consiguen permiso para pocos animales. 
"Siempre amanso algún potro, aprovecho las guardias para galopearlo y cuando lo entrego me gano la amansada. En el verano me amanso casi siempre 4 o 5 por verano. A veces me pagan con un potro que me lo quedo para mi o lo vendo." Jairo, empleado ganadero y multi-ocupado familiar, est. San Fr4ancisco, 10-2-13.

Existe otro grupo que son los que tiene "permiso" para tener algunos caballos, siempre no más de 5 o 6 y que lo utilizan para tomar caballos de terceros, amansarlos y entregarlos o venderlos. En este caso, muy común por cierto, los entrevistados nos cuentan que lo que arregla casi en la totalidad de estos casos es la entrega de dos potros por parte del dueño de los caballos, y el domador le devuelve uno manso, por consiguiente la amansada tiene el valor de un potro, aproximadamente entre 1800 y 2500 pesos según el potro.

"Ahora que estoy en el pueblo tengo dos potros nomás, que estoy amansando, uno ya lo estoy por entregar y le agarro dos potros a el gordo Calafate, como ser uno es para mi....pero cuando estaba en el puesto sabia tener 10 o 12 potros que iba amansando para la estancia y eso me lo pagaban aparte.... Con el caballo siempre tenes algún rebusque"

Mauro, empleado ganadero y domador de caballos, De la Garma, 15-10-12.

Esto exige también que el domador salga por otro lado a vender el otro caballo amansado o se lo saca de encima potro según sea la urgencia de contar con dinero.

Como veíamos en las entrevistas, existe cierta compatibilidad entre esta forma de ingresos extras y las actividades vinculadas a la ganadería, presentándose la situación de poder utilizar los animales que están amansando para hacer el trabajo diario de recorrida y trabajo en los corrales.

Las formas de generar ingresos a través del caballo son diversas, como hemos visto en las entrevistas esta variabilidad tiene directa relación con las posibilidades y destrezas que cada empleado pueda demonstrar. A diferencia de otras actividades esta tiene un alto componente social y los reconocimientos se renuevan en cada caballo que se amansa, siendo mas destacados los que amansan caballos para niños o gente sin experiencia.

Otra actividad realizada por los empleados rurales vinculada al caballo esta ligada a la venta de la carne, conocida entre los lugareños como "carne de potro" y de consumo frecuente entre la población. Si bien normalmente la carne proviene de algún animal que se estropeo, también se suele utilizar animales potros de 2 o 3 años que por alguna razón se decide no amansar y se engordan y se faenan.

La venta se realiza puerta a puerta o por encargue generalmente con conocidos que ya tienen un consumo establecido. Si bien el valor de la carne es algo menor que 
la carne de vaca, generalmente producen un ingreso superior a la venta del animal como potro y por lo tanto es utilizado como un recurso por los empleados y como una alternativa por los consumidores, sobre todo en época de crisis económica. Los cortes mas difundidos en el consumo local son las hamburguesas de potro y las milanesas.

"Cuando puedo me carneo algún potro para vender, la gente me encarga y cuando junto mucho carneo un potro nuevo y lo vendo por trozos en de la Garma.... se come mucho potro, hace unos años cuando no tenia laburo, sabia carnear un potro por semana y lo vendía acá, ya tengo clientes fijos que me compran...yo no como, no me gusta es muy dulce."

Jairo, empleado ganadero y multi-ocupado familiar. Est. San Francisco, 10-2-13.

\subsubsection{ALAMBRADORES Y OTROS TRABAJOS}

Recordemos que acá estamos describiendo la actividad extra-salarial que tienen los empleados ya que el oficio de alambrador fue descrito en el capitulo anterior. Como lo vimos en las entrevistas, esta posibilidad la ejercen mayormente los empleados que trabajan en campo solos, como únicos encargados, en los campos grandes, debido a que los trabajos son grandes también, se contrata el trabajo afuera.

"Acá yo hago todos los trabajos, cuando hicimos líneas de alambrado la hicimos en familia, con las chicas que me ayudaban, ganamos los dos, porque le cobro mas barato y yo trabajo acá, sin moverme y cuando termino de recorrer empiezo con el alambre... es interesante porque se cobra bien, yo le cobro 12 pesos el metro y afuera esta 18 le conviene....y para mi son unos cuantos mangos. También le hice varios alambres al vecino que le recorro."

Juan, empleado mixto y multiocupado tambero, De la Garma, 2-3-13.

Si bien casi siempre hay trabajos de este tipo, lo suelen aprovechar los jóvenes por lo duro del mismo como ya lo hemos explicado antes.

No sucede lo mismo cuando hablamos de instalaciones de trabajo como mangas, corrales, casillas de trabajo, que casi siempre se realiza con mano de obra contratada.

Como planteaba Juan es un trabajo que se paga bien, pero tiene como contra que la reposición de alambres no es continua y esta ligada a los vaivenes de la actividad ganadera, estando en la actualidad ante una etapa de mucho trabajo.

Es usado por los empleados como una estrategia de capitalización para el cambio de vehículos o alguna inversión en el pueblo.

Existe un trabajo intermedio que se conoce como arreglo o "empatillada" y que consiste en cambiar 2 o tres alambres y los palos rotos y que se paga 5 pesos el 
metro. Esto se usa en épocas donde la actividad no anda bien según lo plantean en las entrevistas.

\subsection{PRODUCCIONES FAMILIARES}

\subsubsection{PRODUCCIONES DE AUTOCONSUMO}

Esta estrategia de multiocupación es de las más antiguas, difundida y transversal de las que se han relevado en este trabajo. Casi todos los relatos dan cuenta de una infancia y juventud rural, en el campo, conviviendo con los mayores y criando animales de granja para venta y autoconsumo.

Recurriendo a los datos de la encuesta volvemos a destacar que esta estrategia no la realizan todos los trabajadores, el $45 \%$ del total tiene producciones de autoconsumo, descendiendo al $14 \%$ si nos referimos a los empleados que viven en el pueblo, existiendo una fuerte vinculación entre la radicación en el campo y las producciones para autoconsumo.

Es coincidente y llamativo que en las distintas entrevistas no se hace mención a que existían limitantes desde la patronal en estas actividades extra, fenómeno muy difundido en la actualidad y planteado como una de los impedimentos mas importantes a la hora de realizar producciones familiares. Si se observa también que como en la actualidad, en muchos casos los ingresos generados eran la estrategia de capitalización mas importante de las familias.

Los entrevistados vinculaban la posibilidad de producción con la gracia de contar con los insumos básicos para la misma, fundamentalmente cuando se refieren a la provisión de alimentos para los animales. Queda claro que mas allá de su amplia difusión, la cuestión de los alimentos a bajo costo era un común denominador de las producciones que hacían los entrevistados y sus familias y según cuentan formaba parte de todos los arreglos que pudieran haber hecho los empleados de aquella época.

"Cuando yo era chico, el abuelo criaba chanchos en una laguna que estaba frente del puesto, tenia como 150 chanchos, y todo los días sacaba 2 o 3 bolsas de cereal del galpón y se la llevaba a los animales. Cada tanto cargaba y vendía lechones en el pueblo y después comíamos, facturábamos y todo eso, cambiaba el auto con los lechones... la abuela criaba pavos y cuando salió la televisión con batería y esa antena grande, como de 20 metros que la movías con una manijita para encontrar la señal, la abuela vendió un lote de pavos en Laprida y compró el televisor con antena y 
todo instalado."

Mauro, empleado ganadero y domador de caballos. De la Garma, 15-10-12.

En cuanto a las producciones que se desarrollan hoy día en las familias de los empleados rurales del área del trabajo de investigación, tenemos que distinguir a priori entre dos planteos diferentes, el autoconsumo y la producción para venta.

La estrategia de producción para autoconsumo, en la mayoría de los casos vistos esta conformada por un conjunto de actividades vinculadas con la cría de aves para huevos y para carne, que va desde pollos, gansos y patos hasta la mas compleja cría de pavos. Además también en la mayoría de los establecimientos donde viven familias solas, existe la crianza de cerdos para la producción de lechones para consumo y de capones para realizar facturas de cerdo (ver fotos en el anexo).

Analizando la encuesta, existe una asociación muy fuerte entre la actividad laboral de ganadería a cargo de un establecimiento, el domicilio rural de la familia y las producciones familiares de autoconsumo. 8 de cada 10 empleados ganaderos que viven en el campo y están a cargo de los campos, tienen actividades de autoconsumo y/o de venta.

En cuanto al nivel técnico de las producciones se pudo rescatar de las entrevistas que en la mayoría de los casos existe un manejo tradicional semi-extensivo que está muy difundido en la zona.

Se basa en una buena disposición de alimentos, vinculada a la producción de cereales en el mismo establecimiento o en establecimientos que las firmas poseen en la zona. En este sentido, se rescata que la amplia difusión de bolsa de plástico para el guardado de los cereales, genera un importante nivel de desperdicio que casi siempre es utilizado por los empleados rurales en la alimentación de cerdos y gallinas.

"Criamos chanchos, gallinas y pollos doble pechuga, para consumo propio nomás, tenemos las dos chanchitas del CEPT y una dio lechones que ya comimos.... La otra chancha vieja, la dejamos para hacer chorizos que nos gusta mucho... la semilla la sacamos de las bolsas, lo que queda cuando cargan, nos da el patrón para nosotros porque no se pueden tener sueltos los chanchos por el cultivo."

Miguel, empleado ganadero de origen chaqueño, est. La Colonia, 3-11-12.

En el caso de los empleados que viven cerca el pueblo o en la zona de quintas, es muy común la utilización de desperdicios de verdulerías, panaderías y carnicerías que comúnmente canjean por algún lechón para las fiestas o por huevos en el verano.

En el caso de los empleados que viven en campos donde no se realiza agricultura, la disposición de alimentos se complica, teniendo que tener la posibilidad de contar 
con un carro y camioneta para poder buscar cereal que consigue o canjea en algún campo cercano. Esta complicación hace que las posibilidades de producción giren en torno al autoconsumo, teniendo muy limitada la producción para venta o canje.

Las razas utilizadas, generalmente cruzas, responden a los usos que vienen de generaciones, habiendo una gran variedad e intercambio de animales entre empleados vecinos y amigos.

En el tema de cerdos existe una genética lugareña que se va mejorando con la compra o canje de padrillos provenientes del CEPT o de criadores cercanos de renombre, prefiriéndose los animales de color blanco por su mayor facilidad al momento de ser pelados para la venta.

En el sector de las aves existe una gran variedad de especies que van desde gallinas de distintas razas, patos, gansos, gallinas de guinea y pavos. De estas especies todas tienen utilización en el consumo familiar, pudiendo haber excedente de pollos, huevos y pavos destinados para la venta. Salvo en dos excepciones donde se crían conejos para consumo, el resto de las familias cría solamente aves y cerdos.

Se plantea como la principal falencia la falta de instalaciones adecuadas, que combinado con las bajas temperaturas invernales ocasiona un bajo nivel de producción, sobre todo en invierno. Se utilizan chapas, nylon de bolsa y materiales viejos par realizar reparos y la provisión de agua se hace en forma discontinua, a través de baldes o latas. En el caso de los lechones esto se compensa con las mejores producciones de verano y los mejores precios logrados para las fiestas (ver fotos en el anexo).

Las actividades son realizadas por todos los participantes de la familia, tomando la mujer en la mayoría de los casos un rol protagónico, sobre todo en las épocas de mayor trabajo de sus compañeros. Los chicos se inician desde muy chicos en las actividades productivas, mostrando en general mucho interés, siendo en la mayoría de los casos el primer contacto que van a tener con la actividad comercial a través de la venta de huevos o lechones a amigos y familiares.

En cuanto a la comercialización de los pequeños excedentes de lechones, que ocurren en la época de las fiestas de fin de año, se venden entre las personas conocidas del pueblo o las panaderías de la zona. En cuanto a los huevos de excedente, son las mujeres las encargadas de la comercialización minorista que realizan en los viajes al pueblo, casi siempre los fines de semana, vendiendo a conocidos o realizando un trueque con algún negocio como verdulerías y almacenes, 
achicando de esta manera la cuenta del pedido de mercadería.

Mas allá del valor económico real que alcanzan estas producciones de autoconsumo, surge de las entrevistas un rol muy importante en la economía familiar, al generar una estabilidad de ingresos, un ahorro completo en el rubro alimentación y la posibilidad de retribuir favores y servicios con productos de su producción familiar.

"Siempre hay gastos, vos ahorras y te aparece algo, teníamos guardada la plata de unos lechones y justo le tuvimos que hacer el motor al auto y se nos fueron los ahorros de los lechones, pero sino nos quedábamos a pie hasta cuando?, quien sabe, nos costo 5000 pesos el motor...antes la usábamos para los chicos, viste que siempre se te enferma alguno, remedios, viajes a Bahía al hospital..."

Marta, esposa de Osvaldo empleado ganadero, est. Vizolini, 25-11-12.

Las familias en la mayoría de los casos relevados, sobre todos los empleados ganaderos tienen una majada de ovejas denominada "de consumo" de 50 a 100 ovejas, normalmente propiedad del empleador, y que esta bajo la responsabilidad del empleado con el fin de proveer la carne de consumo familiar a lo largo del año. En algunos casos los empleados venden algún cordero o capón que les sobra o lo hacen para poder cambiar de carne y consumir carne de vaca.

"Nosotros gallinas y pollos siempre tenemos, algunos se comen las comadrejas pero siempre comemos pollos de campo nomas, y huevos siempre... Tenemos tres chanchas para lechones y carnear y unos chivos que los comemos pero esos nos regalaron, no me gusta el chivo es muy dañino... La majada es de la firma, para consumo, aunque a veces cuando alguien carnea una vaca le cambio algún capón, para cambiar, a veces te cansa la oveja"

Alberto "chacho", empleado ganadero, est. 23 de Abril, 16-6-12.

Las familias también manifiestan que cuando hay chicos en la casa, sacan leche de una vaca lechera si hay y sino amansan una vaca de cría para ordeñar, y también aprovechan para elaborar productos lácteos.

"Para que los chicos pudiesen estudiar y tener una profesión y ganarse la vida, hacíamos de todo, te cuento... vendíamos huevos, vendíamos lechones, cuando empecé a trabajar en el negocio hacíamos salsa de tomate, teníamos huerta hacíamos de todo, simplemente tenes que trabajar, hacíamos chorizos, jamones, todo.... Cuando estudiaban no les podíamos dar plata, pero se llevaban todo de acá, la comida hecha les mandaba en encomienda, huevos chorizos todo les mandaba con el comisionista, así pudieron estudiar los dos hasta que se consiguieron un trabajito en Tandil... Mis chicos comían yogurt, se los hacia yo, el me compro una yogurtera y los chicos comían al mediodía y a la tarde, comían manteca casera, nunca Sancor, comían dulce de leche casero.... ahora los chicos comen galletitas, infinidad de 
galletitas, antes yo todos los días le hacia una torta, hay ciruelas, se hace dulce, hay membrillo se hace dulce, siempre hubo postre en mi casa, toda la vida y no somos ricos..."

Mirta, esposa de Abel, empleado mixto, est. La posada, 5-4-13.

Sin embargo a la hora de plantear estrategias vinculadas a la producción vegetal como son la huerta y el monte frutal, vemos que están mucho menos difundidas, y que son de preferencia de empleados mixtos. Sobre el total de entrevistados ganaderos solamente el $30 \%$ tenía una actividad de huerta discreta, y de estos la mayoría estaban ligados a una práctica vinculada a la asistencia de los chicos de la familia al CEPT, donde es obligatoria para la familia la realización de la huerta familiar.

"Huerta no puedo hacer por el agua, es salada y la tierra es muy mala y no nace nada, aunque los chicos ahora tienen que hacer, no se, vamos a hacerlo en el molino que se yo..."

Alberto "Chacho", empleado ganadero, est. 23 de abril, 16-6-12.

\subsubsection{PRODUCCIONES PARA VENTA}

En el otro grupo de actividades productivas, ya mas vinculadas a la venta, se inclinan por alguna especie en particular, en su mayoría se producen lechones para la venta minorista o llegado el caso, sobre todo en invierno se venden al algún lechonero que los compra vivos al barrer.

Es interesante discutir en este punto sobre cual es el verdadero sentido de estas producciones, que siguiendo la línea de pensamiento sobre el carácter suplementario de los ingresos extra-salariales, estas se organizan directamente para la venta y generación de ingresos, destinando a autoconsumo una pequeña parte o lo que no puede ser vendido.

En este sector destacamos un grupo de productores que además de su actividad salarial, tienen la posibilidad de tener un rodeo de vacas propias en el mismo campo como Alberto o ahora en campo alquilado por el tamaño del rodeo como Felipe.

"Yo tengo un rodeo vacas que fui capitalizando con el patrón, de los arreglos y los tenia hasta venderlos como gordos, pero después como se complicaba el manejo, arreglamos que tengo vacas de cría y vendo los terneros destete, así que yo tengo vacas pampa (raza Hereford) y en el campo hay todo angus negro y colorado entonces los terneros caretas (cruza Hereford X A. Angus) son míos y manejamos un solo rodero de vacas sin problemas" 
Alberto grande, empleado mixto con hacienda propia, est. La escondida, 1-11-12.

El caso de Felipe también muestra las ventajas que supone la posibilidad de armar un rodeo propio, que en la actualidad lo tiene en campo arrendado debido a que se agrando y no quiso desprenderse de hembras para seguir agrandando su rodeo.

Resulto muy interesante, sobre todo para quien escribe, la respuesta de Felipe ante la pregunta, quizás apresurada, de si no prefería emanciparse laboralmente y convertirse en un pequeño productor independiente?

"No así estoy bien, ya crié dos chicos y con estos dos voy bien, me compre la casa en el pueblo, compramos la combi para que Mónica haga el transporte y para ir a las pruebas de rienda, tengo un buen arreglo, mis vacas gordas y vivo bien para mi... si te convertís en un productor, soy chico y voy a tener todos los problemas de los productores chicos, que no les alcanza, no tienen pasto y tienen que salir de peón ... deja, a mi me conviene mas así."

Felipe, empleado ganadero, Est. La Argentina, 17-6-12.

\subsubsection{CERDOS}

En el caso de la producción de cerdos la estrategia de los empleados es en general la producción de lechones para venta faenados en el mercado local y en forma minorista y su estrategia alternativa que es la venta de lechones vivos al barrer a un acopiador de lechones para frigorífico.

Todos los entrevistados, manifiestan como definitorio a la hora de llevar delante una producción de este tipo, la posibilidad de contar con la comida para las madres, puede ser cereal, subproductos de la industria láctea o desperdicios de otros alimentos de bovinos, siendo también definitorio la posibilidad de contar con la logística de acarreo, en términos generales hablamos de camioneta con carro.

Este factor de la alimentación, es uno de los motivos por lo que no esta difundida entre los empleados la actividad de invernada o producción de capones de cerdo, ya que la misma necesita mucha cantidad de alimento para su funcionamiento

Los entrevistados plantean que dan alimentos en base a cereales solos o de mezclas gruesas, pero utilizan sobre todo en la zafra verano, alimento balanceado para terminar los lechones y tenerlos bien presentados para las fiestas.

"Tengo 12 chanchas de cría, vendo muchos lechones, en las fiestas vendí 80 lechones a 350 pesos, imagínate, les doy de comer la misma comida que los novillos 
del feed-lot, están re gordas las chanchas. Ahora en el invierno los lechones que se me pasaron los meto en el feed-lot y comen lo que bostean las vacas, imagínate que es puro cereal. Si tengo que pagar la comida yo no puedo hacer nada, tengo que criar gallinas nomás...vendo lechones y crío pollos, también con el alimento de los novillos y maíz, crío 50 pollos por mes, algo como yo y el resto vendo en Laprida cuando voy al pueblo o mando con mi señora si yo no puedo ir... si te quedas solo con el sueldo de peón te comen los piojos...".

Marcelo, trabajador ganadero y multi-ocupado familiar, est. Santa Clara, 25-6-13.

Resulta definitorio para estos planteos la disponibilidad de comida accesible, como en el caso de Marcelo, que maneja un feedlot casero en el campo y que lo utiliza para recriar los lechones hasta el tamaño de capón (aprox. 100 kilos). Los pone en el mismo corral con los novillos y estos aprovechan los desperdicios de comida del comedero y la bosta de los vacunos que contienen una alta cantidad de granos, de esta forma soluciona la principal traba que tienen normalmente los empleados para hacer capones que es la comida en cantidad. Una lógica parecida de utilización de desperdicios tiene el planteo de "Perico" respecto a las sobras de la maquina de limpieza de semillas del equipo de chacra en el cual trabaja.

El otro tema también importante es el de contar con un espacio que pueda ser utilizado para estas actividades. Es necesario aclarar en este sentido que esta posibilidad se ve disminuida en la zona cuando los campos donde hay empleados con posibilidades de criar animales tienen superficie alquilada. Esto se debe a que existen inconvenientes de los dueños de campo en dar permisos para criar cerdos para no tener problemas con los inquilinos y de hecho esto figura tal cual en los contratos de alquiler.

En cuanto al tiempo que llevan estas actividades, se organizan en los tiempos muertos de las actividades asalariadas, siendo una gran ventaja que tienen los empleados que trabajan como únicos en un establecimiento ya que tienen la posibilidad de organizar sus tiempos de trabajo en forma integrada, incluso en muchos casos priorizando actividades de sus producciones para luego hacer sus tareas habituales y sobre todo cuando los dueños no son de la zona y no vienen con frecuencia.

Sin embrago cuando los tiempos son escasos para los empleados, sobre todo en la época de parición donde se recorre con mayor intensidad y durante todo el día, la actividad es realizada por el resto de la familia, incluso los chicos cumplen con la tarea de dar comida y agua a los animales.

En cuanto a las instalaciones, estas mejoran con respecto a los que crían para 
autoconsumo, la mayoría tiene chupetes de bebida par a no acarrear agua, tiene instalaciones fijas como silos para acumular alimento y en dos casos cuentan con maquinaria propia para la elaboración de alimento balanceado.

"Nos ayudo mucho esto del cajón de recría viste, como lo hace el grillo esta muy bueno, lo único es que esos días les tenes que dar alimento comprado pero te conviene, así salen buenos, parejitos y en 20 días los tenes... las chancha las tenemos como siempre, con la comida que consigue "Perico" de la limpiadora que es muy buena y no tiene costo para nosotros, salvo cuando la tenemos que ir a buscar al campo, pero desde que guardan las maquinas acá en la quinta casi siempre me la traen... los chicos ya son grandes y gracias a dios ayudan sino seria muy difícil."

Andrea, Esposa de "Perico" empleado agrícola multi-ocupado, De la Garma, 3-7-12.

Se esta difundiendo entre los criadores de lechones, la técnica del cajón de engorde, que viene de las practicas de los criaderos grandes y que consiste en un confinamiento con condiciones de ambiente adecuadas (cajón de madera cerrado con el alimentador adentro) y buena alimentación. Es utilizado por dos empleados que han trabajado en criaderos comerciales grandes pero que por su practicidad y sus buenos resultados se están difundiendo entre los criadores chicos.

En cuanto a la parte de comercialización, como hemos planteado con anterioridad, se realiza en su totalidad sin ningún encuadre legal, fiscal, ni sanitario. Al consumidor minorista se le vende faenado y pelado listo para cocinar, siendo preferentemente vendido fresco, aunque en algunos casos se vende congelado del freezer.

Todas las autoridades competentes hacen la vista gorda en este rubro como así también con el tema de los corderos, en ambos casos la modalidad de venta directa cubre prácticamente todo el mercado, no existiendo lugares donde se puedan comprar lechones o corderos con habilitación de faena.

En cuanto al precio existe una variabilidad estacional, con buenos valores en la época bien marcada de las fiestas navideñas y de fin de año, y valores irregulares durante el invierno. Para tomar referencia el valor de los lechones vendidos en estas fiestas de 2012 estuvo en 350 pesos por lechón de aproximadamente 10 kilos limpio. Mientras que los lechoneros compraban al barrer, vivo a razón de 220-250 pesos por lechón.

En cuanto al invierno, la demanda es mas pareja y vinculada a cumpleaños o festejos chicos, existiendo mucha oferta de animales y donde la competencia deprime los precios. La reactivación de un par de casas de comidas en la localidad, ha disminuido este problema y genera un movimiento de animales que mejora la 
situación.

Estas casas de comidas están pagando a razón de 300 pesos por lechón de 13-15 kilos limpios, si bien el precio no es tan bajo, el tamaño que exigen para comprar es mayor que el que vende a consumidores particulares (ver fotos en anexo).

En muchos casos el lechón es mercancía de cambio de un variado tipo de servicios, que van desde arreglos mecánicos, favores profesionales (consultas medicas, legales, contables) hasta pago de mercadería en distintos negocios como panaderías, verdulerías etc.

La posibilidad que tengan los distintos empleados de ir ampliando sus vínculos sociales, influyen directamente en la posibilidad de realizar las ventas de sus producciones en este sentido, los empleados que viven en el pueblo y los que viven en las quintas, tienen ventajas respecto de los que viven en el campo y que salen los fines de semana, teniendo estos que liquidar lechones en algunos casos de escasez de comida, aunque con la ampliación de las comunicaciones esto se esta compensando, produciéndose encargues por teléfono y confiando en el animal que le van a traer los empleados del campo.

\subsubsection{TAMBO}

Otra estrategia productiva esta vinculada al ordeñe y venta de leche fresca. En este sentido, esta alternativa ha sido desarrollada por empleados mixtos y ganaderos que viven con su familia en el pueblo y que trabajan en campos cercanos.

En el caso de Juan las vacas son mayoritariamente del dueño del campo, generalmente cruzas de lecheras que vienen en los rodeos de negocio y el las aparta para ordeñar. Además el se esta armando de vacas lecheras raza holando que son de su propiedad y cumplen la doble función de producción y capitalización de ahorros (ver fotos en el anexo).

Ordeña tres veces por semana, el solo o acompañado por sus hijas en la época que no hay clases. Tienen como forma de trabajo ordeñar a la tarde y repartir a la tardecita los días martes, jueves y sábados en el pueblo de De la Garma. Este reparto lo realizan su mujer y sus hijas a clientes en su mayoría fijos. Utilizan para repartir envases plásticos de gaseosas que higienizan y reutilizan para la venta de leche.

"Hace mucho empecé, yo trabaje en un tambo cuando termine la colimba, así que cuando me establecí acá empecé con esto. A la mañana cuando vengo encierro los terneros para que las vacas guarden leche, cuando termino mi actividad, a la tarde 
antes de irme las ordeño y después me voy al pueblo. Allá las chicas llenan las botellas y salen a repartir en el auto y en un rato entregan toda la leche, si sobra me la llevo al campo y se la doy a los lechones, no reparto leche vieja, ahora estamos vendiendo 80 litros, en invierno, porque durante el verano se vende menos, hace mas calor y la leche se pone fea mas rápido... para una familia con chicos le conviene, yo vendo 3 pesos el litro y en el almacén vale 8 . "

Juan, empleado mixto y multi-ocupado tambero, De la Garma, 2-3-13.

En cuanto a la parte económica, la mujer es la encargada de la cobranza y de hacer nuevos clientes, sin embargo cuando se deciden inversiones es el hombre el que tiene mayor peso en la decisión, aunque muchas propuestas provienen de las mujeres de la familia. Según plantean en la entrevista, los ingresos provenientes de esta actividad extra cubren casi la totalidad de los gastos comunes de la familia, quedando el sueldo de empleado libre para generar mejoras en la casa, vehículos y otras necesidades.

Comenta Juan que esta actividad tuvo un auge durante la época de crisis del 2001 2002 donde había en el pueblo como diez lecheros y que todos vendían bien. Ahora hay tres personas que realizan esta actividad de los cuales 2 son productores familiares que viven en la zona de quintas y tiene además de la leche otras actividades.

Es importante resaltar, porque tiene que ver con los objetivos de este trabajo, que los dos lecheros que en la actualidad son productores familiares, comenzaron su producción para venta luego de ser despedidos de sus trabajos ganaderos, y comenzaron con las vacas que tenían de propiedad en sus empleos anteriores.

Sin duda esta estrategia de multiocupación cobra importancia a futuro como reaseguro de cierto periodo de desempleo en la mayoría de los casos, pasando de ser un ahorro de capital para eventualidades a ser el capital inicial de un emprendimiento autogestionado familiar. 


\subsubsection{AVES}

Otra actividad de generación de excedentes que han planteado en la encuesta es la venta de huevos, pero a diferencia de las otras, esta actividad es estacional generando ingresos solamente en la época de primavera y verano, teniendo un lapso de tiempo sin ingresos que dura casi todo el invierno.

Esta actividad esta enteramente a cargo de las mujeres, no solamente de la parte económica sino también son las encargadas de la veterinaria y los suplementos nutricionales en los casos que usan. A diferencia de otras producciones más importantes, los ingresos provenientes de los huevos son administrados por las mujeres para gastos de ellas y de los chicos que tienen que ver con vestimenta y entretenimientos.

"En el verano con los huevos les compro a los chicos toda la ropa para la escuela, zapatillas todo... y me compro algo para mi también, me compre una cámara de fotos para sacarle a los chicos porque tenia una revieja... Tengo que venir al pueblo todas las semanas porque en verano los huevos aguantan menos, se ponen feos si no los vendes. Traigo canastas con 50 a 60 docenas por semana, tengo 120 ponedoras negras mas todas las gallinas de campo, además les traigo a mis vecinos en la estancia que ellos también tienen gallinas."

Daniela, esposa de Jairo, empleado ganadero, est. San Francisco, 10-2-13.

Como lo planteamos con otras producciones, para este caso también es indispensable la disposición de cereal para las gallinas, pudiendo utilizar el producto de la limpieza de semillas para la siembra como en el caso de soja o cereales de poca calidad industrial, como la cebada cervecera.

Las instalaciones están formadas casi siempre por gallineros de chapa de confección propia aunque en algunos establecimientos grandes existen instalaciones de mampostería de muy buena calidad que datan de mucho tiempo atrás pero que se utilizan perfectamente en la actualidad.

En cuanto a la comercialización, si bien se puede realizar como actividad minorista, en el caso de los encuestados canjean en los negocios donde sacan mercadería como el almacén y la panadería. Estos vínculos se van construyendo en la medida que los empleados, en muchos casos son hijos de empleados que tenían esa actividad o sus familias eran clientes del comercio en tiempos anteriores, o compartieron alguna actividad deportiva o la escolaridad con los dueños de los negocios.

En definitiva, son vínculos que se construyeron con el tiempo, en el marco de una relación social previa, de la confianza en el producto y en la seriedad de la transacción comercial. 
Esta situación se da sobre todo en épocas de verano donde la producción es máxima y por ende hay una gran disponibilidad de huevos. Cabe resaltar que en De la Garma y zona no hay un establecimiento que se dedique a la producción de huevos y por consiguiente los huevos consumidos vienen desde Gonzáles Chávez o Tres Arroyos por comisionista, quedando en evidencia el aporte de las producciones de los empleados para generar circuitos cortos de comercialización que favorecen la circulación de recursos dentro de la comunidad generando un beneficio general para todos.

En este capitulo vamos a mencionar también a la difícil producción de pavos, realizada por poca gente, en este caso por solamente dos encuestados, pero que representan un buen ingreso con un periodo de trabajo muy corto, generalmente a cargo de la mujer de la familia. Según comenta Carla, esposa de un empleado ganadero, ella vendió en la temporada pasada 80 pavos a un valor de 200 pesos cada uno, a un señor de una confitería en Tres Arroyos.

Esta producción tiene un gran componente familiar ya que la crianza de estos animales tiene muchos considerandos que se transmiten de generación en generación y se aprenden desde pequeños con la participación en la crianza y fundamentalmente en el cuidado de los pavitos cuando son chicos. Si bien es la mujer la que coordina el trabajo, son los chicos los que andan atrás de los pavitos para evitar que se pierdan o que se los coma algún animal en el campo.

"En el campo que estamos ahora podemos criar pavos, porque no hay muchos zorros porque tenemos muchos perros para trabajar en hacienda, así que las pavas crían bien, desde ya que cuando son chiquitos los pavitos los encerramos porque sino se pierden, pero después andan por el campo los traemos a la tardecita con cereal.... los vendo en una confitería en tres arroyos por que no se come mucho, a la gente le resulta caro y no están acostumbrados, tengo dos o tres que vienen a buscar de vez en cuando pero la mayoría lo vendo a esa confitería faenados."

Carla, esposa de "Chacho", empleado ganadero, est. 23 de abril, 16-6-12.

Desde el punto de vista comercial, esta producción no tiene un consumo masivo local minorista como lo pueden tener los pollos, la leche o los lechones, tendiendo que establecer contactos con comercios que lo utilicen para preparar comidas tal cual to planteo Carla, existiendo también la modalidad de compradores de frigoríficos que dan una vuelta cada tanto buscando lechones pero que también llevan pavos, patos y otros animales. 
4.4 Lo que genera el esparcimiento, caballos, cantores y asadores

Como veremos mas adelante el vínculo que establecen los pobladores rurales con el caballo es muy importante y trasciende lo relativo al trabajo. Ha cumplido muchos roles en la vida rural que van desde el transporte, la potencia para tirar y hacer funcionar maquinaria, la pertinencia social y los deportes con caballos.

Hoy en día como vimos en las entrevistas y hemos observado en los distintos eventos que hemos asistido, el vinculo sigue intacto pero se manifiesta a través de la realización de pruebas o destrezas gauchas que tienen que ver con el domino del mismo. Esto ha generado un "mundo de las destrezas criollas" que mueve muchas personas y mucho dinero por cada fin de semana.

Según nos sale del relato de Martín, durante la fiesta de Barra los espectáculos que se brindan en estos encuentros llevan mucha organización previa y compromisos que hay que cumplir para seguir estando en el circuito. Hoy día se diferencia tres grandes grupos, de actividades, las carreras de sortija y tacuara, las destrezas con tambores y las domas.

Las carreras de sortija y tacuara son tipos de carreras donde la velocidad de los caballos no es lo mas importante. El desafío del juego consiste en acertar con un palito de $30 \mathrm{~cm}$ en el caso de la sortija o con una caña de 1,5 mts en el caso de la tacuara, a una argolla de $3 \mathrm{~cm}$ de diámetro que se encuentra colgada en un travesaño por debajo del cual pasan lo jinetes a la carrera de a pares. El jinete que ensarta mas argollas en 5 pasadas gana.

Las destrezas con tambores consisten en sortear una fila de 8-9 tambores de 200 Its, separados a $7 \mathrm{mts}$ entre si de ida y de vuelta. Si ninguno voltea ningún tambor el que llega primero gana. Se han generado en este juego varias categorías de acuerdo al tiempo de doma que los caballos tienen antes de participar en un encuentro.

Las domas se tratan de espectáculos donde los jinetes tienen que permanecer una cantidad de segundos arriba de un caballo sin domar que intentara sacárselos de encima, es sin duda el espectáculo que mas riesgo supone para el jinete.

Se ha generado en función de esto un mercado de caballos con aptitudes deportivas que se va ampliando y profesionalizando cada día mas. Según nos cuenta Julián, empleado ganadero y organizador de eventos de destrezas, existe un nivel creciente de competencia que hace que os caballos aumenten de valor y sea muy buen negocio para quien sabe dedicarse a producir caballos y venderlos. 
Además esta actividad esta extendida en toda la región ampliando la posibilidad de comercialización de los caballos a otras zonas distintas de la nuestra.

"Ahora es todo mas profesional, los caballos ya son de sangre, cada vez mas le están metiendo sangre buena para competir, se ha hecho muy profesional, hoy cualquier gaucho que quiera correr no puede competir con los profesionales por eso se hicieron otras categorías. Yo y mi hermano amansamos desde siempre y ahora tuvimos que incorporar sangre porque sino no le ganamos a nadie y viste como es esto si no ganas los caballos valen menos.... Aparte esta todo muy caro, ir a una carrera te cuesta 200 pesos la inscripción, 150 de certificado equino, 300 de gasoil 300-400 para comer y ya se te fueron 1000 pesos y es mucho."

Julián, empleado ganadero y productor de caballos, est. La Batea, 30-6-013

Estas actividades traen implícita una vinculación social muy intensa, porque el ser conocido implica que te inviten a participar o que te contraten la tropilla o que lleves algún caballo a la doma. Por consiguiente son oficios que no solo generan ingresos sino que directamente amplían la sociabilidad de los empleados y sus familias teniendo actividad prácticamente todos los fines de semana que dura la temporada, que en el caso de las destrezas transcurre durante el invierno y finaliza a fin de año y en las domas empieza en la primavera y termina a fines de verano.

Hablando de números y de ingresos, nos comentan que el negocio varía según las épocas pero que este año los valores de venta de caballos oscilaron entre 6000 pesos por un caballo criollo que anda bien hasta los 20000 pesos ya caballos de sangre para correr los clásicos. Uno de ellos nos plantea que amansa 4 o 5 caballos por año, aunque a veces no los vende a todos y a veces los cambia por otras cosas que necesita.

En cuanto a los caballos de doma, no es común la compraventa, lo que se comercializa es el servicio de tropilla que consta en 6 a 10 caballos como mínimo para las montas y que los valores oscilan entre 800 y 1500 pesos por caballo según el flete y luego esta lo que se llama monta reservada, que son los caballos mas difíciles de montar y que tiene un precio individual. Martín nos comenta que tiene entre 8 y 9 domas por año, que muchas ya son fijas, hace muchos años que va, así que le permiten una cierta regularidad que el valora mucho.

"Este año venimos bien, acá no se pueden hacer domas porque las cooperadores tienen miedo por el costo del seguro y los accidentes, pero antes se hacían mas nosotros tenemos la tropilla y vamos a varias domas, a Choele Choel en febrero, a Pringles, a Olavaria y varias mas. de acuerdo a como ande el potro te pagan, nosotros tenemos uno muy bueno y otro que se esta haciendo, el resto son del montón pero te ayudan a pagar el flete... si nos compramos el camión que ya lo tengo apalabrado, vamos a poder viajar mas y mas barato... solamente salgo a esto me gusta, ahora 
vine a esta fiesta porque me queda cerca pero generalmente voy solamente a las domas, aunque nunca fui a Jesús María, el día que tenga un reservado bueno voy a ir..."

Martín, empleado ganadero y tropillero, fiesta criolla Juan E. Barra, 15-12-12.

Existen otros oficios que están relacionados ya no con los caballos directamente pero si con las fiestas criollas y tiene que ver con la animación, el canto y la comida. En este sentido la entrevista con Hugo, ex-alumno del CEPT, empleado ganadero en una estancia cercana a Juan E. Barra y cantor folclórico de trayectoria regional, ha resultado muy esclarecedora sobre la socialización que adquieren los empleados que pueden practicar este oficio.

Primero comentó que desde muy chico sale a las domas con el padre y desde que es mayor ya sale solo, que lo contratan en la zona que tiene dos o tres presentaciones por mes, que generalmente son los fines de semana y que esto además de los ingresos extras le ha generado un montón de amigos con los cuales se encuentran en las distintas fiestas o se visitan.

El valor de estas presentaciones oscila entre 300 y 500 pesos según dure la actuación y como sea el traslado hasta la fiesta. Además generalmente venden entre 15 y 20 CDs con sus canciones lo que les genera ingresos extra del orden de los 500 pesos, totalizando un ingresos de 800 a 1000 pesos por fin de semana con actividad.

"Te cuento que hace mucho que toco la guitarra pero recién hace 2 o 3 años que puedo decir que gano plata, antes iba porque me invitaban pero como era chico me pagaban los gastos nada mas, ahora ya cobro por actuación pero me conocen mucho mas, a veces voy a la radio al programa de folclore, tengo un CD y eso ayuda.... Hice un montón de amigos, cuando voy a algún lugar casi siempre como y duermo en la casa de algún amigo y eso me gusta mucho... ya estuve en 2 pre-Cosquín [Fiesta nacional del Folklore que se realiza en el mes de enero en la ciudad de Cosquin, Córdoba] pero no clasifique, así que cuando pueda ir a Cosquín me hago famoso y no trabajo mas".

Hugo, empleado ganadero y cantor, Juan E. Barra, 15-12-12.

En cuanto a los asadores, es un oficio practicado por muchas personas pero solamente muy pocos pueden generar ingresos a través de ello. La diferenciación esta vinculada a la posibilidad de tener todos los materiales y elementos como parrillas, asadores, balanzas y a la seguridad de que no se han cometido errores en los servicios de comidas anteriores.

En nuestra zona de estudio existen dos o tres personas que brindan este servicio, que mas allá de los ingresos, menores e irregulares que en otros oficios, también 
generan muchos vínculos para estos personajes y un reconocimiento social muy extendido.

Destacamos en este sentido el emprendimiento de Fabián, un empleado ganadero y asador reconocido, ganador del primer concurso de asado pampeano, que estando en el pueblo sin ocupación fija, abrió un lugar donde se vende carne asada. Lo habíamos mencionado con anterioridad debido al movimiento que genero en los productores de cerdos y corderos ya que consume en forma regular animales de la zona.

"Anda bien el negocio, yo hago dos o tres corderos cada fin de semana, a veces no hay y me complica porque con la vaca no se gana tanto, también hago lechones, todo al asador.... Estoy contento porque tengo algo fijo, antes asaba para afuera, en fiestas cumpleaños y eso...... y si con lo del premio de Barra me hice mas famoso. Salí en el diario y me invitan a hacer asado a otros lados.... Voy tranquilo, ahora me compre una freidora para hacer papas fritas, le voy agregando cosas..."

Fabián, ex empleado ganadero y asador. De La Garma, 10-3-13.

Como lo habíamos planteado en el caso de los lecheros, un oficio previo, desarrollado en su etapa de trabajador rural, le permite realizar con un emprendimiento propio que le genera un ingreso vital. Esto sigue afirmando la hipótesis de la multiocupación como estrategia de vinculación ampliada, y como en estos casos, precursora de emprendimientos familiares independientes.

Es interesante el proceso de crecimiento que se plantean en este tema de oficios vinculados con las fiestas, ya que cada vez mas aparecen eventos de estos tipos en todas las zonas. Ejemplo de esto es que en Juan E. Barra se viene organizando con éxito creciente la ya reconocida Fiesta Provincial del Asado Pampeano, que congrega en un fin de semana a mas de 2500 personas y mas de 30 artesanos en una comunidad de apenas 250 habitantes.

En igual sentido existen oficios conexos que tiene que ver con el sonido, la iluminación, las comidas y la música para estos eventos que también generan movimiento, pero que en nuestra zona no están vinculados a los empleados rurales y son realizados por habitantes de los pueblos de la región.

Como vemos en estas actividades rurales, el vínculo con lo gauchesco es muy marcado y por ende la presencia de empleados ganaderos y mixtos es muy intensa, familiar y con una tradición de traspaso hacia los más jóvenes.

En el caso de los empleados de origen correntino, si bien son concurrentes a estos espacios de fiestas criollas, no los hacen frecuentemente y prefieren las actividades de 
pialadas (enlazar en equipos de 4 personas terneros que se sueltan de a uno desde un corral, el que enlaza mas terneros gana), que se realizan en forma mas separadas en el tiempo y que implican un gasto menor. Nos comenta Julián que para ir a una pialada por equipos, se suben cuatro a un auto, comparten el combustible y llevan los lazos nada más, es más económico, y por eso preferido por estos empleados. Así practicada nos es una actividad familiar sino que salen solamente los hombres que realizan la pialada.

Esta actividad que es muy popular y esperada por muchos tiene el inconveniente que para realizarlas hay que tener terneros en cantidad, para una prueba se necesitan por lo menos 50-60 terneros, que corren el riesgo de lastimarse durante la prueba. Por ese motivo les cuesta a las comisiones escolares y clubes conseguir quien les preste los terneros, sobre todo en épocas donde la hacienda tiene mucho valor.

4.5 El aporte de la familia: el trabajo de la mujer

En este espacio se aborda el trabajo de la familia en la construcción de este concepto de multiocupación familiar, donde ya no es el hombre trabajador rural el único que aporta a la familia trabajo e ingresos.

Acá observamos dos situaciones bien definidas, y hacen referencia a la localización del núcleo familiar. De la encuesta (ver tabla 5) surgen como un dato llamativo que si uno analiza el total de empleados encuestados, casi el $47 \%$ vive en los pueblos de Barra y De la Garma, validando el continuo proceso de urbanización de la población rural que marcan numerosos autores en la bibliografía y que se comprueba en los censos agropecuario y de población ya mencionados anteriormente.

Pero que si focalizamos el análisis en los distintos tipos de empleados encontramos que en los empleados ganaderos ese porcentaje se reduce al $33 \%$ con la observación de que en ningún caso los empleados de origen correntino dividieron su lugar de trabajo y de morada familiar.

En cuanto a los empleados mixtos ese porcentaje se ubica en el $55 \%$ con radicación de familia en centros urbanos, estando como más significativo este indicador en el caso de los empleados agrícolas ese porcentaje alcanza al $92 \%$ de los empleados que participaron de la encuesta a los equipos de chacra.

Cabe aclarar que si bien en una primera etapa de nuestros objetivos estaban 
incluidos solamente los empleados del medio rural disperso, la incorporación de los pueblos como espacio de análisis y de socialización natural de los individuos rurales, nos obliga a analizar en este sentido a los aportes a la familia que realizan las mujeres de empleados rurales que viven y trabajan en los pueblos del área de estudio.

Como surge del relato de María José muchas de las mujeres de los empleados que viven en De la Garma, trabajan en tareas domesticas en casas de familia o como empleadas de pequeños comercios locales. Estos empleos oscilan entre 1300 y 2000 pesos mensuales por trabajos que duran desde 4 a 8 horas diarias, destinando el tiempo restante a las actividades domesticas y de esparcimiento.

"Hoy la mayoría de la mujeres que viven acá trabajan, de ama de casa, limpian por hora, por día por mes, porque con los chicos en la escuela la plata no te alcanza, mas con los sueldos de ahora, algunas a veces venden lo que traen del campo, huevos, leche, lechones etc.... sino no pueden vivir, imagínate que un alquiler en el pueblo vale 1000 pesos mas otros gastos luz, gas, no hablemos de teléfono y cable, necesitas trabajar si o si."

María José, empleada oficina Uatre-Osprera, De la Garma, 10-6-12.

En cuanto a las posibilidades de realizar otro tipo de trabajos depende de las posibilidades de tener escuela secundaria, debido a que otra alternativa posible es el trabajo en estamentos públicos como porteras, cocineras o personal municipal. Existen en esta situación varias mujeres de empleados rurales que trabajan en blanco, igualan ingresos de sus compañeros en trabajos rurales, sobre todo en los que cobran el salario de convenio sin adicionales.

Un tercer grupo de mujeres de empleados rurales tiene la posibilidad de trabajos de mayor remuneración basados en oficios o profesiones que en su mayoría tenían incluso antes de casarse, como son las mujeres que trabajan de maestras, docentes secundarias y enfermeras profesionales. En este sentido es interesante destacar lo que plantea Marilina, maestra y directora de escuela, que ella nunca vivió en el campo, siempre lo hizo en el pueblo y su marido tuvo una etapa que trabajando en el campo viajaba todos los días y ahora vive en el campo y viene los miércoles y los sábados a la mañana.

"Yo siempre viví en de la Garma y trabaje como maestra, cuando nos casamos con Luís, el trabajaba con Carlos María en los campos de acá y de Barra, muchos años trabajo así, desde los 16 hasta los 36, después decidió cambiar de trabajo, por uno que le pagan menos pero esta mucho mas tranquilo en una estancia. Viene los miércoles a la tarde y los sábados a la mañana pero esta libre, antes vivía acá pero trabajaba todos los días no tenia descanso.... Yo trabajo ahora en una escuelita rural a 
la que van mis nenas, después hago vida de pueblo, tranquila."

Marilina, directora de escuela y esposa de trabajador ganadero, Lasalle, 20-4-13.

Esta categoría de trabajadoras aporta en términos generales más ingresos familiares que sus compañeros, además de los beneficios sociales que tienen por ser trabajadores del estado, que tiene que ver con acceso al crédito y obra social.

Nombramos también en este capitulo a las mujeres que siendo soporte de sus compañeros en las actividades productivas, se dedican a la comercialización, levante de pedidos y cobranza de los productos que venden desde el campo. Ya planteamos comentarios en este sentido de Daniela con la producción de huevos, chorizos y carne de potro y el caso de la señora de Juan que distribuye y cobra la leche que traen del campo.

Desde el punto de vista de los vínculos sociales, se visualiza una socialización de características urbanas, donde se comparten espacios vinculados a actividades escolares de los hijos, vinculados a sus trabajos y en la mayoría de los casos lazos familiares extendidos.

Ahora bien, cuando analizamos la situación de las mujeres que viven con sus familias en el medio rural disperso, vemos una vinculación con las actividades productivas más intensa y definitoria. Ya hemos planteado en las distintas producciones la importancia del trabajo femenino e incluso de los jóvenes quedando para analizar las distintas variantes que se dieron en el transcurso de las entrevistas.

En el caso de Mirta resulta su discurso muy interesante y en consonancia con nuestra hipótesis de una ampliación de posibilidades basada en la vida en el campo.

"Siempre vivimos en el campo, los chicos siempre ayudaron, yo tenia un montón de cosas que hemos hecho entre todos, cuando estudie, me ayudaron todos, luego trabaje muchos años como empelada de comercio hasta que Diego (hijo mayor, profesional contable) me ayudo a poner el negocio y estoy re contenta, desde ya que quedamos solos con Abel y así es mas fácil, realmente cuando tenes los chicos es mucho mas trabajo, así que cuando se jubile capaz que nos vamos al pueblo, Diego vive allá con su familia y nos tira mucho... pero ya tenemos otro ingreso y una ocupación, yo trabajo todo el día, hay muchísimo trabajo... porque con la jubilación sola no se que haces, me imagino que no te alcanza para nada."

Mirta, esposa de Abel, empleado mixto, est. La posada, 5-4-13.

Surge de su relato un avance en las estrategias productivas hasta terminar con un negocio familiar en el pueblo y a través de el, la posibilidad de tener un seguro de ingresos luego de la jubilación de Abel, su esposo pronto a jubilarse. 
Un gran numero de mujeres, con perfil mas rural, contribuyen a la economía y la socialización de la familia en su aporte con las producciones de autoconsumo y en la atención de las actividades con destino para venta. En este caso, la variabilidad de alternativas plantea una diversidad muy importante fundamentada en una combinación de situaciones que ya hemos descrito en las distintas producciones.

Sin embargo surge del relato de María José que todavía se mantienen estructuras sociales en el medio rural donde la mujer tiene menos posibilidades de desarrollo personal y este esta subordinado al desempeño de los hombres de la familia, tanto desde las posibilidades de realizar actividades como también desde el punto de vista de su socialización, teniendo pocas oportunidades de vinculación, sobre todos en campos ganaderos alejados de los pueblos.

"Las chicas del campo, no salen, vienen 3 o 4 veces al boliche, ya se hicieron de novio, ya se juntaron, ya tuvieron chicos, no les dio otro tiempo a disfrutar la vida, no creo que conozcan ir a bailar afuera, y ya ese hombre nos tiene que mantener y todo, ellas limpian la casa, y miran novelas, la palabra es esa, miran novelas... pocas chicas se animan a venir al pueblo a hacer otra cosa, a estudiar, a viajar a dedo a Chávez a estudiar de maestra, pero son pocas.... la mayoría tiene celular, a ellas lo beneficia, conocen mucha gente por celular, incluso se ponen de novio por Internet, a ellos le resulta beneficioso."

María José, empleada oficina Uatre-Osprera, De la Garma, 10-6-12. 


\section{CAPITULO 5 LOS NUCLEOS DE SOCIABILIDAD}

\section{1- Introducción}

5.2- Núcleos de sociabilidad en el pueblo

5.2.1- El fútbol y los clubes

5.2.2- Bares, bochas y barajas

5.2.3- Veterinarias y escritorios

5.2.4- Talleres y galpones.

\subsection{5- Osprera}

5.3- núcleos de socialización en el campo

\subsection{1- Las carneadas}

5.3.2- Las destrezas: prueba de riendas, sortija, tacuara, domas.

5.3.3- Las escuelas rurales

5.3.4- Lo nuevo: playas y balnearios zonales.

\section{1- Introducción}

En este capitulo nos adentramos en las formas de sociabilidad de los distintos actores locales y mas específicamente de los empleados rurales y sus familias.

Las distintas historias familiares de los empleados vinculadas a su trabajo asalariado principal inciden en su sociabilidad, pero también como hemos visto en los capítulos anteriores, la posibilidad de llevar adelante alguna producción o servicio, amplían o restringen sus posibilidades de participar en espacios sociales y por lo tanto nos resulta interesante profundizar. Vimos también como algunas actividades productivas generan espacios de socialización para mujeres y jóvenes que no se producían en su condición de asalariados solos, mejorando así la socialización de la familia completa.

Siguiendo a Ratier (2010) utilizamos el concepto de núcleo de sociabilidad para referirnos a las distintas formas que se dan en el campo y en el pueblo para participar y conectarse con los demás: "llamamos núcleos de sociabilidad a aquellos lugares y situaciones donde el intercambio social es mas intenso, donde la trama de relaciones es mas densa y se van conformando conductas peculiares. Es allí donde se opera la socialización de conjunto, se traspasan valores, se actualizan pautas culturales y se las modifica, se brinda y adquiere información. Allí los diferentes estratos sociales se 
comunican y la estructura social, con sus acuerdos y conflictos, se torna visible con mayor nitidez."

Ya hemos planteado con anterioridad una de las características de los pueblos y del medio rural que mas le pueden llamar la atención a los que hemos crecido y vivido gran parte de nuestras vidas en una ciudad grande, y que Ratier denomina comunidad de inter-conocimiento.

Según cita Ratier a Mendras (1978) "conocerse asume por lo tanto un sentido al mismo tiempo preciso y pleno; cada uno conoce a todo el mundo, esto es, a todos los demás y todos los aspectos de la personalidad del prójimo. $Y$ no se trata de una percepción ocasional y parcial, limitada a un cuadro social o una actividad particular, como es regla en la sociedad urbana, sino, al contrario, de un conocimiento total y prolongado de la persona del otro, en el conjunto de sus posiciones sociales actuales y pasadas y en las particularidades de su personalidad. En suma, primero, cada uno esta ligado a los demás por una relación bilateral de conocimiento global y tiene conciencia de ser conocido del mismo modo; segundo, el conjunto de esas relaciones forma un grupo o colectividad de inter-conocimiento."

Esta situación se pone de manifiesto en las entrevistas cuando cada entrevistado realiza un análisis pormenorizado de algún otro actor con exposición publica, a quien seguramente conoce desde la infancia, ha vivido todos sus vaivenes económicos, en muchos caso tienen algún parentesco lejano y muy a menudo forman parte de una comunión o rivalidad que viene de generaciones anteriores. Esto se hace mucho mas explicito en "el tiempo de la política", que en las comunidades de estudio se refieren a los periodos relacionados con las elecciones.

Otro rasgo que destacamos de las sociedades en estudio es lo que Ratier (2010) denomina multi-pertenencia y que significa que los habitantes de estas comunidades pueden formar parte de distintas organizaciones y participar de distintos núcleos de sociabilidad. En general en otros tiempos se daban frecuentemente la membresía a instituciones que en muchos casos tenían mas de una opción de participación, es la situación del fútbol, que durante mas de 70 años tuvo a dos clubes locales como protagonistas (sin contabilizar los equipos de los parajes, muy activos en otras épocas) y que en la actualidad subsiste uno solo.

Sin embargo mas allá de existir espacios donde se dividían las pertinencias, como en el fútbol y en la política, existían otros espacios donde se juntaban y compartían actividades, en tales casos figuran las cooperadoras escolares, fiestas patronales y 
lugares vinculados con lo lúdico y también con las costumbres gauchescas y con la producción agropecuaria.

Para hacer referencia a los distintos núcleos de sociabilidad, hacemos una división basada un la ubicación del espacio donde se lleva adelante la actividad, desde su localización geográfica y no significa de ninguna manera una división de participantes.

Como veremos a lo largo del capitulo, existe hoy día una sociabilidad distinta, integradora, que como venimos planteando mezcla las mayores posibilidades de movilizarse que tienen los empleados rurales que viven en el campo y al mismo tiempo la cantidad de empleados que viven en los pueblos y participan activamente de su vida social. Pero como vamos a observar existen particularidades que detallaremos en cada espacio que merecen un abordaje especifico.

\section{2- Núcleos de sociabilidad en el pueblo}

\subsection{1- El fútbol y los clubes}

Es sin dudas la pasión popular de todos los argentinos por excelencia, sin distinción de urbanos o rurales el fútbol ha sido siempre un gran aglutinador de los habitantes del medio rural.

Como todo espacio de socialización ha tenido épocas buenas, regulares y males como todas las instituciones de nuestra zona y del país entero. A los efectos de este trabajo vamos a analizar como ha actuado el Fútbol a la hora de generar vínculos sociales entre los pobladores de las distintas comunidades y del medio rural disperso, las rivalidades y como se ha transformado a lo largo del tiempo hasta llegar a la existencia de un solo equipo zonal y la aparición del equipo de Barra como dinamizador de la comunidad.

Si bien la fundación de todos los clubes de la región de estudio se remonta al primer tercio del siglo 20 (Club Deportivo Garmense 1921, Club Atlético Agrario 1930, Club Deportivo Juan E. Barra 1930), sus orígenes y grupos sociales de pertenencia han sufrido grandes cambios a lo largo de la historia.

Todos los clubes han tenido su origen como clubes de fútbol, sin dudas el deporte aglutinante, pero han sabido construir a lo largo del tiempo otras funciones sociales que hasta hoy perduran.

En términos generales se pueden distinguir en la zona dos niveles de participación del fútbol como deporte, por un lado la participación en la liga tres arróyense de fútbol, 
donde existe una larga historia de participación de los tres clubes, donde además hay una organización del fútbol infantil y juvenil que ha permitido la participación deportiva de una gran cantidad de jóvenes.

Por otro lado ha existido durante muchos años una estructura deportiva en los clubes de campo, vinculados a un paraje o estación, que generaban encuentros frecuentes en los cuales participaban pobladores del medio rural que vivían en las inmediaciones de las estaciones, además de los jugadores de los clubes del pueblo.

En la actualidad y desde hace ya mas de 30 años la participación en el fútbol en esta zona, se refiere solamente a la participación a través de los clubes en la liga de Tres Arroyos. En estos momentos participan en dicha competencia el Club Atlético Agrario y el Club Deportivo Juan E. Barra, ambos en la segunda división, conjuntamente con la mayoría de los clubes de las comunidades mas chicas de la región (Claromecó 2300 hab., Orense 3000 hab., Belloq 220 hab., Cascallares 600 hab., Copetonas 1200 hab.).

Esto no es casualidad, evidentemente los procesos de despoblamiento, crisis de empleo y de participación han impactado en estas comunidades de manera mas notoria que en las ciudades medianas y grandes de la región, existiendo en muchos caso como los de De la Garma, Barra, Belloq, etc., la imposibilidad de contar con los jóvenes suficientes para formar una categoría determinada, teniendo que unir dos o en casos tres categorías para poder formar un equipo y poder competir en la liga. Esto se da no solamente por la falta de jóvenes que existe, sino también por que han aparecido distintas actividades sociales, tecnológicas y deportivas que le ofrecen a los chicos y a los padres otras posibilidades de entretenimiento y diversión, quedando la practica deportiva para los chicos mas fanáticos y con mas ganas de participar, donde el apoyo familiar es sumamente importante.

Como consecuencia de esta sola modalidad de participación, que prevé muchos días de entrenamiento, escuelita de fútbol para los mas chicos, encuentros y viajes a otras zonas, etc., se ha dejado afuera a los chicos del medio rural, que al no tener la posibilidad en muchos casos de ir a entrenar, no logran acoplarse a los grupos y deciden directamente no practicar el deporte. Se destaca esto porque en muchos casos es también un factor muy tenido en cuenta por la familia para migrar del campo a la ciudad, sobre todo si el chico reúne condiciones para practicar de forma destacada el deporte.

Este explicación esta basada en lo que sucede en la localidad de De la Garma, 
mientras que en Juan E. Barra existe una situación mas compleja, debido a la menor cantidad total de jóvenes en edad de hacer deportes, y genera una situación intermedia entre la participación en los clubes tal cual se explico anteriormente y la participación vinculada a los fines de semana como se realizaba en la época del fútbol de campaña, generando una rica integración de jóvenes rurales y de pueblo, unidos en muchos casos por lazos parentales. Ejemplo de esto es la participación de chicos de origen rural en sus divisiones inferiores, la participación en sus equipos mayores de jóvenes del medio rural y de su comunidad y la auto denominación de la hinchada del club de Barra conocida como "Los paisanos".

Sin embargo esta participación exige que las familias de los empleados dispongan de un buen vehículo y de disponibilidades económicas que en los casos vistos provienen de actividades o ingresos extra-salariales.

El domingo día del partido o durante la semana los días de reunión de comisión funcionan también para que la familia se acerque, se junten con otros vecinos y en muchos casos este espacio es el lugar donde se intercambian y venden las producciones de estos empleados. También sucede esto cuando el equipo viaja a la localidad de De la Garma y a la ciudad de Chaves.

Esta posibilidad de mayor disposición, ha motivado incluso que la mayoría de los integrantes de la comisión del club de Barra esta formada por empleados rurales, muchos de los cuales viven en el campo y pueden venir al pueblo los fines de semana o algún día intermedio.

Es de destacar que en la actualidad el presidente del club es un empleado ganadero oriundo de la localidad y que vive y trabaja en un establecimiento a 55 kilómetros de Barra, que es multiocupado rural con un planteo de producción ganadera basado en un buen arreglo de habilitación de hacienda, que le permite tener en el campo un rodeo propio de 25 vacas que trabaja y produce por cuenta propia.

Este no es un dato menor, históricamente los clubes si bien han sido espacios para las distintas clases sociales del medio rural, la conducción siempre ha estado en manos de propietarios de campo vinculados a familias tradicionales de la zona, que en muchos casos ejercitan la función aun después de haberse mudado a ciudades cercanas mas grandes.

Este caso, puede ser puesto en el marco de este trabajo de investigación como un ejemplo de las mayores posibilidades de socialización que se generan en los empleados multiocupados aunque sepamos que la situación es en realidad más 
compleja y que no depende solamente de un factor de mayor disponibilidad económica.

"Vos fijate que ahora los chicos del campo pueden venir a entrenar al club, antes no pasaba eso, los chicos del campo venían a jugar a veces y cuando llovía el viernes o el sábado ni aparecían... a los hermanitos Décima, que viven en el campo los trae la combi a la escuela, después se quedan a gimnasia y después vienen a entrenar de 3 a 5 y los viene a buscar el papa y el sábado a la mañana los trae para el partido.... Acá en la cantina yo les doy de almorzar, es un arreglo que tengo con el club así los chicos se quedan y los padres están tranquilos.... Ahora están viniendo unos chiquitos de unos correntinos pero esos vienen menos, a jugar los sábados y a veces entrenan un día cuando vienen todos al pueblo."

Pepe, cantinero del club agrario, De la Garma, 20-2-13.

Sin embargo, más allá de la escasa participación de chicos y jóvenes en clubes y ligas regionales, el fútbol como espacio de socialización en el medio rural disperso sigue vigente, pero como diría Ratier (2010) se ha refugiado en la esfera privada, en reuniones chicas de familia o de amigos cercanos, ya no con el afán de participar y competir en algún torneo, sino solamente a manera de entretenimiento y diversión.

En la actualidad los dos clubes de De la Garma tienen otras actividades deportivas y culturales. En el caso del Club Deportivo Garmense, tiene como actividad deportiva de cabecera la Pelota a Paleta, deporte de origen vasco que se practica en muchas comunidades del interior con presencia de inmigrantes vascos, que ha sido considerado durante mucho tiempo un deporte de clase media alta, siendo poco practicado por empleados rurales y de bajos recursos. En la actualidad tiene escuelita de paleta y diversas categorías que participan en los torneos provinciales, contando también con equipo de primera división del federación de paleta de Buenos Aires. Es de destacar la importancia que adquieren en nuestra zona los deportes cubiertos debido a las bajas temperaturas que se registran en invierno y dificultan los deportes al aire libre.

Este club cuenta también con una confitería, y salón de fiestas que se utiliza para el festejo de casamientos y cumpleaños de 15. Esta confitería, a diferencia de épocas anteriores, es concurrida los fines de semana por gran cantidad de jóvenes rurales, que aprovechan para jugar al pool, al billar y reunirse con amigos tanto rurales como del pueblo. Este club se ha caracterizado siempre por la membresía de personas y familias vinculadas a clase media alta y la utilización de sus instalaciones ha sido casi siempre realizada por esta misma gente. Hoy día esa distinción ya no se refleja tan expresamente y los espacios son mas compartidos por todos lo actores de la 
comunidad, incluso en muchos casos son usados como espacios públicos desde los distintos estamentos del estado a la hora de organizar eventos y espectáculos populares. En el gimnasio que pose la institución no se realizan actividades del club ya que esta alquilado a la dirección de escuelas para el funcionamiento del Centro de Educación Física $n^{\circ} 38$.

El Club Atlético Agrario tiene además de su estructura de fútbol, una estructura de paddle, con similares características en cuanto a funcionamiento y participación con el deporte de la paleta, teniendo una amplia participación de mujeres y jóvenes de la comunidad.

Sin dudas son los clubes los espacios mas masivos de participación popular, donde los domingos de partido se organizan el resto de las actividades del pueblo en función de esto y donde participan como espectadores numerosos empleados rurales que vienen el fin de semana de visita al pueblo e intercambian actividades con la gente del pueblo, provista de mercadería, etc.

\section{2-2. Bares, bochas y barajas.}

Estos lugares son muy variados y numerosos en la zona de estudio. Los hay de diversos tipos y visibilidad. Los mas expuestos al análisis social son los que existen en los clubes y que conviven con el resto de las actividades de la institución.

Durante las entrevistas y recorridas por los distintos hogares de empleados y parajes es factible observar las ruinas de numerosos lugares de socialización como almacenes, bares y clubes de campo, deshabitados y sin pobladores en la mayoría de los casos, generando un vacío de lugares de encuentro en el medio rural disperso y una concentración de estos lugares en la orbita de los pueblos y planteando la socialización en la esfera de lo privado, en las casas, retomando una vieja practica muy común en otras épocas.

En los años 90 el problema de la movilidad para acceder a espacios de sociabilidad se solucionaba con el servicio de autos particulares conocidos como remis, que llevaban a los empleados a fiestas, bailes, al medico o a hacer compras, los esperaban y los traían al campo de vuelta. Sin duda la posibilidad de movilidad que genera el automóvil, sumado a que la mayoría de las familias de los empleados posee uno, y en muchos casos que no poseen se manejan con el vehículo del establecimiento, trae una mejoría a esta problemática. 
Este proceso de tener un automóvil para movilizarse es visto como un avance en el ámbito familiar de los empleados, generando la tranquilidad y la independencia al momento de realizar actividades que no estén vinculadas estrictamente con el trabajo. Casi siempre es la estrategia primera de capitalización que tienen las familias de trabajadores del medio rural, existiendo quienes siguen con esta estrategia y van cambiando los autos y se van modernizando teniendo autos de modelos nuevos y altos valores de mercado.

Otros caso como el de Marcelo, Juan y Alberto, cambiaron a un vehículo tipo camioneta que cumple funciones en sus actividades extra asalariadas, ya sea vinculadas con su actividad productiva como también con la posibilidad de asistir a eventos con caballos que se transportan en carros como es el caso de Julián y Felipe quien además utiliza el vehículo (una combi grande con asientos habilitada para transporte escolar) para el trabajo de su mujer como transportista.

En el marco de este trabajo se realizo una serie de observaciones de estos bares y se realizo una entrevista al encargado de bar del club agrario, el que tiene mayor concurrencia de empleados rurales, destacando varias características interesantes a la hora de analizar los vínculos sociales.

En primer termino surge de la observación la diversidad de actores sociales que participan activamente de las actividades realizadas en los bares (barajas y bochas), mas estrecha en los bares de los clubes y mucho mas extendida en los bares de la periferia. Conviven y se vinculan sin mucha diferencia empleados rurales temporarios, jubilados (los que llegan primero), comerciantes y personas en general alrededor de distintas mesas de juego, destacándose los juegos de cartas (truco y mus) y los dados, sobre todo en los clubes.

"Los viernes se hace el asado del fútbol donde vienen la mayoría gente grande, muchachos que han jugado en el club y ahora viven en el campo, alguno de la comisión y otras personas de acá, se mezclan todos empleados, jubilados chacareros sin problema, los que vienen del campo traen algún cordero o lechón, a veces lo donan y sino se les paga... la gente de la subcomisión atiende la mesa y lo que se recauda de la cena va para las inferiores, para los viajes en combi."

Pepe, cantinero del club agrario, De la Garma, 20-2-13.

La actividad de los días sábados y domingos se plantean como los de mayor participación de empleados rurales que viven en el campo y que aprovechan sus días de franco para ir al bar a compartir un momento con amigos. 
Los bares son lugares donde se realizan muchas operaciones que tienen que ver con actividades rurales, desde la venta de lechones, corderos, leña y otros productos, hasta la oferta y demanda de empleo rural, tanto de empleo agrícola como ganadero, incluso muchos funcionan casi como agencias de empleo debido a la permanente presencia que hay de empleados rurales mientras no están en actividad y es el lugar donde se van a buscar empleados con urgencia o para el día siguiente.

Esta modalidad es muy utilizada por los empleados temporarios en épocas claves como la época de cosecha para los empleados agrícola que van a trabajar en tractores como carreros, ya que el trabajo de maquinista generalmente se resuelve con anticipación y se pacta para toda la campaña, salvo algún imprevisto que haga que se salga a buscar lo con urgencia.

En el caso de los empleados ganaderos, también utilizan este espacio para mostrarse y conseguir changas, siendo la época de mayor demanda de trabajo temporario la que tiene ver con la época de parición en invierno y la de destete en verano, aunque se registran trabajos puntuales durante todo el año.

Según nos comenta Pepe, el cantinero del club, antes también se juntaban los bolseros y paleros, hombres que se dedican a cargar o bajar el cereal de los camiones, pero que ahora ellos tienen una sede aparte que funciona en el gremio de UATRE donde se arman los listados de trabajo y se realiza la espera de los camiones.

Han quedado como espacios de socialización de los pueblos, ya que los almacenes y bares de las zonas rurales han desaparecido en su totalidad, quedando solamente en la historia de los parajes.

Sobre esta situación hay dos líneas de justificación que testimonian la desaparición de estos espacios, que se solapan en cierta medida y que ofician a su vez como consecuencia de la otra tanto como factor desencadenante.

Por un lado la desaparición del ferrocarril como medio de transporte popular, que en forma diaria viajaba a los pueblos y generaba el intercambio de mercaderías, hizo que se cerraran comercios y muchos pobladores se mudaran al pueblo en búsqueda de trabajo. La otra versión esta referida a un cambio en las formas de producción, vinculados a la desaparición de la bolsa como medio de transporte de cereales y la incorporación de los transportes a granel, con la desaparición de un actor muy importante de aquella época "el bolsero". Esto coincide con un fuerte proceso de mecanización y un éxodo de la mano de obra sobrante que género una baja en las personas que frecuentaban estos lugares. 
Con muchas explicaciones posibles acontece la realidad de un despoblamiento rural que arrastra a sus espacios de reunión y sociabilidad, bares, clubes, almacenes, sin que las nuevas generaciones tengan la manifiesta necesidad de recuperarlos. La casi generalizada disposición de vehículos por parte de los empleados rurales como así también de los productores que aun viven en el campo, hace que las distancias a los pueblos no sean un factor limitante a la hora de mover y eso también contribuye a que no se instale la necesidad de un espacio social de reunión en el medio rural.

El caso de los bares con cancha de bochas, tiene su esplendor sobre todo durante la época de primavera verano, debido a que todas las canchas que existen son abiertas y la práctica del deporte se hace imposible en época de invierno.

Si bien existen clientes exclusivos de algún local, es notorio y llamativo la alta rotación que tienen los parroquianos por los distintos bares, no pudiendo establecer un patrón de comportamiento, pero se observan criterios de movilidad vinculados a la posibilidad de armar partidos parejos e interesantes entre algunos participantes y la existencia de desafíos que se concretan en los ámbitos de trabajo o en la ronda de tragos previa a los partidos. Esto forma parte del interconocimiento que planteamos anteriormente, y que hace que haya una gran diversidad y amplitud en las relaciones de los parroquianos

En este sentido esta gran diversidad de asistentes, no solo de sectores sociales distintos sino de parajes distintos confirma el aumento de los vínculos sociales que los empleados construyen en estos tiempos y que amplían sus posibilidades a la hora de vender e intercambiar sus producciones y servicios con gente que vive en los pueblos sino también con otros empleados. Se generan vínculos. En este sentido se generan vínculos de fidelidad hacia los productos de tal o cual productor que se asemejan a lo que en comercialización se llama clientes cautivos.

Nos plantea Pepe también en el marco de la entrevista que muchos empleados agrícolas de residencia en el pueblo tiene una asistencia diaria, con mesa de amigos que solamente se ve alterada en la época de trabajo, pero que genera un vinculo muy fuerte entre los concurrentes, muchos parientes, que se mantiene en el tiempo.

Los empleados que viven en el medio rural y que tiene el habito de ir al bar, también lo hacen en forma frecuente y lo utilizan también para ofrecer sus producciones en el caso que tengan, a través de encargues para el cantinero y últimamente se armo una vitrina en el salón del club donde se ponen avisos clasificados de eventos sociales, domas, jineteadas, de producciones de compra y 
venta.

"La gente que trabaja en la cosecha, vienen todos los días a tomarse un trago y a jugar la baraja, hay mesas fijas y otras que se arman en el momento, pero la mesa de los del mus, hace años que se juntan y se para en la cosecha solamente, donde por los horarios de trabajo no permiten venir... antes cuando empezó la televisación paga de los partidos de fútbol, la gente venia a ver el partido en el televisor grande y de paso tomaba algo y charlaba con amigos, hoy ya no le dan mucha bolilla a la tele y la gente habla de otros temas, mas locales y del club...la gente que viene del campo vienen los sábados y domingos y se integran en las distintas mesas aunque algunos ya son miembros de algún grupo. Siempre ponen cartelitos en la vitrina que ofrecen lechones, pollos, huevos pavos, caballos y otras cosas de campo, para que los llamen si quieren algo".

Pepe, cantinero del club agrario, De la Garma, 20-2-13.

\section{2-3 Veterinarias y escritorios}

Sin duda estos espacios de sociabilidad tienen una vinculación mas estrecha con los perfiles laborales de los participantes. En el caso de la veterinaria la participación y concurrencia de los empleados rurales es mucho mas intensa que en los escritorios de cereales.

Los temas que se charlan en las veterinarias según las observaciones realizadas en dos de ellas, las mas populares, tienen que ver con cosas que se pueden compartir entre empleados y productores, y que giran casi sin diferencias entre todos los casos en un núcleo informativo que esta formado por: los movimientos de empleados y sus vínculos familiares, el desempeño de sus caballos sea en el trabajo o en las pruebas de riendas y las implicancias del tiempo en las situaciones de trabajo. Se puede agregar al núcleo básico algún tema referido a la época de remates o a la época de parición que introducen variantes propicias para la charla.

Es importante destacar que no se arman grupos aparte con los empleados y el veterinario y los productores, estando todos alrededor del fogón (el lugar socializante dentro del local), hablándose raramente de negocios puntuales si bien se puede hablar en términos generales de precios de hacienda.

Los horarios de socialización están distribuidos en la semana de distinta manera. Según nos cuenta Vodo, los lunes por la mañana preferentemente y los viernes todo el día son los tiempos que los empleados rurales de campos ganaderos con sistema de guardia o los que están solos, utilizan para hacer tramites administrativos, pago de impuestos, consultas medicas y provista de insumos; y en ese marco pasan por la veterinaria a buscar algún remedio y a charlar y matear un rato.

Es muy común que sea también el lugar de correspondencia que citan muchos 
empleados que no tienen casa en el pueblo, ya que saben que es un lugar de transito obligado del productor y que lleva las cartas hasta el campo cuando no puede ir el empleado.

Es muy importante el rol que juegan estos espacios a la hora de la oferta y demanda de trabajo, son lugares obligados de referencia y la sentencia del veterinario sobre tal o cual característica de algún empleado o empleador a la hora de concretar un trabajo suele ser definitoria, sobre todo cuando se refiere al empleado. Existen en las dos veterinarias observadas un registro de necesidad de empleo donde los empleados ganaderos se anotan cuando están sin trabajo.

El caso de las veterinarias como veremos también en el caso de los talleres, son espacios donde concurren tanto empleados como productores, si bien estos últimos lo hacen con mas frecuencia y en mayor medida con un vinculo mayor, no deja de llamar la atención la existencia de un lugar común (el fogón) donde todos los actores comparten la charla y la rueda de mate en forma indistinta.

En general es un lugar de socialización masculina, pudiendo participar en forma muy casual la mujer de algún productor haciendo provista de remedios, no participan en términos generales las mujeres de los empleados. Distinto es el caso en las familias de empleados multiocupadas, donde el rol mas activo de las mujeres en la producción familiar las habilita a ir y socializar pero sin una participación muy activa en las charlas.

Es también en este lugar donde se difunden vía afiches todas las actividades gauchas de la zona: carreras, jineteadas, pruebas de rienda, kermese y bailes; habiendo en algunos caso incluso disponibilidad de entradas y planillas para la inscripción de caballos en las pruebas.

También, como lo indicábamos en el caso de los bares, existe la practica del ofrecimiento de los distintos productos que los empleados multiocupados producen, dejando en el caso de las artesanías en cuero, sogas y lazos, alguna muestra para venta o encargue, mientras que para la venta de lechones o corderos se deja casi siempre el numero de teléfono para el pedido.

El caso de los escritorios de cereales plantea una socialización completamente distinta. Al ser un ámbito estrictamente administrativo, ya que los depósitos se encuentran en las plantas de silos, es visitado mayormente por los productores, no asistiendo los empleados rurales. A su vez existen oficinas privadas donde se encierran al momento de hablar de negocios, pagos y estrategias de venta. En los 
únicos momentos que se comporta como un verdadero lugar de socialización es en los días de lluvia, cuando no se realizan actividades agrícolas.

Las plantas de silos tienen si un vínculo entre los empleados agrícolas y los de la planta, teniendo mucha importancia en el caso de los empleados multiocupados productores de cerdos y gallinas que compran cereales de descarte en la planta o intercambian por lechones o chacinados.

"Cereal casi siempre tengo en el campo pero cuando no hay, como ahora, consigo en una planta en de la Garma que voy a buscar el alimento balanceado para los toros, les cambio a los muchachos algún barrido o lo que sale de la limpiadora por algún lechón y traigo un carrito o algunas bolsas depende de que época sea, lo que mas hay es triguillo o cuando limpian los silos sale algo de soja media fea pero a mi para los chanchos sirve igual."

Julián, empleado ganadero y productor de caballos, est. La Batea, 30-6-13.

En el marco de esta investigación se pudo establecer la modalidad de canje que existe entre los empleados de las maquinas limpiadores de cereal de las plantas de silos y los criadores de lechones, existiendo un verdadero mecanismo de oferta y demanda de estos subproductos de cereal, y su cotización en lechones o kilos de capón. Esto es muy importantes en los planteos productivos de los empleados que no cuentan con cereal en el propio campo y tiene que conseguir comida fueras del establecimiento.

\subsection{4 talleres y galpones}

Este es el espacio de socialización temático de los empleados agrícolas, durante el trabajo de relevamiento de los galpones de los equipos agrícolas se pudo observar un fuerte intercambio entre los empleados agrícolas que viven en el pueblo, con productores y empleados rurales que realizan actividades agrícolas. Al igual que lo que sucede con los empleados ganaderos existe un núcleo temático de socialización y que en este caso pasa por las nuevas herramientas que compran los productores de la zona (básicamente cosechadoras, tractores y últimamente casillas rurales), las carreras de turismo carretera y autos zonales (que en nuestra zona son muy populares y suelen tener a estos grupos que socializan en torno a determinado galpón o taller a un corredor esponsorizado), y los autos que cambian los empleados en forma permanente.

Particularmente en De la Garma el deporte automotor tiene una gran parcialidad y que hace que los fines de semana que hay carreras compitan en publico con el fútbol y 
esto se nota.

A diferencia de otros espacios de socialización, en los talleres no se habla de precios y formas de negocios agrícolas, se entiende como que la gente se puede despegar y hablar mas de cosas propias de su interés, sin estar en muchos casos relacionada con el trabajo.

Sin dudas los días de socialización están vinculados principalmente al día de peña, que es el día en la semana que se juntan a cenar, en forma fija una vez por semana (hay peñas como la del "gallego" que tiene mas de 13 años de antigüedad) y cuya afición lleva entre 30 y 50 personas a la carrera como parte de la parcialidad simpatizante del auto que corre el hijo del dueño de la empresa. Se organizan en forma rotativa de a pares o tríos para la realización de la comida y los gastos se reparten en partes iguales entre los comensales. Este ámbito de socialización es exclusivamente masculino, no asistiendo en ningún caso mujeres.

Como ya indicamos anteriormente el día de la carrera es el mas importante en cuanto a concurrencia, este si es un espacio de socialización familiar, y acá concurren tanto las mujeres como los hijos y amigos de los hijos de los empleados rurales, organizándose los viajes zonales con anticipación, y en muchos caso abarca también el sábado previo a la carrera.

"Nosotros trabajamos hasta el sábado al mediodía cuando hay carrera, después me vengo para prepararme para la carrera, a veces me voy con el yerno del dueño el mismo sábado y sino la mayoría de las veces me voy con mi señora el domingo...si estamos en cosecha me cubre Juan Pedro, mi hijo que no va mucho a las carreras y además trabaja por tanto... en la carpa no somos muchos pero siempre juntamos $10 \mathrm{o}$ 12 , la mayoría son amigos del chiflón, el piloto."

Horacio, empleado agrícola, De la Garma, 10-12-12.

Por ultimo el día lunes siguiente a la carrera, por la mañana se reúne el circulo mas intimo en los talleres par comentar los devenires de la carrera, Las acciones mas polémicas y en todo caso hacer algún comentario referido al fútbol grande o a las carreras de Turismo Carretera. Esta instalado de tal manera en la sociedad que nadie va el lunes por la mañana a los talleres que no sea a hablar de la carrera o a dejar algún trabajo para mas adelante.

Este tipo de actividades realizadas en grupo tienen generalmente un costo importante que se afronta en parte por el dueño del auto y el resto es puesto por la peña, donde los empleados que tienen alguna producción propia o en sociedad 
aportan casi siempre algún lechón, pollo o cordero que forma parte central de la cena de recaudación. Esto esta planteado desde los objetivos de esta investigación como una clara estrategia de vinculación y pertenencia a un grupo basada en la posibilidad de aportar elemento de su propia producción.

Recordemos como este espacio integra también a toda la familia en los días de carrera donde los empleados con producciones de alimentos vuelven a mostrar sus cosas y a compartir con los demás, generando también vinculaciones de comercialización de productos.

"Mis salidas son los domingos que hay carrera, nos vamos con la familia todo el día, comemos un asado con los muchachos, siempre llevo algo que tengo, un cordero, un lechón o hacemos alguna comida a la olla...la peña de los viernes es sagrada, hace mas de 10 años que vengo, la mayoría de mis amigos de acá los hice ahí, en la peña, siempre somos varios, y cuando tenemos lechones o corderos los traigo y muchas veces los muchachos me encargan y les vendo, para fin de año siempre tengo varios encargues."

Alejandro, empleado mixto, taller mecánico Guillermo Durquet 15-3-13.

En Barra esto no sucede porque no existen talleres en el pueblo y los equipos de chacra rurales están mas vinculados a actividades campestres y al fútbol regional.

5.2.5 la oficina de Osprera y UATRE, espacio de mujeres

Sin dudas los espacios de socialización en el pueblo de las mujeres de los empleados rurales se ubica mayoritariamente en lo que Arendt (1993) define como la esfera privada, se generan en las casas de parientes o amigas en las cuales comparten charlas y mates o en los comercios en los cuales se aprovisionan de mercadería. Sin embargo también presentan una vida social intensa vinculadas a aspectos laborales, educativo y de salud del grupo familiar.

Existe un espacio funciona como boca de expendio de recetas y bonos médicos de la mutual de los empleados rurales conocida como Osprera siendo por tal motivo muy frecuentada por la familia del empleado rural registrado.

En el marco de la entrevista, María José nos comenta que las familias hacen mucho uso de los servicios de la obra social, en general son las mujeres de los empleados las que realizan los tramites que tiene que ver con la atención de los chicos y el marido, concurriendo el varón solo en casos de extrema necesidad o cuando tiene que firmar papeles.

Como hija de empleados rurales además de su condición de oficinista de la obra 
social, nos cuenta los cambios que han sucedido en los sistemas productivos que mejoraron la salud y la calidad de vida de los empleados, según su visión y marca como datos significativos la inclusión de los cuatriciclos y motos en los campos ganaderos y los nuevos tractores con asientos ergonómicos y cabinas climatizadas en el caso de los empleados agrícolas.

"Antes un empleado llegaba a la jubilación y estaba agotado, no servía mas para nada, tenia problemas de columna, de riñones, estaba curtido por el frió y le dolía todo, hoy ves una persona de 45 años que trabaja con hacienda y esta 10 puntos, trabajan con los cuatri y tardan menos, no se estropean y tiene trajes térmicos que le dan las empresas por ley....los tractores tiene aire acondicionado y calefacción, radio y alarmas por si se rompe algo, la gente trabaja mejor...las casillas de ahora no tienen nada que ver, ahora se controlan y tiene que tener baño con agua caliente y cama para cada empleado, eso también mejoro mucho, tienen televisión, freezers, heladera, pantalla, etc...

María José, empleada oficina Osprera y UATRE, De la Garma, 10-6-12.

En cuanto al proceso de despoblamiento y su vínculo con las ofertas de trabajo, nos comenta que desde hace muchos años ha habido un movimiento de familias que vivían en el medio rural pero que por diversas causas, mayormente la escuela de los chicos, se vienen a vivir al pueblo y los maridos siguen trabajando en el campo.

María José atribuye esto en gran medida a la posibilidad que tiene la mujer de trabajar en el pueblo, como personal domestico en casa particulares, limpieza por día o trabajos en la municipalidad. Si bien muchas de estas mujeres son de origen rural, este fenómeno ha sido más notorio en mujeres jóvenes de origen urbano que en su primera etapa han vivido de matrimonio en el campo pero que luego se han venido al pueblo.

Esta opción plantea María José es tomada en los casos en que la mujer no tiene posibilidad en el campo de generar ingresos, ya sea porque no pueden tener producciones por algún motivo o porque no pueden tener trabajo de cocinera o mucama en el mismo campo y por consiguiente migran para lograr este objetivo.

"Hay lugares que no te dejan criar nada, ni gallinas ni chanchos ni nada, y si la mujer no tiene trabajo que van a hacer con un sueldo de peón, no alcanza, entonces se vienen a trabajar al pueblo, acá siempre algo consiguen y no vuelven mas...Trabajan de domesticas, limpian por hora, casi siempre en negro, igual en el campo también limpiaban en negro, no las blanqueaban, algunos les hacen el monotributo social para no pagar nada... después acá en el pueblo se hacen de grupos de amigas, van a gimnasia, a caminar a la ruta, participan en alguna cooperadora y se integran, se quedan en el pueblo." 
María José, empleada oficina de Osprera y UATRE, de la Garma, 10-6-12.

Como planteábamos en párrafos anteriores, las actividades vinculadas al tema de la obra social están a cargo de las mujeres, muchas de las cuales realizan incluso gestiones en el hospital local y en otros hospitales regionales si es necesario. Estas diligencias son básicamente por temas de salud de los hijos, ya que los trabajadores tienen que seguir una rutina de procedimiento que esta fijada por las ART y que se trasladan a Bahía Blanca u Olavarría.

Como sucede en las escuelas de campo cuando las distancias son importantes, las mujeres que traen los chicos a la escuela se quedan en el pueblo a esperar que salgan y aprovechan para socializar, se juntan en casas de familia a charlar y tomar mate, o van a gimnasia o a caminar por la pista de atletismo, ya que a diferencia de las escuelas de campo las mujeres no se pueden quedar en la escuela.

Nos cuenta María que varias de las esposas e incluso hijas de los empleados tienen una actividad de venta domiciliaria conocida como "venta por librito" de cadenas de comercialización de perfumes, sabanas, y cosas de cocina que utilizan para generar recursos pero también les permite tener una red de vínculos importante que visitan y contactan en forma regular y seguida. En este marco organizan reuniones de demostración en casas de familia y cuando vuelven al campo también hacen lo mismo con sus vecinos rurales.

Estos sistemas de comercialización han demostrado ser en el medio rural un factor de socialización muy importante entre las mujeres, sobre todo en los casos de mujeres que no tienen la posibilidad de un trabajo fijo ni de un sistema de producción de animales o huerta. Incluso esta operatoria se da entre jóvenes de edad de secundaria que ya comienzan a incursionar en estas actividades de vinculación comercial bajo la tutela de una persona mayor que cumple el rol de coordinadora, lo vemos en el CEPT donde las chicas venden a compañeros, docentes y personal auxiliar los productos de su línea.

5.3- Núcleos de socialización en el campo

\subsubsection{Las carneadas}

Esta practica esta asociada a dos estrategias que los empleados rurales utilizan con frecuencia, por un lado se plantea la incidencia económica de los chacinados, en los costos de alimentación de la familia en el medio rural y en la posibilidad de vender 
chacinados afuera. Por otro lado la instancia de socialización que significan las carneadas entre los empleados rurales, sus vecinos y sus familias.

Surge de las entrevistas que existe una relación directa entre las personas que realizan las carneadas y la posibilidad de tener y criar cerdos para faena. La gran mayoría de los empleados rurales que realizan carneadas familiares, tienen cerdos para cría y engorde de capones, tanto los que viven en el pueblo como los que viven en el campo.

Su rol en la alimentación tiene una importancia económica sobre todo en la época de invierno, donde se hacen y se consumen las facturas, siendo en varios casos entrevistados la estrategia de comida nocturna por preferencia.

En cuanto a la posibilidad de vender la producción es algo que los empleados ganaderos sobre todo tiene como estrategia de generación de ingresos en forma más o menos rápida. Según nos comenta Oscar, la venta de lechones es el fuerte de sus producción de verano, pero en invierno su estrategia de ingresos extras pasa por la elaboración de chacinados para venta secos en Laprida y Jamones en De la Garma.

"La ventaja de los chorizos es que triplicas la plata, sobre todo cuando carneo chanchas que tiene algún problema con la parición, que haces sino, los carniceros no te pagan nada, 700 u 800 pesos, y con eso hago 40 kilos de chorizos para secar, aunque tengo gastos un kilo de seco lo vendo a 70 pesos y me lo sacan de las manos... de los capones dejo los jamones para casa y si me sobran los vendo, el jamón vale lo mismo que el capón, mira si es negocio, si no te agarra calor o mosca no tenes problema, no falla... cuando se me fundió el motor del auto lo hice rápido porque tenia dos chanchas, las choricie y las vendí en Laprida, me costo 7000 pesos hacer el motor"

Oscar, empleado ganad. y criador de cerdos y elaborador, est. La Pindonga, 10-5-13.

En cuanto a la carneada como espacio de socialización funciona en la orbita de lo privado, son reuniones que se hacen entre vecinos de relación fluida y en mayor medida en familia. Nos cuenta Oscar que dura por lo menos dos días si se carnea 10 2 chanchos, desde la mañana hasta la noche, y participan todos de la actividad, cada uno con su rol, pero es tomado por parte de padres e hijos como un espacio de aprendizaje, donde se transmiten criterios, recetas y anécdotas que refuerzan vinculo. Las mujeres también comparten y generan mucho intercambio en las actividades que les son específicas, casi siempre vinculadas a la confección de morcilla y queso de chancho. En el caso de que participe otra familia, esto obliga a devolver la visita y cuando carnea la familia visitante, la que tiene que acompañar es la otra. Así por lo menos dos a tres veces cada familia en el transcurso del invierno. Esta practica de 
reciprocidad en la actividad se remonta mucho tiempo atrás según surge de los relatos supieron ser otrora el evento social aglutinante en el campo y se combinaba con bailes y otros festejos, hoy día la urgencia de los tiempos de trabajo actuales hace que realice mas esporádicamente y durante menos tiempo.

En otros casos los entrevistados nos plantean que se hacen carneadas "a medias" donde cada uno pone un cerdo y se reparten el trabajo, los gastos y los productos, esta forma denota una mayor vinculación planteada sobre todos en caso de carneadas familiares entre hermanos, cuñados o padres e hijos, siendo a su vez una oportunidad de reunión familiar.

"Nosotros carneamos con Candela, mi vecina, siempre ponemos un chancho cado uno y trabajamos todos juntos en el galpón de la estancia, en dos días terminamos casi siempre salvo que llueva...tenemos mucha confianza, somos muy amigos.... y los chorizos los condimenta el "tati", un vecino de acá cerca que sabe mucho y nos viene a ayudar con su familia, pero el resto del trabajo lo hacemos nosotros... a nosotros nos cansa un poco los chorizos pero nos rinde mucho, te ahorras mucha plata en comida."

Daniela, esposa de Jairo, empleado ganadero, est. San Francisco, 10-2-13.

Hemos observado que en el caso de los empleados que viven solos en el campo, la carneada se hace un día de semana a la par de las actividades típicas de recorrida, esto supone manejar el sistema productivo, tener mas tiempo y posibilidades de disfrutar con amigos. En cambio cuando se hacen carneadas en campos donde hay más de un empleado y se trabaja durante la semana, la carneada se traslada a los sábados y domingos con menos tiempo de disfrute y más apuro para terminar el trabajo.

En cuanto a la realización de carneadas por parte de empleados que no tengan cerdos, han manifestado que es muy poco frecuente, realizándose solamente en los casos que por algún motivo de canje de cereal o pago de alguna cuenta se logran juntar con el chancho o parte de el.

Como lo habíamos definido antes, este espacio de socialización se encuentra en la esfera de lo privado, por consiguiente para cualquier persona, técnico, dueño de campo o comerciante, ser invitado a una carneada significa trascender hacia el mundo privado de los empleados, de mayor sinceridad y confianza en el trato, cosa que como técnico he tenido la posibilidad de experimentar con gratitud en varias oportunidades.

Sin embargo cuando el destino de la producción es también la venta, esta esfera 
privada se amplia y motiva a la vinculación con otras personas en el marco de la comercialización de sus productos que de otra manera no podrían haber establecido contacto. Se generan en muchos casos vínculos de confianza que agrandan el mercado de los chacinados, que se amplia incluso a otros destinos.

Es muy común según nos plantea Marcelo que le pidan jamón o chorizos para parientes de ciudades grandes y que después estos le encarguen más cantidad para mandar. Esto sucede mucho con gente que vive y trabaja en Tandil o Mar del Plata, que lleva productos de elaboradores locales y que se venden muy bien. Hago la salvedad de que este mecanismo se hace en un marco de mucha confianza pero a su vez de mucha precariedad de todo tipo, donde lo único que se realiza es un control de la carne del cerdo para triquinosis, quedando temas como la cadena de frio y otras medidas bromatológicas sin observarse.

"Yo hago el jamón y la bondiola en salmuera con agua y sal, no con sal sola como lo hace la mayoría, entonces queda mas suave y no tiene tanto gusto a sal ....un día vino a comer un amigo del patrón de Tandil y a toda costa le tuve que vender un jamón en salmuera, después el patrón me empezó a pedir para este amigo y otros amigos de Tandil, incluso me piden también chorizos y panceta en salmuera... tengo la ventaja que el patrón los lleva y los cobra el sino como hago yo, no me voy a hacer un viaje a Tandil para vender un jamón porque pierdo plata...y además si te agarran con chorizos frescos en el auto capaz que te los sacan."

Marcelo, trabajador ganadero y multi-ocupado familiar, est. Santa Clara, 25-6-13.

\subsection{2- Las destrezas: prueba de riendas, sortija, tacuara, domas.}

Estos son sin ningún lugar a dudas los espacios de socialización masiva más importantes del medio rural disperso. Si bien todos tienen a la destreza con el caballo como eje central existen grandes diferencias entre las actividades y entre los intercambios y los asistentes a cada una.

En las tres primeras, sortija, tacuara y riendas en general se asiste como participante o en el grupo de algún concursante, en cambio en las jineteadas la asistencia tiene mas que ver con la concurrencia a un espectáculo que van a dar otros, los jinetes, y que alguien puede conocer alguno pero que son cuestiones muy individuales.

Durante las observaciones a estos eventos, se observan desde empleados rurales criollos, muy gauchescos, de ropas típicas, gestos serios; empleados rurales mas modernos, vestidos de ocasión pero con ropa de marca hasta personajes urbanos bien 
definidos.(ver fotos en anexo)

Es sin dudas el cariño y la pasión por los caballos lo que permite que se vinculen socialmente, aunque sea en forma muy eventual y superficial distintos actores que de otra forma no compartirían ningún escenario.

"Como te decía antes ahora esta de moda y además de la gente común de campo que tiene sus caballitos participan muchos que no son de campo o mayordomos que tienen caballos para negocio pero se lo corren otros, vienen todo el mundo, ni se conocen y vos te fijas no hay ningún problema, todos se llevan bien no es como el fútbol.... Imagínate que en una fiesta como la de Barra tenes capaz que 700 u 800 paisanos con un cuchillo grande en la espalda cada uno y no hay inconveniente y eso que a veces hay muchos que están borrachos, imagínate si pasa en una cancha de fútbol..."

Julián, empleado ganadero y productor de caballos, est. La Batea, 30-6-13.

Los actores que concurren a estos eventos pueden ser empleados rurales humildes, que en muchos casos van a caballo o a pie, o en vehículos característicos como el Falcon o la f100, y para los cuales esta es la única y mas importante instancia de socialización con pares y en las cuales se generan vínculos que se renuevan en cada reunión gauchesca, generando en muchos casos relaciones que se siguen en la esfera privada de las visitas al campo.

En este sentido lo que comienza siendo una vinculación a través de los caballos en una fiesta, sigue con visitas para revisar los caballos en el campo, dando lugar a intercambios de visitas que se repiten, en la esfera privada y que constituyen los nuevos círculos cercanos que van construyendo las familias del medio rural.

En muchos casos estas nuevas vinculaciones se amplían e intensifican generando la formación de peñas o agrupaciones gauchas, con el fin de seguir preservando los valores gauchescos vinculados con los deportes a caballo, las tradiciones y los oficios rurales puestos de manifiestos en desfiles cívicos y fiestas populares.

"Acá en Barra tenemos la agrupación Fortín Gaucho, que antes era muy grande, tenían un fogón para hacer bailes y todo, pero vistes como es eso, en las épocas malas nadie podía salir y los gauchos se hicieron grandes y nadie siguió, ahora quedan algunos chicos que están empezando de nuevo y están desfilando pero acá cerca, en Barra y fueron para el centenario de De la Garma... lo que si se hizo, en realidad lo hizo casi todo el viejo Ferrara, es el campo de doma, donde se hace la fiesta grande de diciembre y ahí si participa todo el mundo porque trabajan también los del club y los de las agrupaciones cercanas... es un fiestón hermoso, con muchos caballos..."

Nestor, trabajador ganadero, Juan E. Barra, 20-5-12. 
Surge de la observación participante que una familia de este sector gasta en una salida entre un 10 y $20 \%$ de su salario y más aun si la fiesta termina en baile.

Otro actor concurrente son los encargados o mayordomos, que asisten en mejores vehículos (camionetas nuevas y carros de caballos confortables), y con pilchas gauchas distinguidas, participando ellos o con un caballo que lo monta una persona de su confianza, generalmente un empleado de su establecimiento. También asisten productores ganaderos y profesionales veterinarios afectos a los caballos pero que rara ves concursan, limitándose a establecer vínculos con los concurrentes o participando de la organización de los eventos.

Es cada vez mas común ver a persona urbanas tomando las destrezas como un hobby pasajero para realizar en familia los fines de semana.

Es en esta diversidad de participantes, muchos con poder adquisitivo importante donde se genera una oportunidad de multiocupación para los empleados rurales, que tiene que ver con la amansada de caballos, la compraventa de los mismos y todo lo referente a la elaboración y venta de sogas para caballos como ya lo hemos planteado en los capítulos de producciones y oficios camperos.

Existe en la actualidad un mercado muy activo de compra y venta de caballos para pruebas de destrezas, básicamente las llamadas carreras de tambores, que cuentan en la actualidad con un campeonato provincial que cierra en Olavarría con una gran fiesta que tiene varios autos en premio para los jinetes y publico en general. Según relata Julián ya se han inscrito para la fiesta del Talar mas de 2000 caballos, con premios que van desde camionetas, autos y trailers para caballos hasta motos, televisores y muchas cosas mas, esto demuestra la dimensión de lo que estamos hablando.

En esta asociación hombre-caballo no existen relaciones dominantes ni vínculos de poder ni diferencias sociales que puedan influir, poniéndose a prueba la destreza con el animal por sobre otras características personales de cada uno.

En cuanto a las actividades, las pruebas de tambores son las que están más de moda y convocan a más público en general. Si bien exigen cierto dominio del animal, no requieren una especialización como son las carreras de sortija y tacuara en las cuales los participantes son verdaderos especialistas en esa destreza.

Últimamente se genero una variante en las carreras de tambores que se denomina "de potros" y consiste en anotar animales sin domar, certificados por los organizadores del evento con 60 días de anticipación y luego de la inscripciones se doman y 
concurren con esos pocos días de doma a correr entre los tambores (recordemos que una doma de un caballo para trabajo dura entre 8 meses y un año), generando una mayor paridad entre los concursantes y cierta incertidumbre sobre quien va a ser el ganador. Esta variante surgió para contrarrestar el dominio de las reuniones que iban adquiriendo ciertos jinetes y sus caballos que hacían que nadie se quiera anotar con ellos para competir.

Generalmente estos espectáculos se organizan en el marco de una cooperadora de una escuela rural, un fortín o agrupación gaucha o para la campaña de fútbol de algún club.

Las domas son también eventos muy populares en el medio rural, con mucha participación de empleados rurales y sus familias y que muy a menudo duran mas de un día abarcando todo el fin de semana.

Este tipo de reuniones ha tenido un marcado cambio en los últimos años, concentrándose en eventos de mucha importancia en asistencia y premios pero muy pocos en cantidad, vinculados casi siempre con las clasificaciones para la fiesta de doma de Jesús María, Córdoba, que se realiza en el mes de enero de cada año. Esto ha sucedido, según explican los organizadores de domas, por la importancia y el valor que tiene los seguros de accidentes para los domadores y las malas experiencias que han tenido cooperadores escolares que quedaron en deuda ante el accidente de algún jinete.

"Nosotros estábamos en la cooperadora de la escuelita de chapar en el campo y se hacían jineteadas para recaudar fondos pero después del accidente que tuvo un jinete de Juárez que hubo que pagarle una operación de cadera casi nos fundimos y no hicimos mas, ahora todo el mundo hace prueba de riendas que no tenes tanto riesgo y el seguro que hay que pagar es barato."

Alberto grande, empleado mixto con hacienda propia, est. La escondida, 1-11-12.

\subsection{3 - Las escuelas rurales}

Plano de distribución de escuelas rurales en zona de estudio 


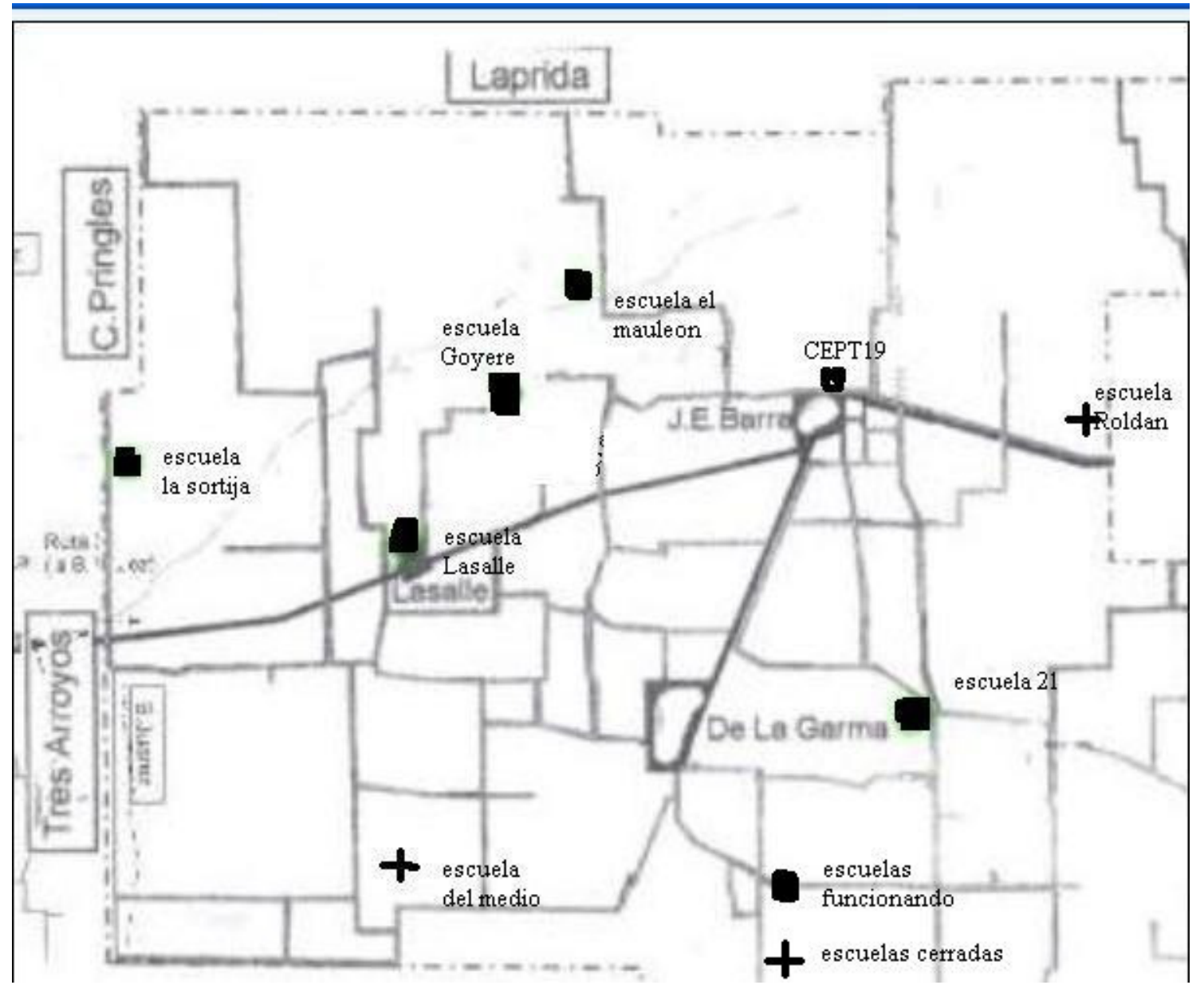

A lo largo de la historia rural, las escuelas han sido el punto de referencia de la población rural dispersa y dentro de esta las familias de los empleados rurales.

En la zona de estudio existen una serie de escuelas rurales que tiene una ubicación estratégica, vinculadas a un paraje con estación del ferrocarril como son las escuelas de Lasalle (13 alumnos), La sortija (18 alumnos), Paraje Chapar (12 alumnos) y que mas allá del numero oficial son identificadas por toda la comunidad con el nombre del paraje en el cuan funcionan. Las otras escuelas están ubicadas en estancias que aseguraban una presencia de alumnos basados en la gran cantidad de familias que trabajaban en dicha estancia, tal es el caso de la escuelita del Mauleon (6 alumnos), estancia cerca de Barra o la escuelita de Goyere (7 alumnos), estancia San Francisco ubicada cerca del limite distrital contra Laprida. Todas las escuelas tiene anexados un jardín de infantes, que recibe a niños desde los 2 años de edad y concurren junto a sus hermanos mayores en el mismo horario. Por las condiciones climáticas severas de la zona, se manejan dos horarios de clase, uno de invierno por la tarde y el de verano 
por la mañana, esto favorece la asistencia de los chicos a clase según nos cuentan las maestras en el marco de nuestro trabajo cotidiano.

"Al jardín van a la misma escuela, que ahora tiene maestra jardinera y funciona un jardincito, con la mas grande que ahora va al CEPT, el jardín no estaba y la tenia que llevar una vez por semana a De la Garma al jardín, era una complicación.... Ahora en un solo viaje los traigo a la mía, a mi sobrino y a una nena de mi vecina, que nos turnamos una semana cada una... lo único que nos quedamos a esperarlos sino es mucho gasto.... colaboramos, preparamos cositas para los actos, estamos en la Cooperadora, tratamos de mejorar el edificio..."

Patricia, esposa de Julián, empleado ganadero, est. La Batea, 30-6-13.

En estos últimos años las escuelas de todos los niveles trabajan en una propuesta conocida como Agrupamiento Rural, donde se apoyan propuestas de las comunidades rurales y que van desde la organización conjunta de una fiesta rural en el paraje la sortija, cursos de formación en todas las escuelas, y un proyecto de huerta para autoconsumo en las escuelas de Lasalle y La Sortija.

En este punto, el de la escuela como espacio de socialización rural, vale la pena mencionar, por su cercanía a la zona de estudio, en el distrito de Juárez, otra modalidad de educación rural conocida como "escuelas de concentración". En este sistema el criterio utilizado fue el de costo-beneficio de la obligatoriedad de la escuela primaria, donde dejaban de funcionar la mayoría de las escuelas rurales de los parajes y estaciones, quedando solamente una escuela de estación Bunge y otra en el pueblo de Lopez llevando los chicos en combi todos los días a la escuela, en cambio quedaron cerradas y luego abandonadas mas de 15 escuelas rurales y con ellas el cierre del principal lugar de vinculación de cada comunidad rural.

Es muy notorio el proceso ocurrido en Mariano Roldan, la estación siguiente a Barra pero en el distrito de Juárez, donde hace 20 años existía la escuela y vivían en el paraje, 8 familias y concurrían muchas mas del medio rural. Luego del cierre de la escuela las tres familias que trabajaban en la escuela se fueron y junto con ellas otra familia mas, en el año 2003 cerro el almacén y se fueron dos familias mas, terminando por emigrar las tres familias restantes. En la actualidad existe una infraestructura de 10 casas, una escuela y un almacén completamente vacío, deteriorándose y siendo utilizada la casa de la estación de ferrocarril por un establecimiento rural privado para morada de uno de sus empleados. También esta cerrada una escuela rural conocida como la escuelita del medio y que tanto esta como la de Roldan están referenciadas 
en el plano con una cruz, emulando su desaparición como espacio de socialización

Volviendo a concentrarnos en nuestro trabajo, mostramos que de las 6 escuelas primarias que hay en la zona de estudio, solamente en una existe una alumna que es hija de productores agropecuarios, el resto de la población escolar son hijos de empleados rurales, estando los padres presidiendo y trabajando en las cooperadoras de 5 escuelas.

Como lo habíamos planteado con anterioridad la escuela rural tiene como característica particular la permanencia de muchas madres en la escuela mientras dura la actividad escolar, generando esto un intenso vinculo entre las madres y familias, que si bien existen algunas experiencias conflictivas en este sentido, en la mayoría de los casos los grupos logran organizarse generando beneficios comunitarios.

Con este sentido se han organizado con éxito de participación cursos de formación profesional en el área de computación, cocina, y en este año comenzó en la zona la secundaria para adultos rurales que se dicta con la modalidad de alternancia y que registra la presencia de estas madres y también de empleados rurales varones que deciden terminar su secundaria, generando en estos casos proceso muy interesante de ampliación de oportunidades de todo tipo.

"Nosotras vamos a la escuela y nos quedamos allá hasta que terminan las clases, la señorita esta con los chicos y nosotras estamos en la cocina, nos dan cosas para hacer, hacemos fideos, empanadas y la maestra las vende en el pueblo, ella trae los pedidos y la plata va a la cooperadora, todas las mamas trabajamos mientras los chicos están con la maestra... ahora viene profesores para hacer la secundaria, si puedo la voy a hacer."

María, esposa de Miguel, empleado de origen chaqueño, est. La Colonia, 3-11-12.

Recordamos que la cuestión de la escolaridad de los chicos ha sido planteada como una de las primeras causas de migración rural-urbana, y responde fundamentalmente a los problemas que se suceden en la época de muchas lluvias. No es la escasez de escuelas ni el nivel, el principal problema de las escuelas de campo, el problema son los días sin clases por cuestiones climáticas sobre todo en invierno, que afectan los caminos y mas que impedir que vayan los chicos a la escuela, lo que impide es que vaya la maestra que en todos los casos vive en el pueblo

\subsubsection{Lo nuevo: playas y balnearios zonales}


En este espacio abordamos la utilización de espacios de socialización que se han intensificado en los últimos tiempos, según entendemos y sale de los relatos debido a la posibilidad que se tiene hoy día de contar con movilidad propia y también por la existencia de servicios de transporte privado que ofrecen llevar a un balneario zonal o a la playa al mar, esperar y a la noche traerlos de vuelta.

Para comprobar esto, mostramos como ejemplo de esta modalidad la existencia en Barra de 2 empresas de transporte que prestan este servicio, una con 2 combis de un comerciante local y otra, que ya habíamos mencionado, propiedad de Mónica, esposa de Felipe, que la utiliza también para prestar el servicio de transporte escolar.

"Con la combi me va bastante bien, le hago kilómetros, pero viste que el consejo escolar me paga medio largo, deci que yo gracias a dios puedo aguantar. En el verano viajo los domingos y a veces los sábados al balneario de Laprida, los sábados llevo muchos chicos que a veces se quedan en casas de parientes y vuelven el domingo. En cambio los domingos llevo más a familias y gente grande voy con la combi llena y también a veces sale Baigorria con su combi. Durante el invierno llevo los chicos al boliche a De la Garma y por ahí a los bailes de Juárez y Tres Arroyos."

Mónica, transportista y esposa de Felipe, est. La argentina, 17-6-12.

El caso del balneario de Laprida, es un espacio publico que se creo alrededor de una laguna en cercanías de la ciudad y que luego de un largo y exitoso proceso de parquización y urbanización, recibe gran cantidad de visitantes durante todo el verano, se estima de acuerdo a lo publicado en los medios locales que asisten alrededor de 5000 personas los fines de semana y entre 1500 y 2000 de lunes a viernes. Surge de los relatos la posibilidad de tener piletas (no hay piletas publicas ni en Barra, ni en De la Garma), parrilleros, baños en buen estado y una proveeduría dentro del predio.

"Cuando puedo nos vamos al balneario. Está hermoso, te llevas para hacer una parrillada y te encontras con muchos amigos, tenes pileta que nosotros cuando, siempre nos bañamos en el tanque o en la laguna.... a veces arman ferias de artesanos y llevo mis cositas para vender, a veces tocan los chicos y te encontras con medio Barra. Mientras el camino esta bueno voy con el auto, tenemos lo mismo que a Chávez, 50 kilómetros, no es nada, pero si el camino se pone feo no podes ir; rompes todo el auto."

Sergio, empleado ganadero y artesano de cuero, Juan E. Barra, 20-5-13.

Resulta muy interesante, lo que sucede con esta vinculación con Laprida, donde vive una gran cantidad de ex-pobladores de Barra y su zona rural y donde el encuentro con familiares oficia también de punto de venta de las producciones, sobre todo de lechones y chorizos, aunque también llevan corderos y pavos. 
También es un punto importante donde los empleados negocian la compra de sus vehículos y artículos del hogar, teniendo comercios en este sentido que trabajan con empleados rurales, con financiación propia.

"Imagínate que cuando voy al balneario me llevo 2 lechones y pago todos los gastos, a veces nos quedamos en lo de mi hermano y el me hace los contactos, me vende mucho chorizo en el invierno y en el verano le traigo corderos y lechones los domingos bien temprano, se los sacan de las manos. Siempre que vengo vendo algo, incluso antes traía huevos, pero en el verano se ponen feos de una semana para la otra así que no traje mas. Venimos siempre en verano menos cuando estoy de guardia que no salgo a ningún lado. Sino me voy a Juárez a visitar a mi mama. " 12.

Alberto "Chacho", empleado ganadero y jinete, multiocupado, est. 23 de abril, 16-6-

En los últimos tiempos han sido varios los empleados que han tenido la posibilidad de vacacionar en otros lugares como las playas de Necochea que están a $150 \mathrm{~km}$, Claromecó a 160 km, y Marisol a 180 km; este ultimo se elige por ser un muy buen pesquero. Es importante marcar la diferencia de estos balnearios ya grandes y populares donde los empleados concurren con sus familias o con grupos de amigos en jornadas de pesca como en el caso de Marisol, pero en ningún caso manifiestan que lo utilicen como espacios para ubicar su producción o sus objetos artesanales, estando todo el tiempo dedicado a disfrutar en familia y a distenderse.

"Nos vamos a Necochea 15 días en febrero después que termina la cosecha, no hace mucho... nunca nos tomábamos vacaciones con los chicos chicos, ahora que ya quieren salir, vamos a la playa, al casino y a comer afuera. Empezamos yendo a una casa alquilada y ahora vamos siempre al hotel de UATRE, que hay que reservarlo con tiempo pero en febrero siempre hay lugar. También fuimos a conocer las termas en el Médano, que es del gremio y no te cuesta nada, un lugar hermoso para descansar. Este año los chicos ya son grandes y nos fuimos con mi señora de excursión a las Cataratas una semana y lo pagamos en cuotas, estuvo muy bueno.

Alberto grande, empleado mixto con hacienda propia, est. La escondida, 1-11-12.

Es interesante rescatar del relato de Alberto un comportamiento enteramente vinculado a distintas estrategias de disfrute en familia, entre otras cosas debido a su trayectoria que le ha permitido poder tener un buen arreglo salarial, un rodeo propio de 25 vacas en el mismo campo y animales de granja para ventas en el circuito corto de De la Garma. Disponiendo de posibilidades económicas para realizarlo, amen de mejorar su casa en el pueblo, su vehículo personal y apoyar fuertemente a varias de sus hijas que han formado familia propia.

Esta situación si bien existe, no es muy frecuente entre los empleados y en el caso 
de nuestros entrevistados lo vemos además en el caso de Felipe y seguramente le sucederá lo mismo a Marcelo y a Julián que van por caminos similares pero que por el momento no tienen esas posibilidades, estando en plena etapa de capitalización.

En todos estos casos que podemos llamar exitosos o de sociabilidad extendida, es notorio y corresponde con lo que venimos planteando desde el principio del trabajo. Se tienen que dar por lo menos tres situaciones que son comunes en estos empleados, por un lado buenos arreglos laborales, que incluyen buenos arreglos salariales con habilitaciones expresadas en porcentajes de la producción. También tienen que estar presente la posibilidad de contar con tierra e insumos para realizar las actividades productivas y además tiene que haber una iniciativa impronta familiar que lleve adelante estas propuestas donde la mujer del empleado tiene un rol indiscutible

A todo esto le sumamos una trayectoria laboral que les permite generar este tipo de vínculos beneficiosos con la patronal, en el caso de Alberto hace 18 años que trabaja en el mismo establecimiento, viviendo en el campo y si bien ahora tiene mayores comodidades esta desde las épocas donde no había condiciones para que una familia viva bien. Felipe que comenzó con un buen arreglo salarial, ya lleva 16 años trabajando y viviendo en el mismo establecimiento y desde hace 10 años que tiene hacienda propia. 


\section{CONCLUSIONES GENERALES}

Para comenzar esta etapa de conclusiones generales, consideramos pertinente volver a plantear la pregunta de investigación y cuales son las hipótesis planteadas al comienzo del trabajo.

Pregunta de investigación:

Como influyen las actividades productivas de los empleados rurales en los vínculos dentro de la familia y en su relación con la vida social de los pueblos y su entorno?

\section{Hipótesis 1:}

La realización de actividades diversas extra asalariadas está relacionada con ciertas características del empleado: actividad salarial, residencia, tipo de familia, tamaño y cantidad de empleados del establecimiento, asistencia al secundario técnico, y otras acciones de desarrollo.

\section{Hipótesis 2:}

La multi-ocupación pasa por la participación directa de otros miembros de la familia. Esto cambia las actividades realizadas por sus integrantes, sus vínculos en el seno familiar y sus vínculos sociales locales. El hecho de que la mujer o los chicos sean responsables de una producción puede mejorar su situación y su autoestima a partir de la generación de ingresos y vínculos.

\section{Hipotesis 3:}

la realización de actividades productivas cambia los vinculos sociales de la flias de empleados rurales con sus vecinos y con el pueblo, esto pasa por la constitucion de redes de comercializacion directa, trueque, aumentar la frecuencia de viajes)

En cuanto a las limitaciones del trabajo, como ya lo hemos mencionado, no nos metemos con el sector de trabajadores golondrinas de la papa, debido a la brevedad del periodo que están en nuestra zona, pero su creciente incidencia en la actividad de los comercios locales y la creciente importancia de la superficie del cultivo dejan abiertas las puertas para una futura investigación sobre el tema.

Otro tema sobre el cual no se avanzo es referido a los pormenores de los circuitos 
de comercialización de las mayorías de los productos referidos a que normas están faltando para que estas producciones puedan enmarcarse en una actividad licita, si realmente es muy difícil adecuarse y sobre todo a quien le conviene esta situación. Sin embargo hemos descrito con grado de detalle como acontecen estos circuitos comerciales en la actualidad, generando de por si una información importante para comprender los sistemas productivos de los empleados rurales

Hemos observado durante este trabajo la diversidad de empleados que existen en nuestra zona de estudio y como estas tienen implicancia en la posibilidad de que las familias realicen otras actividades productivas $o$ servicios. Analizando las características de los distintos tipos de empleados, observamos una relación importante entre la actividad y el lugar de residencia. Como surge del trabajo los empleados agrícolas viven mayoritariamente en los pequeños pueblos y trabajan en empresas de servicios conocidas localmente como "equipos de chacra". Esta localización sumado a la característica del trabajo actual con tiempos corridos de trabajo en el campo y tiempos de no actividad en el pueblo, no permiten que lleven adelante producciones para autoconsumo y venta. Existen sin embargo un grupo de estos empleados agrícolas que se ubican en las zonas de quintas que se permiten desarrollar ciertas actividades productivas con apoyo de sus familias, y los trabajadores que viven en los pueblos tienen otras actividades vinculadas en muchos casos a la construcción y otros empleos urbanos. Plantean además mayores posibilidades de trabajo asalariado para sus esposas, que en muchos casos generan ingresos superiores a los varones empleados de la familia.

Por otro lado, empleados que viven en el campo, en su gran mayoría empleados ganaderos, llevan adelante algún tipo de producciones agropecuarias y otras que tienen que ver con ciertos oficios y servicios a la producción, mas aun si son los únicos habitantes del campo junto a su familia. Esta situación es altamente preferida por los empleados debido a la posibilidad de lograr mejores arreglos salariales y a la mayor posibilidad de manejar los tiempos de trabajo y de otras tareas.

Referido al tema del grupo familiar, surge como relevante la conformación de la familia como núcleo para residir en el medio rural. Prácticamente todos los empleados relevados que viven en el campo en forma permanente lo hacen con sus familias, sin embargo esto no prevé la presencia de adultos mayores que en su mayoría tienen que irse a vivir al pueblo, motivados básicamente por la infraestructura limitada que existe en los campos referido a las casas de los empleados y por normativas que tienen la 
mayoría de los campos vinculadas con el trabajo de ajenos al establecimiento . Esta situación de la radicación familiar se pone en duda cuando no existen posibilidades de escolaridad cercana y de buen acceso para los chicos en edad primaria o cuando las personas son de edad avanzada.

En cuanto a la presencia de empleados de origen correntino, suponen características definitorias de rasgos culturales y sociales particulares. Se acentúa la morada rural en grupo familiar, ninguno de los empleados correntinos relevados vive en el pueblo o con su familia en el pueblo. Mayoritariamente realizan algunas actividades pequeñas para autoconsumo pero no plantean la realización de actividades con destino a la venta, si notándose un proceso lento pero continuo de capitalización a escala familiar (muebles, electrodomésticos, vehículo familiar, caballos). Tienen una estrategia de vinculación vía lazos familiares que se acentúa en la medida que siguen viniendo familiares y amigos a trabajar en la zona recomendados y traídos por ellos mismos.

Esta estrategia de vinculación familiar y su introspección característica, provocan que sus redes de socialización se vayan extendiendo de manera muy lenta y no tengan una impronta que les genere las oportunidades de comercialización de productos que si bien no producen actualmente, estarían en condiciones potenciales de producir. Sin embargo, los hijos que concurren a escuelas locales ya tienen amistades de la zona, seguramente tengan una realidad distinta a la hora de diseñar sus estrategias de socialización y capitalización mas parecidas a los empleados locales.

No surgen de los relatos ventajas importantes que los empleados se reconozcan por haber ido a una escuela técnica como es el caso del CEPT. Pero si lo consideran importante a la hora de plantear estrategias productivas extra salariales vinculadas principalmente con las producciones de animales de granja y ciertos espacios de socialización.

En este sentido los distintos planes de estímulo y formación técnica que se han propuesto desde el CEPT para las producciones familiares de animales de granja y la producción hortícola, han sido el puntapié para que numerosas familias comiencen o retomen con cierta regularidad y resultados las producciones familiares de animales de granja, básicamente cerdos y aves y que en muchos casos son una fuente interesante de ingresos familiares y han ampliado sus posibilidades de vinculación.

En cuanto a los espacios de socialización, la participación de los chicos y padres 
vía consejo de administración en las distintas propuestas de acción con una impronta solidaria que se realizan en la zona, promoción de las actividades mas populares vinculadas con los deportes de caballos, fiestas y bailes criollos, gestión de servicios e infraestructura para el medio rural como los caminos, la secundaria rural y la ambulancia, han permitido una integración y un vinculo con el estado municipal y otros actores de la zona que difícilmente se pudieran haber sido trabajados desde la opción particular de cada familia.

Cambiando de tema, con respecto a la evolución de estos tipos de trabajos observamos también una diferencia clara en los procesos de cada actividad y sus posibilidades de generar empleos.

En el trabajo del sector agrícola, confirmamos lo dicho por autores como Neiman (2010), Cloquell (1982), Craviotti (2006) y otros sobre la tendencia a la tercerización del trabajo, al carácter temporario del mismo, el mayor índice de trabajo no registrado y a la morada urbana de los empleados. Estas características van haciendo que el empleo como operario agrícola forme parte como una estrategia más de empleo de los pobladores urbanos y vaya perdiendo ese sentido de pertinencia y exclusividad que tuvo cuando los actores tenían otras características "mas rurales", que estaban vinculadas a un aprendizaje del oficio a través de la participación desde chicos en los trabajos agrícolas y a la constante participación en las actividades de los talleres donde muchos realizaban actividades de desarme y arme como una forma de aprender el oficio y para poder después resolver sus problemas en el campo.

En cambio en el sector del empleo ganadero, las características mencionadas como la morada rural, las actividades productivas extra-salariales y la vinculación con las actividades de a caballo favorece un apego al territorio, una satisfacción con su forma de trabajo y una intención de seguir perteneciendo a este mundo rural.

En este sentido los cambios en las posibilidades de comunicación y transporte de los empleados rurales, han mantenido e incluso han revitalizado espacios de socialización, como las agrupaciones gauchas, las fiestas regionales y de destreza que tienen mucho que ver con este aspecto, ampliando las distancias hasta donde se trasladan algunos empleados para participar de estos eventos y generando a su vez una masiva concurrencia que genera una mayor diversidad de vínculos entre los asistentes.

En cuanto a la presencia del viejo empleado mixto, tradicional de la zona, se esta convirtiendo en un empleado ganadero moderno, con manejo de tractor para 
actividades de dar comida, rollos e incluso sembrar algún verdeo, siendo los cultivos agrícolas de estos campos mixtos sembrados y trabajados mayormente con maquinas de terceros o por los propios productores.

Acá se encuadran también las actividades realizadas en el engorde a corral o Feedlots caseros que se realizan en numerosos campos ganaderos de la zona y donde el empleado maneja tractor y pala o en muchos caso ya tiene un mixer para realizar la alimentación de los animales. Esta actividad de engorde a corral, si bien no es nueva y ha tenido vaivenes a lo largo de los últimos años, tiende a generalizarse como una opción productiva estable y por ende supone ciertas calificaciones que el empleado ganadero debe tener para manejar los mismos, aunque no son muchas ni difíciles de aprender en términos generales.

Esta tendencia, podríamos llamarla así, hacia una separación sustancial en el modo de trabajo y de vida de los empleados ganaderos respecto de los agrícolas, supone también diferencias en el plano de las relaciones laborales tal cual lo plantea Ohaco M. (2012) en un trabajo reciente sobre ocupación y empleo, y Neiman y otros (2003) con anterioridad, donde se vincula la estabilidad, la formalidad y el registro del trabajo con el tiempo de duración y la periodicidad de mismo, coincidiendo con lo establecido en este sentido en nuestra zona de estudio respecto a los trabajadores agrícolas de los equipos de chacra y a los empleados ganaderos.

Por los motivos planteados con anterioridad consideramos que la hipótesis numero 1 es validada, quedando como interrogantes el verdadero impacto que tendrán sobre el empleo agrícola la nueva era tecnológica de la automatización de maquinarias y quienes serán los encargados de transmitir este oficio en el marco del cambio cultural del oficio agrícola que observamos en este trabajo.

Surge también en este sentido el aumento en la diferenciación de las características dentro mismo de los empleados agrícolas y mixtos que aun siguen ligados a empresas rurales y viven dentro del modo rural mas tradicional respecto de los empleados de empresas de servicios agrícolas responsables de los trabajos tercerizados de los campos hoy día.

Coincidiendo con lo planteado por Preda G. y Blanco (2010) en su trabajo sobre los cultivos de trigo y soja en la región de Córdoba, creemos que esta diferenciación va a seguir en aumento, sustentado en el cambio tecnológico de las maquinas agrícolas donde la impronta mecánica tradicional cede espacio ante la tecnología electrónica y computarizada de difícil acceso para la mayoría de los trabajadores, dejando fuera del 
universo de acción de los tractoristas la posibilidad del contacto con los fierros y de resolver en el mismo campo los problemas de la maquinaria.

También planteamos en coincidencia con Villulla (2012) que esta modificación en la forma de trabajo agrícola supone una mayor precarización y disciplinamiento salarial de los trabajadores

En cuanto a lo planteado en la hipótesis 2 y 3 , referida al rol de la multiocupación han surgido una cantidad importante de situaciones que merecen una reflexión.

En primer termino validamos el interés del concepto de multiocupación para referirnos a estos procesos donde además de la actividad primaria salarial existe en el marco del grupo familiar otras actividades que completan su panorama laboral. Marcamos una diferenciación con el concepto trabajado por Giarraca y Aparicio (1991) y por Radonich (2003) en lo referido a las actividades extra-salariales, a esta situación la definimos como "Multiocupación rural" ya que las actividades extra-salariales también pertenecen al mundo de las actividades rurales, tanto las de producción de alimentos, como la de servicios y otras vinculadas a actividades y espacios de socialización característicos del medio rural.

Coincidimos con lo planteado por Schneider (1999) sobre el carácter permanente de esta situación y no como una cuestión solamente coyuntural de crisis económica poniéndose en juego en muchos casos, actividades que se transmiten de generación en generación.

Sin embargo surge en la discusión, cual es el verdadero rol de estos ingresos, cuando a comienzos del trabajo planteábamos su carácter complementario, mejorador y superador de condiciones generales básicas, vemos como en varios casos los mismos empleados plantean su carácter suplementario de los magros ingresos salariales que tienen de sus actividades de base.

Si bien esto se ha manifestado con mayor intensidad en épocas de crisis del país a fines de los 90 y principios de los 2000 , no ha podido modificarse demasiado y sigue siendo una opción productiva que esta fuera del encuadre legal y bromatológico en términos generales.

Sumado a esto, hemos planteado como estas estrategias suponen la falta de ciertos controles o como se dice "hacer la vista gorda" de parte de organismos de control, para que estas producciones se puedan llevar a cabo y ser vendidas en el pueblo.

Si bien no es un objetivo de este trabajo, creemos importante poner en discusión en 
próximos trabajos, si esto que podemos definir en muchos casos como plusvalía del trabajo agrario, no implica de cierta manera favorecer la existencia de salarios mas bajos que en la medida que se suplementen con estos ingresos extra-salariales no toman una verdadera dimensión de su capacidad de cubrir las necesidades básicas de un trabajador rural y su familia para desarrollar una forma de vida digna.

Aceptamos como una opción digna de trabajo la que le permite al trabajador vivir bien en similitud con las posibilidades que plantean el restos de los trabajadores de la sociedad, que en su gran mayoría no tienen la posibilidad de de realizar actividades extrasalariales para la generación de ingresos. Por eso es urgente la instalación del debate sobre la verdadera distribución de la renta del sector agropecuario, la necesaria plusvalía que pertenece a los empleados y las distintas formas de habilitación que se realizan en la actualidad como un verdadero reconocimiento salarial pero que no es contemplado en la hora de las remuneraciones para elaborar las escalas salariales y provisionales de los empleados rurales.

A titulo personal, creo en la valorable puesta en marcha del nuevo estatuto del peón rural a través de la ley 26727 del congreso nacional, superador de muchas situaciones reales de explotación de las formas de empleo como de las condiciones dignas del mismo.

Sin embargo creo que la ausencia explicita de las posibilidades de realizar actividades productivas de los empleados en los mismos campos no han generado el espacio concreto para tratar este tema como realmente merece, en cuanto es generador de ingresos que tendrían que estar incorporados en los montos sujetos a la remuneración jubilatoria de los trabajadores del sector.

Esto ha sido vivido como un revés por todos los que trabajamos en el sector de la agricultura familiar y que creemos que los empleados rurales también lo son, en tanto trabajadores del medio rural. Esta situación ya que había sido un derecho planteado explícitamente en el estatuto del peón rural mediante el decreto-ley 28169 del año 1944 durante la gestión del Coronel Juan Perón como secretario de trabajo y previsión de la nación y ratificado por la ley 12921 del año 1946.

En cuanto a la participación de la familia en el proceso de multi-ocupación, comprobamos la verdadera existencia de un proceso de orden familiar, tal cual lo planteaba Vitelli (2002) donde en la mayoría de los casos, todos los actores familiares, incluso los mas chicos tienen un rol activo muy importante y definitorio. Acá hacemos una diferenciación con los empleados de morada urbana, donde la principal estrategia 
esta basada en el empleo asalariado de las esposas en distintos niveles de inserción y en changas para los empleados varones.

En el caso de los empleados que viven en el campo, la participación de la mujer y los chicos generan una mejora y un reconocimiento al aporte familiar, mejorando la autoestima y la valoración de lo que se denomina trabajo no remunerado familiar, mejorando sustancialmente las oportunidades de socialización de toda la familia.

Hemos observado como las mujeres manejan ciertas actividades productivas en exclusividad como el caso de la producción de huevos o son encargadas de la parte comercial como en el caso de los tamberos repartidores de leche, teniendo la posibilidad e manejar el dinero y las compras de la familia.

En el caso de los chicos y los jóvenes esta participación implica comenzar a transitar una participación mas activa en los espacios de socialización, con disposición de dinero personal, que traducen en acceso a celulares, ropa o la compra de animales para negocios, fundamentalmente caballos. Sin embargo esta situación de independencia y autoestima alta suele tener efectos en la escolaridad de los jóvenes que, a los 16 años, ya tienen posibilidades de conseguir ingresos vía trabajo o vía actividades extra-salariales que los hacen en algunos casos abandonar los estudios secundarios para irse a trabajar..

A diferencia de épocas anteriores, la obligatoriedad escolar y las nuevas leyes laborales han modificado esta conducta del trabajo de los niños luego de su educación primaria, a los 12 o 13 años y que indefectiblemente no podía ser en condiciones legales, estirando ese periodo a partir de los 16 años, aunque lamento decirlo con efectos similares en las trayectorias laborales de los jóvenes.

Sin embargo existen todavía situaciones donde este proceso de multiocupación es exclusivo del empleado varón y donde la mujer sigue teniendo un rol mas pasivo, vinculado a las actividades domesticas tradicionales, que vemos en algunos casos de empleados correntinos y en empleados ganaderos que viven alejados de centros urbanos y con regímenes de trabajo con pocas salidas.

Tiene una importancia significativa la posibilidad del acceso a un vehículo de transporte familiar e incluso en muchos casos para transportar los caballos. Esto facilita que las familias accedan con mas facilidad a los pueblos vecinos para vender o colocar sus productos (por el carácter perecedero de los mismos) y a los espacios de socialización en el medio rural disperso.

Lo hemos marcado a lo largo del trabajo, cuando hablamos de la mayor 
participación de los empleados en eventos sociales, en los clubes de los pueblos, las cooperadoras escolares, en el comercio de cadena corta de animales de granja, artesanías y servicios incluso a la hora de tomarse vacaciones.

Si bien el vehiculo propio ha sido durante mucho tiempo el anhelo y el esfuerzo de los empleados que vivían en el medio rural disperso, la característica de estos tiempos es la posibilidad de acceso que han tenido los empleados a vehículos de buena calidad, superando la vieja escuela del falcón como vehiculo casi exclusivo de su clase debido a su rusticidad y nobleza, pero que en la mayoría de los casos implicaban mas problemas que soluciones a la hora de gastar y movilizarse.

A esto han contribuido también la mejora en los caminos rurales, las facilidades para la compra de autos y cierta bonanza del sector productivo que como ya hemos citado en el trabajo genera estos estímulos como una estrategia de vinculación patrónempleado, cuando en general siguen siendo parte de la plusvalía que le corresponde en tanto actores fundamentales del proceso productivo.

Esto funciona en la mayoría de los casos también como una estrategia de capitalización de ahorros o premios de producción en el caso que no pudieran tener otra estrategia productiva, en muchos casos previa a la compra o construcción de una casa en el pueblo.

Desde la mirada de su vinculación con los pueblos, destacamos la importancia que tienen ciertas producciones, fundamentalmente la de animales de granja como estrategias de circuitos cortos de comercialización, generando múltiples beneficios como la circulación local de recursos, cierto control social de la calidad de los productos y un real abastecimiento de productos que de otra manera no lograrían instalarse en el consumo de la gente debido a su costo y a la dificultad del acceso. Recordamos como dato que en los pueblos relevados del trabajo, la totalidad de los corderos y lechones como así gran cantidad de huevos y pollos son provistos por estas familias de empleados multiocupadas.

Si bien esto ha sido así a lo largo de la historia, ha sido en la crisis del 2001 y fundamentalmente luego de ella donde estas producciones han adquirido un rol mas importante en las economías familiares y en la socialización de los empleados, motivado básicamente por un aumento del precio y de la demanda creciente de estos productos por parte de los pobladores en general.

Como ya lo hemos mencionado en el trabajo, estas estrategias productivas de multiocupación, han sido puestas en marcha en caso de empleados despedidos, 
incluso durante la misma crisis, remarcamos que dos de los lecheros mas importantes en la venta domiciliaria de leche eran desempleados rurales que luego siguieron con su actividad productiva como cuentapropistas en lo que definimos como agricultura familiar en pequeñas quintas de la zona.

Esta modalidad de trabajadores rurales desempleados que se reorganizan en el marco de las producciones familiares cerca de los pueblos es bastante frecuente, aun a pesar que no existen grandes disponibilidades de terrenos fiscales para que se desarrollen las mismas, limitándose estos a estaciones viejas del ferrocarril, ya que los espacios de las vías muertas han quedado en uso y tenencia por parte de los frentistas de los campos y las plantas de silos y galpones han sido concesionados en su totalidad a las empresas cerealeras.

Por todos estos conceptos planteados validamos la segunda y la tercera hipótesis pero dejamos constancia de que todavía no es un proceso que abarque a la totalidad de los empleados y que requiere un análisis mas profundo de su carácter complementario o suplementario y de las condiciones en las cuales se desarrolla el rol del Estado en este sentido. 


\section{BIBLIOGRAFIA}

-AGUILERA, María Eugenia. (2001). "Modalidades de intermediación en la contratación de cosecheros citrícolas en Tucumán". En APARICIO, S. Y BENENCIA, R. (Coords.), Antiguos y Nuevos asalariados en el agro argentino, La Colmena, Buenos Aires.

-ALBADALEJO, C. (2004). Innovaciones discretas y reterritorialización de la actividad agropecuaria en Argentina, Brasil y Francia". En: Desarrollo local y nuevas ruralidades en Argentina / Développement local et multifonctionnalité des territories ruraux enArgentine. C. Albaladejo \& R. Bustos Cara, Roberto (compiladores). Ed. UNS Departamento de Geografía / IRD UR102 / INRA SAD / Univ. Toulouse Le Mirail UMR Dynamiques Rurales, Bahía Blanca, Argentina.

-ALFARO, María Inés. (1999). "Los espacios para la negociación laboral en la citricultura tucumana: actores y estrategias. Disciplinamiento, conflictividad y resistencia", Estudios del Trabajo, Nro. 18, Buenos Aires.

-ALONSO, L. E., \& Benito, L. E. A. (1998). La mirada cualitativa en sociología: una aproximación interpretativa (Vol. 218). Editorial Fundamentos.

-ANSALDI, W. (2000). "Chacareros y trabajadores" en "problemas de la historia agraria" de Bjerg y Reguera, IEHS, Tandil.

-ANSALDI, Walter. (1995). "El fantasma de Hamlet en la pampa. Chacareros y trabajadores rurales, las clases que no se ven”. En: BJERG, M. y REGUERA, A. (compiladores), Problemas de la historia agraria. Nuevos debates y perspectivas de investigación, IEHS, Tandil.

-APARICIO, Susana, Benencia Roberto (1999). Empleo rural en tiempos de flexibilidad, editorial la colmena.

-APARICIO, Susana y GIARRACA Norma (1991) "Los campesinos cañeros: multi ocupación y organización, cuaderno 3 del Instituto de Ciencias Sociales de la UBA. 
Buenos Aires

-APARICIO, S. (2004). Proyectos productivos y empleo agrario. In II Congreso Nacional de Políticas Sociales: Política social y política económica: tensiones en busca de equidad. Mendoza: Asociación Argentina de Políticas Sociales (AAPS).

-ARENDT, H., \& Cruz, M. (1993). La condición humana (Vol. 306). Barcelona: Paidós.

-BALSA, Javier (2006). El desvanecimiento del mundo chacarero. Transformaciones sociales en la agricultura bonaerense. 1937 - 1988. Bernal: Universidad Nacional de Quilmes.

-BENDINI, M., Radonich, M., \& Steimbreger, N. (1999). Historia de la vulnerabilidad social de los «golondrinas» en la cuenca frutícola del río Negro.De golondrinas y otros migrantes.

BENDINI, M. (2002). La configuración de una región agrícola dinámica en Argentina: actores sociales en la negociación local. In Políticas, instrumentos y experiencias de desarrollo rural en América Latina y Europa. Centro de Publicaciones Agrarias, Pesqueras y Alimentarias.

-BENDINI, Mónica y Nora GALLEGOS. (2002). "Precarización de las relaciones laborales y nuevas formas de intermediación en un mercado tradicional de trabajo agrario". Políticas Agrícolas, Nro. 12, México, Bogotá-Colombia, REDCAPA, Pontificia Universidad Javeriana

-BENDINI, M. et. all (2003),“. Globalización, regionalización y reestructuración del mercado de trabajo frutícola", Informe Final de Investigación PIP-CONICET.

-BENDINI, M., M. Murmis \& P. Tsakoumagkos. (2009). Pluriactividad: funciones y contextos. Preguntas teóricas y análisis en dos zonas frutícolas del Alto Valle rionegrino. En: La Argentina Rural. De la Agricultura familiar a los agronegocios. C.Gras \& V. Hernández (coordinadoras). Ed. Biblos. Buenos Aires. 
-BUSTAMANTE, Marina; MALDONADO, Gabriela Inés. (2009) “Actores sociales en el agro pampeano argentino hoy.: Algunos aportes para su tipificación." Cuadernos geográficos de la Universidad de Granada no 44.

-CASTRO, H., \& Reboratti, C. E. (2007). Revisión del concepto de ruralidad en la Argentina y alternativas posibles para su redefinición. PROINDER, Proyecto de Desarrollo de Pequeños Productores Agropecuarios.

-CITADINI, R., Manchado y Mosciaro. (1990). Las Formas de Organización Social de la Producción: Marco conceptual y planteo operativo. Serie Avances de Investigación $N^{\circ}$ 2. Área de Economía y Sociología Rural. CERBAS-INTA.

-CLOQUELL, S., \& Martínez, A. (1982). Diagnóstico de las limitantes al aumento de la productividad en el sur santafecino. Rosario. Convenio INTA-MAG-UNR. Mimeo.

-CRAVIOTTI, Clara. (2001). "Los procesos de cambio en las explotaciones familiares pampeanas: Tendencias en el trabajo agrario y dinámicas familiares" en Cuadernos de Desarrollo Rural № 45, Bogotá, Colombia.

CRAVIOTTI, C. (2006). Concertación social y territorio. Revista Internacional de Desenvolvimento Local.

-DE SARDAN, J. P. O. (1995). Anthropologie et développement: essai en socioanthropologie du changement social. KARTHALA Editions.

-DIEZ Tetamanti, J.M. 2008. Despoblamiento y Acción del Estado en la región Sudeste de la Provincia de Buenos Aires entre 1976 y 2004. Estudio de caso en las localidades de Mechongué (Partido de General Alvarado) y San Agustín (Partido de Balcarce).Tesis de Licenciatura. Colección Veracrúz Nº 17. Ed. FCl. Palmas de Mallorca.Versión digital en:

Http://www.uib.es/catedra_iberoamericana/publicaciones/tetamanti/

-DUHAlDE, A. J., Perea, Z. A., Massigoge, A. J., Jensen, V. M., \& Intaschi, A. D. (2011) Implantacion de forrajeras megatermicas, Chacra Experimental Integrada Barrow 
-EXBOIR, J. M., Lunardelli, R. F. L. (1990). La ocupación de la mano de obra rural en Argentina. Desarrollo Económico, (119).

FIDELI, R., \& Marradi, A. (1996). Intervista. Enciclopedia delle scienze sociali.

-FORJAN, H. (2000). Rotaciones en sistemas mixtos. La pastura perenne base de la agricultura sustentable en la región. INTA - Chacra Experimental Integrada Barrow. Material Didáctico No 1.

-FORNI, F.y Neiman G. (1991) "Estructura y tendencias del empleo rural en Santiago del Estero" en empleo, estrategias de vida y reproducción, Centro Editor de América latina, Bibliotecas universitarias.

-FORNI Floreal. y NEIMAN Guillermo (2001): "Trabajadores y Sindicatos Agrarios en la Argentina". En Neiman G. (comp.) Trabajo de Campo. Producción, Tecnología y empleo en el medio rural. Ediciones CICCUS. Bs. As.

-FORNI, Floreal. (1993). "Organizaciones económicas populares”. CEIL-SCC, Buenos Aires.

-GIARRACCA, Norma. "APARICIO. (1991) " Susana Los campesinos cañeros: multiocupación y organización, Instituto de Ciencias Sociales, Cuaderno 3.

-GONZALEZ, Angela Redondo. (1998)"Las encuestas y las entrevistas en las investigaciones geográficas." Métodos y técnicas cualitativas en geografía social. Oikos-Tau.

- IGLESIAS, Daniel (2000) “competitividad de las pymes agroalimentarias pampeanas" tesis doctoral

-LARA, Sara (1998). "Nuevas experiencias productivas y nuevas formas de organización del trabajo en la agricultura mexicana”. Juan Pablos Editor, México.

-MARRADI, A., N. Archenti \& J.I. Piovani. (2007). Metodología de las Ciencias 
Sociales. Ed.Emecé Editores. Buenos Aires.

-MENDRAS, H. (1978). Sociedades camponesas. Zahar.

-MINISTERIO de Asuntos Agrarios. Gobierno de la Provincia de Buenos Aires. (2007).Nuestra Provincia. Nuestro Campo.

-MURMIS, M. (1998). Agro argentino: algunos problemas para su análisis. En: Las agriculturas del MERCOSUR. El papel de los actores sociales. N. Giarracca S.Cloquell (compiladoras). Ed. La Colmena. Buenos Aires.

-MURMIS, M., (1996) “Pobreza rural”, Proinder Sagpia.

-MURMIS, Miguel. (1998)“Agro argentino: algunos problemas para su análisis” en Giarraca N. y Cloquell, S. (compiladores), las Agriculturas del MERCOSUR, Buenos Aires, edit. La Colmena.

-MURMIS, M. (1994) "Temas en la sociología rural latinoamericana: reestructuración, desestructuración y problemas de excluidos e incluidos". Ruralia.

-NEIMAN, G., Jiménez, D., \& Bardomás, S. (1999). Continuidad y cambio en las explotaciones familiares pampeanas. El caso de la pluriactividad en la provincia de Buenos Aires. I Jornadas Interdisciplinarias en Estudios Agrarios y Agroindustriales. Buenos Aires.

-NEIMAN, Guillermo; QUARANTA, Germán.(2000) “¿ Trabajo flexible o producción flexible. En Sobre los cambios en la organización del trabajo en la agricultura". Ponencia presentada en III Congreso ALAST. México DF.

-NEIMAN, Guillermo y Germán QUARANTA. (2000). "Reestructuración de la producción y flexibilidad funcional del trabajo agrícola en la Argentina". Revista Latinoamericana de Estudios del Trabajo, Año 7, Nro. 12, Asociación Latinoamericana de Sociología del Trabajo.

-NEIMAN, G. (2001). Trabajo de campo. Produccion, technologia y empleo en el medio 
rural. Buenos Aires: Ediciones CICCUS.

-NEIMAN, Guillermo Y BARDOMAS, Silvia (2001), "Continuidad y cambio en la ocupación agropecuaria y rural en la argentina", en trabajos de campo, producción, tecnología y empleo en el medio rural. Buenos Aires, CICCUS

- NEIMAN, G., Bardomás, S., \& Quaranta, G. (2003). El trabajo en el agro pampeano. Análisis de la demanda de trabajadores asalariados. Revista Interdisciplinaria de Estudios Agrarios, 19

-NEIMAN, G. y Craviotti C. Compiladores. (2005). Entre el campo y la ciudad. Ediciones Ciccus

-NEIMAN, Guillermo. (2010) "Los estudios sobre el trabajo agrario en la última década: una revisión para el caso argentino". Mundo agrario, vol. 10, no 20.

- OHACO, M. (2012). Precariedad y no registro en los trabajadores asalariados rurales de la Argentina. Investigaciones sobre Protección Social y Relaciones Laborales Argentina .

-PREDA, G., \& Blanco, M. (2010). La demanda de mano de obra en trigo y soja, provincia de Córdoba. En Neiman G. , Estudio sobre la demanda de trabajo en el agro argentino. Editiral Ciccus. Buenos Aires

-QUARANTA, Germán. (2010). "Estructura ocupacional, características de la demanda y perfil de la oferta laboral en el agro argentino a principios de la década actual". En NEIMAN, Guillermo (Dir.) Estudio sobre la demanda de trabajo en el agro argentino, Buenos Aires, Ediciones CICCUS.

-RADONICH, Martha. (2003). “Migrantes, asentamientos y desagrarización del empleo. Un estudio de caso en el Alto Valle del Río Negro y Neuquén, en Mónica Bendini y

Norma Steimbreger (coord.) Territorios y organización social de la agricultura. Editorial La Colmena. Buenos Aires. 
-RATIER, Hugo (2009) "poblados bonaerenses: vida y milagros. Editorial la colmena

-RUIZ Olabuénaga, J. \& M.A. Ispizua. (1989). La decodificación de la vida cotidiana. Métodos de investigación cualitativa. Ed. Universidad de Deusto. Bilbao, España.

-SCHNEIDER, Sergio. (1999) Agricultura familiar e industrialização: pluriatividade e descentralização industrial no Rio Grande do Sul. Editora da Universidade, Universidade Federal do Rio Grande do Sul.

-SILI, M. (2000). Los espacios de la Crisis Rural. Geografía de una pampa olvidada. Editorial de la Universidad Nacional del Sur. Bahía Blanca, Argentina. 180 pp.

-SOUTO, Julián y URIZA Jorge. (2012) “Centenario de De la Garma 1912-2012” edición limitada

-STEIMBREGER, N., Radonich, M., \& Bendini, M. (2003). Expansiones de frontera agrícola y transformaciones territoriales: procesos sociales diferenciales. Territorios y organización social de la agricultura. Buenos Aires: La Colmena.

-TORT, M.I. \& M. Roman.(2005). Explotaciones familiares: diversidad de conceptos y criterios operativos. En: Productores familiares pampeanos: hacia la comprensión de similitudes y diferenciaciones zonales. M.C. González (coordinadora). Ed. Astralib. Buenos Aires.

-UNION de trabajadores y Estibadores Rurales, - www.uatre.org.ar

-VALLES, m (1997) "técnicas cualitativas de investigación social. Edit. Síntesis, Madrid - VILLULLA, J. M. (2012). Las formas del salario en la agricultura pampeana: su rol en el disciplinamiento, el aumento de la productividad y el abaratamiento de la fuerza de trabajo. Mundo agrario, 13

-VITELLI, R. (2002), El fenómeno de la pluriactividad desde un enfoque de género, ponencia para el VI Congreso de la Asociación Latinoamericana de Sociología Rural, Porto Alegre. 
ANEXO 1 DE FOTOS

FOTO 1 AFICHE DE JINETEADA EN PUERTA DE SALON DE LA VETERINARIA

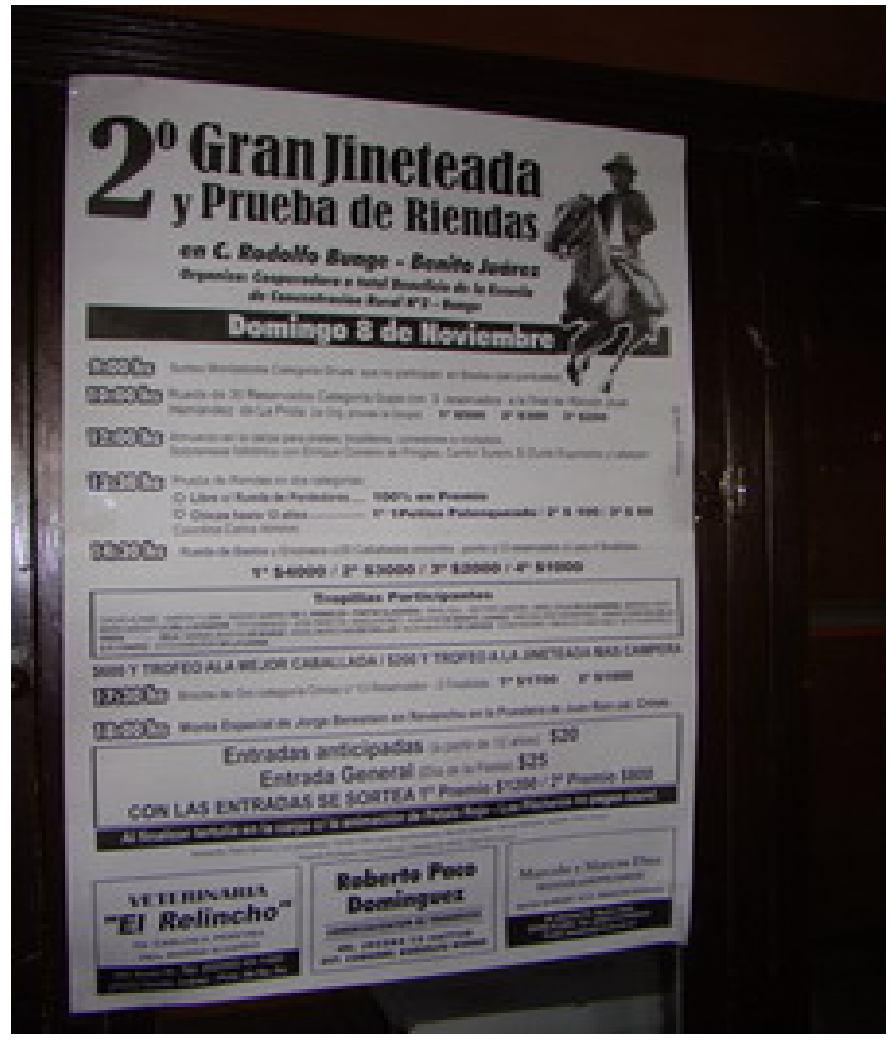

FOTO 2 AGRUPACION GAUCHA EL CENCERRO DE LAPRIDA EN JUAN E. BARRA

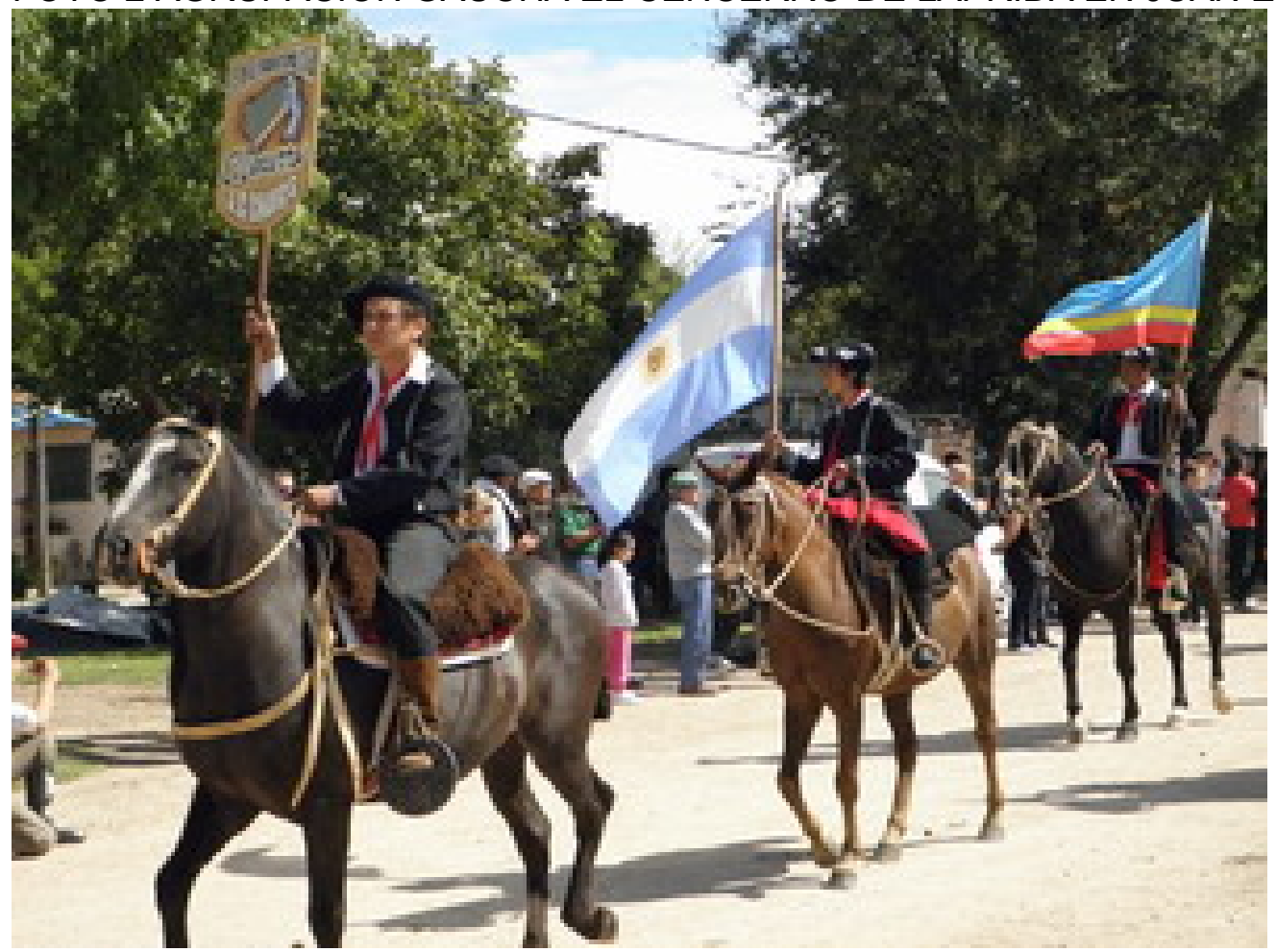


FOTO 3 NIÑOS DE AGRUPACION GAUCHA EL FORTIN DE BARRA EN DESFILE

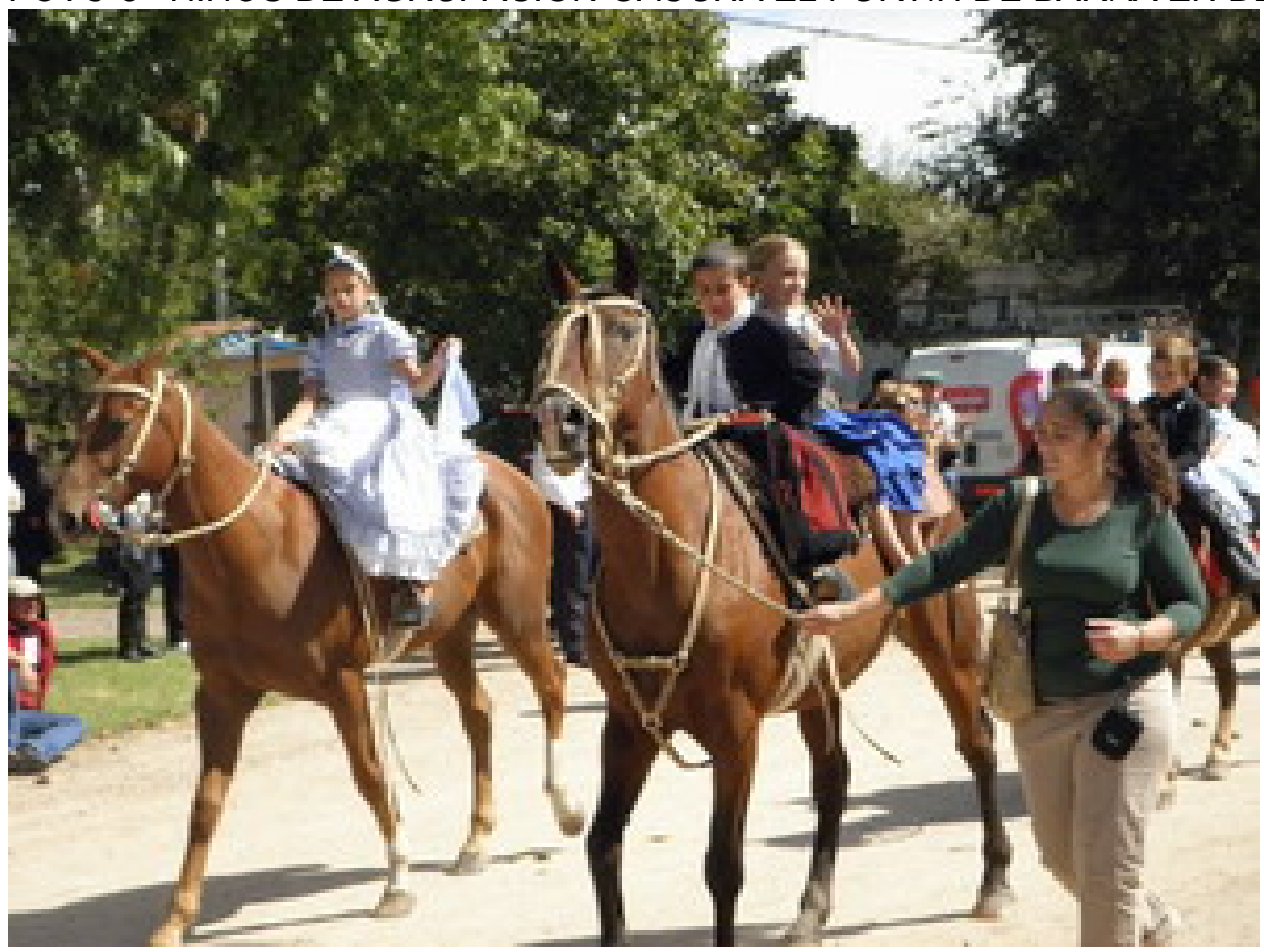

FOTO 4 TROPILLA DE MARTIN EN DESFILE DE BARRA

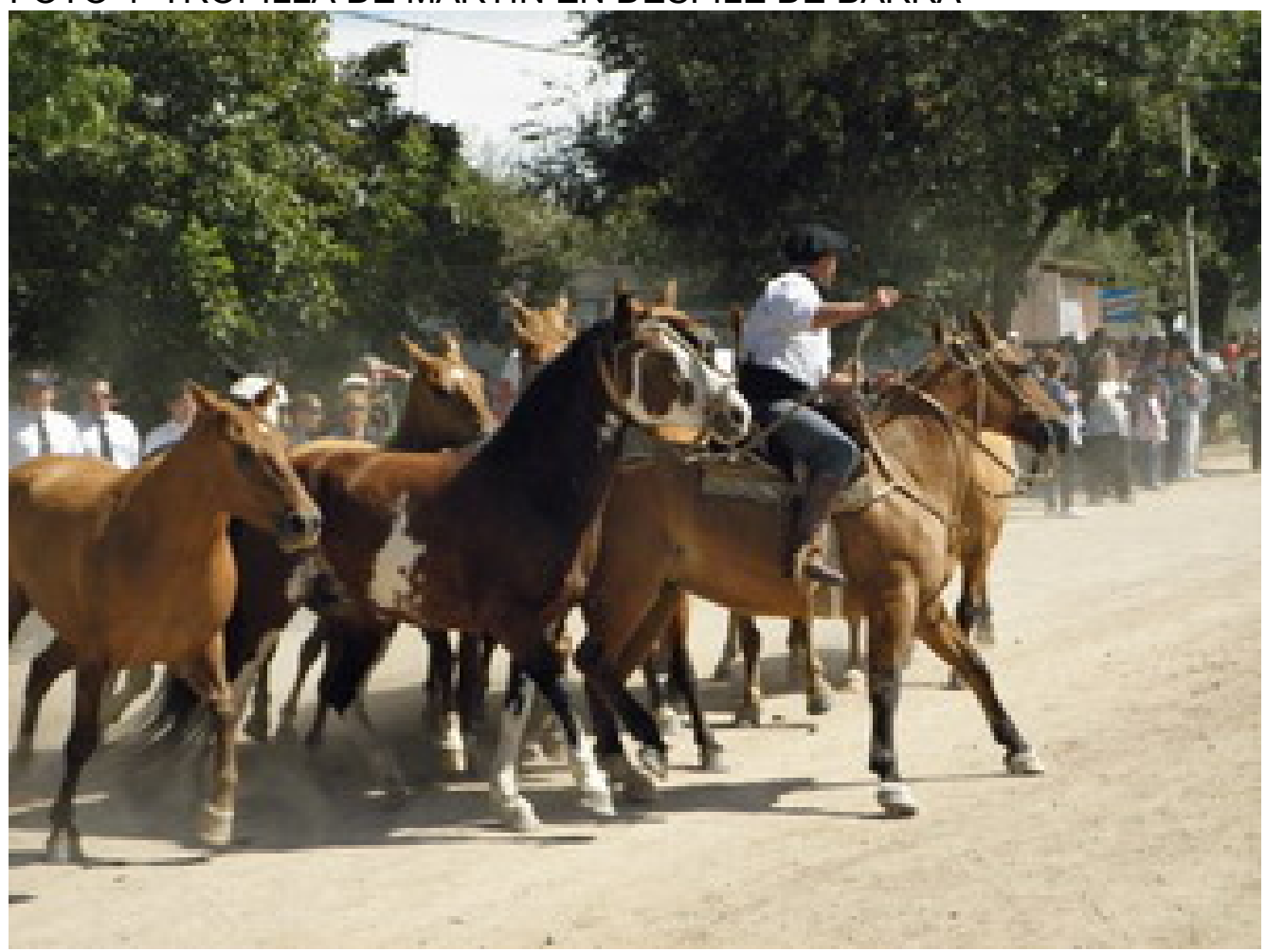


FOTO 5 ARTESANIAS FINAS EN CUERO DE SEGIO

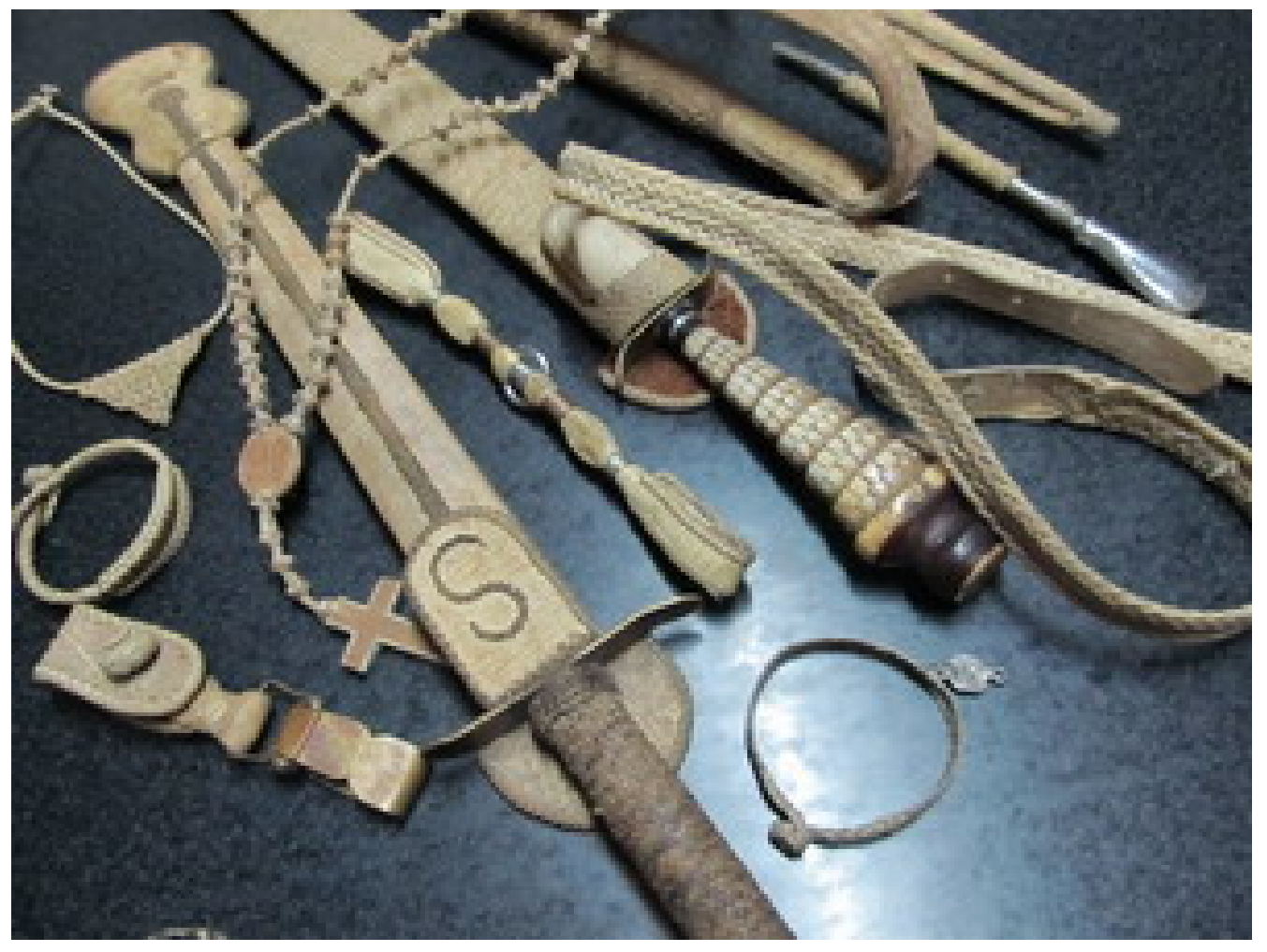

FOTO 6 DETALLE DE CABO DE CUCHILLO HECHO POR SERGIO

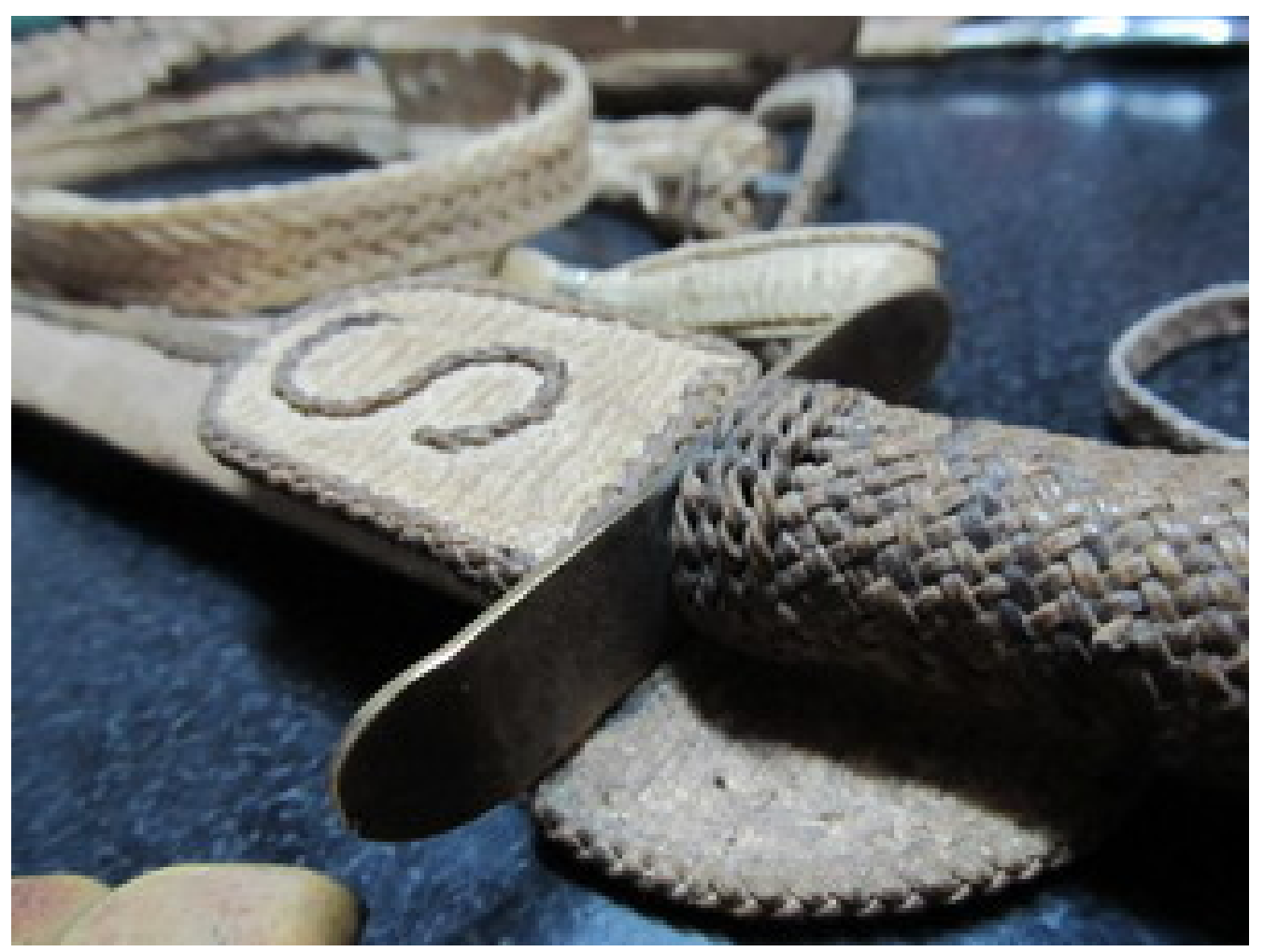


FOTO 7 JINETE EN CARRERA DE TACUARA EN EL CEPT

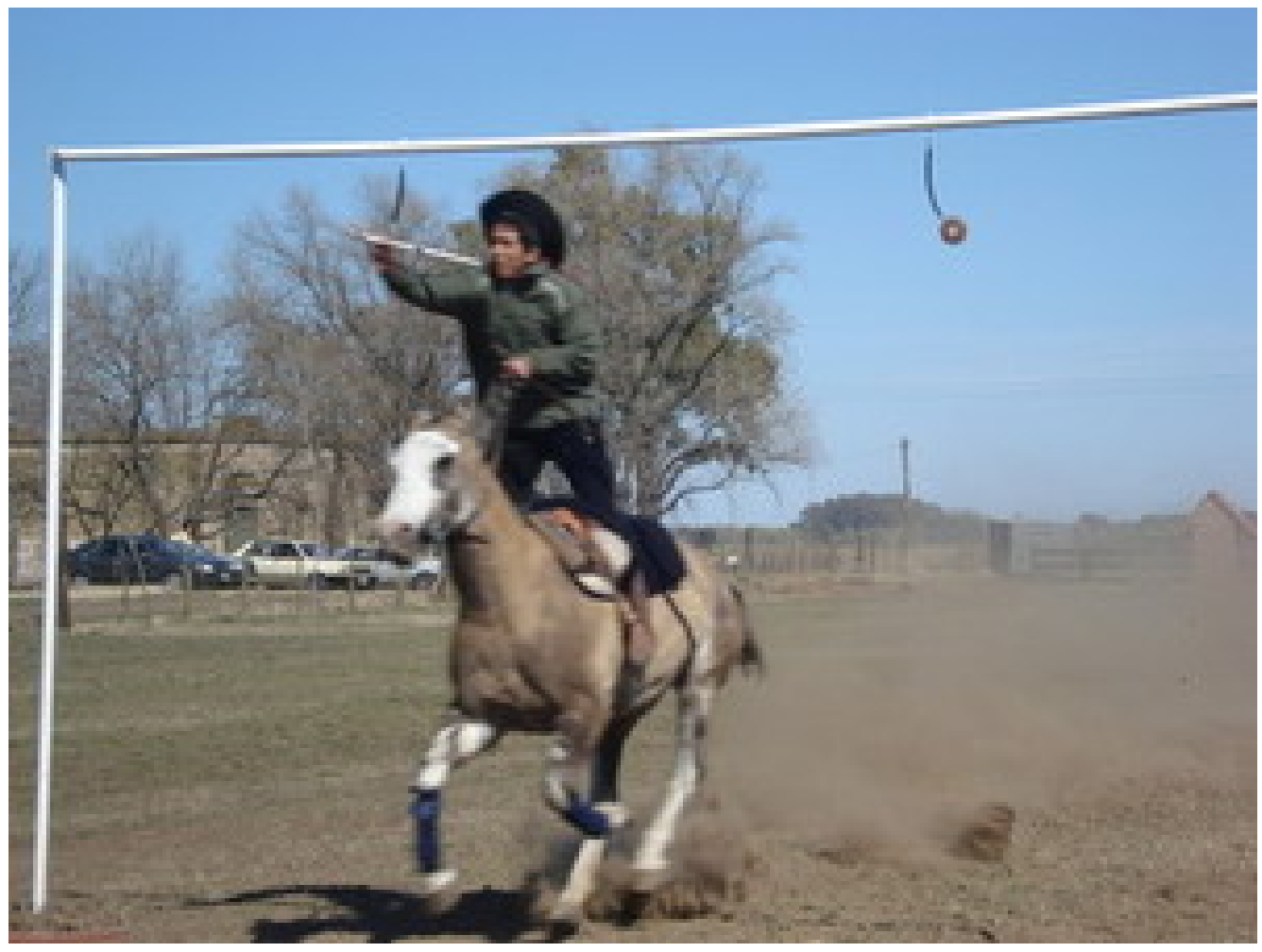

FOTO 8 CAMIONETA Y CARRO DE EMPLEADO RURAL EN FIESTA DE BARRA

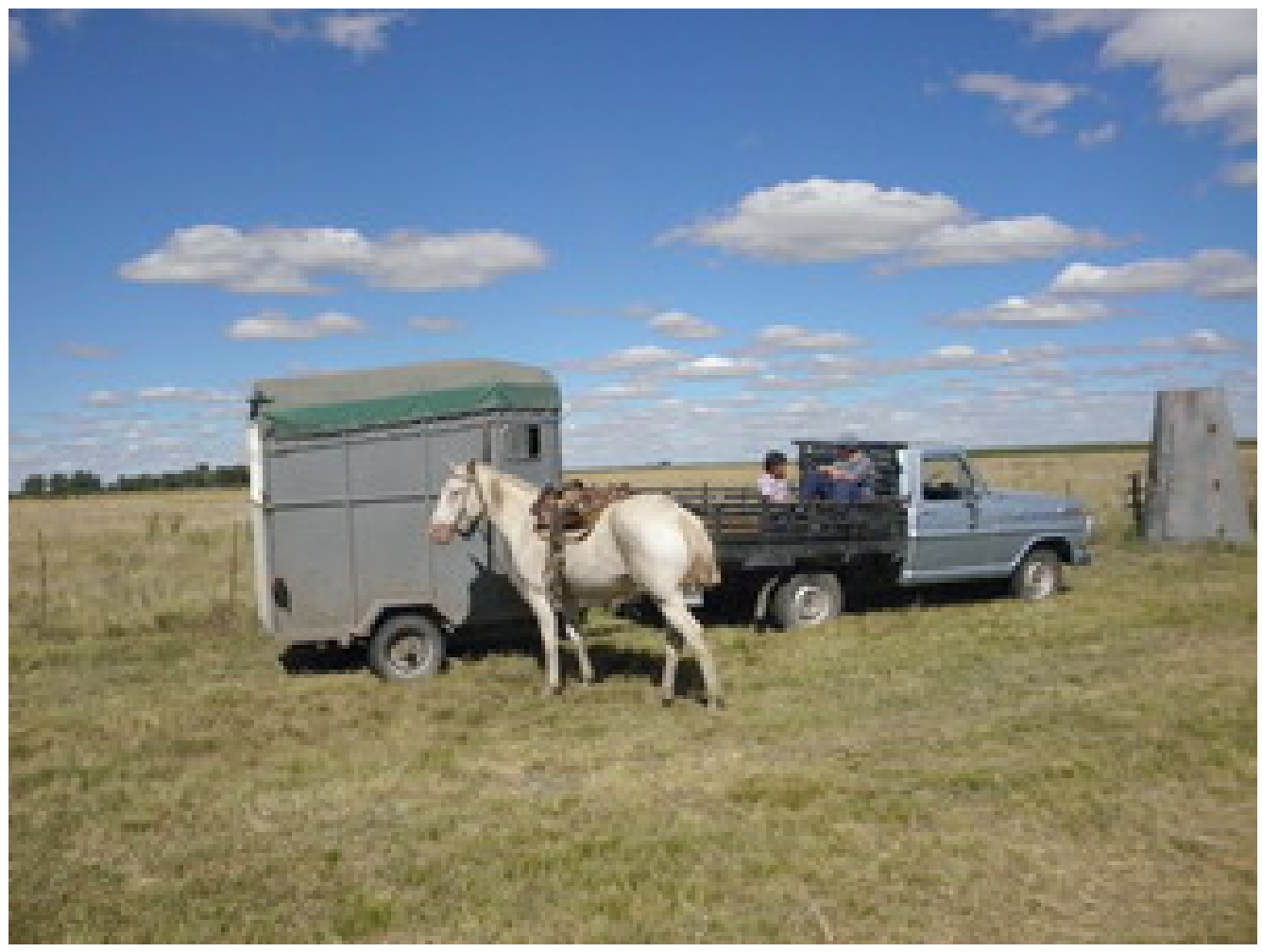


FOTO 9 CAMIONETA Y CARRO MAS MODERNO EN FIESTA DE BARRA

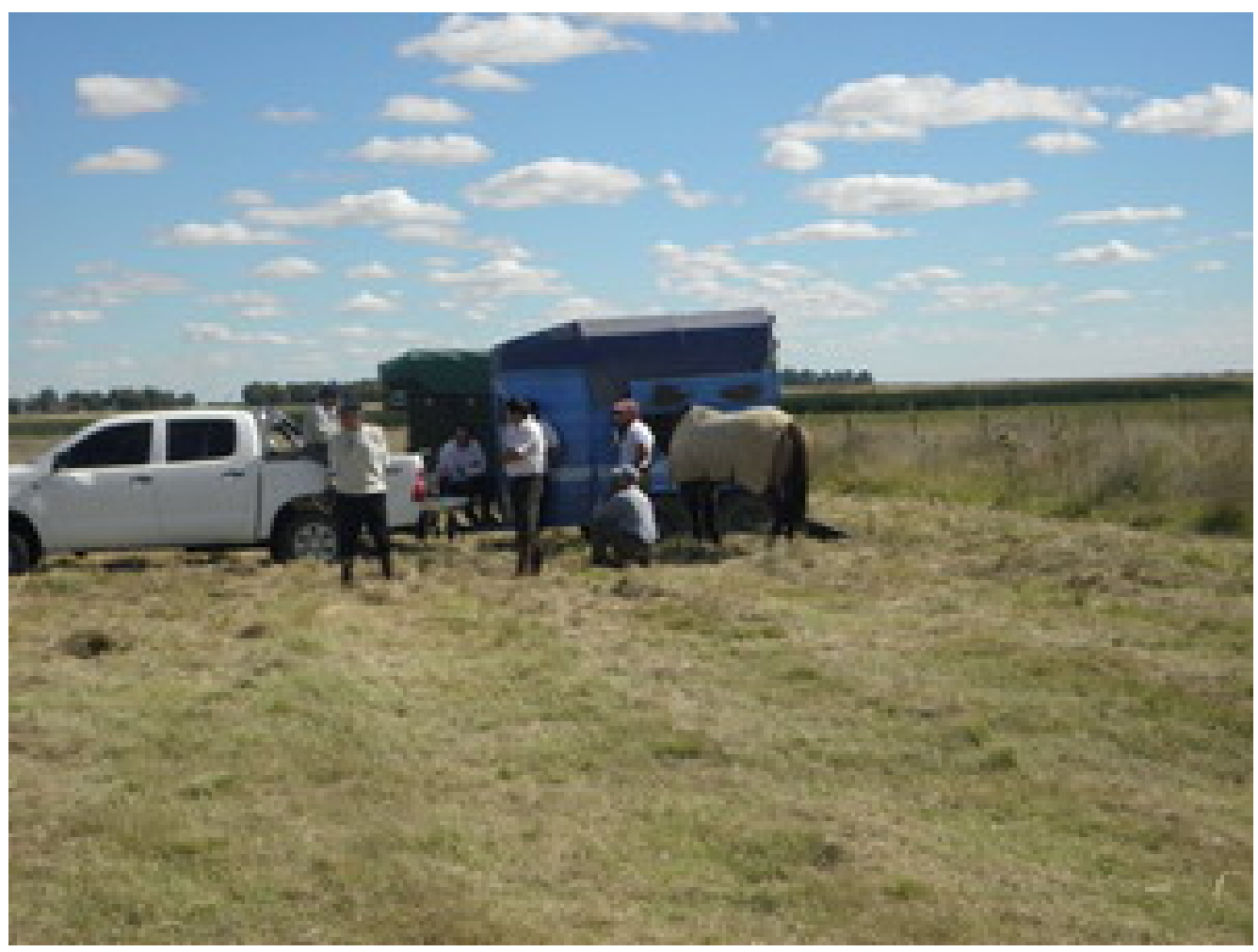

FOTO 10 JINETE EN CARRERA DE TAMBORES

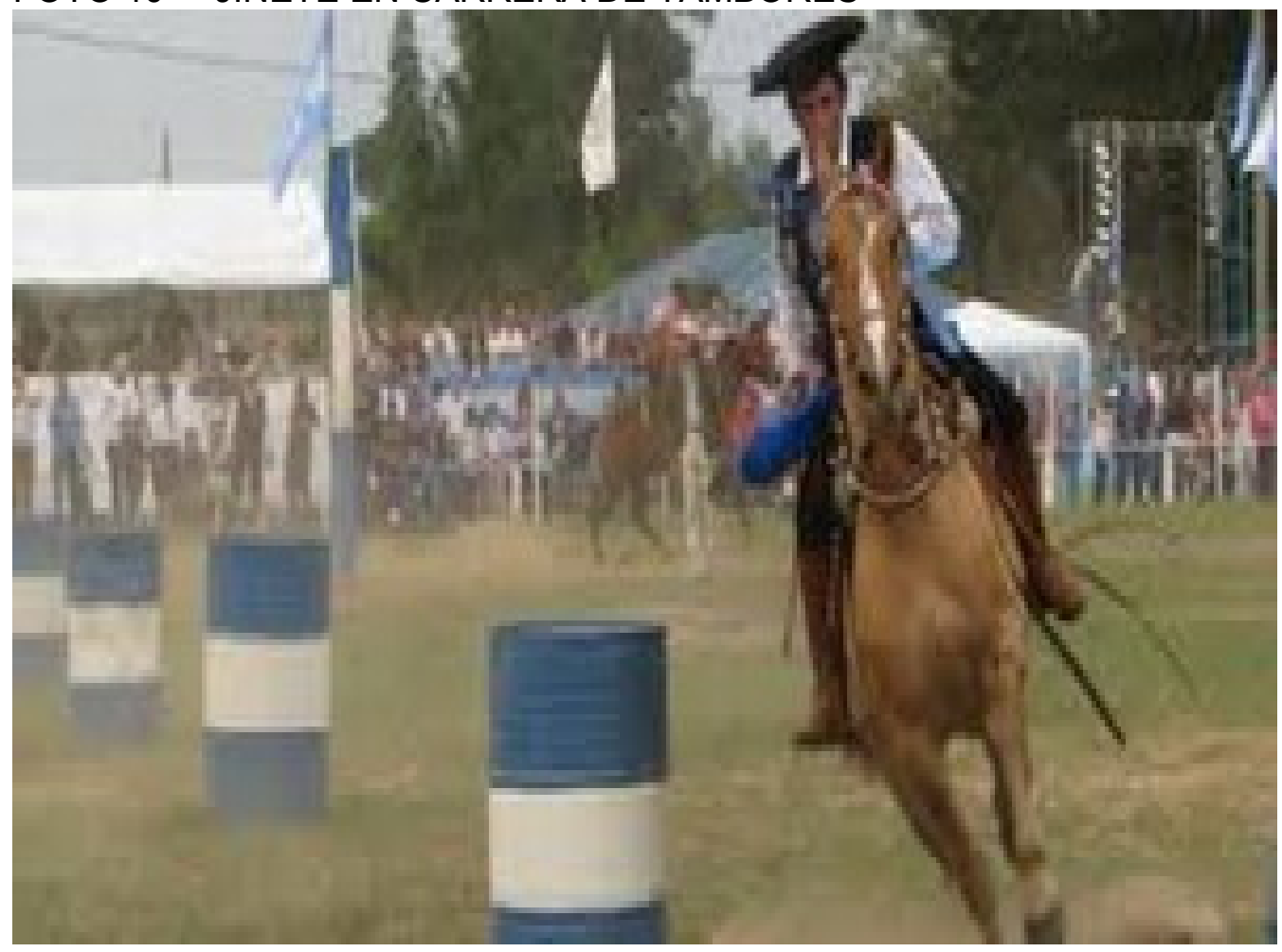


FOTO 11 CHICOS CON VESTIMENTAS GAUCHAS EN FIESTA DE BARRA

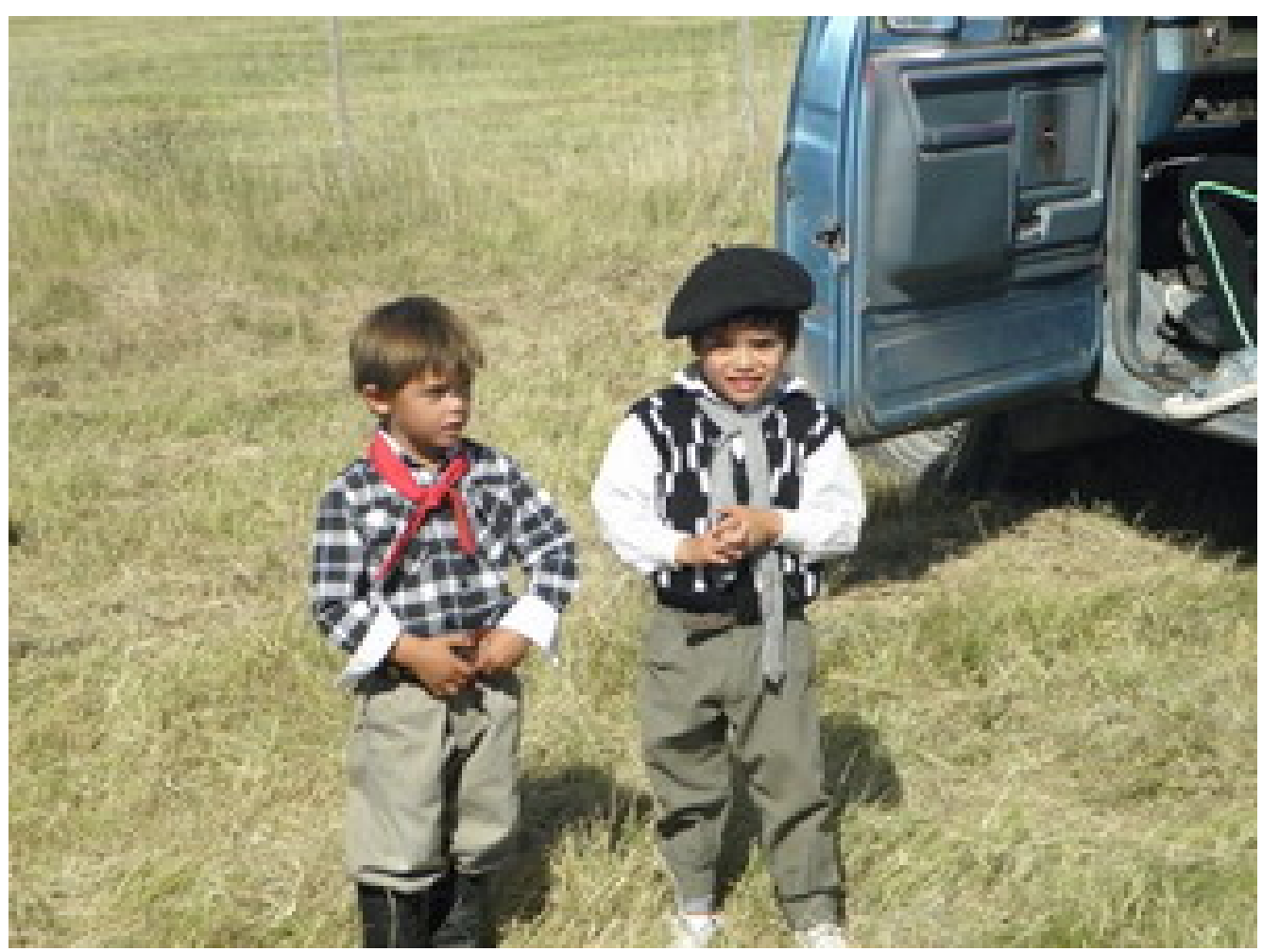

FOTO 12 EQUIPO DE PIALADORES EN FIESTA DE BARRA

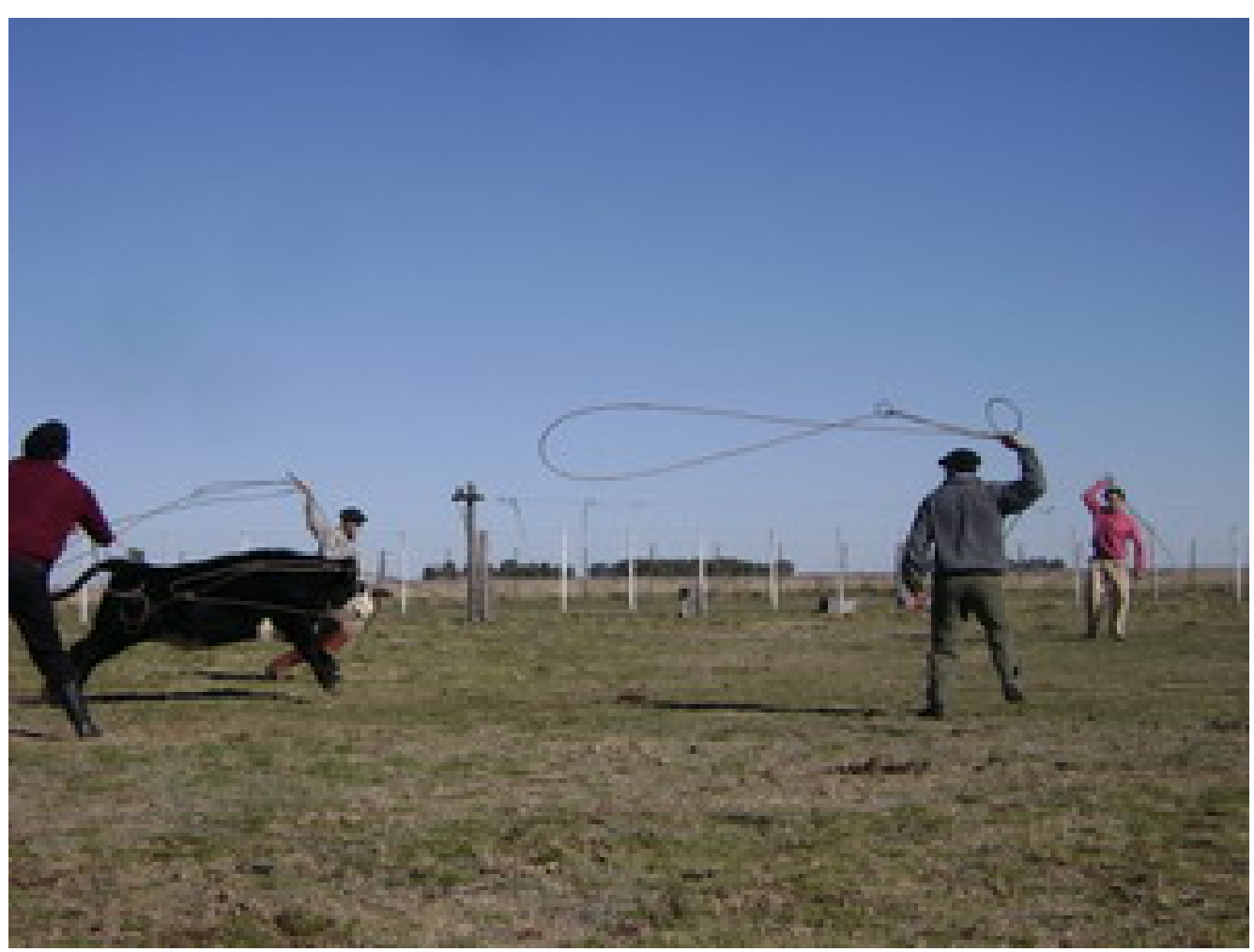


FOTO 13 SERGIO Y FABIAN EN LA FIESTA DEL ASADO PAMPEANO EN BARRA

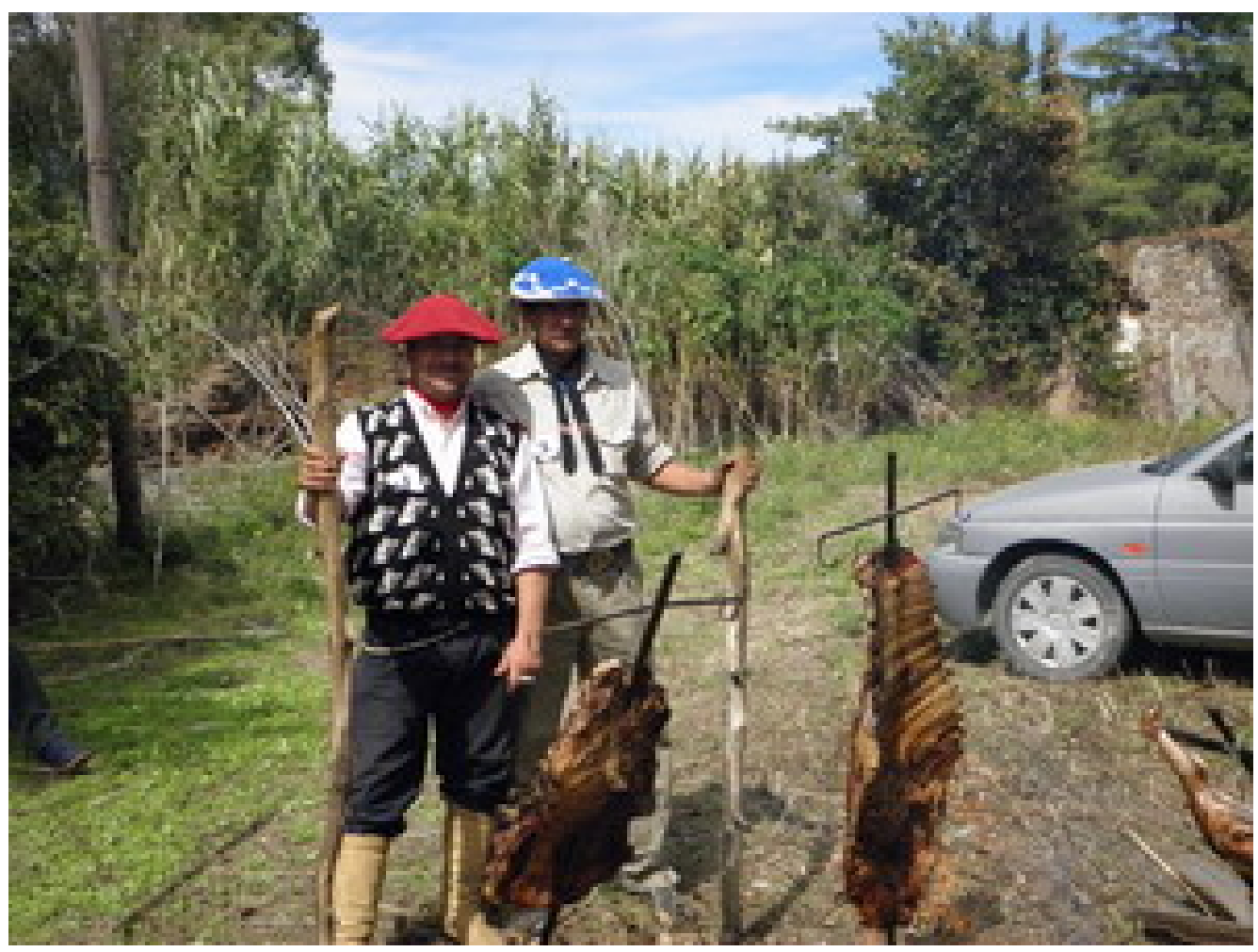

FOTO 14 JOVENES EMPLEADOS JUGANDO EN UN PUESTO

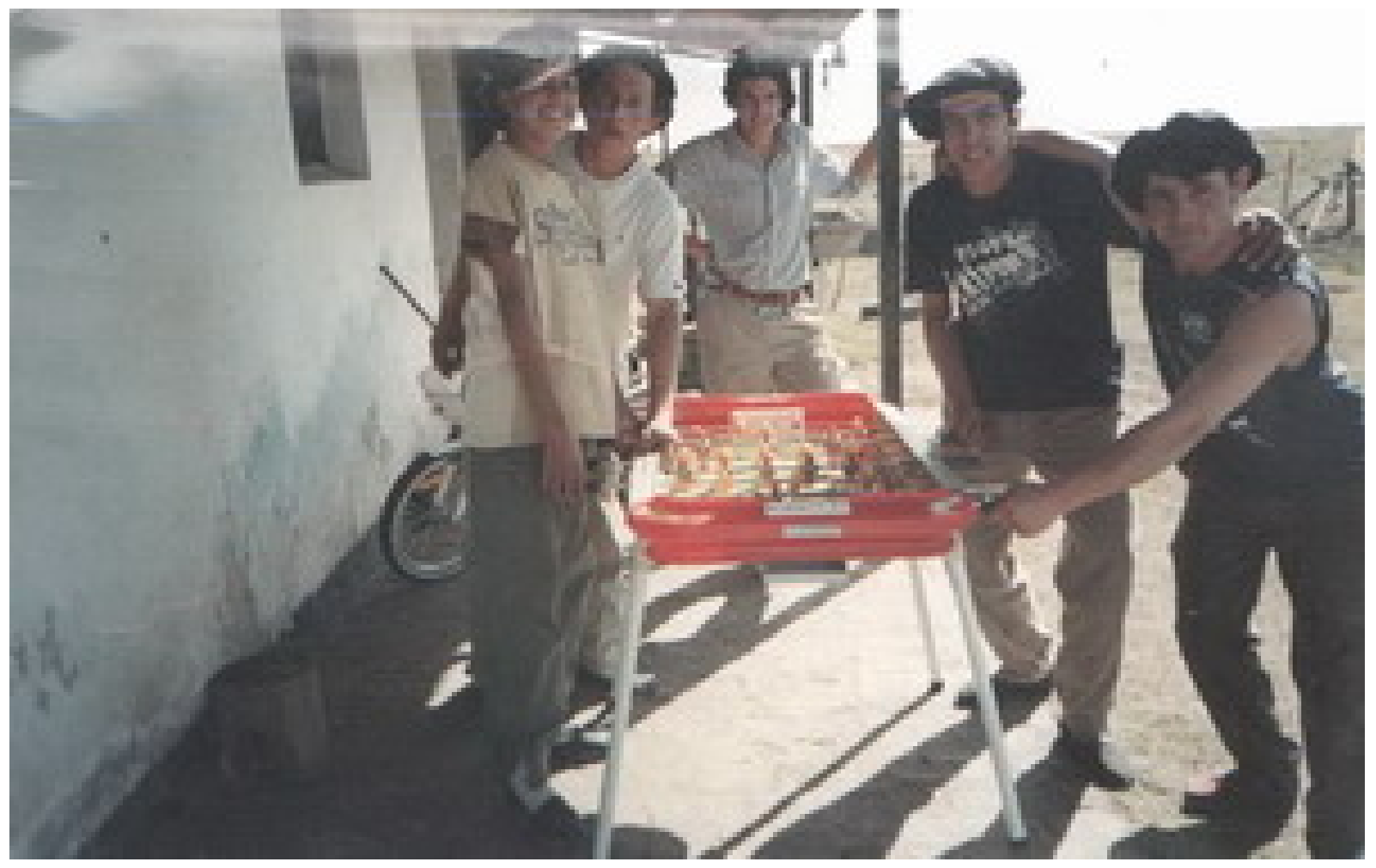


FOTO 15 PRODUCCION DE CHORIZOS EN GALPON DE MARCELO

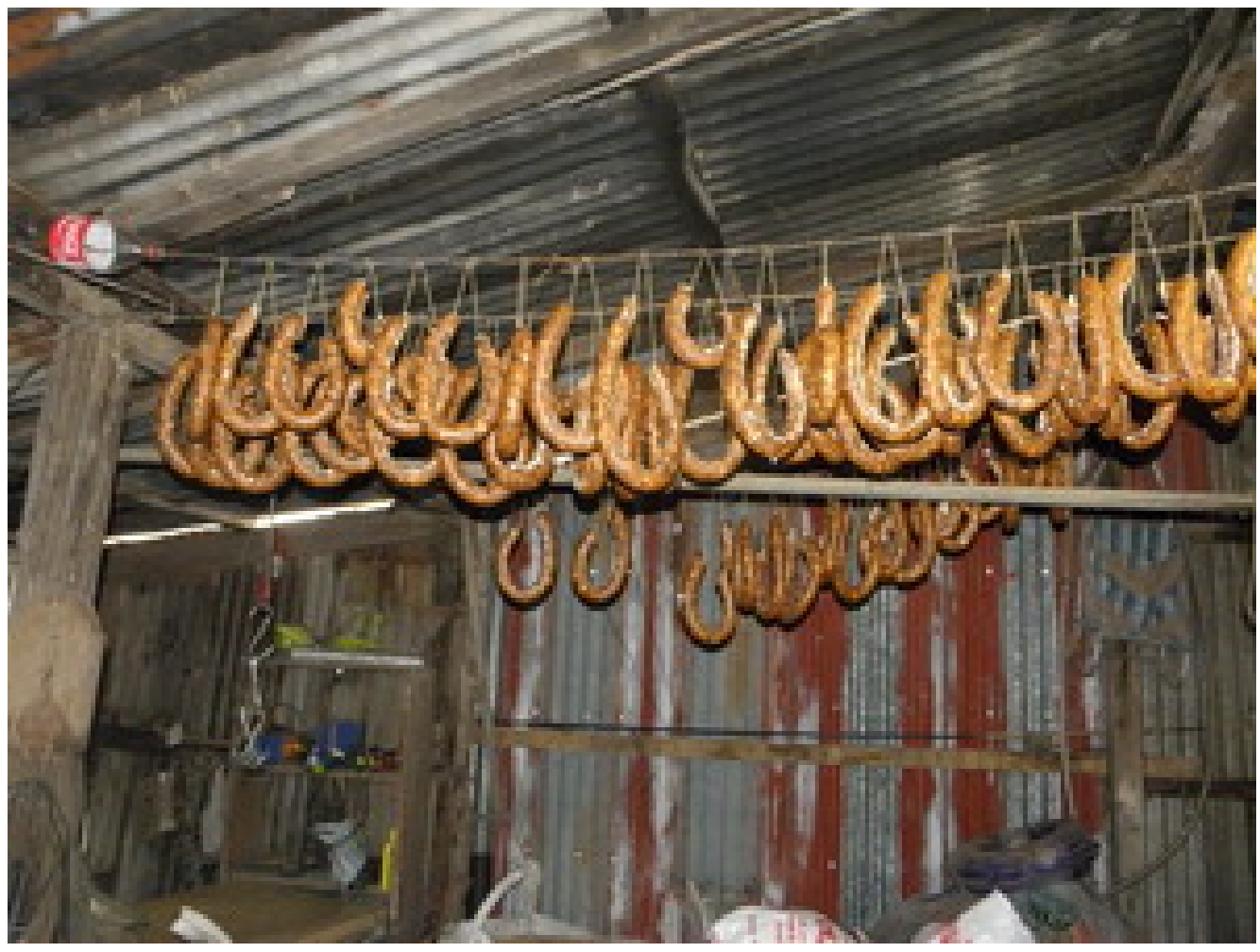

FOTO 16 CRIANZA DE POLLOS EN GALPON DE CAMPO

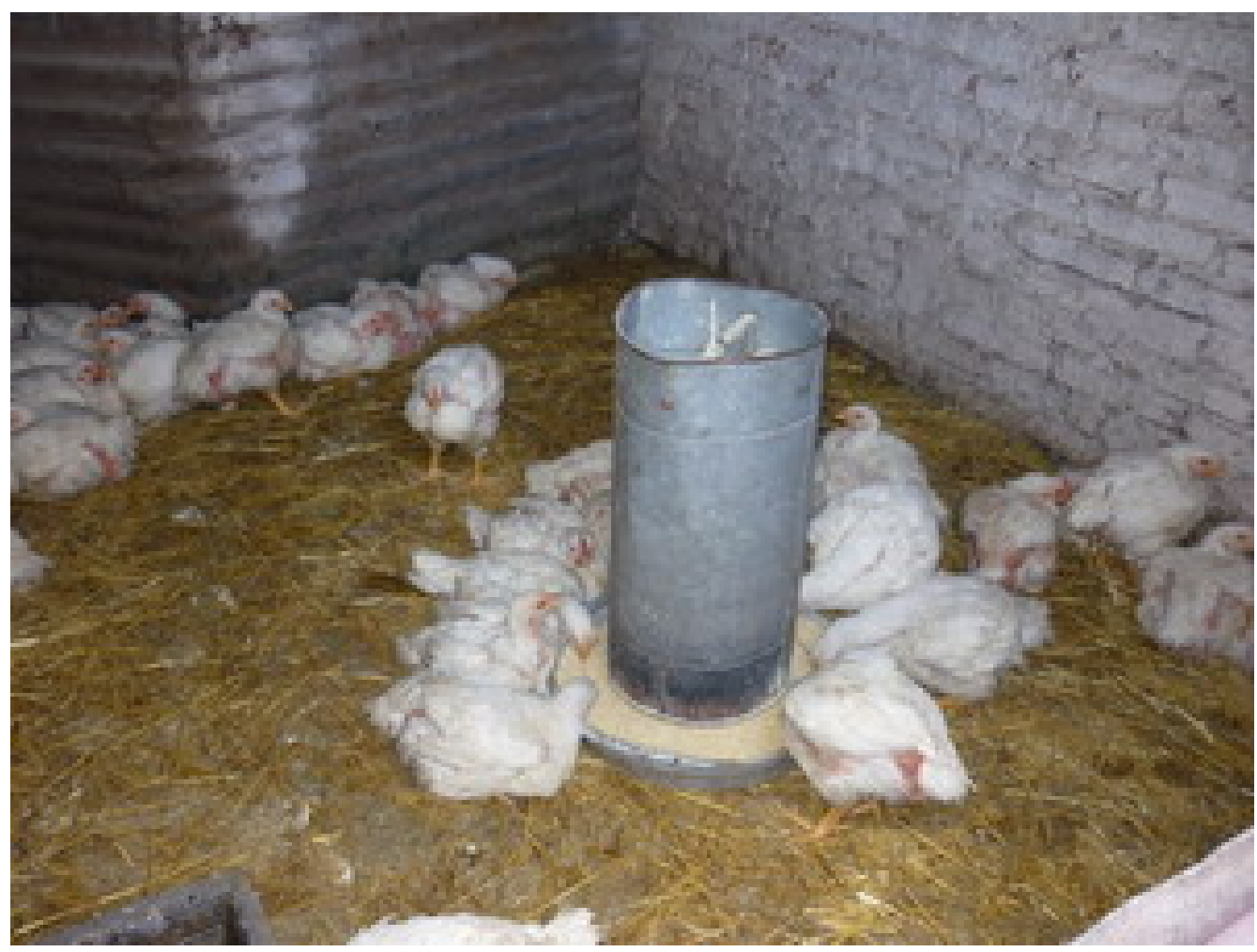


FOTO 17 CHIQUERO CON LECHONES EN LO DE JAIRO

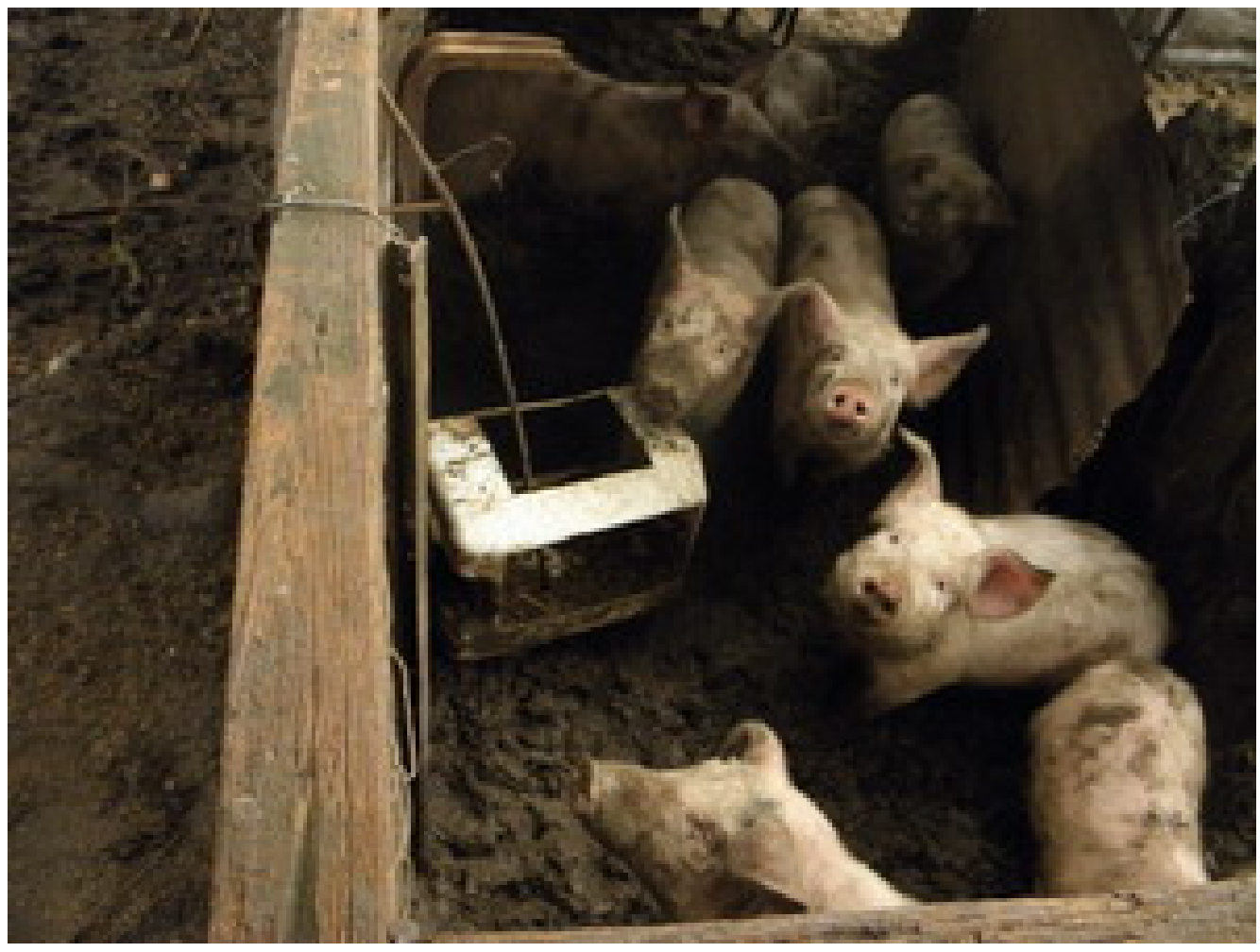

FOTO 18 CLASE DE SECUNDARIA ADULTOS (MADRES DE CHICOS ) QUE ESTAN EN LA ESCUELA RURAL SAN FRANCISCO

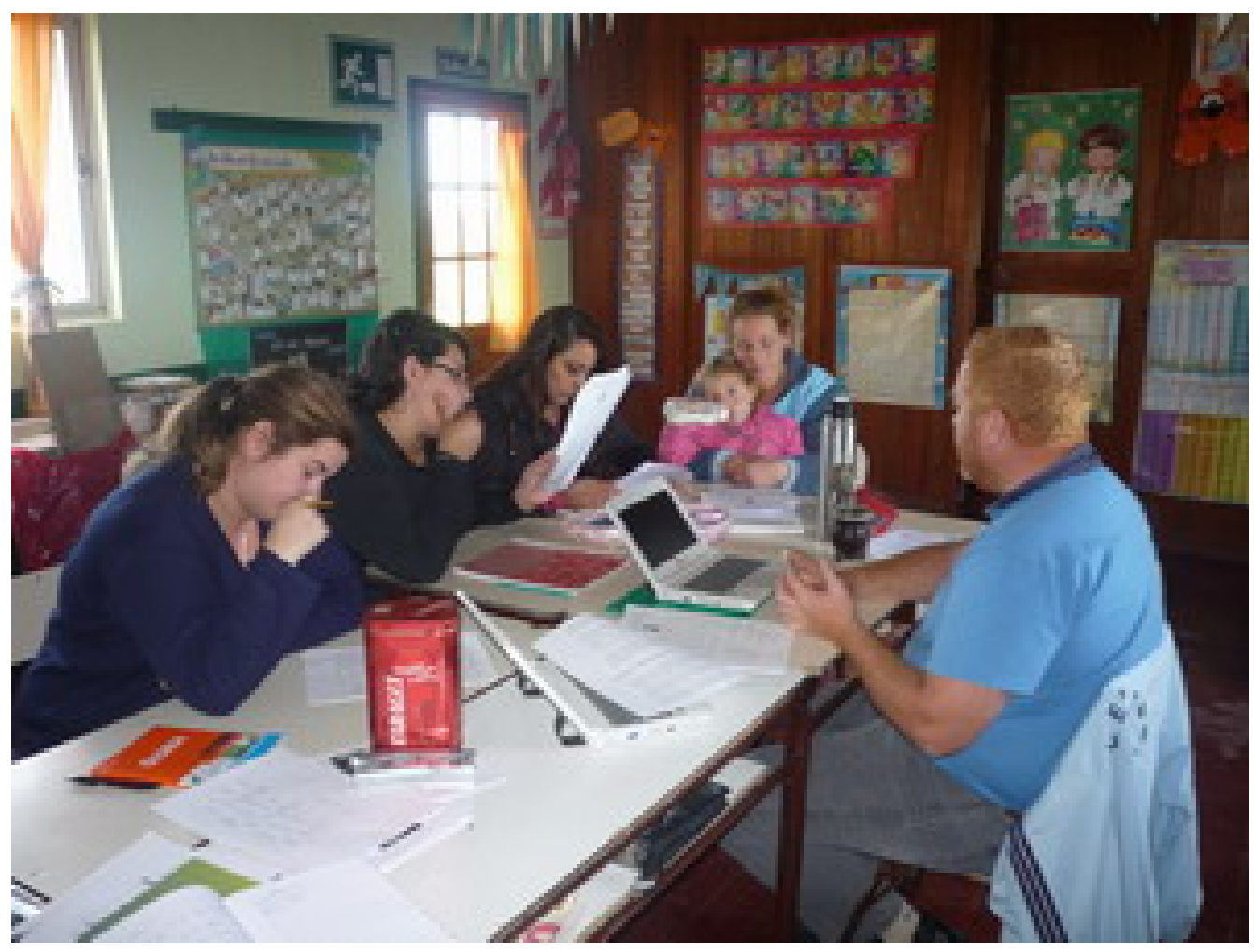


FOTO 19 ESCUELA RURAL SAN FRANCISCO

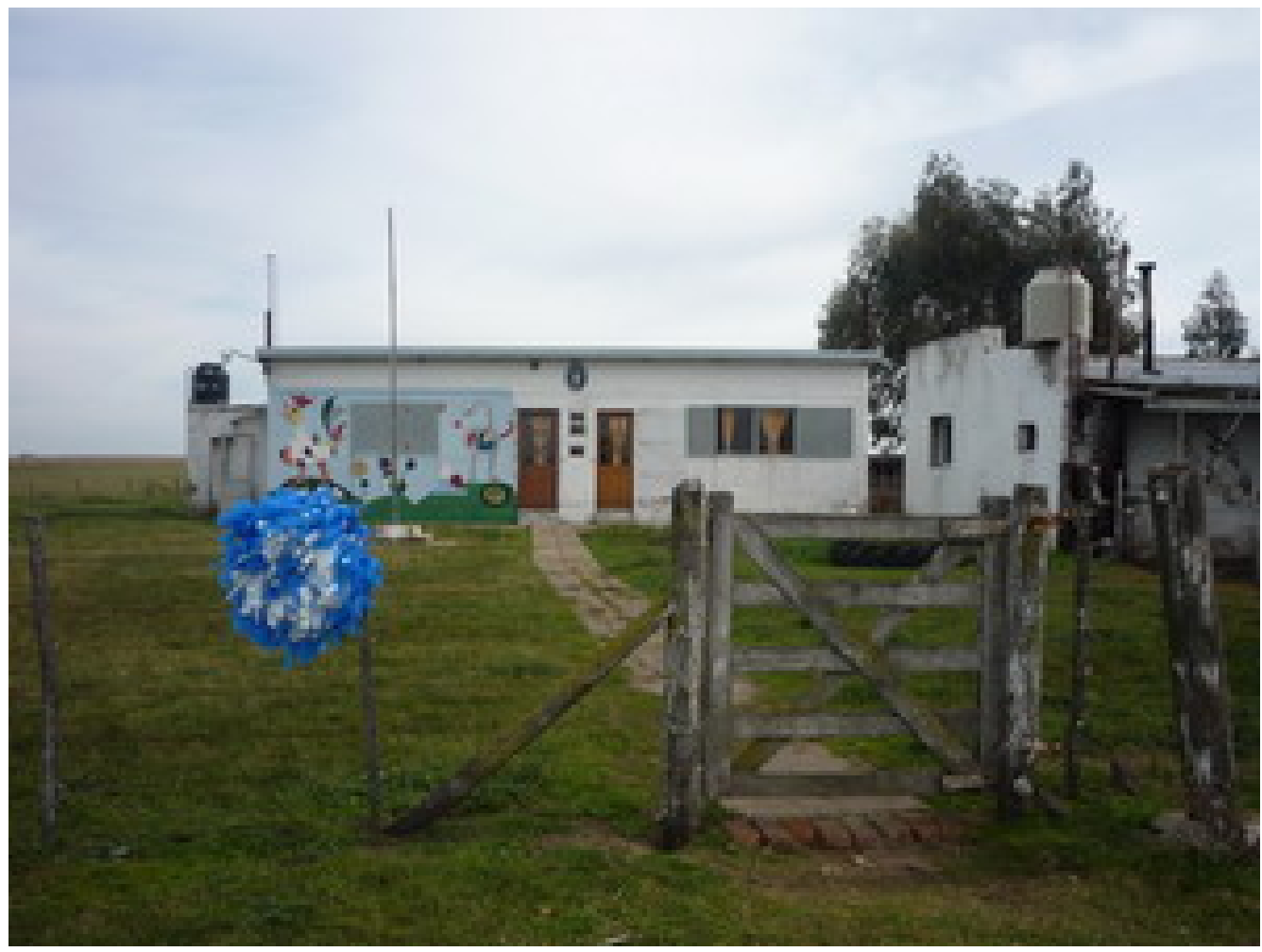

FOTO 20 ESCUELA RURAL 21 DURANTE EL IZADO DE LA BANDERA

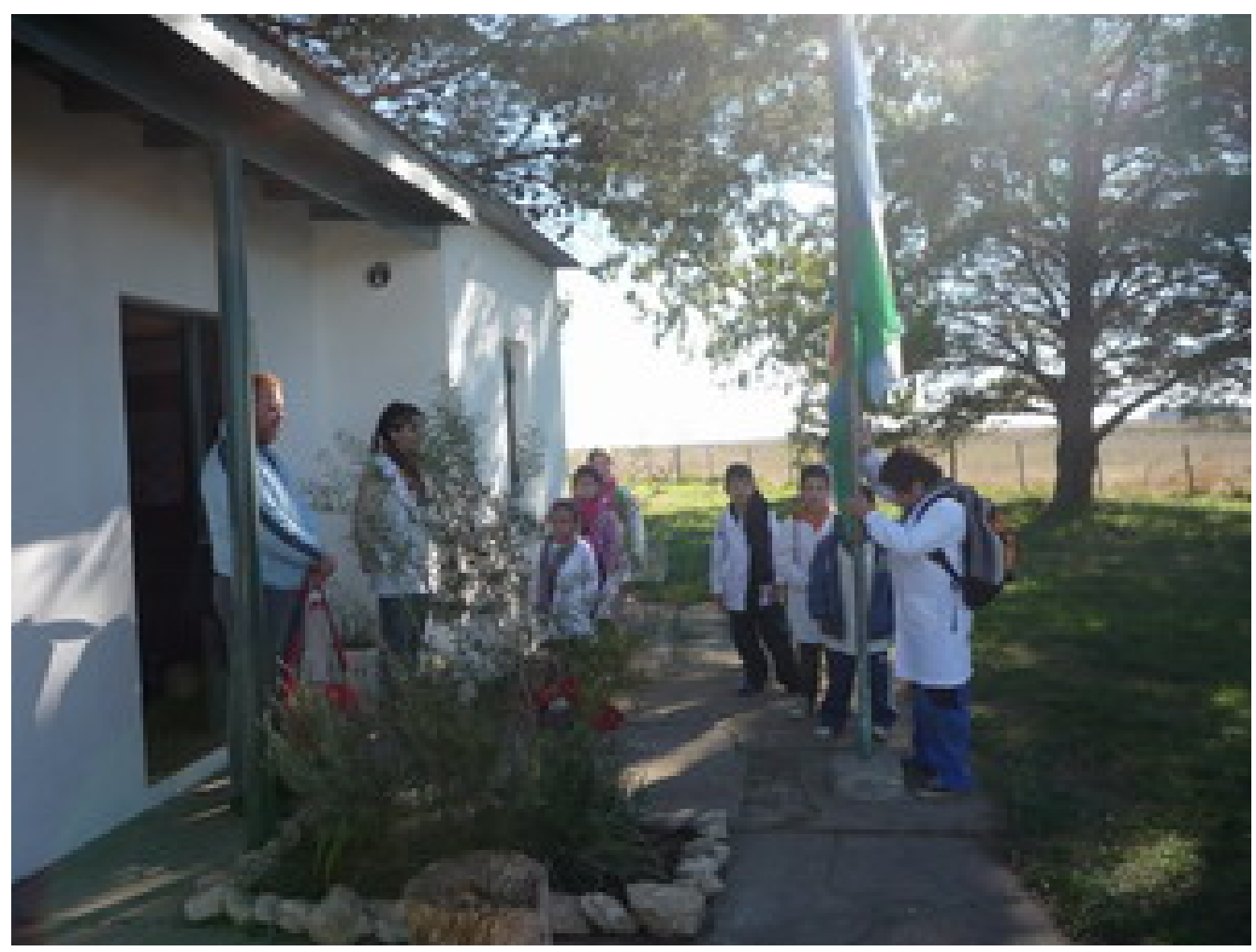


FOTO 21 HUERTA ESCOLAR CON CHICOS DE ESCUELA RURAL DE LASALLE

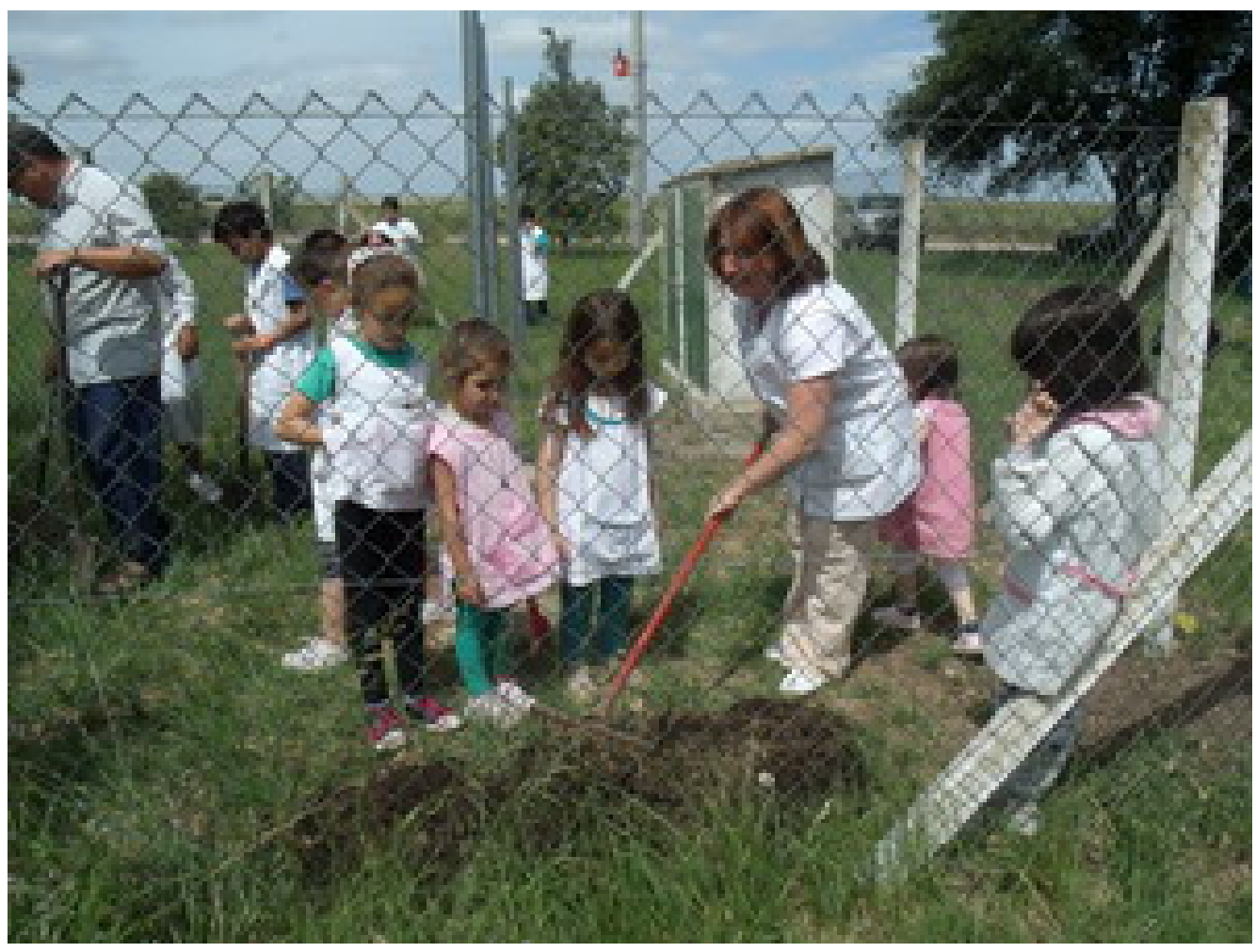

FOTO 22 HISTORICA VISITA DE DIEGO MARADONA AL CLUB AGRARIO PARA LA INAUGURACION DEL CAMPO DE JUEGO QUE LLEVA SU NOMBRE

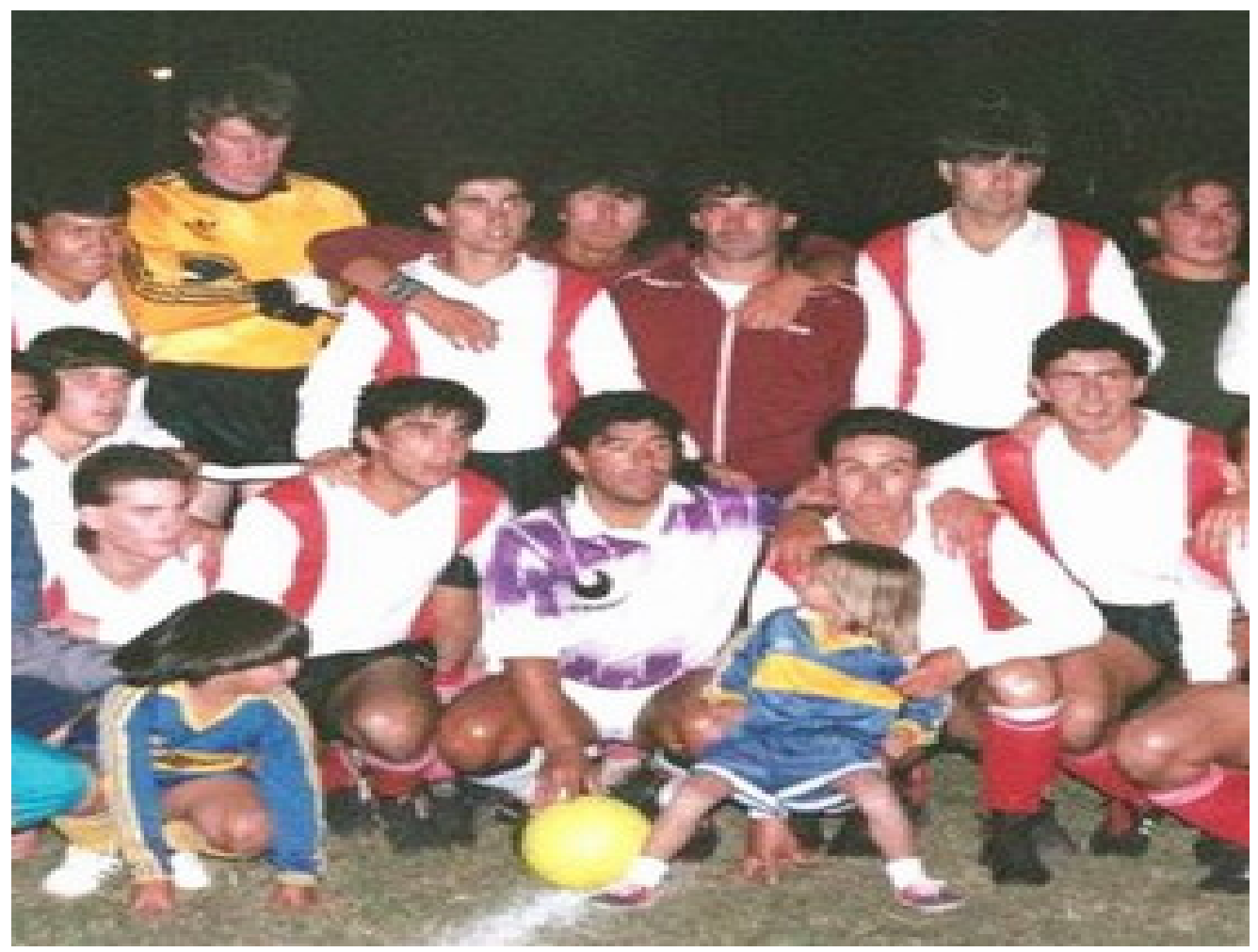




\section{ANEXO 2 LISTADO DE PERSONAS ENTREVISTADAS}

1- Abel Burgois, 64 años empleado mixto y Mirta Burgois 60 años, multiocupada, comerciante. Viven en el campo a $5 \mathrm{~km}$ de De la Garma. Tres hijos, dos universitarios recibidos.

2- Jairo Forte, 32 años, empleado ganadero, multiocupado, soguero de trabajo, fabrica chacinados, caza liebres, Daniela Contreras, 29 años, multiocupada, producciones familiares y empleada domestica. Viven en campo grande, a $25 \mathrm{~km}$ de Barra. 3 hijos, 1 en el CEPT otros primaria rural en el propio campo.

3- Mauro Diaz, 35 años, empleado ganadero por día y plan de trabajo social en cooperativa, amansa caballos para terceros. Casado, 2 hijos, esposa ama de casa, vive en casa propia en De la Garma.

4- Juan Alberto Farias, 59 años, empleado ganadero, multiocupado, tambero y producción de huevos, hacienda propia. Esposa reparte leche. Tres hijas, una estudiante terciaria, una secundaria, una capacidades diferentes. Vive en el pueblo y trabaja a 14 kilómetros, viaja todos los días.

5- Mario Cantero, 45 años, empleado ganadero, chaqueño, producciones autoconsumo. Cuatro hijos, 2 estudian en el CEPT, otros primaria y jardín rural. Vive en el campo a 17 km. de De la Garma, vinieron a la zona hace 12 años.

6- Horacio Dirrocco, 63 años, empleado agrícola y Juan Pedro Dirrocco 40 años empleados agrícolas, padre e hijo. Trabajan en empresa contratista de la zona, hacen la campaña en casilla rural. Esposas trabajan como empleadas domesticas. Viven en De la Garma

7- Luciano Segovia, 29 años, empleado ganadero, correntino. Hace 7 años que esta en la zona. Casado 3 hijos de primaria y jardín en Benito Juarez, esposa ama de casa, vive en el campo a $20 \mathrm{~km}$. de Chaves

8- Felipe Gonzáles, 56 años, empleado ganadero, multiocupado, hacienda vacuna propia y producciones de autoconsumo. Mónica Gonzáles ama de casa y transportista. 4 hijos, 2 grandes que no viven con ellos y 2 adolescentes que si. Viven en el campo a $12 \mathrm{~km}$. de Barra 
9- Sergio Gonzáles 52 años empleado ganadero, multiocupado, soguero fino, casado esposa ama de casa y empleada domestica, 2 hijos secundaria, viven en el pueblo de Barra, trabaja en el campo y se queda, viene los fines de semana.

10- Alberto Araujo, 42 años, empleado ganadero, multiocupado, jinete profesional, amansa caballos y producciones de granja para venta. Casado 5 hijos edad escolar, uno egresado CEPT resto primaria rural. Esposa trabaja en producciones familiares. Vive en el campo a $45 \mathrm{~km}$. de Barra.

11- Jorge Vergara, 58 años, empleado agrícola, trabaja en contratista de cosechadora, hace campaña y resto del tiempo galpón. Casado, esposa empleada domestica.hijos grandes. Vive en De la Garma.

12- Nestor del Valle, 61 años, empleado ganadero, jubilado por discapacidad física (perdió una pierna de joven en trabajo agrícola), 1 hija con hemiplejia severa, esposa ama de casa, trabajó como cuentapropista y volvió al empleo. Trabaja a $5 \mathrm{~km}$. de Barra y vive en el pueblo, viaja en tractor todos los días. Miembro fundador del CEPT de Barra.

13- Hugo del Valle, 27 años, empleado ganadero, multiocupado, artista regional, cantante de folclore en fiesta populares, ex alumno del CEPT. Soltero. Trabaja y vive en el campo a $10 \mathrm{~km}$. de Barra. los fines de semana viaja a la zona.

14- Oscar Moretti, 42 años, alambrador, hoy cuentapropista, antes empleado, separado, 3 hijos edad escolar, vive en De la Garma, trabaja de campaña en casilla, viene los fines de semana.

15- Manuel Rodríguez, 41 años, empleado ganadero, hoy por día. Multiocupado, amansa caballos, compra-venta de caballos, caza. Vive en el pueblo de Juarez. 3 hijos uno en el CEPT. Esposa empleada domestica.

16- Alberto arguello, 49 años, empleado mixto, multiocupado, amansa caballos, hacienda 
vacuna propia, producciones autoconsumo. Casado, esposa ama de casa y multiocupada, hijos grandes ex alumnos del CEPT. Vive en el campo a $25 \mathrm{~km}$. de Chávez.

17- Ruben Zoppy, 48 años, empleado agrícola, multiocupado, producción de cerdos y huevos para venta, esposa empleada domestica y ayuda en producciones. 2 hijos en secundaria. Vive en quinta en De la Garma.

18- José Aguilar, 53 años cantinero del club Agrario, periodista deportivo de la radio local, hijo de empleados rurales.

19- Vodo von Saldern, 64 años, medico veterinario, administrador de campos grandes, 70 empleados en su organización, productor ganadero.

20- Guillermo Durquet, 53 años, mecánico rural, piloto de categoría regional, propietario de un taller con peña de auto de carrera.

21- Mary Iriart, 61 años, encargada oficina de SENASA en De la Garma, encargada del tramite de guías y marcas.

22- Maria Jose Aberastegui, 38 años, encargada oficina UATRE-OSPRERA en De la Garma

23- Darío Monges, 40 años, casado un hijo en escuela primaria rural, esposa ama de casa, vive en el campo, empleado agrícola y cuentapropista de maquinaria.

24- Marcelo Peralta, 48 años, trabajador ganadero, multiocupado, criador de cerdos y pollos, esposa multiocupada, hijos ex alumnos del CEPT.

25- Julian Sosa, 41años empleado ganadero y multiocupado, 2 hijas, producciones de autoconsumo, criador y amansador de caballos para destreza de tambores. Esposa multiocupada, Hija en el CEPT y otra en primaria rural.

26- Julio Ganin, 55 años, trabajador sin empleo fijo, ex cabañero en cañaba grande, changas urbanas y rurales, casado, esposa empleada domestica, hijos grandes, vive en De la Garma 


\section{ANEXO 3 OTROS EMPLEADOS QUE FUERON CONSULTADOS PARA ESTE TRABAJO.}

1- Ricardo Saavedra,43 años, empleado agrícola y albañil cuentapropista, casado 2 hijos edad escolar, vive en de la Garma. Trabaja como albañil cuando no hace la cosecha registro en el bar de la torre el 15-8-12.

2- Alejandro Díaz, 19 años, alumno de sexto año del CEPT, soltero, vive con su familia en Juan E. Barra, en la alternancia trabajaba como alambrador en el equipo de Darío. Registro realizado en el CEPT el 13-4-13

3- Eduardo ferrara, 44 años, empleado mixto, trabaja en campo de la zona, trabajo en la alambrada cuando se quedo sin empleo, casado 2 hijas vive en Juan E. Barra. Registro realizado en desfile aniversario de Juan e. Barra el 10-4-13

4- Agustín Díaz, 25 años, soltero, ex -alumno del CEPT, constructor, trabajo en equipo de alambrada cuando era adolescente, vive en Chávez. Registro realizado en asamblea comisión CEPT 20-3-13.

5- Martín Fernández, 52 años, empleado ganadero y tropillero, casado, dos hijos en el CEPT, registro realizado en fiesta grande de destrezas en Juan E. Barra el 15-12-12.

6- Marta, esposa de Osvaldo, empleado ganadero multiocupado, pronto a jubilarse, registro realizado en establecimiento Vizzolini Hnos. el día 25-11-12.

7- Fabián Carrizo, 49 años, soltero, ex -empleado ganadero y asador, posee emprendimiento en De la Garma, registro realizado en su emprendimiento el 10-3-13.

8- Alejandro Almada, 53 años, empleado mixto, casado vive en el campo, forma parte de la peña del flaco Durquet, registro realizado en la visita al taller del flaco Durquet el 153-13 luego de una carrera zonal.

9- Oscar Díaz, 47 años, empleado ganadero y elaborador, casado 4 hijos, dos en el CEPT, vive en el est. La Pindonga. registro realizado en el CEPT el 10-5-13

10- Marilina Barrios, 44 años, directora escuela Lasalle, casada con Luís, empleado ganadero, vive en De la Garma, registro realizado en escuela de Lasalle el dia20-4-13. 
ANEXO 4 LUGARES OBSERVADOS CON REGISTRO DE FOTOS Y COMPORTAMIENTOS SOCIALES

1- Fiesta de destrezas gauchas en Barra. 15-12-12

2- Carreras de sortija en el CEPT 8-11-12

3- Reunión de bochas en bar de Latorre. 15-8-12

4- Desfile gaucho aniversario del pueblo de Barra.10-4-13

5- Festejos de centenario de De la Garma. 10-12-12

6- Después de carrera en taller de Durquet 15-3-13

7- Veterinaria de Carlos Maria Yañez 22-5-13

8- Carreras de autos zonales en Gonzáles Chávez 7-7-13

9- Partido de fútbol de liga regional Tres Arroyos, clásico entre Agrario de De la Garma y Deportivo de Barra.1-5-13

10- Asamblea de la comisión del CEPT 20-3-13

11- Planta de silos de Cooperativa agraria de Tres Arroyos en De la Garma.15-6-13

12- CEPT 19 10-5-13 